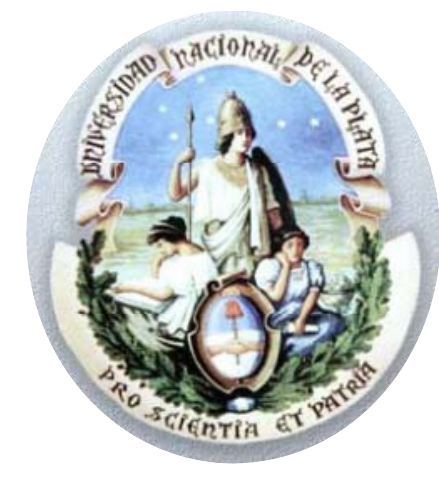

\author{
Universidad Nacional de La Plata \\ Facultad de Ciencias Exactas \\ Departamento de Ciencias Biológicas
}

\title{
"Estudio biofísico y estructural de Na-FAR-1, miembro de una nueva familia de proteínas de nematodos que unen ácidos grasos y retinol”
}

\author{
Licenciada en Biotecnología y Biología Molecular \\ María Florencia Rey
}

Directora: Dra. Betina Córsico

Co-director: Dr. Brian O. Smith

Tesis propuesta para optar por el Título de Doctor de la Facultad de Ciencias Exactas Universidad Nacional de La Plata

La Plata 2014 
Febrero 2014

Universidad Nacional de La Plata

\title{
“Estudio biofísico y estructural de Na-FAR-1, miembro de una nueva familia de proteínas de nematodos que unen ácidos grasos y retinol”
}

\author{
Licenciada en Biotecnología y Biología Molecular \\ María Florencia Rey
}

Directora: Dra. Betina Córsico

Co-director: Dr. Brian O. Smith 
El presente trabajo de tesis, para optar por el título de Doctor de la Facultad de Ciencias Exactas de la Universidad Nacional de La Plata, fue realizado en el Instituto de Investigaciones Bioquímicas de La Plata (INIBIOLP), Facultad de Ciencias Médicas, Universidad Nacional de La Plata (UNLP) - Consejo Nacional de Investigaciones Científicas y Técnicas (CONICET), bajo la dirección de la Dra. Betina Córsico y en dos estadías por un total de nueve meses en la Universidad de Glasgow bajo la dirección del Dr. Brian Smith.

Se recibió apoyo económico de la organización no gubernamental Welcome Trust, Reino Unido, a través de un subsidio a la Dra. Córsico en colaboración con un grupo de Glasgow. De la Welcome Trust y del Consejo Nacional de Investigaciones Científicas y Técnicas (CONICET), a través de becas doctorales de tipo I y tipo II respectivamente. Del Ministerio de Edicación de la Nación a través de una beca para docentes doctorandos. De European Molecular Biology Organization (EMBO) mediante una beca para estadía en el laboratorio del Dr. Smith en Glasgow.

Parte de los resultados aquí presentados fueron publicados en forma de artículos en revistas nacionales e internacionales: 
"(1)H, (13)C and (15) N chemical shift assignments of Na-FAR-1, a helix-rich fatty acid and retinol binding protein of the parasitic nematode Necator americanus"

Autores: M. Florencia Rey Burusco, Marina Ibáñez Shimabukuro, Alan Cooper, Malcolm W. Kennedy, Betina Córsico, Brian O. Smith.

Año: 2012

Nombre de la revista: Biomol. NMR. Assign.

Publicación electrónica previa impresión

"Two crystal forms of a helix-rich fatty acid-and retinol-binding protein, Na-FAR-1, from the parasitic nematode Necator americanus".

Autores: Mads Gabrielsen, M. Florencia Rey Burusco, Kate Griffiths, Andrew J. Roe, Alan Cooper, Brian O. Smith, Malcolm W. Kennedy, Betina Corsico.

Año: 2012

Nombre de la revista: Acta Crystallogr. Sect. F Struct. Biol. Cryst. Commun.

Volumen: 68(7) Páginas: 835-8

"Análisis Estructural y Funcional de Proteínas Solubles que Unen Lípidos de Parásitos Helmintos."

Autores: Gisela R. Franchini, Betina Córsico, Jorge L.Pórfido, Valeria Silva, Marina Ibañez Shimabukuro, M. Florencia Rey Burusco.

Año: 2013

Nombre de la revista: Acta bioquímica clínica latinoamericana.

Volumen: 47(2) Páginas: 1-6

"Structural and ligand binding site diversity within the fatty acid and retinol-binding proteins of nematodes, revealed by Na-FAR-1 of the parasite Necator americanus"

Autores: M. Florencia Rey Burusco, Marina Ibáñez Shimabukuro, Mads Gabrielsen, Andrew J. Roe, Kate Griffiths, Alan Cooper, Malcolm W. Kennedy, Betina Córsico, Brian O. Smith.

Trabajo en preparación 


\section{Resumen}

Los parásitos nematodos producen diversas proteínas solubles que unen lípidos (LBPs) estructuralmente distintas a las del huésped. Las funciones que cumplen se desconocen pero se hipotetiza que estarían involucradas en las funciones típicas internas de organismos multicelulares, como la utilización y transporte de compuestos no solubles, y en externas especializadas. Algunas de estas proteínas participarían en la modificación del entorno local en el tejido del huésped, posibilitando la modulación y la evasión de la respuesta inmune.

Entre las LBPs producidas por nematodos se encuentran las FAR ( binding proteins), una clase novedosa de proteínas que unen ácidos grasos y retinol. Tienen un tamaño aproximado de $19 \mathrm{kDa}$ y sus estructuras que parecen ser ricas en alfa-hélices aún no han sido completamente dilucidadas.

La comprensión del rol que cumple esta familia de proteínas tiene gran interés fisiopatológico ya que podrían desempeñar funciones relevantes en la biología de los parásitos que las producen y dadas las diferencias estructurales que presentarían con respecto a las LBPs de sus huéspedes, servirían como potenciales blancos para el diseño de nuevas terapias antiparasitarias.

Con la finalidad de contribuir a la caracterización de las proteínas FAR y avanzar de este modo en la determinación de su función biológica, se llevaron a cabo estudios biofísicos y estructurales que permitieron resolver la estructura de Na-FAR-1 en solución por espectroscopía de resonancia magnética nuclear. Determinándose que consta de once hélices que conforman una cavidad interna de gran tamaño, donde podrían ubicarse ligandos hidrofóbicos. La estequiometría de unión de los complejos formados por Na-FAR-1 estaría dada por cuatro moléculas de ácido oleico por molécula de proteína, pero se limitaría a una única molécula de ligando en el caso del retinol y de los análogos fluorescentes de ácidos grasos empleados para su estudio.

A su vez se evidenció que además de los ligandos esperados como ácidos grasos y retinol, esta proteína es capaz de unir fosfolípidos y diacilglicéridos. 
La amplia diversidad de unión a ligandos, sumada a su localización en el intestino del nematodo, indicarían que podría participar en el direccionamiento hacia los distintos tejidos de los lípidos ingeridos. 


\section{Índice}

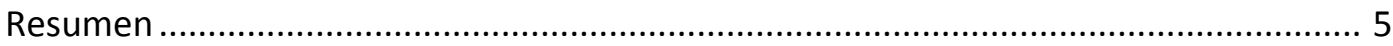

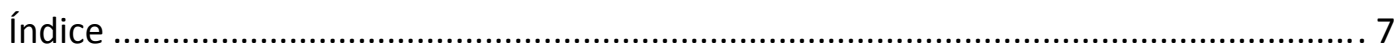

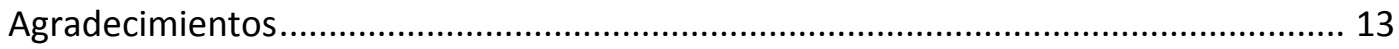

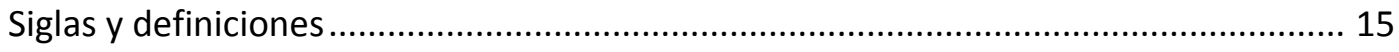

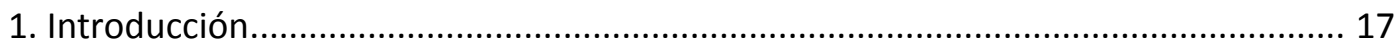

1.1. Proteínas de helmintos que unen lípidos ..................................................... 19

1.2. Proteínas que unen ácidos grasos y retinol de nematodos (FAR) ...................... 21

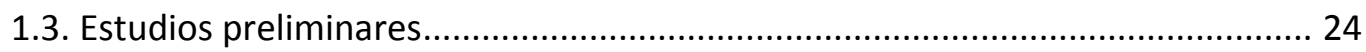

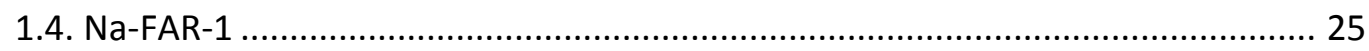

1.5. Comparación de secuencias........................................................................ 26

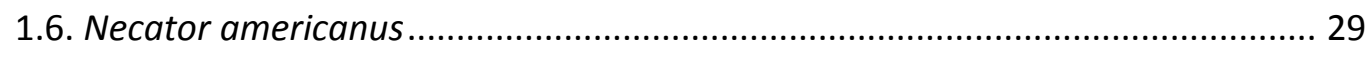

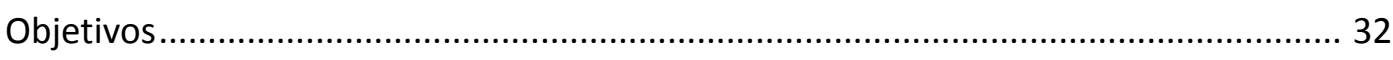

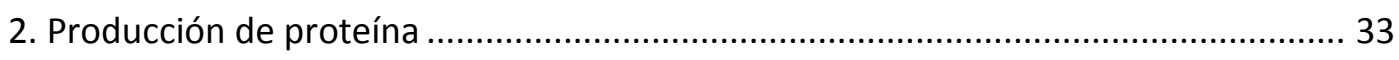

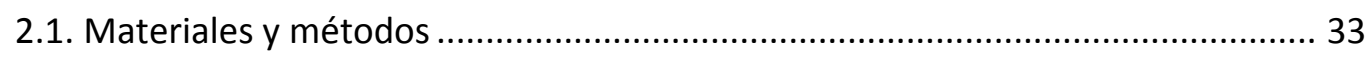

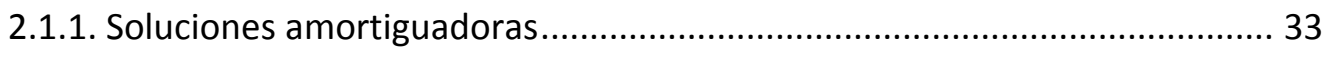

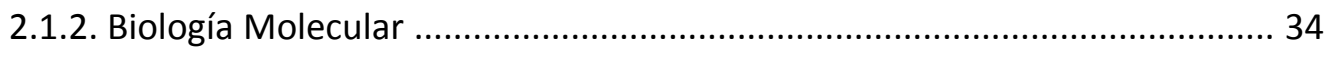

2.1.2.1. Minipreparación de Plásmidos ........................................................... 35

2.1.2.2. Electroforesis en geles de agarosa ................................................... 36

2.1.2.3. Purificación de DNA a partir de geles de agarosa ................................. 36

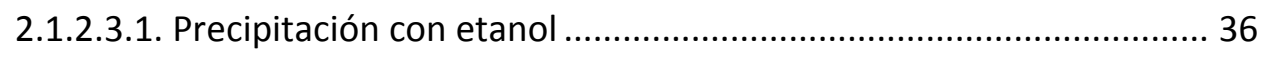

2.1.2.4. Digestión con enzimas de restricción ................................................... 37

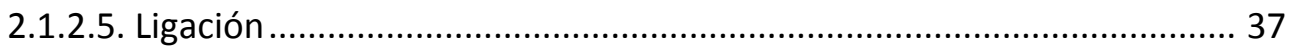

2.1.3. Obtención de bacterias competentes................................................... 37

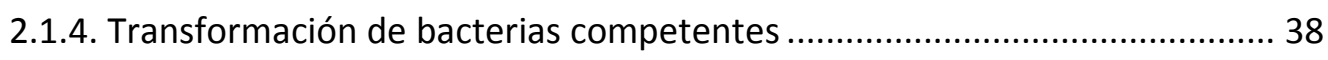

2.1.5. Expresión y purificación de proteínas ....................................................... 38 


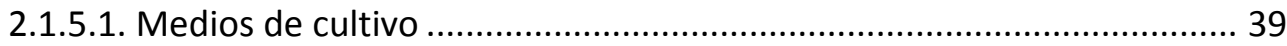

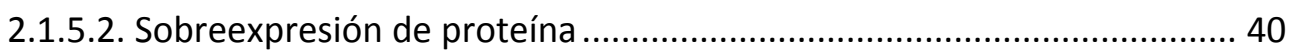

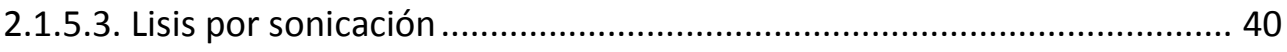

2.1.5.4. Cromatografía de afinidad en columna de níquel.................................. 40

2.1.5.5. Cromatografía de exclusión molecular ................................................. 41

2.1.5.6. Cromatografía en fase reversa (rp-HPLC) ........................................... 41

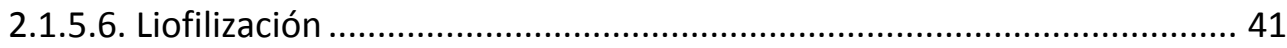

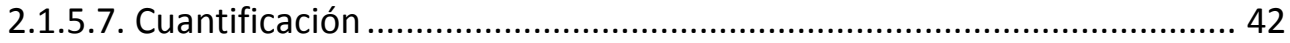

2.1.5.8. Electroforesis en geles de poliacrilamida.......................................... 42

2.1.6. Control de integridad estructural ....................................................... 43

2.1.6.1. Espectros de dicroísmo circular (CD) ................................................ 43

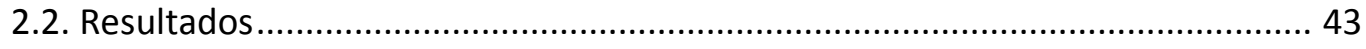

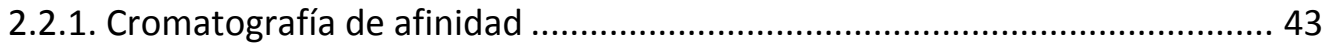

2.2.2. Cromatografía de exclusión molecular .................................................... 44

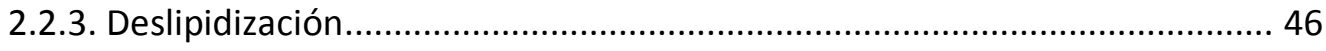

2.2.4. Controles de integridad estructural ........................................................... 49

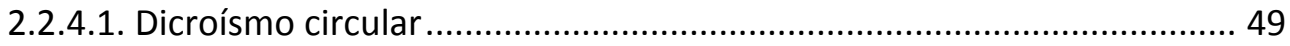

2.2.4.2. Espectros de RMN unidimensionales ${ }^{1} \mathrm{H}$............................................ 51

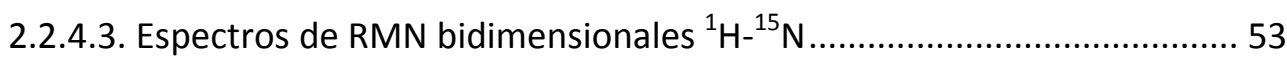

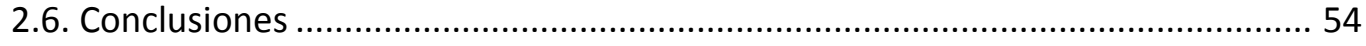

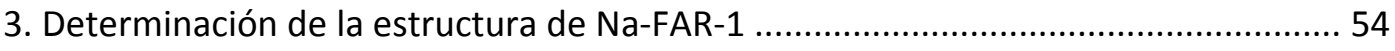

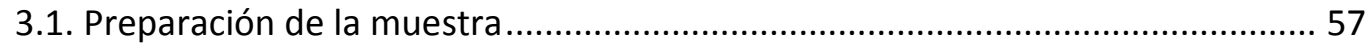

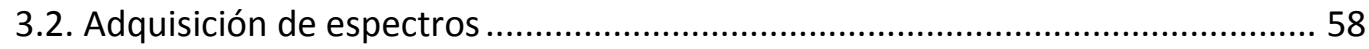

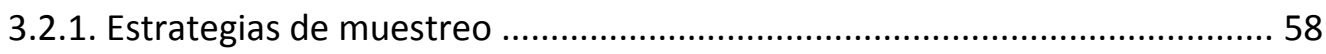

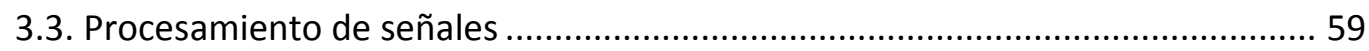

3.3.1. Procesamiento con transformada de Fourier directa................................. 59

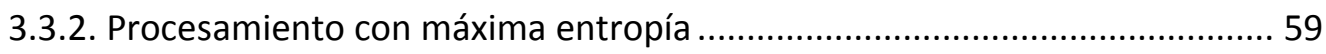

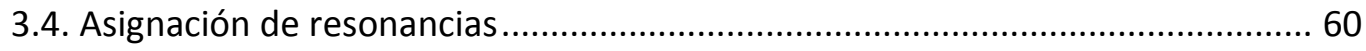


3.4.1. Asignación secuencial de la cadena principal 60

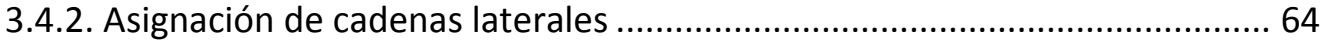

3.4.2.1. Asignación de cadenas alifáticas ............................................................ 66

3.4.2.2. Asignación de cadenas aromáticas......................................................... 70

3.4.3. Asignación de espectros NOESY ............................................................... 70

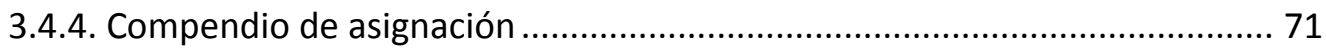

3.5. Restricciones para el cálculo de estructura ........................................................ 73

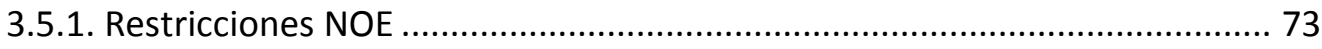

3.5.2. Restricciones de ángulos diedros .......................................................... 76

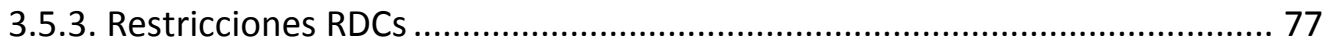

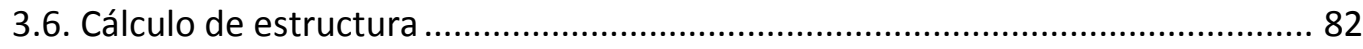

3.6.1. Dinámica molecular restringida y annealing simulado ................................ 83

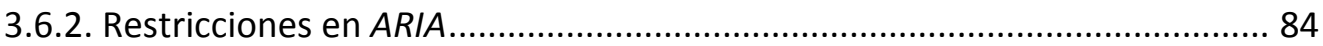

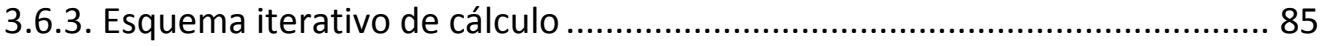

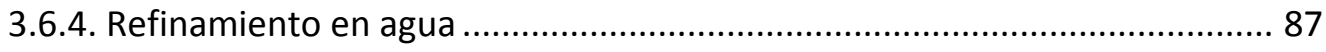

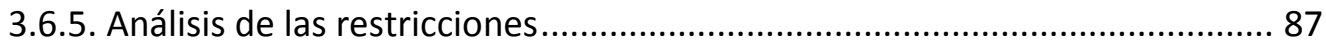

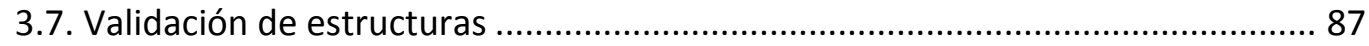

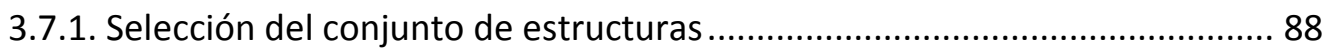

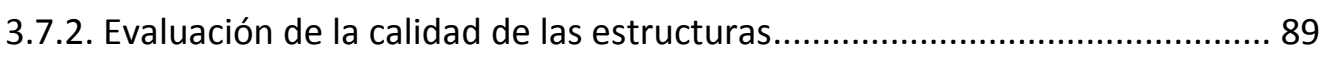

3.7.3 Calidad geométrica del conjunto de estructuras de NA-FAR-1 ................... 93

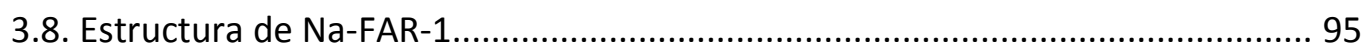

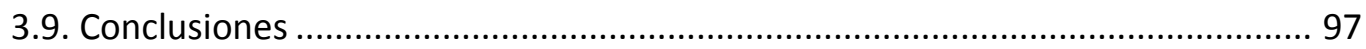

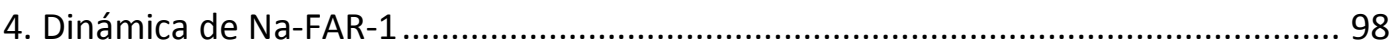

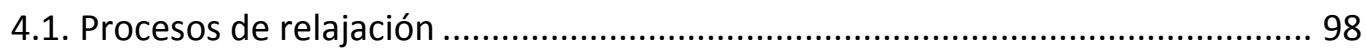

4.2. Medida de $T_{1}, T_{2}$ y NOE heteronuclear ...................................................... 102

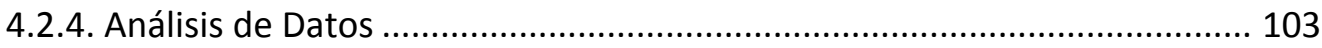


4.2.5. Resultados 104

4.3. Estimación de los tiempos de correlación y del tensor de difusión rotacional. 106

4.4. Análisis libre de modelo (Model Free Analysis) ................................................ 110

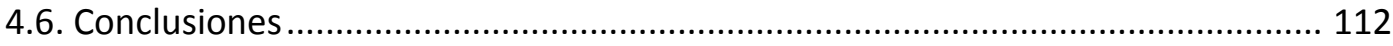

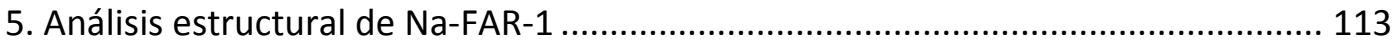

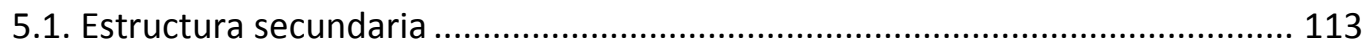

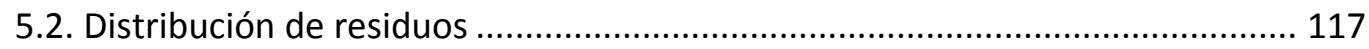

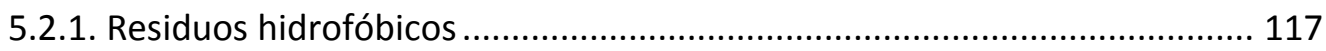

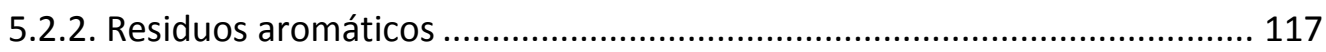

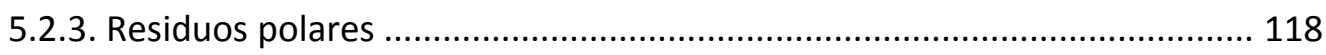

5.3. Estructura cristalográfica de Na-FAR-1 ..................................................... 120

5.4. Comparación entre las formas apo y holo.................................................. 122

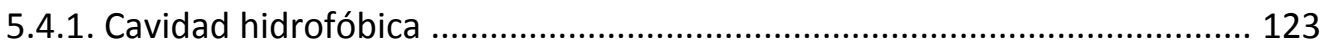

5.3.1.1 Cavidad de la forma Apo ............................................................... 125

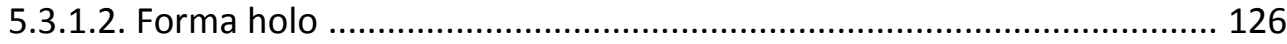

5.4. Comparación con otras estructuras............................................................. 128

5.4.1. Análisis comparativo con Ce-FAR-7 ..................................................... 129

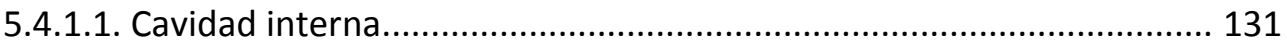

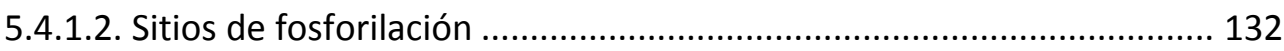

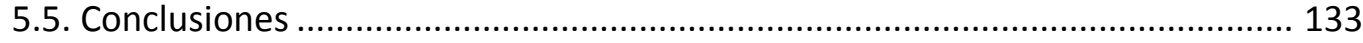

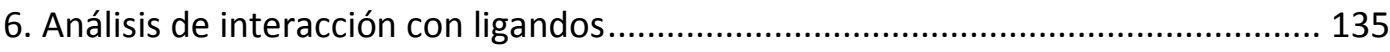

6.1. Caracterización de la composición lipídica ........................................................ 135

6.1.1. Extracción de lípidos de rNa-FAR-1 ......................................................... 136

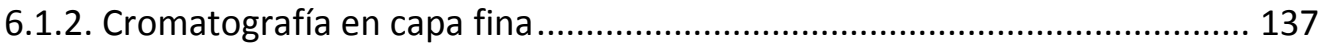

6.1.3. Saponificación y esterificación de ácidos grasos ........................................ 140

6.1.4. Cromatografía gaseosa......................................................................... 140

6.2. Análisis de interacción con ligandos por RMN .............................................. 143 
6.2.1. Titulación 146

6.2.2. Perturbación en los desplazamientos químicos ...................................... 151

6.3. Análisis de interacción con ligandos por espectroscopía de fluorescencia....... 153

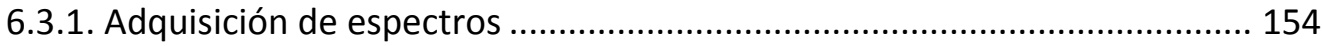

6.3.2. Evaluación de la preferencia por ácidos grasos de distinta longitud de

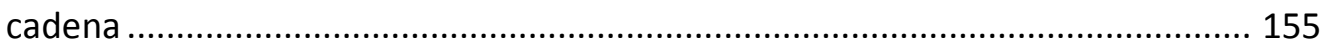

6.3.3. Titulaciones fluorimétricas y análisis de unión a ligandos ......................... 157

6.3.3.1. Unión a antroiloxi-derivados de ácidos grasos ................................... 158

6.3.3.2. Unión a ligandos naturales fluorescentes ........................................ 160

6.3.3.3. Unión a ácidos grasos naturales........................................................ 161

6.3.3.4. Discusión titulaciones fluorimétricas ............................................... 162

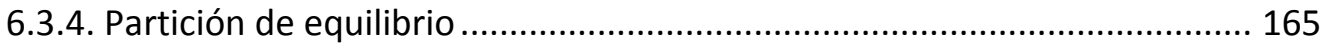

6.3.4.1. Preparación de vesículas unilamelares pequeñas (SUV)..................... 165

6.3.4.2. Cálculo del coeficiente de partición .................................................. 166

6.3.4.3. Resultados coeficiente de partición ................................................. 167

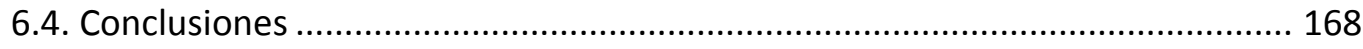

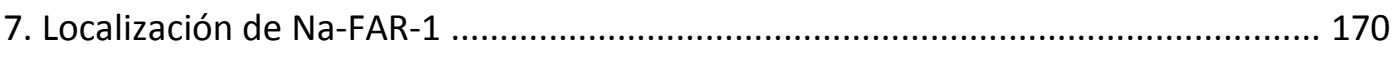

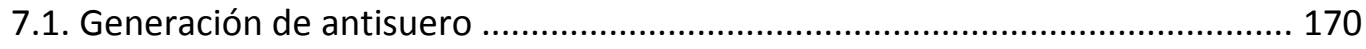

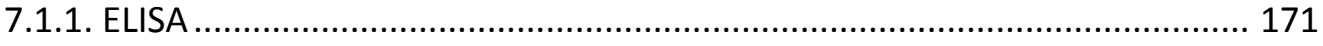

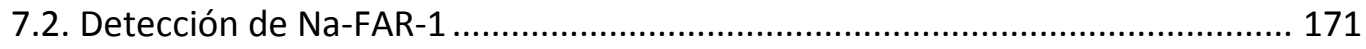

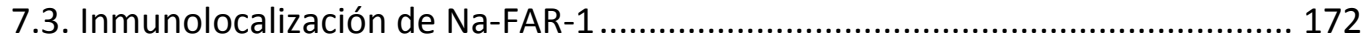

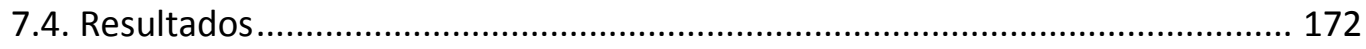

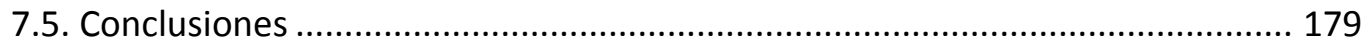

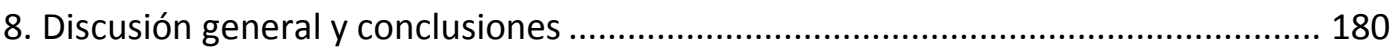

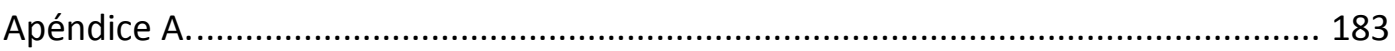

Asignación de los desplazamientos químicos de Na-FAR-1 .................................. 183

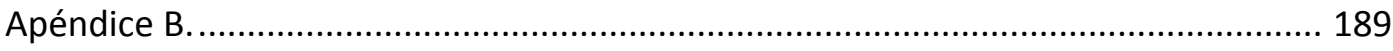

Resultados PROCHECK_NMR de Na-FAR-1 ....................................................... 189 
Gráficos Ramachandran (20 modelos) .......................................................... 189

Distribución de frecuencia Chi (20 modelos) .................................................... 195

Propiedades por residuo (20 modelos) ........................................................... 198

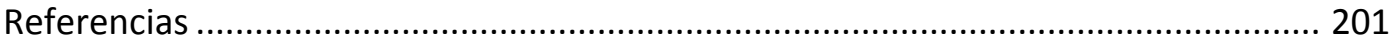




\section{Agradecimientos}

A la gran familia del laboratorio 10 por haber conformado un excelente grupo de trabajo, totalmente dispuestos a festejar en las buenas y a dar todo para salir adelante en las malas.

A Betina, por la dirección de mi tesis, por haber depositado en mí su confianza y haberme dado esta oportunidad que me permitió crecer.

A Lisandro por toda su ayuda con el manuscrito.

A Gise, Vale, Jor, Lu, Nati por su compañerismo, su amistad y por haber estado junto a mi cada vez que los necesité, y a King Julien, Nati S. y Kari por su buena onda.

Especialmente a Mari por haberse convertido en mi hermana gemela durante estos años y haber recorrido juntas el largo y escarpado camino de la biología estructural.

A todo el personal del INIBIOLP por su apoyo y camaradería. Especialmente a Annie, Juan Pablo y los Anitos por su valiosa ayuda con los lípidos, a Ana Bernasconi y Marcos Dreón por su asistencia con el HPLC y al grupo de Patricia Juárez con el equipo de GC, a Mabel y a Mario.

A Brian por su invaluable guía, su paciencia y por todo lo que aprendí a lo largo de estos años.

A su esposa Rose, y sus hijos Seamus, Tara y Sam por haberme abierto las puertas de su casa y adoptarme como a una más de su familia.

A Roger y Lisa por su cariño, su increíble sentido del humor y por hacerme sentir como en casa.

A Malcolm y Alan por transmitirme su entusiasmo, experiencia y por las hermosas cenas y encuentros musicales.

A Steve, Margaret y a todos los miembros del laboratorio en Glasgow por su calidez y compañerismo. A Kate por toda su ayuda, sus charlas a la hora del café con chocolates y los partidos de squash. A Sharon Kelly por su enorme ayuda con el CD. 
A Fede, Romi, Gabriel y Myriam por los buenos momentos en la cátedra.

A todos mis amigos por bancarme durante todos estos años.

A Pau por toda una vida juntas, a Vicky por los buenos momentos de convivencia y especialidades culinarias, a Dave, Bruno y Matthias por sus buenos consejos, a Seba por las remadas en el delta de Berisso.

A Eme por haberme cuidado, estimulado y servido siempre de ejemplo, a Gusy por haberme dado todo, a Sofi y Santi por hacer siempre las veces de hermanos mayores, a mis abuelas Conce y Pichona por mimarme y a toda mi familia por su apoyo y contención sin los cuales nada de esto hubiera sido posible. A Ana por todo su amor que voy a llevar siempre en mi corazón.

A la familia de Edu, Carmen, Jesús, Incoronata, Sebastián, Paula, Francisco, Valentín, Joaquín y Solcito por recibirme con tanto cariño en Balcarce.

A Edu por acompañarme, cuidarme, sostenerme y no dejarme bajar los brazos.

$\mathrm{Y}$ a tantos seres valiosos que me han dado su afecto $\mathrm{y}$ han enriquecido mi vida. 


\section{Siglas y definiciones}

ARIA Ambiguous restraints for iterative assignment

CNS Crystallography and NMR suite

COSY COrrelation SpectroscopY

CSP Chemical shift perturbation

FA Fatty acid. Ácido graso

FAR Fatty acid and retinol binding protein

FID Free induction decay. Caída libre de inducción

HSQC Heteronuclear Single Quantum Correlation

INEPT Insensitive Nuclei Enhanced by Polarization Transfer

MaxEnt Máxima Entropía

RMN Resonancia magnética nuclear

NOE Nuclear Overhauser Effect

NOESY Nuclear Overhauser Effect SpectroscopY

TOCSY TOtal Correlation SpectroscopY

rMD Restrained molecular dynamics. Dinámica molecular restringida

PDB Protein Data Bank

RMSD Root mean square deviation. Desviación cuadrática media

RDC Residual dipolar coupling. Acoplamiento dipolar residual

SUV Small unilamelar vesicle. Vesícula unilamelar pequeña

Desplazamiento químico es el corrimiento en la frecuencia de absorción de un núcleo debido a su entorno químico.

Frecuancia de Larmor Frecuencia a la cual precesiona un núcleo cuando es introducido bajo un campo magnético. Es característica de cada núcleo para una fuerza de campo magnético determinada.

Lock señal para evitar la deriva y mantener constante el campo magnético de un espectrómetro durante la medida. Normalmente se utiliza la señal de deuterio con este fin. 
Simulated annealing Proceso de cálculo mediante el cual una secuencia de aminoácidos en estructura al azar y a muy alta temperatura, se pliega en sucesivos pasos hacia un mínimo local de energía cuando se disminuye la temperatura. 


\section{Introducción}

Los nematodos son los animales multicelulares más numerosos sobre la tierra, con cerca de 23000 especies clasificadas dentro del phylum Nematoda, se estima que la gran mayoría de estos organismos aun no ha sido estudiada y existe gran desconocimiento biológico al respecto ${ }^{1}$.

Son gusanos pseudocelomados, de cuerpo redondeado y alargado, que habitan tanto en ecosistemas terrestres como acuáticos donde existen especies de vida libre que se alimentan de bacterias, hongos e incluso de otros nematodos y especies parásitas de plantas y animales, incluyendo al hombre ${ }^{2}$.

Los nematodos, junto a los cestodos y trematodos (gusanos aplanados o plathelmintos) se agrupan bajo el término general no taxonómico de helmintos (del griego gusanos) y las especies parásitas de estos organismos causan enfermedades severas en humanos, animales y plantas.

Las infecciones causadas por los helmintos se encuentran dentro de las denominadas "Enfermedades infecciosas desatendidas" (EID). Esta denominación se debe a que son enfermedades crónicas cuyos efectos en la salud son perdurables y afectan poblaciones en condiciones socioeconómicas y ambientales desfavorables, que habitan en áreas rurales o periurbanas, con viviendas precarias, sin acceso a servicios, como agua potable, sin saneamiento y con limitado acceso a servicios de salud ${ }^{3}$.

Las parasitosis constituyen un importante problema de salud pública dado que afectan a un gran porcentaje de la población mundial, principalmente en países en vías de desarrollo ${ }^{3,4}$. Puntualmente en América Latina un $30 \%$ de la población se ve afectada 5 . Dentro de las parasitosis causadas por helmintos cabe mencionar: geohelmintiasis, esquistosomiasis, hidatidosis, dracunculosis y filariasis. Muchas de estas enfermedades debilitan al hospedador afectando el crecimiento, el desarrollo físico e intelectual y la capacidad de aprendizaje. Las geohelmintiasis se caracterizan por ser especialmente silenciosas dado que las manifestaciones clínicas relacionadas con lo antes mencionado, carecen de otros síntomas más evidentes, por lo que han sido históricamente desatendidas, viéndose intensificadas entre las décadas de los 70 y 90 , 
encontrándose en la actualidad cerca de 2700 millones de personas en riesgo de contraer estas enfermedades en las zonas más pobres del planeta ${ }^{6}$.

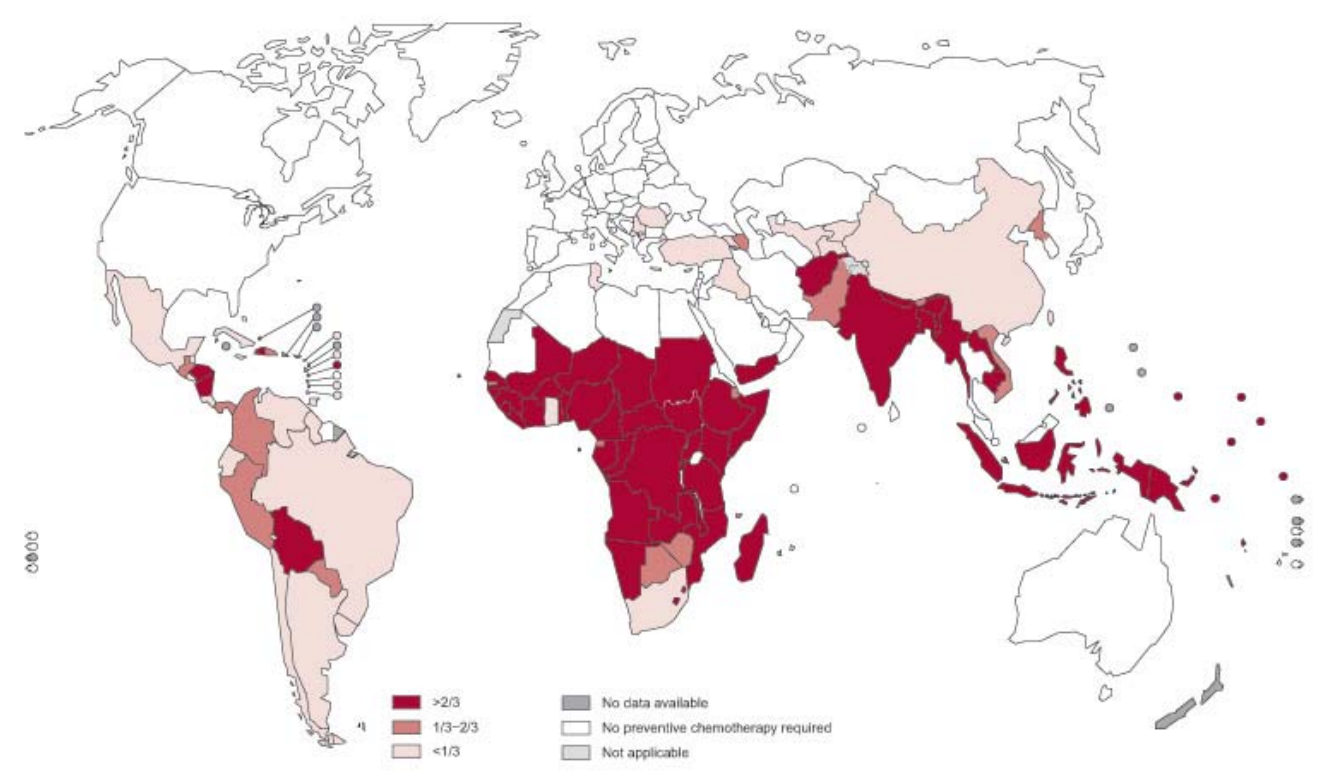

Fig.1.1. Distribución mundial de geohelmintiasis. Las zonas coloreadas indican la proporción de niños que habitan en esas zonas que requieren terapias antihelmínticas. Rojo intenso $>2 / 3$, moderado $1 / 3$ a $2 / 3$, suave $<1 / 2$, blanco no requiere y gris no hay datos. Imagen tomada y adaptada de http://www.who.int/intestinal_worms/epidemiology/en/\#.

Por otra parte, las infecciones por helmintos también afectan a cultivos agrícolas, animales domésticos y de cría, pudiendo generar grandes pérdidas económicas.

Actualmente existen programas de la Organización Mundial de la Salud tendientes a erradicar estas enfermedades y si bien las drogas antihelmínticas actuales son efectivas, existe la preocupación de que a largo plazo se desarrollen resistencias como ha ocurrido con helmintiasis de ganado ${ }^{7}$. Asimismo, dado que las larvas o huevos se encuentran diseminados en el ambiente generalmente se produce la reinfección luego del tratamiento ${ }^{8,9}$.

No obstante el impacto de estas infecciones, existen grandes deficiencias en materia de diagnóstico e intervenciones, incluyendo el control de vectores, desarrollo de nuevas drogas y vacunas ${ }^{10}$. La prevención y el control de estas enfermedades 
relacionadas con la pobreza requiere acciones integradas, con tratamientos combinados a mejoras de las condiciones de vida de los pueblos afectados ${ }^{11,12}$.

En los últimos años han surgido iniciativas, de organismos no gubernamentales, humanitarios y entidades estatales para financiar la investigación de estas parasitosis a fin de desarrollar nuevas terapias y métodos de diagnóstico ${ }^{13,6,9,14,15}$.

La ausencia de una contraparte en vertebrados atrae especial atención hacia ciertas proteínas debido a que podrían ser potenciales herramientas de diagnóstico e incluso blancos de vacunas o drogas para el desarrollo de nuevas terapias antihelmínticas ${ }^{16}$. Entre las proteínas que cumplen con estas características se encuentran las proteínas de helmintos que unen lípidos. Los parásitos helmintos producen y secretan una amplia variedad de este tipo de proteínas, la mayoría de ellas estructuralmente distintas a las de sus huéspedes.

\subsection{Proteínas de helmintos que unen lípidos}

Para facilitar la solubilización y transporte de lípidos requeridos en los procesos celulares, han evolucionado proteínas con motivos estructurales muy variados, que tienen la capacidad de unir de modo no covalente y en forma reversible diversos lípidos, facilitando así su transporte y disponibilidad en sistemas acuosos ${ }^{17,18,19,20}$. A este gran grupo heterogéneo de proteínas solubles se las conoce como proteínas de unión a lípidos o LBPs (del inglés lipid binding proteins) y se presentan tanto a nivel citosólico como extracelular.

Las LBPs son componentes mayoritarios de las secreciones de parásitos helmintos y fueron detectadas por ser antígenos inmunodominantes en distintas infecciones ${ }^{21,22}$ ${ }^{23}$. Si bien no se conocen con exactitud las funciones que cumplen, se postula que estas proteínas podrían estar involucradas en funciones internas relacionadas al metabolismo lipídico comunes a cualquier organismo multicelular, o bien específicas de los tipos celulares y organizaciones estructurales de los helmintos. Algunos de estos parásitos presentarían un metabolismo lipídico restringido y se cree que las LBPs serían sintetizadas para captar y proteger a estos compuestos adquiridos desde el hospedador a modo de compensar esta falta metabólica ${ }^{19,24}$. A su vez, podrían 
participar en funciones externas especializadas en la interacción con el hospedador, estando involucradas en la modulación del entorno tisular local mediante la captación de lípidos y en la evasión de las respuestas del sistema inmune a través del secuestro de moléculas hidrofóbicas mediadoras.

Entre las LBPs producidas por helmintos se encuentran proteínas muy similares a las proteínas citosólicas de unión a ácidos grasos FABP (del inglés fatty acid binding protein), algunas de las cuales presentarían modificaciones estructurales exclusivas de nematodos nemFABPs, así como también proteínas para las cuales no se han identificado homólogos en otros organismos, como las proteínas de unión a compuestos hidrofóbicos HLBP (del inglés hydrofobic ligand binding proteins) de cestodos y dos clases diferentes de proteínas exclusivas de nematodos, las poliproteínas NPA (del inglés nematode polyprotein antigen/allergen) y las FAR (del inglés fatty acid and retinol binding proteins).

Las FABP son una familia multigénica de proteínas de bajo peso molecular (14-15kDa) con una distribución filogenética muy amplia ${ }^{25}$. Estudios estructurales han revelado que las proteínas EgFABP detectadas en quistes hidatídicos producidos por el cestodo Echinococcus granulosus presentan una estructura barril beta coronada con motivos $\alpha-$ hélice del tipo FABP de corazón ${ }^{26}$. Estudios de caracterización indicarían que estas proteínas, que tienen cierta preferencia por ácidos grasos insaturados, ejercerían funciones especiales en la parasitosis ${ }^{27,28}$. Por su parte, las nemFABP presentarían cierta homología con las FABP pero a su vez contarían con características novedosas como la presencia de señal de secreción (todas las FABP previamente descriptas son citosólicas) y con ciertas modificaciones que las harían estructuralmente distintas a las del hospedador ${ }^{29}$. Se cree que estas proteínas, que unen ácidos grasos, estarían involucradas en la gran resistencia a factores de estrés que presentan los huevos de estos parásitos, que permanecen infectivos en el ambiente durante largos períodos. Si bien sus estructuras se desconocían al inicio de este trabajo, la estructura de la nemFABP de Ascaris suum, Asp-18, está siendo determinada ${ }^{30}$.

Por otra parte las HLBP, las NPA, y las FAR si bien parecen ser estructuralmente distintas entre sí, tienen estructuras secundarias mayoritariamente $\alpha$-helicoidales y son capaces de unir una mayor diversidad de ligandos. Las HLBPs son proteínas que 
han sido encontradas en cestodos, una de las cuales, Antígeno B, es la proteína mayoritaria del líquido proveniente del quiste hidatídico de E. granulosus ${ }^{31}$. El antígeno B estaría formado por distintas isoformas de $8 \mathrm{KDa}$ que tienen una estructura secundaria rica en hélices- $\alpha$, que se asociarían con lípidos heterogéneos formando lipoproteínas cuya estructura aún no ha sido determinada ${ }^{32}$.

En tanto las poliproteínas de nematodos NPAs, se expresan como precursores de alto peso molecular conteniendo unidades repetitivas en tándem. Estas unidades son clivadas postraduccionalmente en múltiples entidades proteicas de unos 15 kDa que presentan un alto contenido de $\alpha$-hélices ${ }^{33}$. El interés por estas proteínas surge por su potencial relevancia en el éxito del parasitismo como consecuencia de que son encontradas como el antígeno inmunodominante en las infecciones causadas por nematodos, y en algunos casos constituyen potentes alérgenos ${ }^{34}$.

Las NPAs, al igual que las FAR, unen lípidos pequeños como ácidos grasos y retinol ${ }^{24}$. De esta manera, las NPAs pueden ser clasificadas como LBPs no específicas y su probable función sería como proteínas transportadoras extracelulares presentes en el líquido pseudocelómico y tejido conectivo de nematodos, así como también en el fluido secretado en estrecho contacto con los tejidos del hospedador ${ }^{35}$. Recientemente se ha resuelto la estructura en presencia del ligando de la proteína ABA-1A de Ascaris suum que presenta dos sitios discretos de unión a ligando ${ }^{36}$.

Seguidamente se brindará una descripción más detallada de las FAR, que son el objeto de estudio del presente trabajo.

\subsection{Proteínas que unen ácidos grasos y retinol de nematodos (FAR)}

Las FAR (del inglés fatty acid and retinol binding proteins) son una clase novedosa de proteínas exclusivas de nematodos que unen ácidos grasos y retinol.

Ov-FAR-1 del parásito de la ceguera del río, Onchocerca volvulus, fue la primera de estas proteínas en ser descripta ${ }^{37}$. Este parásito es capaz de secuestrar retinol en una relación ocho veces mayor que en los tejidos circundantes del huésped y las manifestaciones clínicas características de esta enfermedad son el daño ocular y pérdida de visión nocturna coincidentes con deficiencias de retinol. En la fracción 
proteica capaz de unir retinol e ivermectina, un antiparasitario empleado para controlar esta enfermedad, se encontraría Ov-FAR-1 ${ }^{38}$. Se hipotetiza que Ov-FAR-1 puede desempeñar un rol importante en la interacción huésped-parásito y en la patogénesis, pero es muy poco lo que se sabe de su rol biológico en el nematodo o si sus homólogos ejercen funciones similares en otras especies ${ }^{39}$.

Las FAR tienen un tamaño aproximado de entre 19-20 kDa y poseen sitios de glicosilación conservados, pero los patrones de glicosilación varían de una proteína a otra registrándose la usencia de estas modificaciones postraduccionales en muchos de los $\operatorname{casos}^{40}$. Poseen asimismo, sitios potenciales de fosforilación para caseína quinasa de tipo II conservados ${ }^{41}$.

Esta familia de proteínas se expresa en estadios adultos de los parásitos ${ }^{37}$. Se ha descripto que las FAR son componentes mayoritarios en las secreciones de parásitos en humanos, animales y plantas ${ }^{37,42}$, lo que ha posibilitado emplearlas como herramientas de diagnóstico ${ }^{43}$. Se hipotetiza que podrían ejercer roles en la interacción con el hospedador y en la patogénesis mediante el transporte o secuestro de lípidos farmacológica e inmunológicamente activos ${ }^{39}$. Se ha propuesto que son capaces de facilitar la infección mediante la interferencia en señales de defensa del huésped ${ }^{44}$ y ejerciendo efectos inmunomodulatorios en células del sistema inmune ${ }^{34}$. Cabe destacar que se ha demostrado que una FAR, Ace-FAR-1 de Ancylostoma ceylanycum, es potencialmente útil como vacuna por ser capaz de conferir inmunidad en ensayos de desafío en animales de laboratorio ${ }^{45}$.

Las FAR unen ácidos grasos naturales, sus derivados fluorescentes artificiales y ligandos fluorescentes naturales como cis-parinárico y retinol con una afinidad en los órdenes micromolar y submicromolar y son capaces de transferir ligandos hacia membranas artificiales ${ }^{41,46,47}$. Pero se desconoce si su especificidad se limita a estos compuestos o son capaces de unir una más amplia variedad de ligandos. Es posible suponer que estas proteínas puedan participar en la captación, el transporte y/o el almacenamiento de lípidos en el parásito que la sintetiza por lo cual resulta interesante explorar las capacidades de unión a diferentes ligandos. El análisis de las propiedades de unión puede ser importante para entender el rol de la proteína en la biología del parásito y su relación con el huésped. 
Actualmente se están estudiando estas proteínas desde el punto de vista bioquímico para lograr un mejor entendimiento de su función biológica. Sin embargo, es aun hoy mucho lo que se desconoce sobre la biología de estos organismos, y los esfuerzos que actualmente se están llevando a cabo para secuenciar sus genomas permitirán complementar esta información ${ }^{48,49}$.

Desde el punto de vista estructural, sus estructuras ricas en alfa-hélices presentan alta estabilidad y no poseen análogos estructurales en otros grupos animales. Si bien al inicio de este trabajo no se conocía la estructura de ningún miembro de esta familia de proteínas, recientemente se ha determinado la estructura de una FAR, Ce-FAR-7, del nematodo de vida libre Caenorhabditis elegans ${ }^{50}$. De acuerdo a su estructura cristalográfica, Ce-FAR-7 presentaría dos cavidades discretas en las que podría ubicar distintos tipos de ligandos. Sin embargo, en base a su identidad de secuencia, esta proteína podría no ser representativa de las proteínas de parásito.

Conocer las estructuras y funciones de las proteínas de parásitos podría contribuir no sólo al conocimiento de la biología de los parásitos helmintos, sino también a la generación de nuevas estrategias de prevención y/o tratamiento de las enfermedades provocadas por ellos, así como al mejoramiento de los métodos diagnósticos. Las SLBPs exclusivas de parásitos presentan ciertas características que permitirían postularlas como posibles blancos para quimioterapia contra las diversas helmintiasis, ya sea como diana en sí mismas o para incrementar la asimilación y/o distribución de las drogas hacia sus lugares de acción. Teniendo en cuenta todas estas razones en este trabajo de tesis se propone la caracterización estructural y funcional de una proteína FAR de parasito helminto.

En la actualidad, las metodologías que aportan información más precisa acerca de las estructuras tridimensionales de proteínas son: la cristalografía de rayos $\mathrm{X}$ y la resonancia magnética nuclear (RMN). Si bien ambas metodologías permiten conocer con un detalle atómico las estructuras de las proteínas, el estudio por RMN, a diferencia de la cristalografía, no requiere de la formación cristales y permite la determinación de la estructura en solución. De este modo, resulta una técnica ventajosa para analizar la interacción de las proteínas con sus posibles ligandos, así como también sus aspectos dinámicos. 


\subsection{Estudios preliminares}

Estudios previos por RMN no publicados, realizados por el Dr. Brian Smith en la Universidad de Glasgow, con proteínas recombinantes purificadas por cromatografía en columna de afinidad, no mostraron buena dispersión en espectros ${ }^{1} \mathrm{H}$. Esto indicó que para la determinación de las estructuras de proteínas FAR por esta técnica debía llevarse a cabo una puesta a punto de la purificación dado que se requerían encontrar las condiciones de homogeneidad de muestra suficientes para obtener espectros ${ }^{1} \mathrm{H}$ con buena dispersión.

Con la finalidad de determinar la estructura tridimensional de esta familia de proteínas se purificaron cuatro proteínas FAR y se analizaron en cuanto a la calidad de los espectros de RMN y la factibilidad de determinar su estructura por esta técnica. Las proteínas seleccionadas en esta primera instancia fueron:

Ov-FAR-1, primera FAR en ser descripta por ser el antígeno inmunodominante en la ceguera del río, cuyo agente causal es el nematodo parásito Ochocerca volvulus ${ }^{37}$.

Ac-FAR-1 del parásito Ancilostoma caninum, presente en los productos de secresión/excresión del nematodo adulto, que infecta perros y es prácticamente indistinguible del parásito de humanos ${ }^{42}$.

Na-FAR-1 de Necator americanus, parásito de alta prevalencia en el norte argentino, cuyo gen se detectó por homología de secuencia con otras FAR en un análisis de secuencias expresadas (ESTs) y que no fue caracterizada previamente ${ }^{51}$.

Ce-FAR-5 del nematodo de vida libre Ceanorhabditis elegans empleado como organismo modelo para el estudio de nematodos parásitos. Esta proteína es una de las 8 FAR que este nematodo posee, y presenta un llamativo corrimiento del espectro de fluorescencia hacia el azul por unión a ligando, lo cual es indicativo de que posea una cavidad con muy alta hidrofobicidad ${ }^{46}$.

Mediante el análisis de los espectros unidimensionales de ${ }^{1} \mathrm{H}$ y bidemensionales ${ }^{15} \mathrm{~N}$ HSQC se seleccionaron Na-FAR-1 y Ce-FAR-5 como posibles candidatas para la determinación estructural por RMN. Estos resultados son presentados en el capítulo 2 de este trabajo de tesis. 
Teniendo en cuenta la incidencia de Necator americanus en nuestra región se seleccionó a Na-FAR-1 para completar la caracterización funcional y estructural. Los conocimientos previos acerca de esta proteína y la fundamentación que sustenta la elección de Na-FAR-1 se desarrollarán en los apartados subsiguientes.

\subsection{Na-FAR-1}

Entre los genes expresados por el nematodo $N$. americanus adulto se identificó una proteína FAR ${ }^{51}$, a la que hemos denominado Na-FAR-1 según la nomenclatura sugerida 39. Esta proteína presenta homología de secuencia con las FAR presentes en otros nematodos, que han sido caracterizadas previamente ${ }^{37,42,46}$ pero no ha sido aislada ni expresada en forma recombinante por otros autores.

La información acerca de la secuencia codificante de Na-FAR-1 se obtuvo de NEMBASE4 bajo el número de identificación NAC00128.

El cDNA de Na-FAR-1 codifica para una proteína de 19364.57 Da, cuya secuencia presenta una señal de secreción de catorce aminoácidos, según lo predicho con SignalIP ${ }^{52}$. El clivaje postraduccional del péptido señal resultaría en una proteína madura de 155 aminoácidos con un peso molecular de $17082.49 \mathrm{Da}$. La secuencia de Na-FAR-1 con el péptido de secreción se muestra en la figura 1.2.

1 MIRQ I AL I VLLFTQF LLVPAF KYEDI PADYRDLMPPEARDF LQNLSDGDKTVLKEVF KA59 60 GPYKNTEES I AALKKKSPELGAKVEKLHAMVKSKI AALGPEAKGFAEKS I EI ARG I KAR 118 119 YYTGNEPTKDDLKASVKEVLKLYKAMSDAGKADFGKQFPFLAKVFESGKAAKFAGEN 175

Fig.1.2. Secuencia de aminoácidos de Na-FAR-1. Los aminoácidos se colorean según su naturaleza. En negro se señala el péptido señal de secreción en el extremo N-terminal, el sitio de glicosilación conservado N29, L30, S31 y el sitio de fosforilación para caseína quinasa II S31-D34.

Hasta el momento Na-FAR-1 era la única FAR derivada de Necator americanus de cuya secuencia se tuviera conocimiento, pero a partir del muy reciente secuenciamiento del 
genoma de este nematodo se detectaron por homología las secuencias codificantes de otras proteínas FAR ${ }^{49}$.

La comparación de secuencias entre Na-FAR-1 y distintas FAR de otros nematodos se presenta a continuación.

\subsection{Comparación de secuencias}

La comparación de secuencias se realizó mediante el porgrama jalview $2.8^{53}$ empleando los algoritmos de T-Coffe prestablecidos ${ }^{54}$. El alineamiento obtenido se muestra en la figura 1.3. Para el análisis se incluyeron proteínas del nematodo de vida libre Caenorhabditis elegans (Ce-FAR-1 a Ce-FAR-8), de los parásitos de animales Ancylostoma caninum (Ac-FAR-1 y Ac-FAR-2), Ancylostoma ceylanicum (Ace-FAR-1), Ostertagia ostertagi (Oo-FAR-1) y Heligmosomoides polygyrus (Hp-FAR-1) y Acanthocheilonema vitae (Av-FAR-1), de especies parásitas de humanos Onchocerca volvulus (Ov-FAR-1), Brugia malayi (Bm-FAR-1), de los nematodos parásitos de plantas Globodera pallida (Gp-FAR-1) y Meloidogyne javanica (Mj-FAR-1). Además de Na-FAR-1 se emplearon las proteínas FAR recientemente identificadas en $N$. americanus, NECAME_09996, NECAME_04475, NECAME_04474, NECAME_14206, NECAME_14205

y NECAME_14203 ${ }^{55}$. Una proteína identificada con el código NECAME_14208 resultó ser Na-FAR-1 por presentar una identidad de secuencia del $100 \%$. El alineamiento se construyó a partir de secuencias maduras, para lo cuál se removió el péptido señal predicho mediante SignallP de los transcriptos primarios.

Las secuencias de aminoácidos de las proteínas FAR presentan un alto grado de diversidad, con ciertos aminoácidos en posiciones conservadas, entre los que se incluyen un sitio potencial de $\mathrm{N}$-glicosilaciones y un sitio de fosforilación para caseína quinasa II.

A partir del alineamiento de secuencias se construyó un dendrograma de distancia media mediante una matriz de porcentaje de identidad (figura1.4). 
Na-FAR-1/1-155 AC-FAR-1/1-165 Ac-FAR-2/1-165 Ace-FAR-1/1-165 AV-FAR-1/1-162 Do-FAR-1/1-166 Ho-FAR-1/1-154 Ov-FAR-1/1-162 Bm-FAR-1/1-162 GP-FAR-1/1-169 Ce-FAR-1/1-165 Ce-FAR-2/1-165 Ce-FAR-3/1-169 Ce-FAR-4/1-187 Ce-FAR-5/1-159 Ce-FAR-6/1-167 Ce-FAR-7/1-138 Ce-FAR-8/1-212 SF-FAR-1/1-170 NECAME 09996/1-117 NECAME 04475/1-208 NECAME 14206/1-156 NECAME_14205/1-173 NECAME_14203/1-163 NECAME_04474/1-158

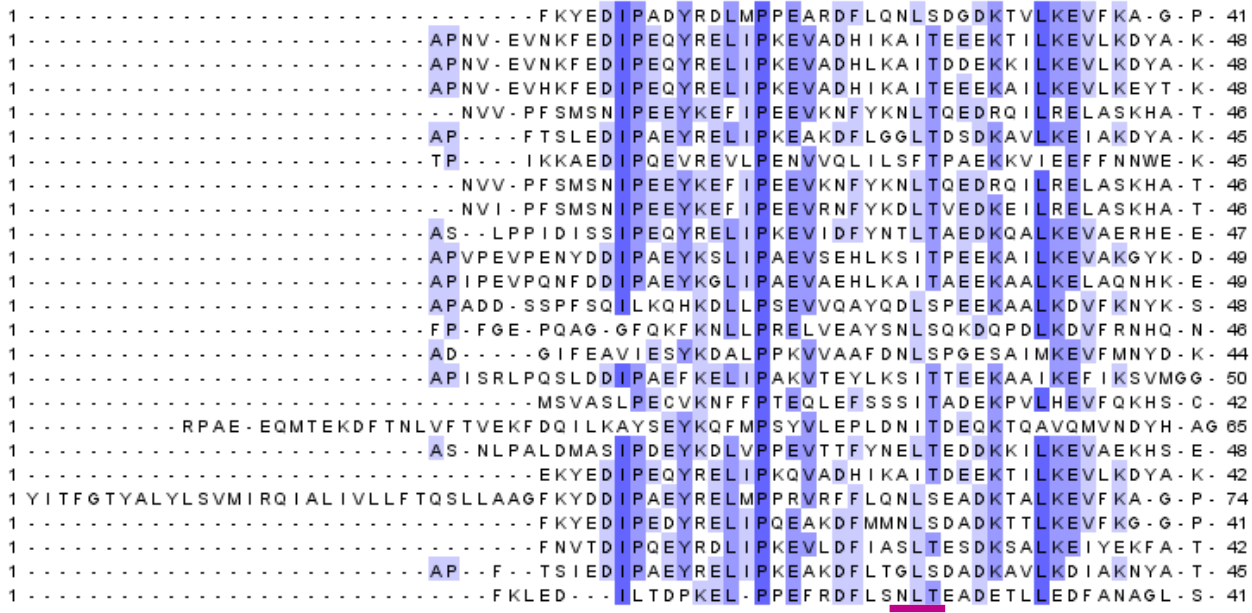

Na-FAR-1/1-155 Ac-FAR-1/1-165 AC-FAR-2/1-165 Ace-FAR-1/1-165 Av-FAR-1/1-162 OOFAR-1/1-16 TDFAR-1/1-154 OV-FAR-1/1-162 BM-FAR-1/1-162 Gp-FAR-1/1-169 Ce-FAR-1/1-165 Ce-FAR-2/1-165 Ce-FAR-3/1-169 Ce-FAR-4/1-187 CeFAR-5/1-159 CeFAR-51. Ce-FAR-7/1-138 Ce-FAR-8/1-212 CI-FAR-1/1-170 NECAME_09996/1-117 NECAME_04475/1-20 NECAME_14206/1-156 NECAME 14205/1-173 NECAME- 142051-17\% NECAME_14203/1-163

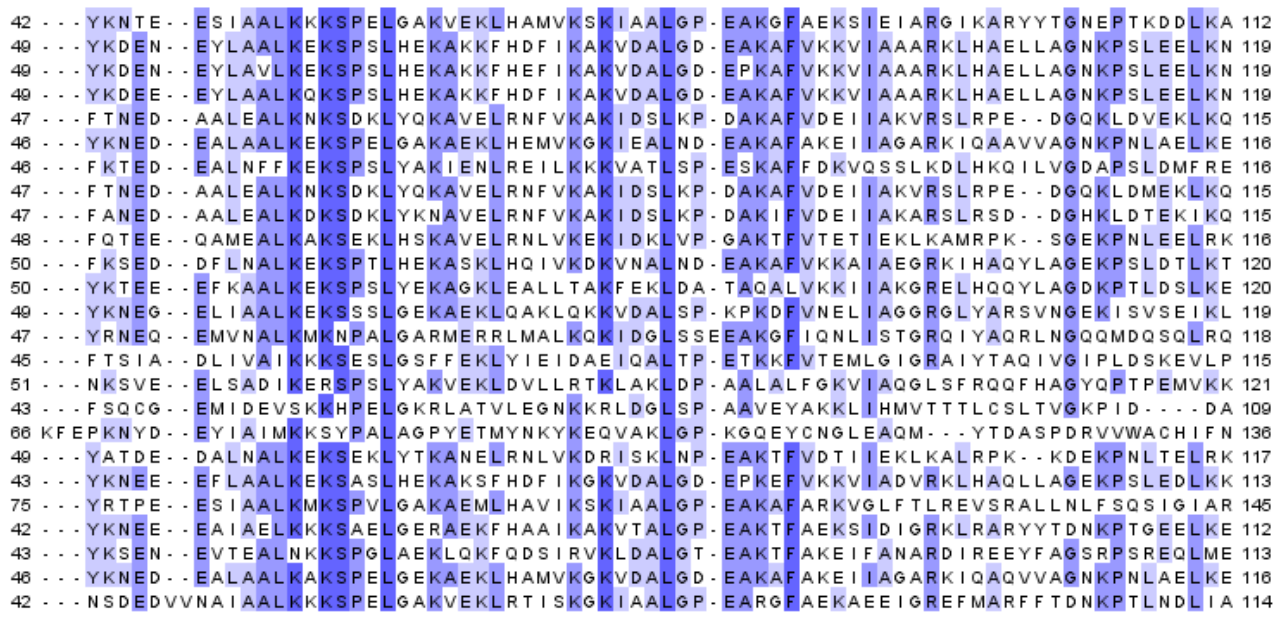

Na-FAR-1/1-155 AC-FAR-1/1-165 AC-FAR-2/1-165 Ace-FAR-1/1-165 AV-FAR-1/1-162 Oo-FAR-1/1-166 Ho-FAR-1/1-154 OV-FAR-1/1-162 $B M-F A R-1 / 1-162$ CeFAR-11Ce-FAR-2/1-165 Ce-FAR-3/1-160 Ce-FAR-4/1-18 Ce-FAR-5/1-159 Ce-FAR-6/1-167 Ce-FAR-7/1-138 CeFAR-8/138 Ce-FAR-8/1-212 NECAMTENECAME_04475/1-208 NECAME_14206/1-156 NECAME_14205/1-173 NECAME-142031-163 120 TVKKYVAEF DAL TAAA 120 TVKTYMAEF NALSPAA 120 TVKKYMAEFEALSAAA 116 AARD I I AKYEALNEET 117 KAXKAIEKYKALSEPA 117 VLRKHVDTYKALSADS 116 AARD I I AKYEALNEET 110 AARD I IAKYOALSEET 110 AARD I IAKYQALSEE 117 GANDTIIEKF KALSVEA AYKGLSQDA 121 LAKGYIAEYKALSDDA 120 L I ETQVAAYKALPAEA 119 VGMG I AMHYRSLPPYA 116 VFAKQFTSFKSLSDAT 122 LFKGYIAEYKTLSENA. 110 DAKRLHQEFQSLSSED 137 NAKSAVSGAKALLQDD
118 EANE I VEKFKALSEEA 114 OAKK

146 G I KARYYTGNKPTLDDL 113 KTAEVL KMYKSLSEDG 114 RTLNT INKYQAMSDAG 115 KAGE I VKLYKALSDDA

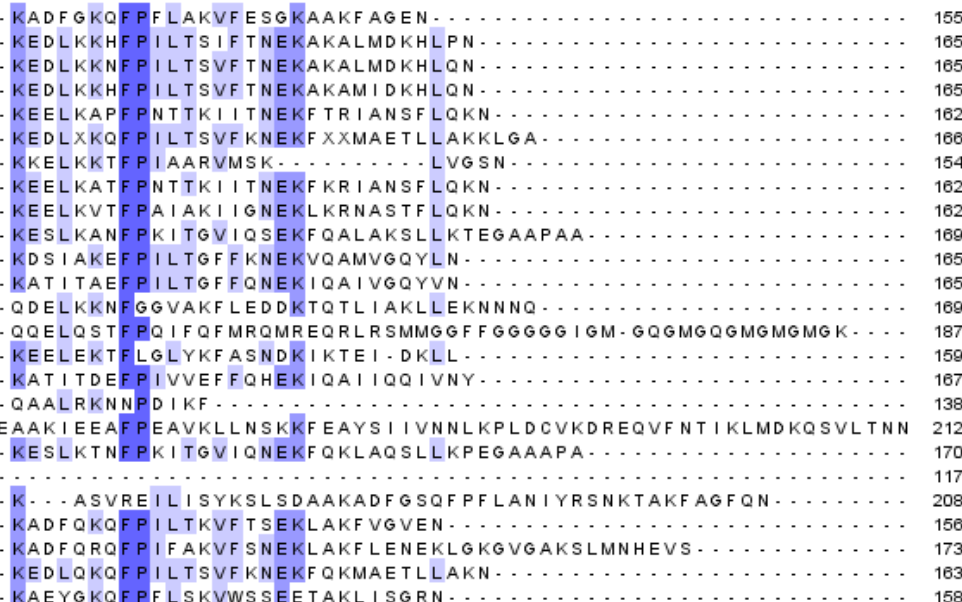

Fig.1.3.Alineación de secuencias de aminoácidos de proteínas FAR. Los aminoácidos con distinto grado de conservación se indican en tonos de azul. La posición de los sitios conservados se indica debajo de las secuencias, un sitio de $\mathrm{N}$-glicosilaciones (rojo) y un sitio de fosforilación para caseína quinasa II (verde). 


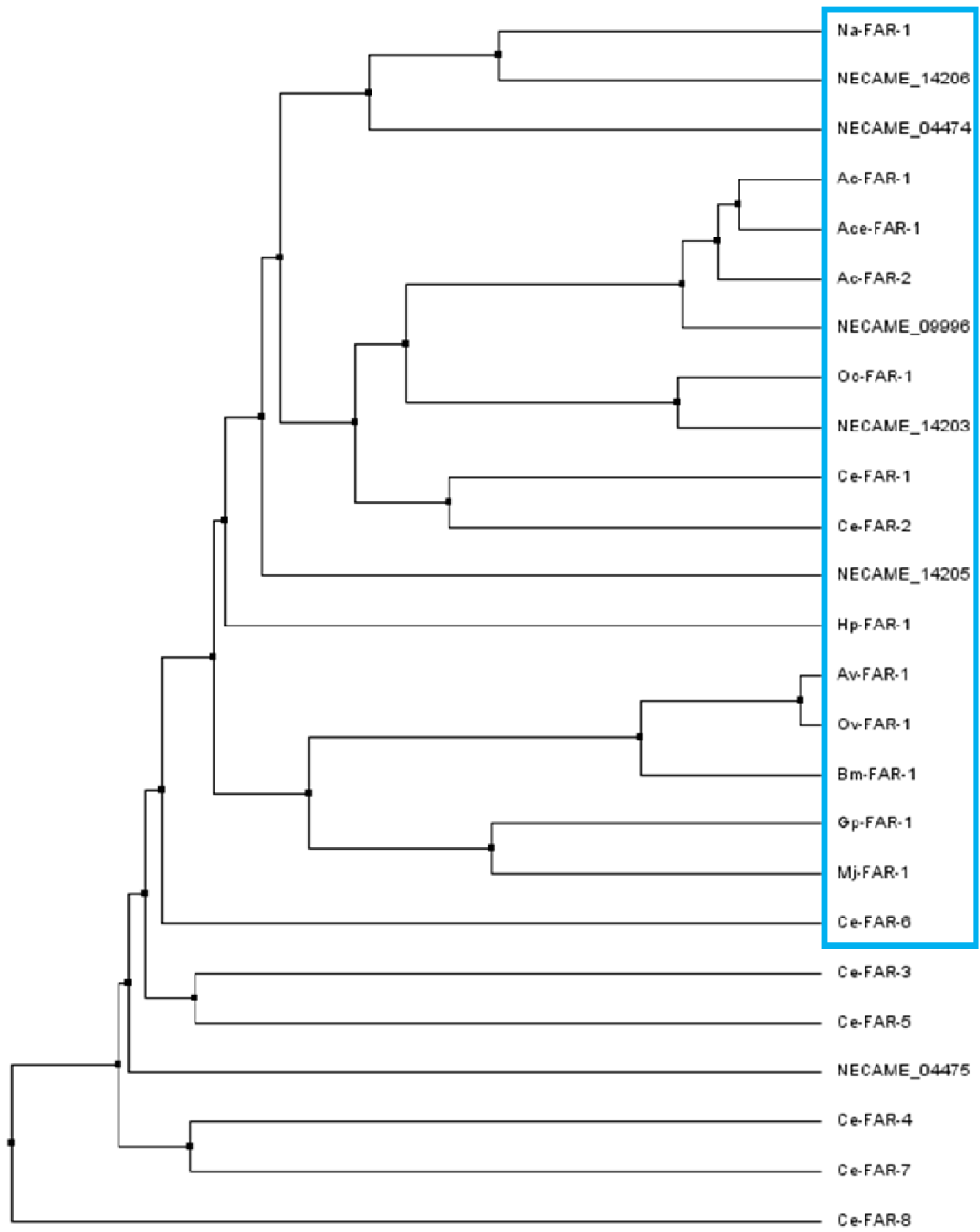

Fig.1.4.Dendrograma de las secuencias de aminoácidos de proteínas FAR. Se construyó una representación de la distancia media con una matriz de porcentaje de identidad. El grupo de las proteínas FAR de parásito se señala en celeste.

En el dendrograma se observa que las proteínas FAR derivadas de nematodos parásitos se ubican en un gran clúster, que incluye además a las proteínas de $C$. elegans Ce-FAR-1, Ce-FAR-2 y Ce-FAR-6. Las proteínas Ce-FAR-3, Ce-FAR-5, Ce-FAR-7 y Ce-FAR-8, de $C$. elegans se agrupan fuera de este clúster y parecen ser los miembros más divergentes de esta familia de proteínas. La única excepción la constituye una de 
las FAR de N. americanus, NECAME_04475, que se agrupa fuera del grupo de parásitos, con las FAR de C. elegans.

En estudios previos, todas las FAR de organismos parásitos se agrupaban en el mismo clúster junto con Ce-FAR-6, 2 y 1 46,42,50,44. En estos análisis se incluía solo una proteína de nematodo parásito de la cual se tenía conocimiento. La presencia de NECAME_04475 indicaría que los nematodos parásitos podrían sintetizar más de una clase de FAR, que aún no han sido identificadas en otros organismos, con funciones potencialmente diferentes.

La identidad de secuencia de Na-FAR-1 con respecto a otras proteínas FAR de $N$. americanus se encuentra entre un 44 y un 67\%, con las FARs de nematodos parásitos Ancylostoma y Ostertagia de la clase Rhabditida (a la que N. americanus pertenece) entre un 40 y un $50 \%$, con las FAR de $C$. elegans (nematodo no parásito de la clase Rhabditida) entre un 25 y un 38\% y con FARs de nematos parásitos de las clases Spururida (Onchocerca, Brugia, Acanthocheilonema) y Diplogasterida (Globodera y Meloidogyne) presenta entre un 28 y un $31 \%$ de identidad. El menor nivel de identidad de secuencia se observa para Ce-FAR-7, que es la proteína cuya estructura se ha determinado por cristalografía de rayos $\mathrm{X}$.

\subsection{Necator americanus}

Necator americanus, es un parásito intestinal que se alimenta de sangre cuya transmisión es por contacto con suelos contaminados. Junto a Ancylostoma duodenale y otros miembros de la familia Ancylostomatidae se los denomina uncinarias, siendo $N$. americanus el más ampliamente distribuido. Más de 740 millones de personas alrededor del mundo están infectados con estos nematodos ${ }^{56}$.

El ciclo de vida requiere la maduración de huevos y larvas en el ambiente, por lo que estas parasitosis se ubican dentro de las geohelmintiasis. El ciclo de vida de $N$. americanus se describe a continuación (figura1.2) ${ }^{57}$ : 


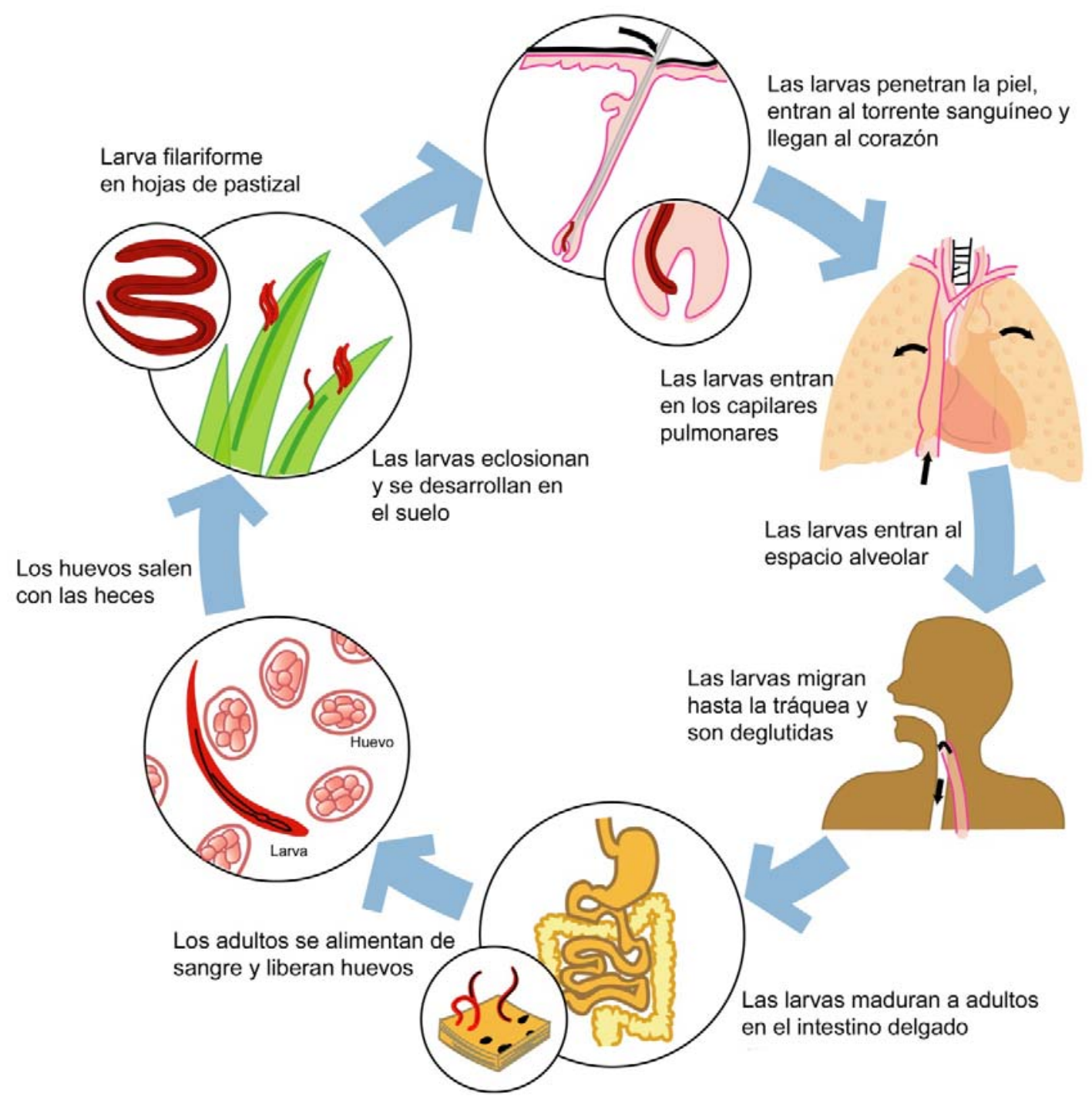

Fig.1.2. Ciclo de vida de Necator americanus. Imagen tomada y adaptada de ${ }^{6}$.

Los huevos embrionan y eclosionan en el suelo bajo las condiciones favorables de humedad y temperatura que se dan en regiones tropicales y subtropicales. Las larvas salen de los huevos se mueven y alimentan en la tierra. En esta primera etapa juvenil, L1, se denominan larvas rabditiformes (en forma de bastón). Estas larvas crecen y mudan en el suelo, transformándose en la segunda etapa juvenil, L2. Allí, mudan una vez más alcanzando la tercera etapa juvenil, L3, también llamada filariforme (en forma de filaria). Esta última es la forma infectiva y presenta geotropismo negativo ubicándose en los extremos de las hojas de las áreas infectadas donde pueden 
permanecer varios meses. Las larvas L3 son capaces de penetrar la piel humana, migrar por el torrente sanguíneo y alcanzar los pulmones. Una vez ahí, estas larvas filariformes perforan y penetran la cavidad alveolar y ascienden por la tráquea donde son deglutidas, para descender hasta el intestino delgado. En la mucosa del intestino mudan una vez más al estadio larval L4, maduran y se convierten en adultos fijándose a la pared intestinal, a través de sus dientes acerrados. En el intestino, donde pueden permanecer por más de cinco años, los adultos se alimentan de sangre y se aparean. Finalmente los huevos producidos por las hembras se liberan al ambiente a través de las heces completando el ciclo.

Estos gusanos hematófagos que causan pérdida de sangre, anemia, deficiencias de crecimiento y desarrollo intelectual afectan a poblaciones del norte argentino, hallándose una positividad superior al 30\%, que puede llegar al 50\% en comunidades aborígenes ${ }^{58,59}$.

Las infecciones por $N$. americanus y $A$. duodenale aumentan con la edad y se estabilizan alrededor de los 25 años y esto las diferencia de otras geohelmintiasis causadas por Ascaris lumbricoides y Trichuris trichura cuya incidencia es mayor en la niñez. Estas observaciones indican que las uncinarias no desarrollan defensas en los huéspedes, lo cual se debe a que producen diversas moléculas antiinflamatorias e inmunomoduladorias entre las que podrían encontrarse las FAR ${ }^{56}$.

Teniendo en cuenta el escenario antes planteado y considerando la gran incidencia de esta parasitosis nos propusimos realizar una caracterización estructural y funcional de Na-FAR-1 con los objetivos que se describen a continuación. 


\section{Objetivos}

Los objetivos generales del presente trabajo están vinculados al análisis estructural y biofísico de las proteínas solubles que unen lípidos de helmintos, para desarrollar un mejor entendimiento de la relación estructura-función, de su rol biológico y en la patogénesis.

Entre las proteínas de helmintos con características estructurales novedosas, se ha seleccionado para estos estudios a Na-FAR-1, perteneciente a la familia de proteínas que unen ácidos grasos y retinol de nematodos. Na-FAR-1 cuya secuencia primaria parece ser representativa de las FAR sintetizadas por nematodos parásitos, proviene de Necator americanus, un geohelminto de gran incidencia en nuestra región, no existiendo ningún reporte previo sobre la caracterización de esta proteína en la actualidad.

Nos proponemos desarrollar los siguientes objetivos específicos:

- Purificar la proteína recombinante en un alto grado de pureza, compatible con estudios biofísicos y estructurales.

- Resolver la estructura tridimensional de Na-FAR-1 mediante resonancia magnética nuclear. En este sentido se pretende: Adquirir espectros y analizarlos para la asignación de resonancias y generar las restricciones para su incorporación en el cálculo de la estructura. Validar de las estructuras calculadas y analizar las propiedades dinámicas de la molécula.

- Evaluar la capacidad de Na-FAR-1 de unir ligandos hidrofóbicos: Caracterizar los compuestos hidrofóbicos unidos a la proteína recombinante para tener una mayor aproximación acerca de qué ligandos une la proteína preferentemente. Estudiar la especificidad, afinidad y la estequiometria de los complejos formados. 


\section{Producción de proteína}

Los estudios estructurales y ensayos de caracterización biofísica requieren muestras de proteína homogéneas, con un elevado grado de pureza. Asimismo, es fundamental poder obtener buenos rendimientos en la purificación dado que en los experimentos de RMN se emplean grandes cantidades y altas concentraciones. La proteína debe ser estable en el tiempo requerido para los experimentos y no formar agregados al ser concentrada. Es por esto que la producción de proteína constituyó un paso fundamental en el desarrollo del presente trabajo de tesis. Las proteínas FAR no habían sido purificadas previamente en nuestro laboratorio y en particular Na-FAR-1 nunca purificada en ningún otro laboratorio que se tenga conocimiento, debido a ello se buscaron las condiciones óptimas para su producción en medio rico y en medio mínimo.

Las proteínas FAR se sobreexpresaron en forma recombinante en $E$. coli como proteínas de fusión con secuencias de polihistidina. Para su purificación, luego de la lisis celular por sonicado, se realizaron sucesivos pasos cromatográficos y se evaluó por distintos métodos la calidad de la muestra.

Si bien la puesta a punto de la purificación se llevó a cabo para las cuatro proteínas FAR seleccionadas inicialmente como objeto de estudio, a continuación detallaremos únicamente los resultados obtenidos para Na-FAR-1, que fue la proteína finalmente seleccionada para completar los estudios estructurales y en la que se centra este trabajo de tesis.

\subsection{Materiales y métodos}

\subsubsection{Soluciones amortiguadoras}

- Buffer de unión: Tris 20 mM, NaCl 500 mM, Imidazol 5 mM, NaN 1 mM, pH=7.4.

- Buffer de lavado: Tris 20 mM, NaCl 500 mM, Imidazol 25 mM, NaN 1 mM, pH=7.4.

- Buffer de elución: Tris 20 mM, NaCl 500 mM, Imidazol 250 mM, NaN 1 mM, pH= 7.4 .

- Buffer PBS: $137 \mathrm{mM} \mathrm{NaCl}, 10 \mathrm{mM} \mathrm{Na}_{2} \mathrm{HPO}_{4}, 1.8 \mathrm{mM} \mathrm{KH}_{2} \mathrm{PO}_{4}, 1 \mathrm{mM} \mathrm{NaN}, \mathrm{pH}=7.4$.

- Buffer NMR: $\mathrm{NaCl} 20$ mM, NaPi 20 mM, pH=7.4. 


\subsubsection{Biología Molecular}

La secuencia codificante de Na-FAR-1 se obtuvo de la base de datos de transcriptómica de nematodes, Nembase4 (http://www.nematodes.org/) ID de secuencia: NAC00128, el cDNA codificante fue sintetizado químicamente (GeneArt AG, Regensburg, Alemania) con una cola de polihistidina adicionada en el extremo $\mathrm{N}$-terminal y clonada en el vector de expresión pET11a (Novagen). El cDNA sintetizado codifica para la secuencia de aminoácidos de la proteína Na-FAR-1 recombinante detallada en la figura 2.1.

1 MG SSHHHHHHSSGHMFKYED I PADYRDLMPPEARDFLQNLSDGDKTVLKEVF KAGPY57

58 KNTEES I AALKKKSPELOAKVEKLHAMVKSKI AALGPEAKGF AEKS I E I ARG I KARY114

115 YTGNEPTKDDLKASVKEVLKLYKAMSDAGKADFGKQFPFLAKVFESGKAAKF AGEN 170

Fig.2.1. Secuencia de aminoácidos de Na-FAR-1 recombinante. La proteína rNa-FAR-1 presenta un tag de polihistidina no clivable en su secuencia.

Este trabajo de tesis se desarrolló con la proteína Na-FAR-1 recombinante con la secuencia de polihistidinas en el extremo N-terminal. La denominación rNa-FAR-1 se empleará en casos en que se quiera diferenciar de la proteína madura nativa, de otro modo se nombrará simplemente Na-FAR-1.

El cDNA codificante de Ov-FAR-1 fue sintetizado químicamente (GeneArt AG, Regensburg, Alemania) con una cola de polihistidina adicionada en el extremo Nterminal y clonada en el vector de expresión pET11d (Novagen).

Los plásmidos conteniendo las secuencias codificantes de Ac-FAR-1 en el vector pET30a y Ce-FAR-5 en pET30 Xa/LIC, fueron cedidos por el laboratorio de Malcolm W. Kennedy de la Universidad de Glasgow. 


\subsubsection{Minipreparación de Plásmidos}

La obtención de DNA plásmídico se realizó a partir de cultivos de $E$. coli según el protocolo de ${ }^{60}$. Se emplearon $5 \mathrm{ml}$ de cultivo bacteriano fresco, crecido toda la noche a $37^{\circ} \mathrm{C}$ en un tubo Falcon ${ }^{\mathrm{TM}}$. Se centrifugó a $3000 \mathrm{rpm}$ durante $10 \mathrm{~min}$ a $4{ }^{\circ} \mathrm{C}$. Se removió el sobrenadante y se resuspendió el pellet con $100 \mu$ l de una solución Tris-ClH $25 \mathrm{mM}$, EDTA $10 \mathrm{mM}, \mathrm{pH}=8$, agitando en vórtex. Se adicionaron $200 \mu \mathrm{l}$ de una solución $\mathrm{NaOH}$ 0,2 M, SDS $1 \%$, recientemente preparada. Se agitó suavemente por inversión, hasta resuspensión completa del pellet, y se incubó a temperatura ambiente por no más de 5 minutos. Se adicionaron $150 \mu \mathrm{l}$ de una solución acetato de potasio $5 \mathrm{M}$, ácido acético $11,5 \% \mathrm{v} / \mathrm{v}$, enfriada en hielo para detener la lisis. Se agitó suavemente por inversión y se incubó en hielo por 5 minutos. Se centrifugó a 1200 xg por 10 minutos a $4{ }^{\circ} \mathrm{C}$ y se transfirió el sobrenadante a un tubo limpio. Se adicionaron $450 \mu \mathrm{l}$ de fenol-cloroformo (1:1), estabilizado con solución de Tris- $\mathrm{HCl} 100 \mathrm{mM} \mathrm{pH} \mathrm{8,} \mathrm{y}$ se incubó a temperatura ambiente por 5 minutos eliminando así proteínas y restos de lípidos. Se centrifugó a 12000 rpm por 5 minutos y se transfirió el sobrenadante a un tubo limpio. Se adicionó $1 \mathrm{ml}$ de etanol $96 \%$ y se incubó a $-20{ }^{\circ} \mathrm{C}$ durante 30 minutos. Se centrifugó a 12000 rpm durante 25 min. Se removió el sobrenadante y se lavó el pellet con etanol 70 \%. Se centrifugó a 12000 rpm durante 5 minutos, se removió el sobrenadante y se invirtió cuidadosamente el tubo sobre un papel absorbente para secar a temperatura ambiente. Se disolvió el pellet en 20-50 $\mu$ l de agua bidestilada estéril y se midió en una dilución apropiada la absorbancia a 280 y $260 \mathrm{~nm}$ para evaluar su grado de pureza. Se agregó RNAsa en una concentración aproximada de 20 $\mu \mathrm{g} / \mathrm{ml}$ y se guardó a $-20^{\circ} \mathrm{C}$.

Alternativamente se emplearon kits comerciales QuickLyse Miniprep Kit (Qiagen) siguiendo las especificaciones del fabricante.

La presencia de plásmidos con los distintos insertos se evidenció mediante una digestión con las enzimas de restricción correspondientes y electroforesis en geles de agarosa. 


\subsubsection{Electroforesis en geles de agarosa}

Bajo la acción de un campo eléctrico los fragmentos de DNA se separan en base a su peso molecular. Este análisis se realizó mediante electroforesis en geles de agarosa para comprobar la integridad de las construcciones en los plásmidos. Para la visualización de vectores linealizados y sus correspondientes insertos se emplearon geles de agarosa 1\%. La solución se preparó en buffer Tris-borato 90 mM, EDTA 2 mM, $\mathrm{pH}=8$. Para evidenciar la presencia de ácidos nucléicos en un transiluminador UV, se agregó $1 \mu \mathrm{l}$ de bromuro de etidio de una concentración $10 \mathrm{mg} / \mathrm{ml}$. Debido a su alto carácter mutagénico el bromuro de etidio se reemplazó por SYBR ${ }^{\circledR}$ Safe, Invitrogen siguiendo especificaciones del fabricante.

\subsubsection{Purificación de DNA a partir de geles de agarosa}

La técnica utilizada para la extracción de DNA a partir de geles de agarosa fue una adaptación del procedimiento descripto en el manual de DNA Gel Extraction Kit, Millipore. Se cortaron con bisturí las distintas bandas de interés del gel de agarosa bajo luz ultravioleta y se trituró sobre una superficie lisa. Los trocitos de gel fueron depositados en filtros de 0,22 $\mu \mathrm{m}$, los cuales encastran en tubos Eppendorf de 1,5 ml. Se centrifugó a 13000 rpm en una microcentrífuga refrigerada durante 10 minutos. Se repitió el procedimiento rehidratando el gel previamente con $200 \mu \mathrm{l}$ de $\mathrm{H} 2 \mathrm{O}$ bidestilada estéril. Con el volumen eluido se realizó una precipitación con etanol.

\subsection{Precipitación con etanol}

Para concentrar y/o purificar una muestra de DNA se realizó una precipitación con etanol ${ }^{60}$. Se agregó dos veces el volumen de etanol $96 \%$ y el equivalente al $10 \%$ del volumen de la muestra de una solución acetato de sodio 3M. Se incubó 30 minutos a $20{ }^{\circ} \mathrm{C}$. Se centrifugó a $14000 \mathrm{rpm}$ durante 15 minutos y se removió el etanol. Se lavó el pellet con $500 \mu \mathrm{l}$ de etanol $70 \%$. Se centrifugó a $14000 \mathrm{rpm}$ durante 5 minutos y se

removió el etanol, se dejó secar a temperatura ambiente. El pellet se resuspendió en agua bidestilada estéril y se guardó a $-20^{\circ} \mathrm{C}$. 


\subsubsection{Digestión con enzimas de restricción}

Las enzimas de restricción presentan gran especificidad y generan terminales ligables, lo que permite el corte y análisis del DNA. Las enzimas de restricción Nde I, Nco I, Xho I, Xba I fueron obtenidos de Promega (USA). Todas las digestiones fueron realizadas según el siguiente protocolo: 1 a $5 \mu$ l de DNA (0.5-1.0 $\mu \mathrm{g}), 1 \mu \mathrm{l}$ 10X Buffer provisto junto con las enzimas, $0,1 \mu \mathrm{l}$ BSA, $0,5 \mu \mathrm{l}$ de cada enzima a utilizar y $\mathrm{H}_{2} \mathrm{O}$ bidestilada estéril necesaria para completar el volumen. En un volumen final de $10 \mu \mathrm{l}$. Se incubó 2 hrs a $37^{\circ} \mathrm{C}$.

Na-FAR-1: Nco I y Nde I; Ov-FAR-1: Nde I y Nco I; Ac-FAR-1: Xho I y Xbal; Ce-FAR-5: Xho I y Xbal.

\subsubsection{Ligación}

Mediante una reacción de ligación, catalizada por la enzima ligasa del fago T4, se favorece la formación de enlaces fosfodiéster, pudiendo unir fragmentos de DNA de distinto origen. Para la ligación, se utilizó una relación inserto/vector 3:1 (mol:mol), 1 $\mu \mathrm{l} 10 \mathrm{X}$ buffer ligasa provisto junto con la enzima, $1 \mu$ l enzima T4 DNA ligasa, $\mathrm{H}_{2} \mathrm{O}$ bidestilada estéril hasta completar un volumen final de $10 \mu$ l. Las reacciones fueron incubadas durante toda la noche a una temperatura de $4^{\circ} \mathrm{C}$.

\subsubsection{Obtención de bacterias competentes}

Para la generación de bacterias capaces de ser transformadas, se siguió el protocolo detallado por ${ }^{60}$. Se inocularon $3 \mathrm{ml}$ de medio de cultivo líquido LB (triptona $1 \%$, levadura $0,5 \%, \mathrm{NaCl} 1 \%$ ) sin antibiótico con un stock de bacterias no competentes recién descongeladas. Se incubó toda la noche a $37^{\circ} \mathrm{C}$, con agitación fuerte. Se diluyeron los $3 \mathrm{ml}$ de cultivo en $100 \mathrm{ml}$ de medio LB sin antibiótico y se incubó con agitación fuerte hasta D0600nm=0,5. Se dejó enfriar depositando el cultivo sobre hielo durante aproximadamente 10-15 minutos. Se centrifugó a $2000 \mathrm{rpm}$ durante 15 minutos a $4^{\circ} \mathrm{C}$. Se descartó el sobrenadante y se resuspendió el pellet con $30 \mathrm{ml}$ de buffer TFB1 ( $\mathrm{RbCl} 100 \mathrm{mM}, \mathrm{MnCl} 250 \mathrm{mM}$, acetato de potasio $30 \mathrm{mM}, \mathrm{CaCl} 210 \mathrm{mM}$, 


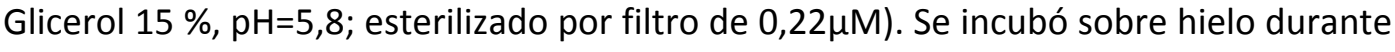
90 minutos y se centrifugó a $2000 \mathrm{rpm}$ durante 15 minutos a $4^{\circ} \mathrm{C}$, se descartó el sobrenadante. Se resuspendió el pellet con $4 \mathrm{ml}$ de buffer TFB2 (10 mM, RbCl 10 mM, $\mathrm{CaCl} 275 \mathrm{mM}$, Glicerol $15 \%, \mathrm{pH}=8,0$; esterilizado en autoclave). Las bacterias fueron almacenadas a $-70^{\circ} \mathrm{C}$ en alícuotas de $500 \mu \mathrm{l}$.

\subsubsection{Transformación de bacterias competentes}

Mediante esta técnica se logra la incorporación de DNA plasmídico en el citoplasma bacteriano. En este trabajo de tesis se han transformado células pertenecientes a distintas cepas de E. coli. La cepa JM109, utilizada para obtener masa de plásmido; y la cepa BL21 (DE3), utilizada para obtener masa de proteína. Se tomaron $5 \mu$ de una reacción de ligación y se depositaron en un Eppendorf de 1,5 ml. Se agregaron $100 \mu \mathrm{l}$ del stock de bacterias competentes y se incubó en hielo durante 30 minutos. Se aplicó un shock térmico incubando en un baño termostatizado a $42^{\circ} \mathrm{C}$ durante 50 segundos, seguidos de dos minutos de incubación en hielo. Se agregaron $900 \mu \mathrm{l}$ de medio LB sin antibiótico y se incubó con agitación fuerte durante 2 horas a $37^{\circ} \mathrm{C}$. Se realizaron al menos dos diluciones del cultivo y se distribuyeron con ayuda de una espátula de Drigalsky (esterilizada por incineración a la llama con alcohol 70\%) sobre placas de medio LB con Agar 1.5\% conteniendo el antibiótico correspondiente, que depende del vector que se usó para la transformación. Se incubó toda la noche en estufa a $37^{\circ} \mathrm{C}$. Se seleccionaron varias colonias y se constató la presencia del plásmido mediante una minipreparación de plásmidos. Las bacterias transformadas fueron almacenadas a $70^{\circ} \mathrm{C}$ con una concentración final de glicerol del $20 \%$.

\subsubsection{Expresión y purificación de proteínas}

La expresión de proteínas se realizó en el sistema pET de Novagen. En este sistema la expresión génica se encentra regulada bajo el promotor del bacteriófago T7. La ARN polimerasa de T7 transcribe nucleótidos cinco veces más rápido que el de $E$. coli y el promotor T7 no es reconocido por la RNA polimerasa de E. coli, por lo cual es 
altamente selectivo. En las células huésped, el gen de la T7 ARN polimerasa se encuentra bajo el la regulación del promotor lacUV5, que es inducido por el $\beta$-D-1thiogalactopiranosido (IPTG). El represor Lac, codificado en el genoma bacteriano, inhibe al promotor lacUV5 evitando expresión basal. La expresión se inicia por la adición de IPTG que se une al represor lac, liberando el promotor y permitiendo la transcripción de la ARN polimerasa T7 y consecuentemente del gen que codifica para la proteína recombinante.

\subsubsection{Medios de cultivo}

LB:

$\mathrm{NaCl}$ $10 \mathrm{~g}$

Triptona $10 \mathrm{~g}$

Extracto de levadura $5 \mathrm{~g}$

$\mathrm{H}_{2} \mathrm{O}$ destilada csp

\section{Medio mínimo:}

M9 (5X) $50 \mathrm{ml}$

$\mathrm{MgSO}_{4}(1 \mathrm{M})$ $0,5 \mathrm{ml}$

$\mathrm{CaCl}_{2} \quad(50 \mathrm{mM})$ $0,5 \mathrm{ml}$

Glucosa (20\%P/V) $2,5 \mathrm{ml}$

$\mathrm{NH}_{4} \mathrm{Cl}(2 \mathrm{M})$ $2,5 \mathrm{ml}$

Tiamina $(50 \mathrm{mg} / \mathrm{ml}) \quad 0,25 \mathrm{ml}$

$\mathrm{H}_{2} \mathrm{O}$ bidestilada csp $250 \mathrm{ml}$

\section{M9 5X:}

$\mathrm{Na}_{2} \mathrm{HPO}_{4}$ $34 \mathrm{~g}$

$\mathrm{KH}_{2} \mathrm{PO}_{4}$ $25 \mathrm{~g}$

$\mathrm{NaCl}$ $2,5 \mathrm{~g}$

$\mathrm{H}_{2} \mathrm{O}$ bidestilada csp $\quad 1 \mathrm{~L}$

El medio mínimo se empleó para la producción de proteína marcada isotópicamente para los experimentos de NMR. La marca se incluyó mediante la incorporación de ${ }^{15} \mathrm{~N}$ - 
$\mathrm{NH}_{4} \mathrm{Cl}$ y ${ }^{13} \mathrm{C}$-glucosa, en reemplazo de los reactivos no marcados, según requerimientos de cada experimento.

\subsubsection{Sobreexpresión de proteína}

El medio de cultivo se preparó con antibiótico adecuado, según el gen de resistencia codificado en cada vector, a fin de ejercer presión de selección. Para Na-FAR-1 y OvFAR-1 s empleó ampicilina (Invitrogen) y para Ac-FAR-1 y Ce-FAR-1 kanamicina (Invitrogen). Se inoculó con una dilución 1000x de un cultivo en LB crecido toda una noche. Se incubó a $37^{\circ} \mathrm{C}$, con agitación a $170 \mathrm{rpm}$, hasta que la DO a $600 \mathrm{~nm}$ alcanzó $\approx$ 0.8 punto en el cuál se incorpora Isopropyl $\beta$-D-1-thiogalactopyranoside (IPTG) de Promega (USA) para inducir la expresión. Se siguió incubando para permitir la expresión. Se cosecharon las bacterias por centrifugación a 7000rpm por 20 min.

\subsubsection{Lisis por sonicación}

Las bacterias se resuspendieron en buffer de unión conteniendo $0.01 \%$ de Benzonasa (Novagen) o DNAsa (Invitrogen) e inhibidor de proteasa (Promega). La sonicación se realizó en un sonicador Sanyo Soniprep 150 a una amplitud de 10 micrones en dos series de 5 minutos o hasta observar pérdida de viscosidad y cambio de coloración. Durante el proceso se empleó un baño de hielo para evitar el calentamiento de la muestra.

Las fracciones soluble e insoluble se separaron por centrifugación a 20000 xg por 30 minutos en centrífuga Avanti JE.

\subsubsection{Cromatografía de afinidad en columna de níquel}

La fracción soluble obtenida tras la centrifugación del sonicado bacteriano fue filtrada con jeringa empleando filtros de $0.4 \mu \mathrm{m}$ (Nalgene) para remover restos de membrana celular. Seguidamente se pasó por gravedad a una columna de afinidad con resina Ni- 
NTA (Novagen) o (GE Healthcare), de $5 \mathrm{ml}$, se lavó con $40 \mathrm{ml}$ de buffer de unión, $40 \mathrm{ml}$ de buffer de lavado y finalmente se eluyó la proteína con $20 \mathrm{ml}$ de buffer de elución.

\subsubsection{Cromatografía de exclusión molecular}

Con la finalidad de eliminar contaminantes tales como moléculas pequeñas presentes en los buffers o proteínas de diferentes pesos moleculares se realizó una cromatografía de filtración en geles. Se empleó una columna Superdex 75 GL 10/300 (GE Healthcare) en un equipo de FPLC Åkta design (GE) con buffer PBS a un flujo de $0,5 \mathrm{ml} / \mathrm{min}$.

\subsubsection{Cromatografía en fase reversa (rp-HPLC)}

Para remover moléculas hidrofóbicas unidas a la proteína se realizó HPLC en fase reversa empleando un equipo Merck-Hitachi con detector UV a $280 \mathrm{~nm}$ con una columna Vydac C8 (4.6 x 250mm) equilibrada con 90\% de solvente A [0.1\%(v/v) ácido trifluoroacético (TFA) en agua] y $10 \%$ de solvente B [acetonitrilo, TFA $0.1 \%$ (v/v)]. La corrida se realizó a un flujo de $1 \mathrm{ml} / \mathrm{min}$ empleando los siguientes gradientes lineales: 10-30\% solvente B en 5 min; 30-70\% de B en 13 min; 70-100\% de B en 2 min; $100 \%$ de B por 5 min.

\subsubsection{Liofilización}

Luego de la cromatografía rp-HPLC, la fracción correspondiente a la proteína se transfirió a un balón con pico esmerilado o a un tubo Falcon ${ }^{\mathrm{TM}}$ y se congeló sobre las paredes (con $\mathrm{N}_{2}$ líquido, en el dispositivo de enfriado con etanol presente en el liofilizador o en freezer a $-80^{\circ} \mathrm{C}$ según disponibilidad). Se liofilizó hasta sublimación completa de los solventes y se resuspendió en agua. Se ajustó el pH agregando bicarbonato de amonio y se volvió a liofilizar. Este segundo paso de liofilización se realizó para asegurar la total remoción de TFA. Finalmente se reconstituyó la muestra en buffer acuoso. 


\subsubsection{Cuantificación}

Se calculó la concentración proteica aplicando la Ley de Lambert-Beer, para la absorbancia medida a $280 \mathrm{~nm}$ :

\section{$A b s=I \times c \times €$}

Donde I es el recorrido de la luz, c es la concentración de la muestra y $\in$ es el coeficiente de extinción molar de la proteína (expresado en $\mathrm{M}^{-1} \mathrm{~cm}^{-1}$ ).

El coeficiente de extinción molar calculó en forma teórica en una solución de guanidina-ClH 6M. El cálculo se realizó considerando que los únicos residuos que contribuyen significativamente al espectro de absorción en el rango 276-282 son tirosinas, triptofanos y cisteinas (Edelhoch et al., 1967). Se utilizó la fórmula:

$$
\Theta_{M, G d n . H C l}=a \epsilon_{M, T y r}+b \epsilon_{M, T r p}+c \epsilon_{M, C y s}
$$

donde $\epsilon_{\mathrm{Tyr}}, \epsilon_{\mathrm{Trp}}, \mathrm{y} \epsilon_{\mathrm{Cis}}$ son los coeficientes de extinción molar de residuos tirosina, triptofano y cisteina a la longitud de onda deseada ${ }^{61}$ y $a, b$, y c corresponden al número de residuos por molécula de proteína. En el caso de Na-FAR-1 la fórmula se simplificó dado que de los residuos que contribuyen a la absorción sólo presenta tirosinas.

\subsubsection{Electroforesis en geles de poliacrilamida}

La electroforesis en geles de poliacrilamida se realizó según el método SDS-PAGE ${ }^{62}$. Se emplearon geles en una concentración de $15 \%$ acrilamida 0,4\% bisacrilamida, con un espesor de 0,7 ó $1 \mathrm{~mm}$. Primero se forma el gel de 15\% acrilamida donde se resuelven las proteínas y que tiene $6 \mathrm{~cm}$ de alto y $8 \mathrm{~cm}$ de largo. Luego de su gelificación, se forma sobre el anterior el gel de "apilamiento" o stacking, un gel con menor contenido de acrilamida (3,9\% acrilamida $0.1 \%$ bisacrilamida), en el cual se logra concentrar la muestra a una banda concentrada de unos pocos $\mathrm{mm}$ de espesor debido a los cambios de $\mathrm{pH}$. Los geles se armaron en un equipo para celdas MiniProtean III (BioRad) y se corrieron por $20 \mathrm{~min}$ a 200 Volt y $50 \mathrm{~min}$ a 150 Volt. La tinción se realizó con una 
solución 0,1 \% Coomasie Blue R-250 en H2O:metanol:acético (5:5:2). La decoloración se efectuó con una solución $10 \%$ ácido acético $30 \%$ etanol. Las muestras fueron incubadas, en buffer muestra, durante 5 minutos a $100^{\circ} \mathrm{C}$ antes de la siembra.

\subsubsection{Control de integridad estructural}

\subsubsection{Espectros de dicroísmo circular (CD)}

Se midieron espectros de CD en el UV lejano con el objetivo de evaluar los componentes de estructura secundaria de la proteína y espectros en el UV cercano que son característicos de la estructura terciaria ${ }^{63}$. Los espectros de CD fueron tomados en un espectropolarímetro Jasco J-810 (Jasco Corporation, Japan). Las condiciones generales que se utilizaron fueron; velocidad de $50 \mathrm{~nm} / \mathrm{min}$ con un tiempo de respuesta de 1 segundo. Los datos se obtuvieron en el UV cercano (entre 250 y 320 $\mathrm{nm}$ ) en cubetas de $0.5 \mathrm{~cm}$ con $1.43 \mathrm{mg} / \mathrm{ml}$ de proteína y en el UV lejano (190-240 nm) midiendo en cubetas de $0.02 \mathrm{~cm}$ una solución de proteína $0.71 \mathrm{mg} / \mathrm{ml}$. Se tomaron 5 espectros y se promediaron. Los datos de elipticidad en grados que mide el equipo son luego normalizados por la medida de concentración y son expresados como Elipticidad Molar en función de la longitud de onda. Finalmente se estimó el contenido de estructura secundaria empleando los algoritmos presentes en el sitio Dichro web (http://dichroweb.cryst.bbk.ac.uk/html/home.shtml).

\subsection{Resultados}

\subsubsection{Cromatografía de afinidad}

El primer paso de purificación es la cromatografía de afinidad y es común a las cuatro proteínas debido a que todas cuentan con una secuencia de polihistidina en el extremo $\mathrm{N}$-terminal. La proteína se une a los iones de $\mathrm{Ni}^{2+}$ inmovilizados en la columna, por medio de las seis histidinas y queda retenida. Se lavan las impurezas con una concentración intermedia de imidazol (buffer lavado) y luego es eluída con altas concentraciones de imidazol (buffer elución) que compite por su interacción con el $\mathrm{Ni}^{2+}$. Las interacciones inespecíficas se evitan por la presencia de $\mathrm{NaCl}$ en los buffers. 
En la figura 2.2 se puede observar un gel de electroforesis de poliacrilamida en codiciones desnaturalizantes (SDS-PAGE) realizado para evaluar esta etapa de purificación. Se sembraron muestras correspondientes al pellet $(P)$ y sobrenadante del sonicado bacteriano (Sb), la fracción correspondiente a la elución de proteínas contaminantes que no presentan afinidad por la columna (I), la fracción que eluye al lavar con buffer de unión (Bu), la fracción de buffer de lavado (L) y finalmente la elución de la proteína (E).

Con 170 aminoácidos, Na-FAR-1 recombinante presenta un peso molecular teórico de 18767.4 Da. En la elución se obtiene una banda mayoritaria correspondiente al tamaño molecular esperado. Si bien la abundancia relativa de la proteína es mayor al $90 \%$ al eluirla de la columna de afinidad, se realizaron pasos subsiguientes de purificación para eliminar las impurezas presentes.

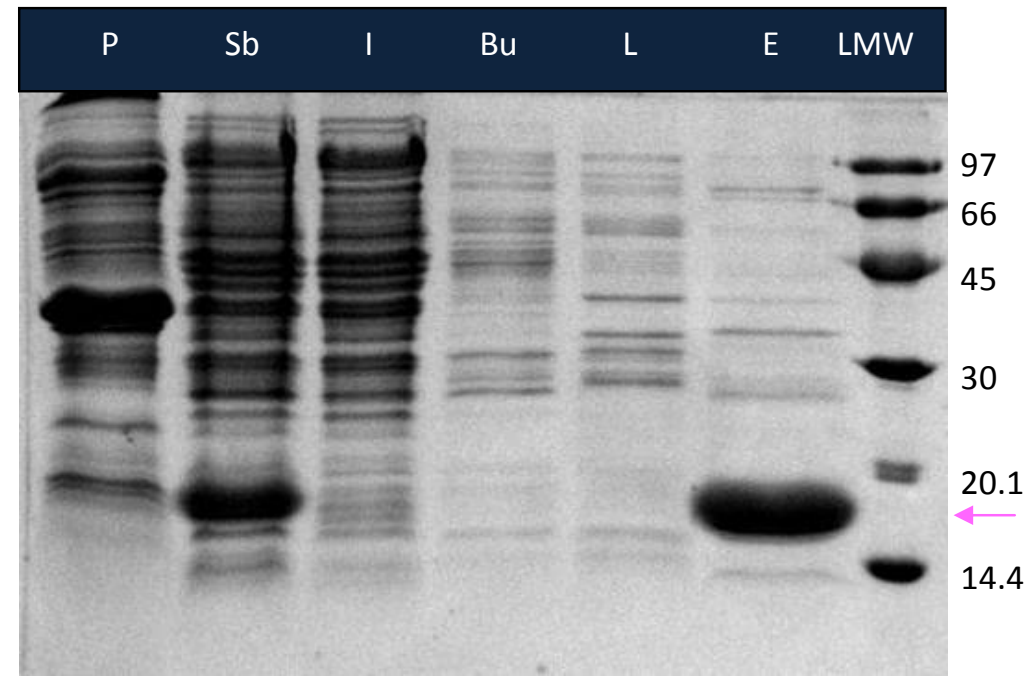

Fig.2.2. SDS-PAGE de las distintas fracciones de la cromatografía de afinidad de Na-FAR-1. P: pellet; Sb: sobrenadante; I: fracción de la muestra que no se une a la columna; Bu: lavado con buffer de unión; L: lavado con buffer de lavado; E: elución de la proteína; LMW: marcador de bajo peso molecular.

\subsubsection{Cromatografía de exclusión molecular}

Mediante una filtración en geles las proteínas se separan en base a su tamaño y pueden eliminarse las impurezas presentes cuyos pesos moleculares difieran al $\mathrm{Na}$ FAR-1: las moléculas grandes tienen una menor interacción con la matriz inerte, entran 
en pocos poros eluyendo primero, y las pequeñas que entran en más poros, son más retenidas y eluyen a un volumen mayor.

La elución se visualiza por seguimiento de la absorvancia a $280 \mathrm{~nm}$ en función del volumen. En el cromatograma se observa un pico de pequeño tamaño seguido de una meseta y finalmente un pico bien definido y mayoritario (fig.2.3).

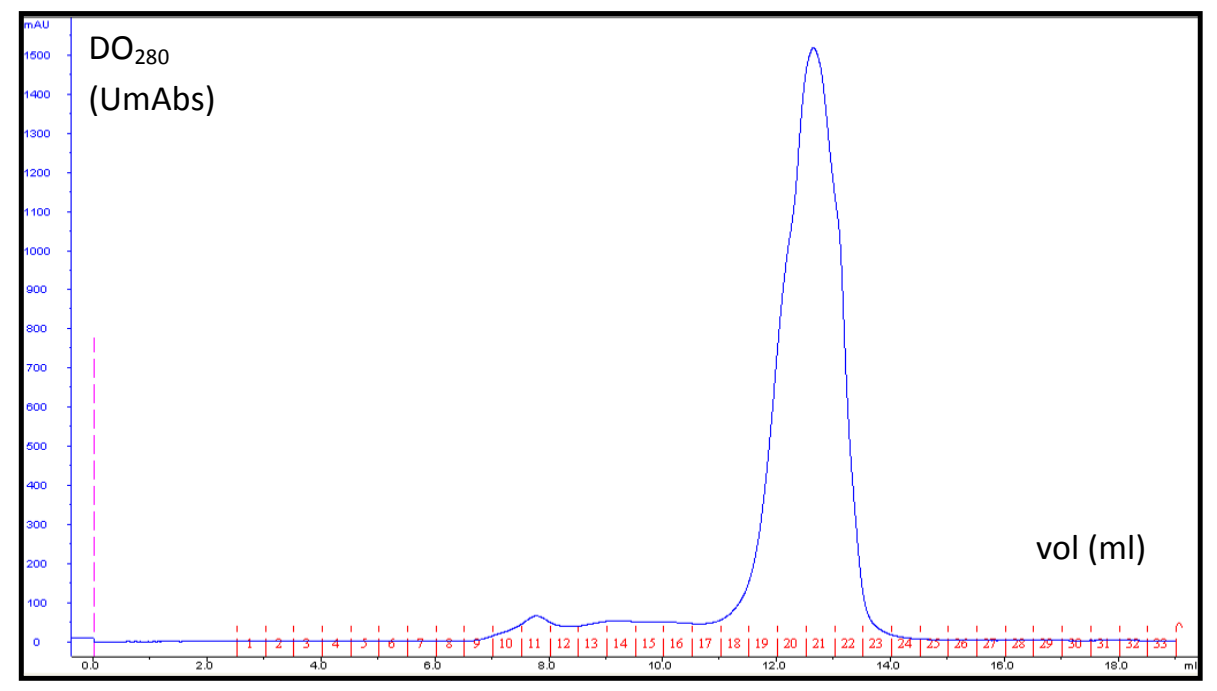

Fig.2.3. Cromatograma de exclusión molecular por seguimiento de la DO a $280 \mathrm{~nm}$ en función del volumen de elución. El número de tubo en que se colecta la muestra se indica en color rojo. Se observa la presencia de un pico mayoritario correspondiente a la proteína Na-FAR-1.

Para controlar este paso de purificación e identificar la fracción correspondiente a NaFAR-1, se tomaron muestras de los distintos tubos y se analizaron mediante SDS-PAGE (fig.2.4).

El pico mayoritario corresponde a la proteína Na-FAR-1, que eluyó a un volumen de aproximadamente $12.5 \mathrm{ml}$. Por comparación con los volúmenes de retención obtenidos en la elución de otras proteínas FAR y FABP de diferentes tamaños, se estima que el volumen de elución obtenido para Na-FAR-1 se correspondería con el estado monomérico en solución.

Se observa que la meseta observada en el cromatograma corresponde a la presencia de proteínas de mayor tamaño, colectadas en los primeros tubos. Se descartaron los tubos con mayor proporción de contaminantes y se juntaron los enriquecidos en NaFAR-1 para continuar con la purificación. 


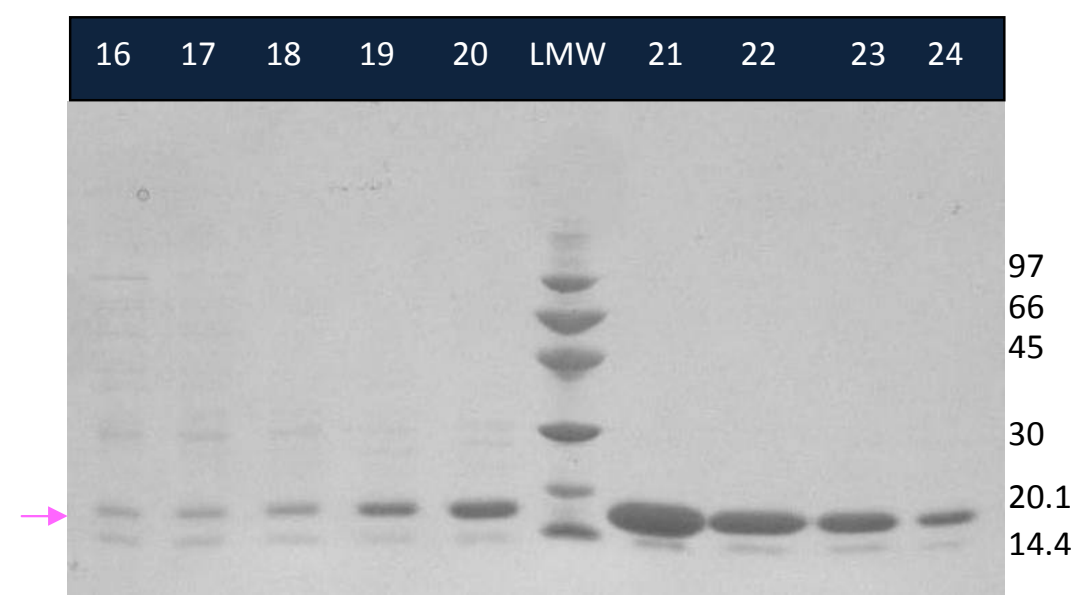

Fig.2.4. SDS-PAGE de las distintas fracciones de la cromatografía de exclusión molecular de Na-FAR-1. La numeración corresponde a los tubos que se colectan a la salida de la columna; LMW: marcador de bajo peso molecular.

Este paso de purificación permitió eliminar impurezas proteicas de distintos tamaños, así como también el imidazol presente en el buffer de elución en la cromatografía de afinidad.

\subsubsection{Deslipidización}

La remoción de los lípidos unidos a la proteína constituye un paso fundamental en la purificación y es clave para el éxito de los ensayos de determinación de estructuras por NMR debido a la multiplicidad de ligandos, y por ende de configuraciones (entornos químicos) presentes en la población de proteínas estudiadas. Por ello, se realizó este paso de manera exhaustiva por RP-HPLC, siendo los resultados de las técnicas clásicas con Lipidex (Sigma) no satisfactorias. Su importancia quedó demostrada en los controles de integridad estructural por 2D NMR que son descriptos más adelante.

La presencia de lípidos se evidenció por seguimiento de la marca de ácido palmítico ${ }^{14} \mathrm{C}$ agregado para evaluar esta etapa de purificación.

En una primera instancia se empleó la columna de interacción hidrofóbica Lipidex, ampliamente utilizada en nuestro laboratorio para deslipidizar las FABP de mamífero ${ }^{64}$, pero no se logró remover la totalidad de los lípidos unidos a las distintas FAR. 
Se procedió entonces a deslipidizar por HPLC en fase reversa (del inglés high performance liquid chromatografy). La fase estacionaria consiste en una matriz de sílica derivatizada con moléculas hidrofóbicas de determinado número de carbonos. La fase móvil es un sistema de solventes en gradiente de polaridad decreciente acompañado de un agente desnaturalizante. La proteína se desnaturaliza y mediante sus regiones hidrofóbicas expuestas es retenida en la columna, al igual que los lípidos que pudiera contener. Ambos tipos de compuestos eluyen en distintas regiones del gradiente permitiendo su separación.

Como fase estacionaria se probaron columnas C18 y C8, y como fase móvil diferentes gradientes acetonitrilo-agua ambos conteniendo $0,1 \%$ de ácido trifluoroacético para desnaturalizar la proteína. La columna C8 resultó la más apropiada para la purificación de Na-FAR-1 con esta mezcla de solventes, ya que la C18 necesitó de más altas temperaturas y mayor porcentaje de acetonitrilo para la elución de las proteínas. En la figura 2.5 se puede observar un cromatograma de HPLC para Na-FAR-1 obtenido por seguimiento a 280nm en función del tiempo de elución.

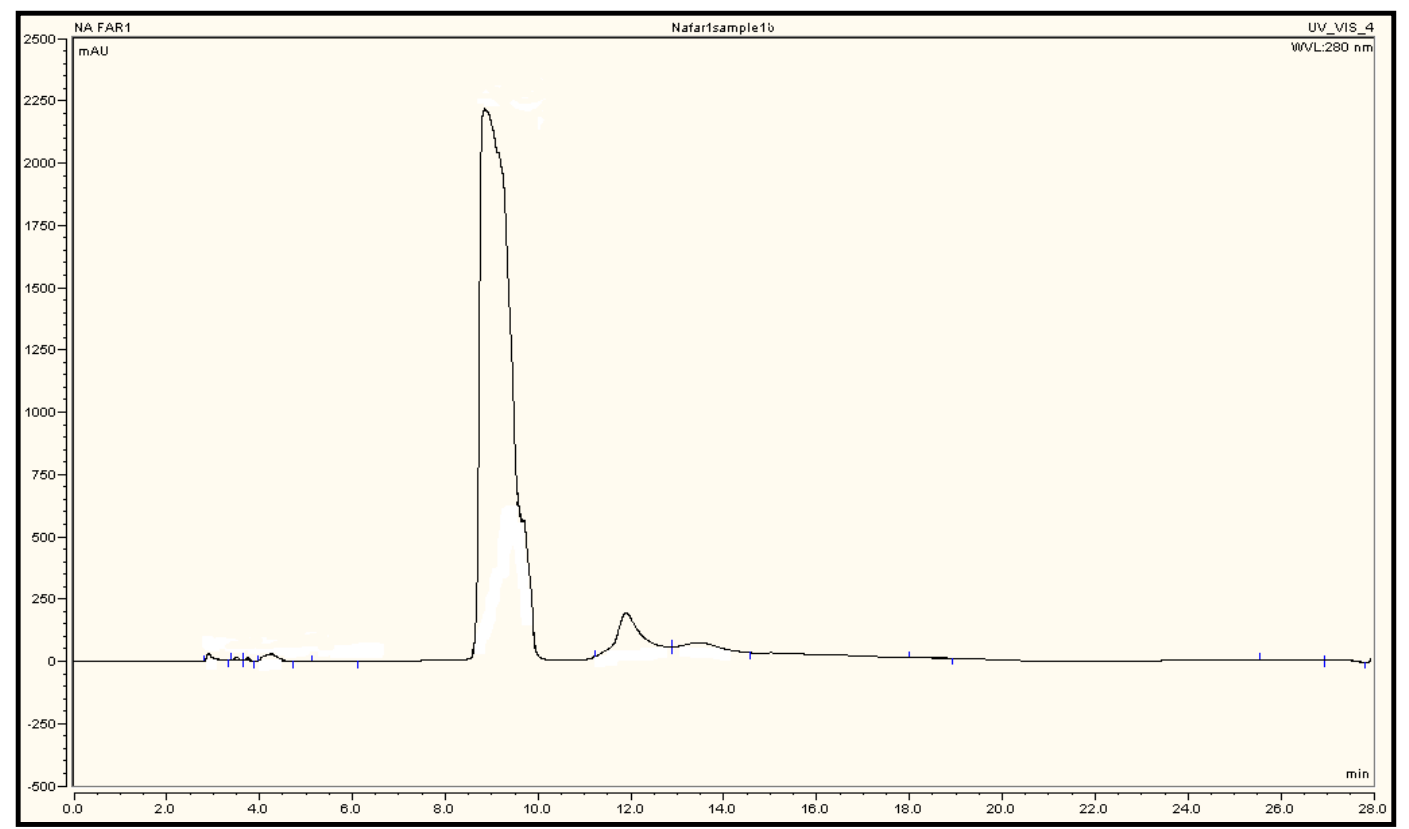

Fig.2.5. Cromatograma de HPLC por seguimiento de la DO a $280 \mathrm{~nm}$ en función del tiempo de elución. Se observa la presencia de un pico mayoritario correspondiente a la proteína Na-FAR-1.

La corrida se realizó a $20^{\circ} \mathrm{C}$ para todas las proteínas excepto Ce-FAR-5 que requirió incubación a $40^{\circ} \mathrm{C}$ para ser eluida, denotando su alta hidrofobicidad. 
Para identificar las fracciones correspondientes a la proteína se realizó un SDS-PAGE (figura 2.6).

A partir del gel se observa que el pico mayoritario del cromatograma, corresponde a la proteína Na-FAR-1, que eluye alrededor de un 50\% de acetonitrilo. Posteriormente, a un porcentaje cercano al $85 \%$ de acetonitrilo, eluye más proteína Na-FAR-1 pero esta vez acompañada de la fracción lipídica, según se comprobó por seguimiento de la marca ${ }^{14} \mathrm{C}$.

Mediante HPLC se logra la remoción de la fracción lipídica dado que la proporción mayoritaria de proteína se halla libre de marca ${ }^{14} \mathrm{C}$. También se logra por este método la eliminación de un contaminante proteico remanente de menor peso molecular que eluye antes que Na-FAR-1, como se observa en la calle 18 del gel (fig.2.6).

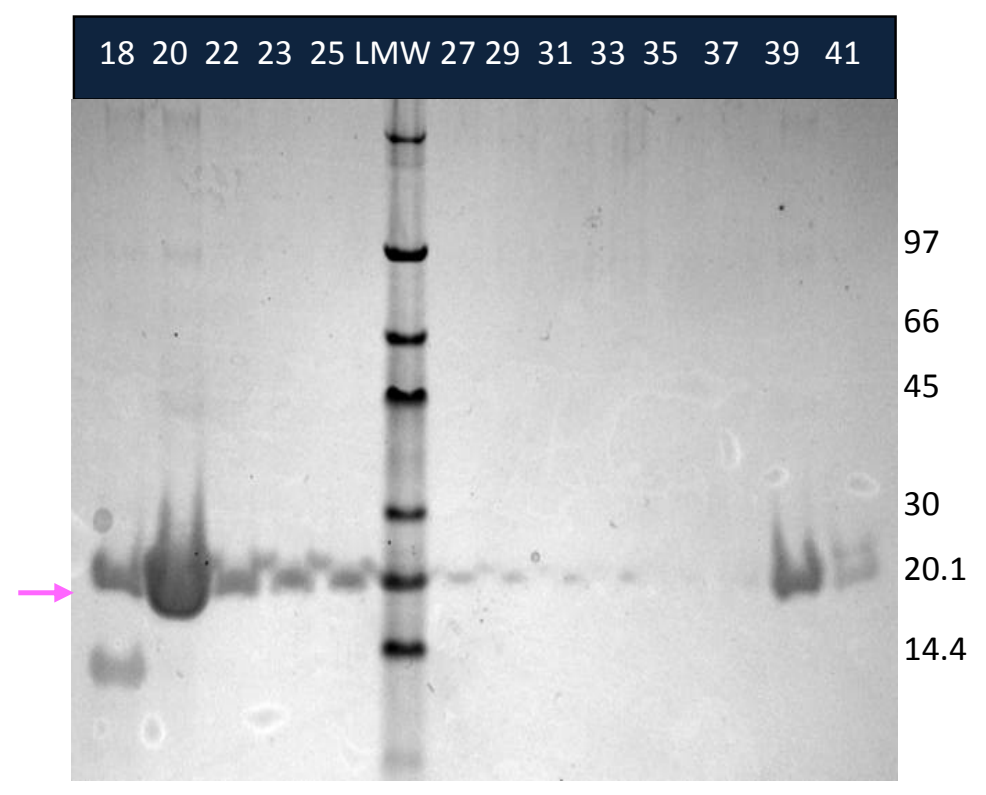

Fig.2.6. SDS-PAGE de las distintas fracciones de la cromatografía de HPLC de Na-FAR-1. La numeración corresponde a los tubos que se colectan a la salida de la columna; LMW: marcador de bajo peso molecular.

A fin de comprobar la total separación de los ligandos hidrofóbicos unidos a la proteína, se realizó un control de la deslipidización por extracción con el reactivo de Folch y posterior cromatografía en capa fina como se detalla en el capítulo 6. 
Cabe destacar que este paso de purificación requiere la desnaturalización de la proteína en buffer orgánico con TFA y su posterior reconstitución mediante una liofilización, seguida de una renaturalización en buffer acuoso. Teniendo esto en cuenta, es de vital importancia evaluar si la proteína preservó tanto su estructura como su capacidad de unión a ligandos hidrofóbicos después de este procedimiento. Para tal fin se realizaron además de los controles de integridad estructural detallados a continuación, ensayos de unión a ligando mediante espectroscopía de fluorescencia que confirmaron que no se produjo pérdida de funcionalidad.

\subsubsection{Controles de integridad estructural}

Para confirmar que la proteína Na-FAR-1 recombinante purificada preserva la estructura secundaria y terciaria, y se encuentra en estado monomérico en solución, se realizaron controles por dicroísmo circular y resonancia magnética nuclear en una y dos dimensiones.

\subsubsection{Dicroísmo circular}

Se realizaron controles de integridad estructural midiendo espectros de dicroísmo circular (CD) en los que se emplean distintas regiones del espectro de luz ultravioleta (UV) circularmente polarizada ${ }^{63}$. La estructura secundaria puede ser evaluada mediante espectros $C D$ resultantes de absorciones del enlace peptídico en la región ultravioleta lejana, mientras que la estructura terciaria y el entorno de los aminoácidos aromáticos puede estudiarse mediante espectros $\mathrm{CD}$ en la región ultravioleta cercana.

Los espectros UV lejano de CD permitieron confirmar una alta composición de $\alpha$-hélice en la estructura secundaria de Na-FAR-1 (figura 2.7). 


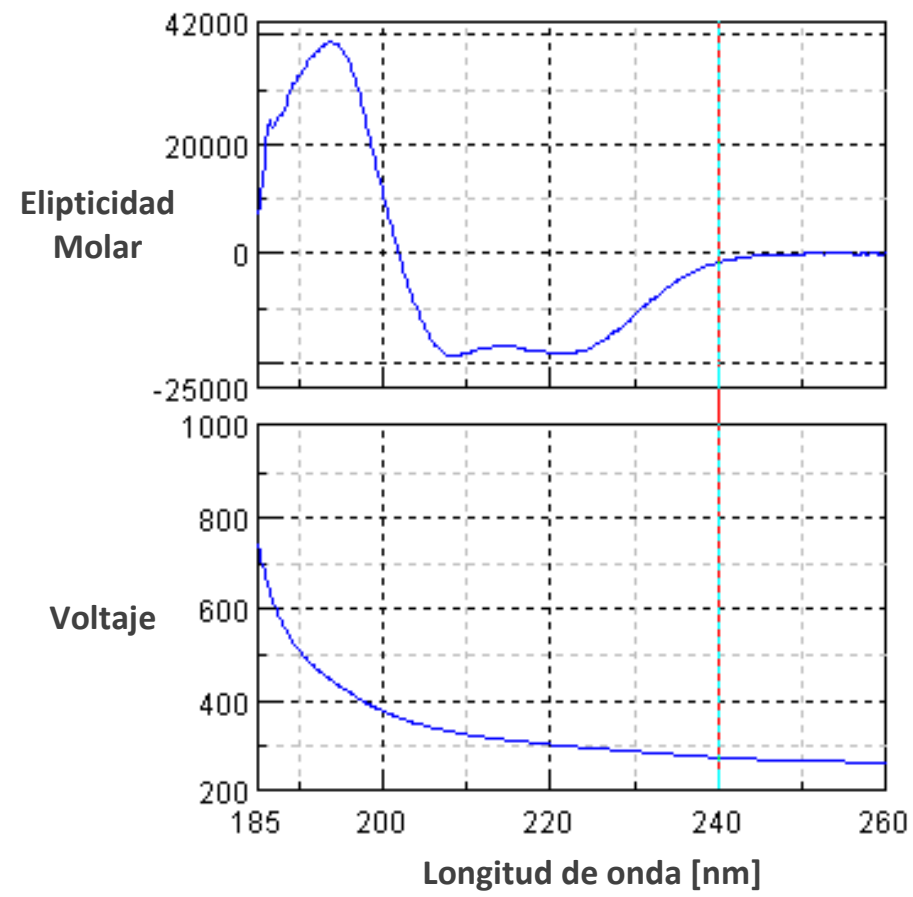

Fig.2.7. Espectro UV lejano de dicroísmo circular de la proteína Na-FAR-1 $(0.71 \mathrm{mg} / \mathrm{ml}$, en celda de $0.02 \mathrm{~cm}$ de camino óptico). Puede apreciarse un alto contenido $\alpha$-helicoidal característico de la familia de proteínas FAR. El voltaje se mantiene en valores aceptables en todo el rango de longitudes de onda.

Se obtuvo un espectro típico de estructuras $\alpha$-helicoidal con máximo de helipticidad molar alrededor de $190 \mathrm{~nm}$ y dos mínimos en aproximadamente 208 y $222 \mathrm{~nm}$.

Empleando tres algoritmos distintos se obtuvieron resultados similares, estimándose que la estructura secundaria de la proteína presenta un $62 \%$ de $\alpha$-hélice ${ }^{63}$. Los resultados obtenidos están en concordancia con los de otras proteínas FAR previamente descriptas en literatura ${ }^{37}$. El contenido de $\alpha$-hélice varía entre un 62 y un 72\% para la mayoría de las proteínas FAR, con excepción de Ce-FAR-7 que presenta una menor proporción de este tipo de estructura secundario, cuya estimación es cercana al $37 \%{ }^{65}$.

El espectro de UV cercano presenta las contribuciones de fenilalaninas, (255 a $270 \mathrm{~nm}$ ) y de tirosinas ( 275 a $282 \mathrm{~nm}$ y mayores longitudes de onda) presentes en la proteína (fig.2.8).

A longitudes de onda mayores, entre 290 y 305 nm, no se evidencia el pico característico de triptofanos debido a la ausencia de los mismos en la secuencia de NaFAR-1. 


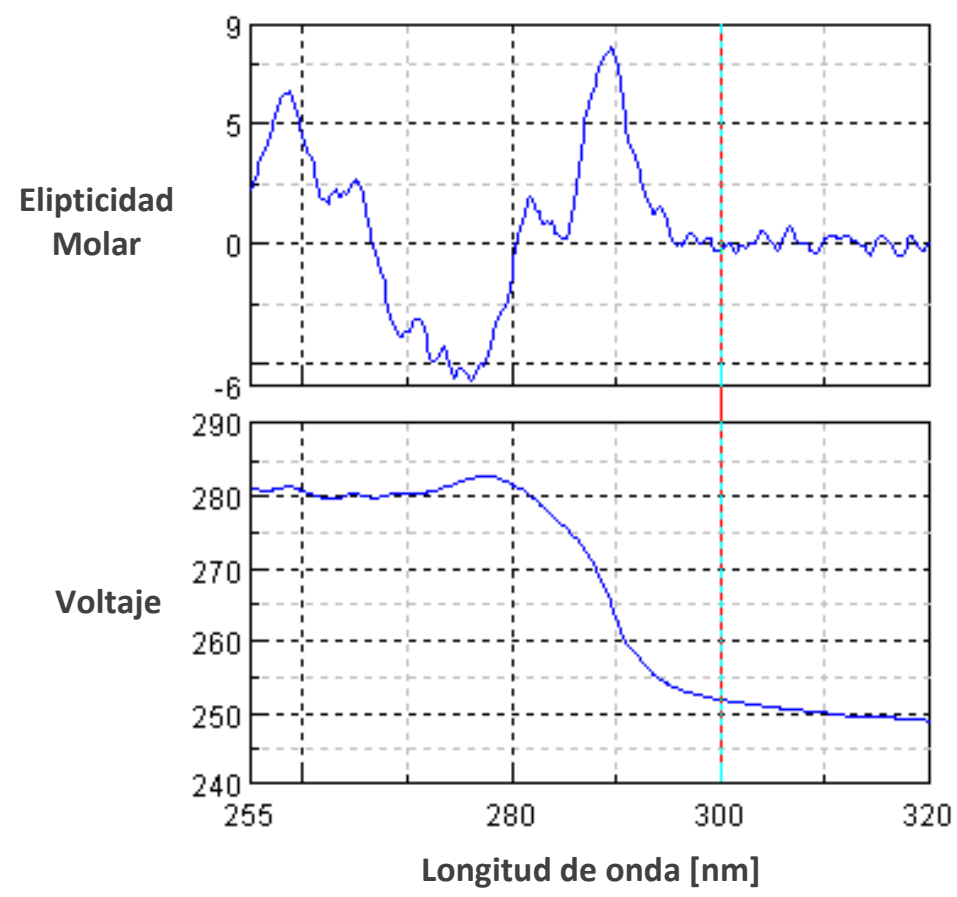

Fig.2.8. Espectro UV cercano de dicroísmo circular de la proteína Na-FAR-1 $(1.43 \mathrm{mg} / \mathrm{ml}$, en celda de $0.5 \mathrm{~cm}$ de camino óptico). El voltaje se mantiene en valores aceptables en todo el rango de longitudes de onda.

\subsubsection{Espectros de $R M N$ unidimensionales ${ }^{1} \mathrm{H}$}

En una primera instancia, para evaluar la calidad de la muestra y por ende la factibilidad de determinar la estructura proteica por RMN, se realizaron espectros de

${ }^{1} \mathrm{H}$ unidimensionales (1D- ${ }^{1} \mathrm{H}$ ). Se emplearon como criterio forma del pico y dispersión en el espectro 1D ${ }^{1} \mathrm{H}$. A continuación se muestran dos espectros representativos (figura.2.9 y figura.2.10). Los espectros de Na-FAR-1 y Ce-FAR-5 presentaron picos angostos, afilados y con una buena dispersión de desplazamientos químicos (figura.2.9).

En cambio, en el caso de las proteínas Ac-FAR-1 y Ov-FAR-1, sus espectros presentaron picos más anchos y menos definidos y una menor dispersión sobre todo en la región entre 6 y 10 ppm que corresponde a las amidas del esqueleto carbonado (figura.2.10). 


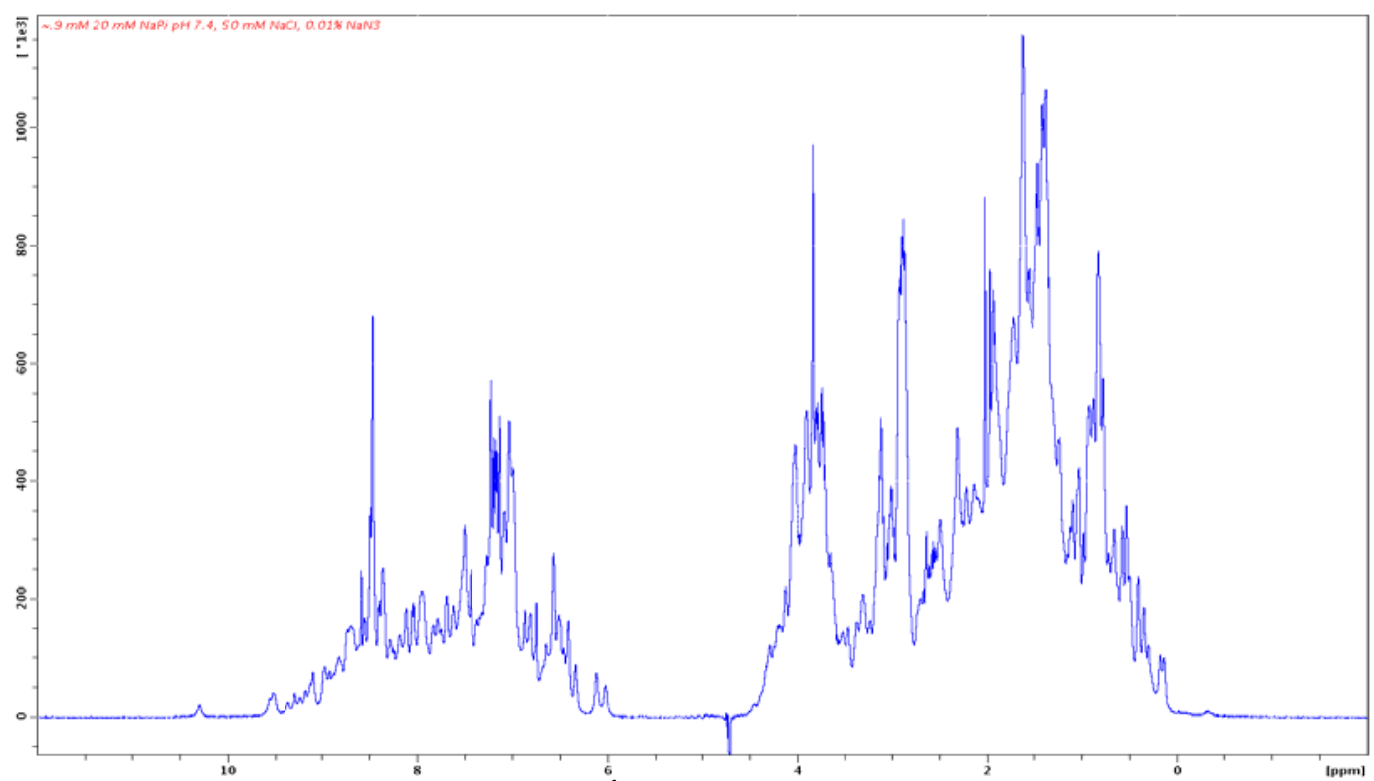

Fig.2.9. Espectro RMN unidimensional (1D) ${ }^{1}{ }^{1} \mathrm{H}$ para Na-FAR-1. En el espectro correspondiente a NaFAR-1 se observa una buena dispersión de los picos sobre todo en la región entre 6 y 10 ppm que corresponde a los grupos amida del esqueleto carbonado, asimismo los picos son angostos y definidos.

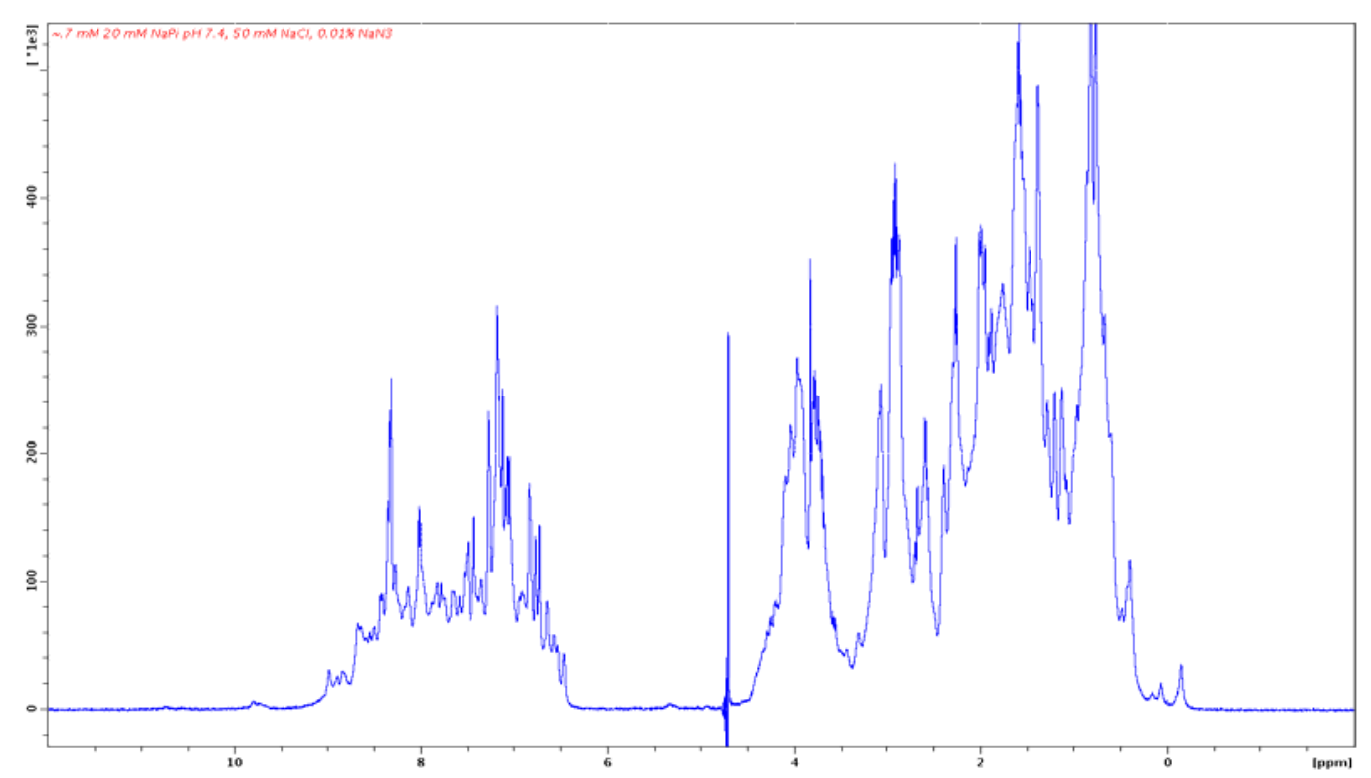

Fig.2.10. Espectro RMN unidimensional (1D) ${ }^{1} \mathrm{H}$ para Ov-FAR-1. En el espectro de la proteína OV-FAR-1, se observa un solapamiento de picos mayor y una menor dispersión en comparación con Na-FAR-1.

Dado que estos resultados implicarían el mismo comportamiento en espectros en dos o tres dimensiones, se estima que el análisis de estas últimas dos proteínas, mediante esta técnica, resultaría complicado. 
Teniendo en cuenta estos resultados, se seleccionaron las proteínas Na-FAR-1 y CeFAR-5 para continuar con el análisis.

\subsubsection{Espectros de RMN bidimensionales ${ }^{1} \mathrm{H}-{ }^{15} \mathrm{~N}$}

Na-FAR-1 y Ce-FAR-5 se purificaron en medio mínimo $M 9$ enriqueciendo con ${ }^{15} \mathrm{~N}$ y se registraron espectros 2D heteronucleares ${ }^{15} \mathrm{~N}-\mathrm{HSQC}$ (Heteronuclear single quantum coherence) ${ }^{66}$. En este caso Na-FAR-1 presentó un espectro levemente mejor, con un menor solapamiento de las señales por lo que se decidió continuar los estudios de RMN con esta proteína, sin descartar que la estructura de Ce-FAR-5 pueda determinarse por esta técnica.

Se registraron espectros ${ }^{15} \mathrm{~N}$-HSQC de la proteína antes y después de ser tratada para la extracción de ligandos, observándose cambios en las señales que indicarían múltiples conformaciones estabilizadas por la presencia de los diferentes ligandos que copurificaron unidos a la proteína, reafirmando la necesidad del paso de deslipidación (figura 2.11).
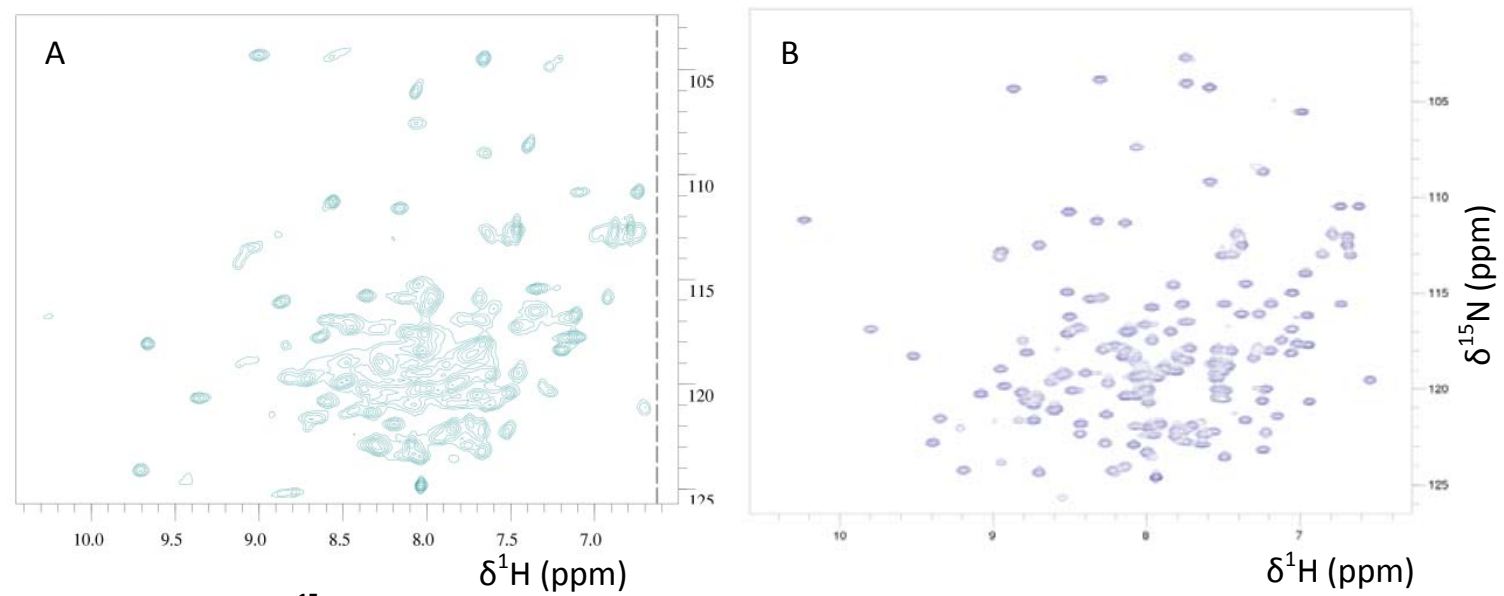

Fig.2.11. Espectros ${ }^{15} \mathrm{~N}$ HSQC de la proteína antes y después de ser tratada para la extracción de ligandos. En A se observa el solapamiento de las señales debido, probablemente, a la presencia de multiplicidad de conformaciones en la proteína inducidas por los ligandos. Cuando los ligandos son extraídos en B, se observa una mayor dispersión de las señales indicativo de una conformación homogénea.

De esta observación se desprende que la estructura de Na-FAR-1 sufre importantes cambios conformacionales por unión a ligando y que estos cambios varían según la identidad del ligando unido. 


\subsection{Conclusiones}

Se optimizaron las condiciones para la obtención de proteína Na-FAR-1 en cantidad y calidad necesarias para su análisis por biología estructural. Se obtuvo un rendimiento de $80 \mathrm{mg}$ de proteína por litro de cultivo bacteriano, que permitió producir proteína en la cantidad requerida.

Los controles de integridad estructural evidenciaron que Na-FAR-1 se purificó en un alto grado de pureza, y se mantuvo en estado monomérico en solución al ser concentrada para llevar a cabo estos estudios.

Se obtuvo una buena dispersión de picos en los espectros de una y dos dimensiones de RMN para la proteína Na-FAR-1, por lo que se consideró una buena candidata para continuar con la determinación de estructura.

\section{Determinación de la estructura de Na-FAR-1}

Na-FAR-1 no ha sido estudiada previamente, por lo que no existe en literatura información biofísica ni estructural acerca de esta proteína.

La estructura cristalográfica de una proteína FAR de C. elegans (Ce-FAR-7) ha sido reportada recientemente ${ }^{50}$. Sin embargo, por falta de densidad electrónica el sitio de unión a ligando no se encuentra bien definido. Por otra parte, Ce-FAR-7 es una proteína de un nematodo de vida libre y es un miembro de un subgrupo diferente a Na-FAR-1 dentro de la familia FAR, como se desprende de la comparación de secuencias presentada en la introducción de este trabajo de tesis. Por lo tanto, dada la limitada información que existe hasta el momento acerca de esta familia de proteínas, y las potenciales aplicaciones que podría tener el conocimiento de la estructura de $\mathrm{Na}$ FAR-1, hacen de esta proteína una opción interesante para la determinación estructural.

La técnica utilizada en este trabajo de tesis para la determinación de la estructura de Na-FAR-1 es la resonancia magnética nuclear (RMN). Complementaria a la cristalografía de rayos $\mathrm{X}, \mathrm{RMN}$ es una herramienta espectroscópica poderosa que permite estudiar a nivel atómico moléculas de interés biológico en solución.

Aquellos núcleos que poseen un número cuántico de espín (I) distinto de cero son susceptibles a un campo magnético aplicado y se alinean con este de modo tal que 
presentan diferentes estados cada uno con un nivel de energía asociado. Así, los núcleos con $\mathrm{I}=1 / 2$ presentan $2 \mathrm{I}+1=2$ estados de energía y se comportan como dipolos magnéticos ${ }^{67}$. La excitación de estos núcleos (también llamados espines) con radiofrecuencias que coincidan con la diferencia entre los niveles de energía produce la absorción de energía y da lugar a las señales de RMN.

Los experimentos de RMN consisten en secuencias de pulsos, para la detección de los núcleos deseados, que constan de cuatro etapas descriptas a continuación:

Durante la preparación (i) se excita al núcleo deseado mediante una serie de pulsos. Luego, durante la evolución (ii), se le permite precesar libremente un determinado tiempo $t_{1}$, en que la magnetización se marca con el desplazamiento químico del primer núcleo (dimensión indirecta). Seguidamente, durante el mezclado (iii) se aplican las secuencias de pulsos que producen la transferencia de magnetización a un segundo núcleo. Existen dos mecanismos para la transferencia de magnetización: el acoplamiento escalar y la interacción dipolar. El acoplamiento escalar es la influencia del estado de un núcleo sobre otro mediada por los electrones a través del enlace. La magnetización de un espín puede ser transferida a otro espín a través de los enlaces con una constante escalar J. En cambio, la interacción dipolar se manifiesta a través del espacio, dependiendo de la proximidad espacial y de la orientación respecto al campo magnético. La transferencia de magnetización se produce mediante un proceso de relajación cruzada que se conoce como efecto nuclear Overhauser (NOE, de acuerdo a sus siglas en inglés). Finalmente, los datos se adquieren en el período de detección (iv). Durante este tiempo la magnetización se marca con el desplazamiento químico del segundo núcleo (dimensión directa) y se produce un decaimiento de las señales libre de inducción conocido como FID (del inglés free induction decay).

En el espectro bidimensional resultante de aplicar una secuencia de pulsos como la antes mencionada, se obtendrá un pico (llamado crosspeak en inglés) donde se entrecruzan las frecuencias detectadas en la dimensión directa e indirecta. En experimentos multidimensionales, se incorporan períodos de evolución adicionales para los núcleos que se desean detectar.

Los experimentos de RMN convencionales se llevaban a cabo con proteínas purificadas desde su fuente natural y solían estar restringidos al empleo de transferencia de 
magnetización entre hidrógenos que son el único núcleo cuyo isótopo naturalmente abundante presenta un $I=1 / 2$. Mediante la incorporación de marcaje isotópico se pudieron reemplazar los núcleos ${ }^{12} \mathrm{Cy}^{14} \mathrm{~N}$ presentes naturalmente en las proteínas por ${ }^{13} \mathrm{C}$ y ${ }^{15} \mathrm{~N}$ con I= 1/2, generándose nuevas vías para la transferencia de magnetización. Esto permitió el desarrollo de experimentos de triple resonancia para estudios de estructura y dinámica de proteínas ${ }^{68}$.

La estrategia general para resolver la estructura de proteínas por RMN se esquematiza a continuación (figura3.1):

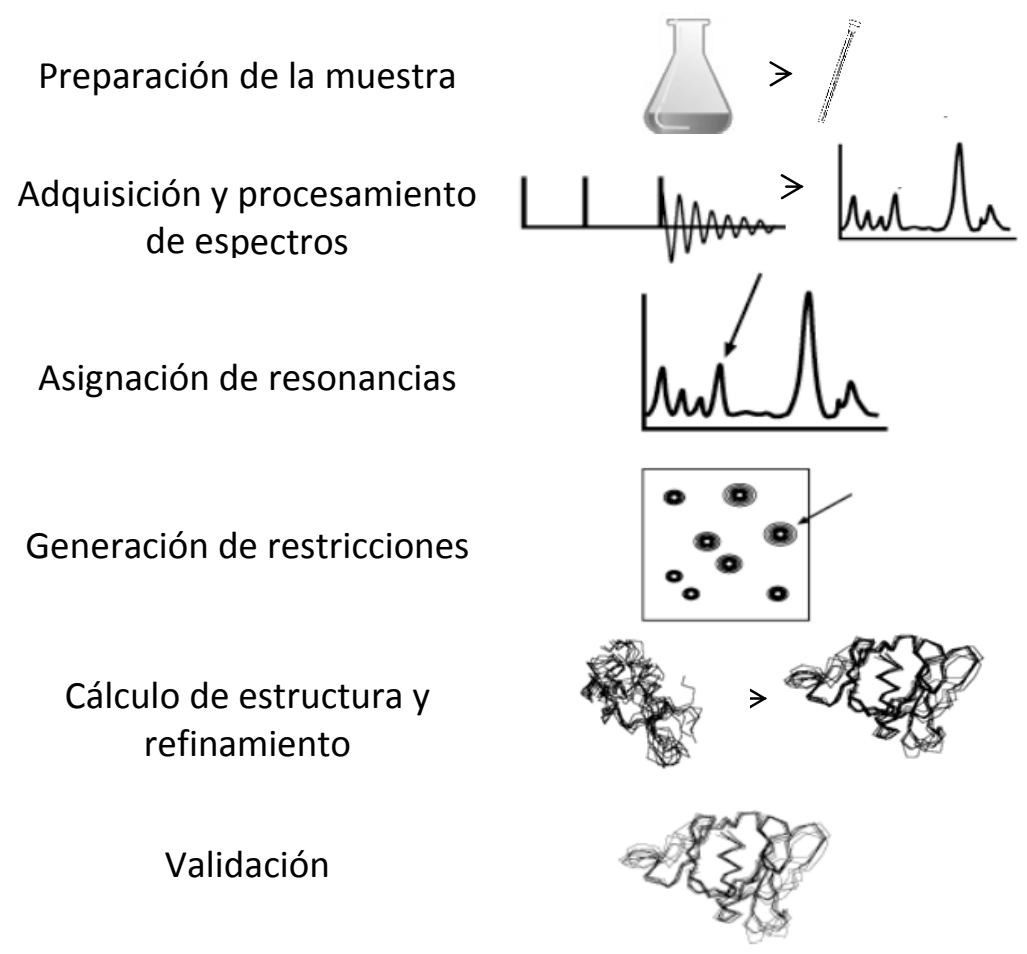

Fig.3.1. Esquema de la estrategia para la determinación de estructura de una proteína. Las imágenes se tomaron y adaptaron de http://aria.pasteur.fr/documentation/courses/saclay-november2011/saclay_nmr_school.pdf.

Los desplazamientos químicos observados en los experimentos deben ser asignados a átomos específicos para interpretar los espectros de RMN a modo de emplearlos en la determinación estructural. Con ese objetivo se han desarrollado diferentes estrategias 
de asignación basadas en los experimentos de triple resonancia multidimensionales cuya elección depende del sistema en estudio. Estos experimentos correlacionan frecuencias ${ }^{1} \mathrm{H},{ }^{15} \mathrm{~N},{ }^{13} \mathrm{C}$ que conforman lo que se denomina un sistema de espines. En el sistema de espines se agrupan todas las señales correspondientes a espines de un residuo dado, que se correlacionan con señales provenientes de espines de residuos secuenciales en la cadena polipeptídica. Rastreando las señales de espines de residuos consecutivos, se conectan los sistemas de espines contiguos que son luego identificados sobre la base de la secuencia de aminoácidos. La asignación de resonancias comienza generalmente desde la cadena principal y se extiende a los carbonos y protones de las cadenas laterales.

Una vez que se han asignado todos los desplazamientos químicos de los átomos observables de la proteína, esta información se emplea para la generación de restricciones para el cálculo de estructura. Generalmente, la asignación se transfiere a los experimentos basados en interacciones dipolares NOESY (del inglés Nuclear Overhauser effect spectroscopy) a partir de los cuales se generan las restricciones espaciales. A su vez, pueden emplearse para el cálculo restricciones de ángulos diedros, de acoplamientos J y las estructuras pueden refinarse con restricciones de puentes disulfuro, de puentes hidrógeno y restricciones adicionales de largo alcance como las que brindan los experimentos basados en acoplamientos residuales dipolares (RDC). Finalmente, las estructuras calculadas se someten a un proceso de validación donde se evalúa la calidad de las mismas.

Los detalles correspondientes a la determinación de la estructura de Na-FAR-1 siguiendo el esquema antes mencionado se desarrollarán en los apartados subsiguientes.

\subsection{Preparación de la muestra}

La proteína se purificó siguiendo los protocolos antes descriptos, sin marca, marcada con ${ }^{15} \mathrm{~N}$ y doblemente marcada $\operatorname{con}{ }^{15} \mathrm{~N}$ y ${ }^{13} \mathrm{C}$, según los requerimientos de cada experimento. Luego de ser resuspendida en buffer $\mathrm{NaCl} 20$ mM, NaPi 20 mM, pH=7.4, la proteína se concentró a $500 \mu \mathrm{M}$ empleando concentradores Vivaspin de $20 \mathrm{ml}$ con 
membrana de corte en $5 \mathrm{kDa}$. Se transfirió a un tubo eppendorff y se agregó $5 \% \mathrm{D}_{2} \mathrm{O}$ para monitorear la frecuencia del deuterio (lock). La muestra se centrifugó a 13000xg a $4^{\circ} \mathrm{C}$ por 10 min para remover las posibles partículas presentes y se transfirió a un tubo de RMN de $5 \mathrm{~mm}$ de diámetro.

\subsection{Adquisición de espectros}

Todos los datos se recolectaron en un espectrómetro de RMN Avance $600 \mathrm{MHz}$ de Bruker equipado con una criosonda $\mathrm{TCl} 5 \mathrm{~mm}$, a 311K. En la mayoría de los experimentos se emplearon secuencias de pulsos estándar presentes en la biblioteca del espectrómetro. Para algunos de ellos de realizaron modificaciones específicas que se mencionan en cada caso.

La adquisición, procesamiento y posterior análisis de los espectros se realizaron en procesadores con entorno Linux CentOS.

\subsubsection{Estrategias de muestreo}

Una limitación que presenta la RMN multidimensional es el tiempo requerido para adquirir un número de puntos suficiente en la dimensión indirecta, de modo de obtener espectros bien resueltos. En consecuencia, se requieren semanas e incluso meses para adquirir todos los espectros multidimensionales necesarios para la determinación de una estructura. A fin de solucionar este inconveniente, se recurrió a la técnica de muestreo no-uniforme, que permite la adquisición de espectros de modo más rápido. En los experimentos de RMN multidimensional convencionales, se emplea un incremento regular de los tiempos de evolución para obtener la señal de la dimensión indirecta con una resolución apropiada. Con cada dimensión adicional, el número de puntos muestreados en las dimensiones indirectas aumenta, así como también aumenta el tiempo necesario para la adquisición. En el muestreo no uniforme, introducido por primera vez por Barna ${ }^{69}$, en lugar de muestrear todos los puntos de tiempo para ambas dimensiones indirectas, se recolecta un número reducido de datos en el dominio del tiempo. Empleando un esquema de recolección de datos y de 
procesamiento adecuados, el muestreo no uniforme produce espectros de igual calidad que con esquemas convencionales pero en escalas de tiempo mucho menores

${ }^{70}$. En este trabajo, los experimentos multidimensionales se llevaron a cabo siguiendo la estrategia de muestreo no uniforme.

\subsection{Procesamiento de señales}

Las señales adquiridas durante la FID se encuentran en el dominio del tiempo y es necesario realizar un pasaje al dominio de frecuencia. Esto implica la aplicación de diferentes funciones matemáticas durante el procesamiento de las señales para generar los espectros.

\subsubsection{Procesamiento con transformada de Fourier directa}

Los espectros muestreados convencionalmente se procesaron usando el paquete de programas Azara (Dr. Wayne Boucher, www.ccpn.ac.uk/azara). Los scripts de procesamiento iniciales se crearon desde los archivos de datos Bruker mediante el programa ReferenceB (desarrollado por la Dra. Krystyna Bromek, University of Glasgow). ReferenceB brinda una referencia para los desplazamientos químicos de acuerdo al método descripto ${ }^{71}$.

Todos los datos se ajustaron con una función ventana apropiada y se agregaron puntos posteriores a la caída libre de inducción con valor igual a cero (zero filling). Esto permite optimizar la resolución de la señal y minimizar artefactos de truncado antes de aplicar la transformada de Fourier. La transformada de Fourier transforma la FID del dominio del tiempo al de frecuencias. Seguidamente se aplicó una corrección de fase al espectro transformado. Cuando fue requerido se realizó una corrección en la línea de base o de convolución para eliminar la señal residual del agua.

\subsubsection{Procesamiento con máxima entropía}

En RMN multidimensional existen limitaciones en cuanto a la cantidad de datos que pueden recolectarse, por lo que no siempre es posible tomar la FID hasta que haya 
decaído a cero. La transformada de Fourier de estos datos truncados puede llevar a la aparición de artefactos en el espectro resultante. Para minimizar la aparición de artefactos en los espectros se han desarrollado alternativas a la transformada de Fourier.

En este trabajo se empleó el procesamiento de entropía máxima (MaxEnt) como alternativa de la transformada de Fourier Directa, para procesar espectros truncados. El procesamiento MaxEnt crea varios dominios de frecuencia de prueba a los que luego aplica la transformada de Fourier inversa y compara con los datos medidos. De los posibles dominios de frecuencia simulados que son consistentes con la FID medida, se selecciona aquel que presenta la mayor entropía ${ }^{72}$.

En el caso de los experimentos con muestreo no uniforme, la transformada de Fourier directa produce espectros con artefactos debido a los puntos faltantes, pero si se realiza un procesamiento de máxima entropía para la reconstrucción de los datos se evita la aparición de los mismos.

\subsection{Asignación de resonancias}

Los espectros se analizaron en el programa CCPNAnalysis para la asignación de resonancias ${ }^{73}$. Así, se identificó la frecuencia de resonancia de casi todos los núcleos presentes en la proteína Na-FAR-1 sobre la base de su secuencia primaria.

\subsubsection{Asignación secuencial de la cadena principal}

Las resonancias de los grupos amida se establecieron a partir de espectros ${ }^{15} \mathrm{~N}-\mathrm{HSQC}$ (del inglés Heteronuclear Single Quantum Coherence) ${ }^{66}$ de Na-FAR-1.

El experimento ${ }^{15} \mathrm{~N}-\mathrm{HSQC}$ correlaciona resonancias de átomos de ${ }^{1} \mathrm{H}$ y ${ }^{15} \mathrm{~N}$ covalentemente unidos, con una constante de acoplamiento escalar, ${ }^{1} \mathrm{~J}$ de $90-94 \mathrm{~Hz}$ (figura 3.2).

La secuencia de pulsos de este experimento comienza con la excitación de los núcleos

${ }^{1} \mathrm{H}$. Luego, se transfiere la magnetización a los núcleos ${ }^{15} \mathrm{~N}$ mediante un bloque de pulsos INEPT (del inglés Insensitive Nuclei Enhanced by Polarization Transfer) 
modulado por ${ }^{1} \mathrm{~J}$. La magnetización de los núcleos ${ }^{15} \mathrm{~N}$ evoluciona modulada por sus desplazamientos químicos. Seguidamente la magnetización se transfiere a ${ }^{1} \mathrm{H}$ mediante un INEPT reverso. Finalmente se detecta la magnetización en ${ }^{1} \mathrm{H}$ modulada por sus desplazamientos químicos.

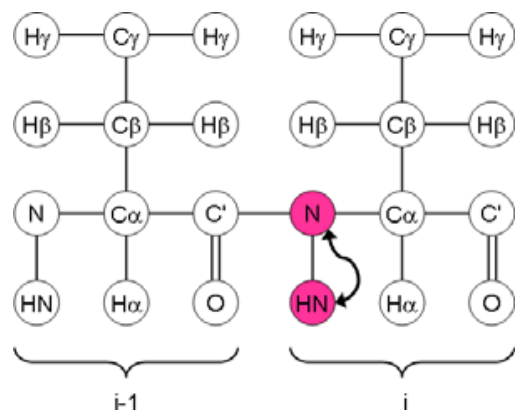

Fig.3.2. Esquema del espectro ${ }^{15} \mathrm{~N}$-HSQC. Los núcleos que son detectados se señalan en fucsia y las flechas indican el camino de transferencia de la magnetización. La imagen se tomó de http://www.protein-nmr.org.uk/.

Como la magnetización ${ }^{1} \mathrm{H}$ que evoluciona durante la detección (dimensión directa) contiene información de los desplazamientos químicos de ${ }^{15} \mathrm{~N}$ acoplados escalarmente (dimensión indirecta), el espectro bidimensional resultante presenta un pico por cada par de núcleos ${ }^{1} \mathrm{H}-{ }^{15} \mathrm{~N}$ unidos. En una proteína esto incluye a las amidas de las cadenas laterales de glutaminas y asparaginas; aminas de argininas, histidinas y triptófanos y las amidas de la cadena principal de todos los aminoácidos, exceptuando a las prolinas (que no poseen $\mathrm{H}$ unido a $\mathrm{N}$ ).

Los picos obtenidos en el espectro ${ }^{15} \mathrm{~N}-\mathrm{HSQC}$ se seleccionaron y se asignaron a un sistema de espines con resonancias amida ${ }^{1} \mathrm{H}$ y ${ }^{15} \mathrm{~N}$ asociadas.

Para identificar cuáles son las resonancias específicas que se correlacionan con las resonancias de los grupos amida se emplearon experimentos heteronucleares de triple resonancia adaptados a un esquema de muestreo no uniforme por el Dr. Brian Smith (figura 3.3).

El nombre de los experimentos suele estar compuesto por los núcleos involucrados en la transferencia de magnetización, con los núcleos cuyos desplazamientos químicos no se dejan evolucionar indicados entre paréntesis. 


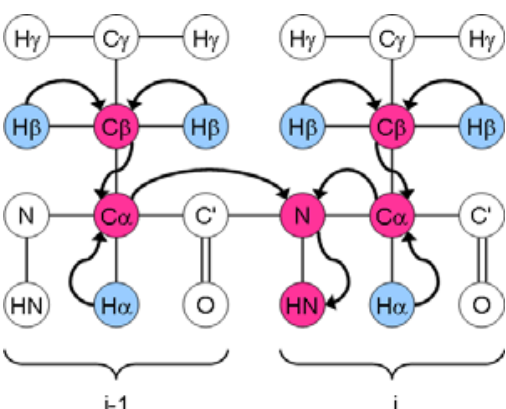

HNCACB

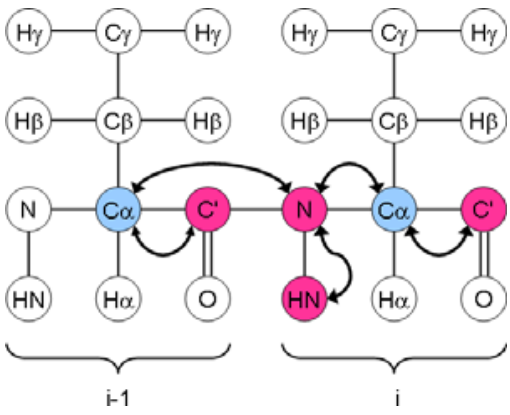

$\mathrm{HN}(\mathrm{CA}) \mathrm{CO}$

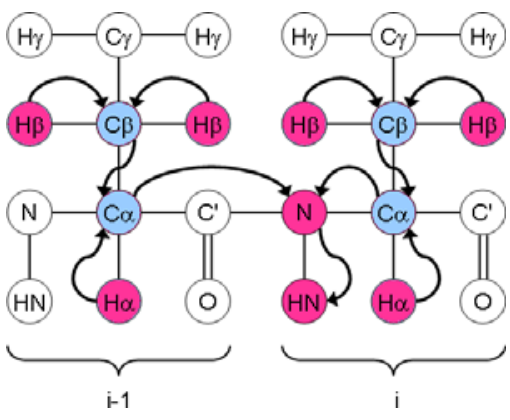

$\mathrm{HBHA}(\mathrm{CBCA}) \mathrm{NH}$
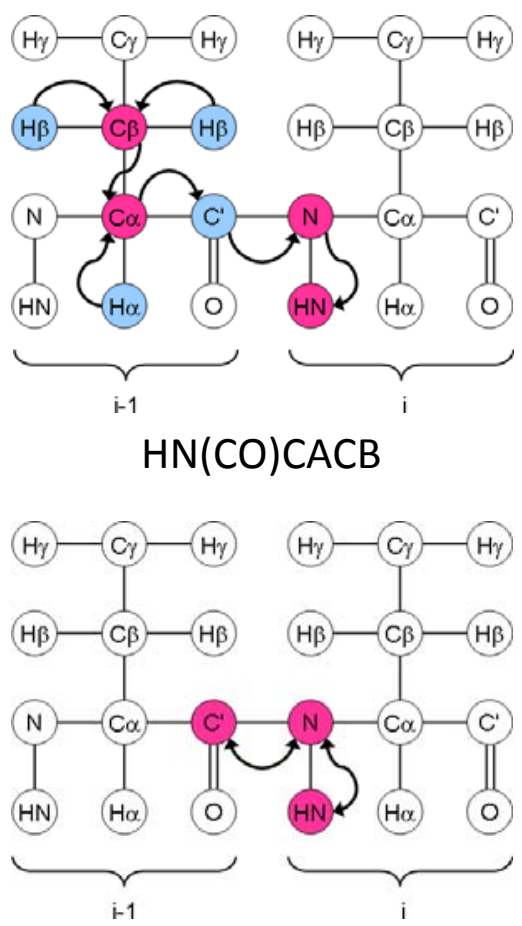

HNCO

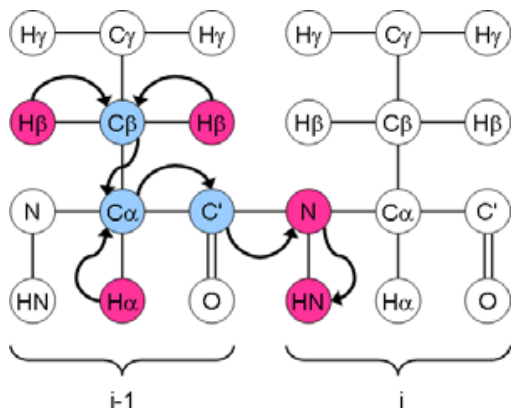

$\mathrm{HBHA}(\mathrm{CBCACO}) \mathrm{NH}$

Fig.3.3. Esquemas de los experimentos de triple resonancia utilizados para la asignación de la cadena principal de Na-Far-1. Los pares de experimento empleados fueron HN(CO)CACB y HNCACB; HNCO y $\mathrm{HN}(\mathrm{CA}) \mathrm{CO}$; $\mathrm{HBHA}(\mathrm{CBCA}) \mathrm{NH}$ y $\mathrm{HBHA}(\mathrm{CBCACO}) \mathrm{NH}$. Los núcleos que son detectados se indican en fucsia mientras que en azul se señalan aquellos a través de los cuales se transfiere la magnetización. Las flechas indican los caminos de transferencia de la magnetización. Las imágenes se tomaron de http://www.protein-nmr.org.uk/.

Los pares de experimentos complementarios de este tipo, permiten la identificación de resonancias del residuo propio i (intra-residuo) y del residuo anterior i-1 (inter-residuo) con respecto al grupo amida. Se emplearon los experimentos $\operatorname{HNCACB}^{74} \mathrm{y}$ $\mathrm{HN}(\mathrm{CO}) \mathrm{CACB}{ }^{75}$ que correlacionan los carbonos $\mathrm{C} \alpha$ y $\mathrm{C} \beta$ intra- e inter-residuo con el pico amida. En el experimento HNCACB la magnetización se transfiere entre las 
resonancias amida y las resonancias $C \alpha / C \beta$ de ambos residuos, tanto del residuo propio como del anterior. El experimento complementario, $\mathrm{HN}(\mathrm{CO}) \mathrm{CACB}$, discrimina entre correlaciones intra- e inter residuo dirigiendo la magnetización mediante el grupo carbonilo del residuo previo y por ende solo identifica la resonancias $C \alpha$ y $C \beta$ del residuo i-1. Así, usando este par de experimentos, se pueden determinar las identidades de las resonancias $C \alpha$ y $C \beta$ de residuos contiguos y agregarse a los sistemas de espín apropiados.

Además de HNCACB y $\mathrm{HN}(\mathrm{CO}) \mathrm{CACB}$ en este trabajo se emplearon otros dos pares de experimentos complementarios: $\mathrm{HNCO}$ y $\mathrm{HN}(\mathrm{CA}) \mathrm{CO}$ para identificar correlaciones entre carbonos carbonílicos intra- e inter-residuo (i-1) ${ }^{76}$, y $\mathrm{HBHA}(\mathrm{CBCA}) \mathrm{NH}$ y $\mathrm{HBHA}(\mathrm{CBCACO}) \mathrm{NH}$ que permiten identificar correlaciones $\mathrm{H} \alpha$ y $\mathrm{H} \beta$ intra- e interresiduo ${ }^{75}$.

Los tres pares de experimentos brindan rutas complementarias de información para la asignación secuencial lo cual reduce los casos de ambigüedad producidos por la degeneración de desplazamientos químicos presentes en una proteína relativamente grande como Na-FAR-1. La asignación secuencial se llevó a cabo con estas combinaciones de espectros empleando el modo "protein sequence assignment" del programa CCPNAnalysis ${ }^{73}$. Este software identifica y ordena sistemas de espín con resonancia intra-residuo que coinciden con las resonancias inter-residuo de un sistema de espín dado.

En instancias en que se identifica una correspondencia no ambigua, los sistemas de espín se conectan secuencialmente (figura 3.4).

Los desplazamientos químicos característicos de $\mathrm{C} \alpha$ y $\mathrm{C} \beta$, y en menor medida de $\mathrm{H} \alpha$ y $H \beta$, permiten predecir el tipo de aminoácido del cual provienen, ya que dependen más de la identidad química que del entorno. Sumando estas predicciones a la información proveniente de la secuencia de la proteína, los sistemas de espín secuencialmente unidos se pudieron asignar a regiones de la cadena principal de la proteína. Esta información fue suficiente para asignar más del $90 \%$ de la cadena principal de Na-FAR1. 


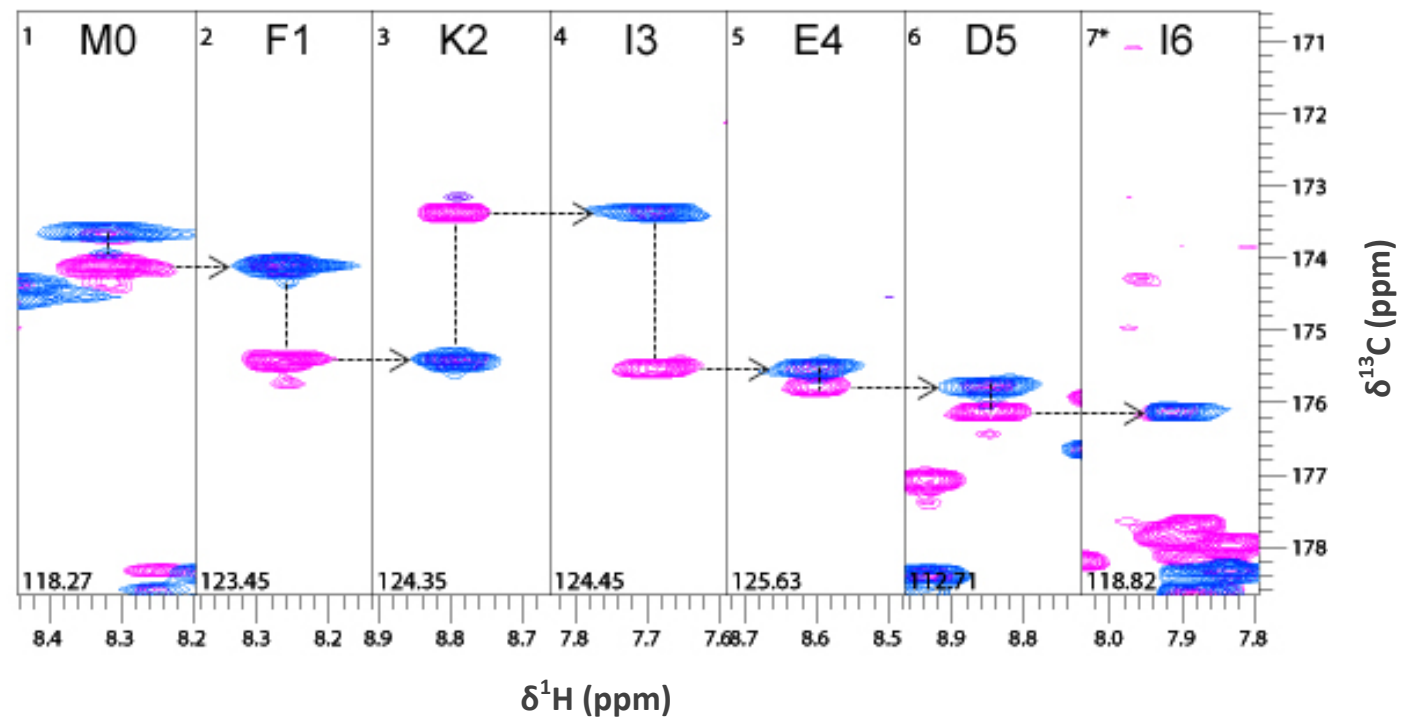

Fig.3.4. Espectros HNCACO y HNCO empleados para conectar sistemas de espín secuenciales. Cada banda corresponde a las resonancias amida de sistemas de espín consecutivos, en el interior se indica el desplazamiento químico ${ }^{15} \mathrm{~N}$ en ppm. Se muestra la conectividad de secuencia de Na-FAR-1 desde el residuo -1 hasta el 5 para los experimentos HNCO (azul) que muestra el carbonilo del residuo propio y HNCACO (rosa) que muestra el carbonilo del residuo propio y del anterior.

\subsubsection{Asignación de cadenas laterales}

La asignación de cadenas laterales realizada se basó en dos tipos de estrategias: asignación de cadenas alifáticas y aromáticas. Los experimentos empleados se esquematizan en la figura 3.5 . 


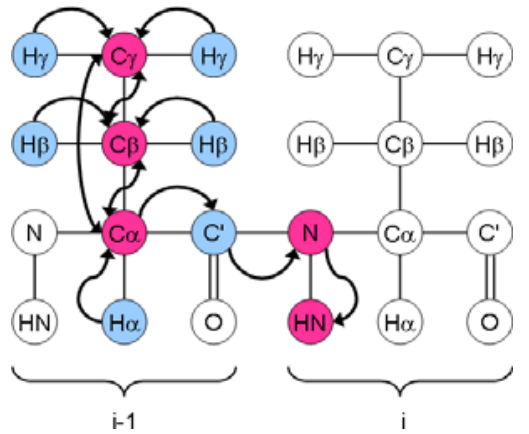

(H)C(CCO)NH-TOCSY
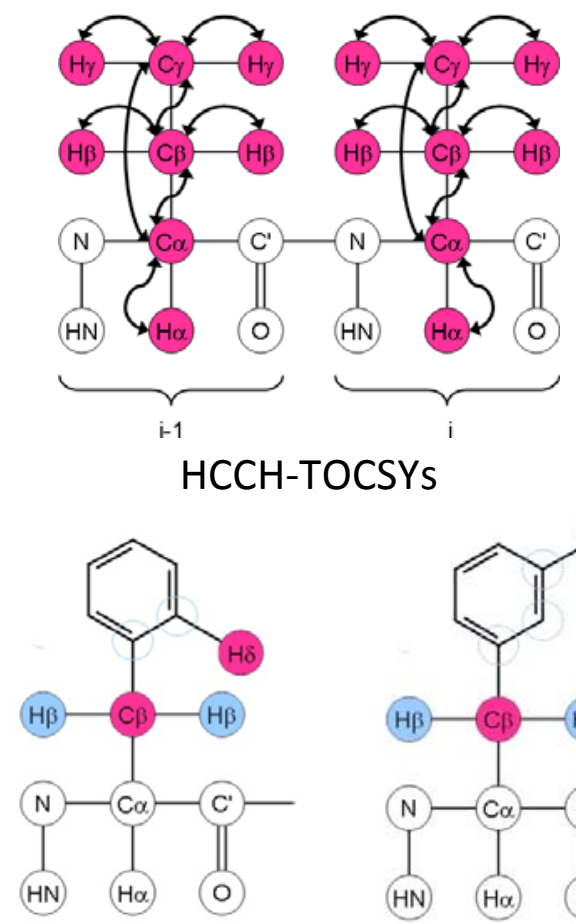

(HB)CB(CGCD)HD (HB)CB(CGCDCE)HE

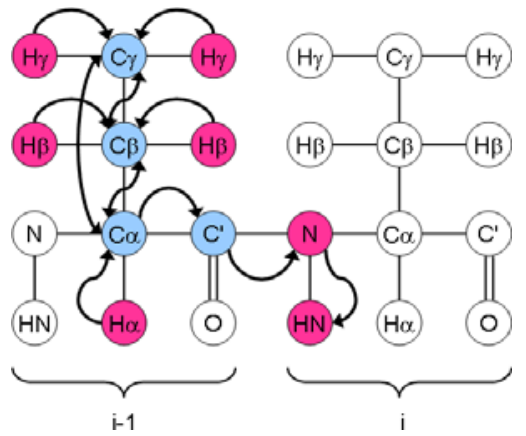

$\mathrm{H}(\mathrm{C})(\mathrm{CCO}) \mathrm{NH}-\mathrm{TOCSY}$

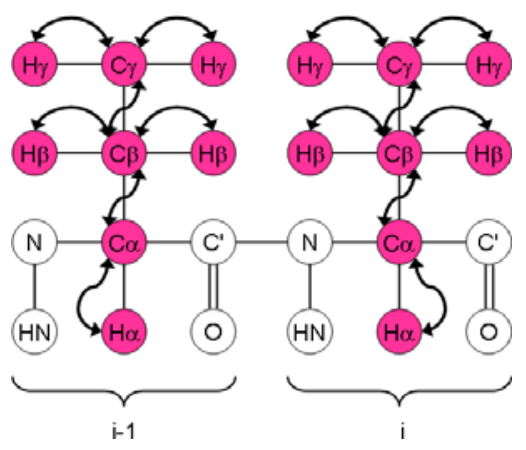

$\mathrm{HCCH}-\mathrm{COSY}$

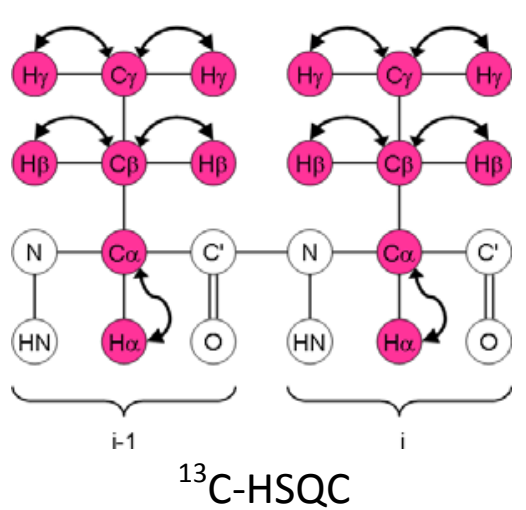

Fig.3.5. Esquemas de los experimentos utilizados para la asignación de las cadenas laterales. Los experimentos de triple resonancia empleados para la asignación de las cadenas alifáticas fueron (H)C(CCO)NH-TOCSY, H(C)(CCO)NH-TOCSY, HCCH-COSY, H(C)CH-TOCSY y $(\mathrm{H}) \mathrm{CCH}-\mathrm{TOCSY}$ y para la asignación de las cadenas aromáticas se emplearon los experimentos bidimensionales (HB)CB(CGCD)HD, (HB)CB(CGCDCE)HE y ${ }^{13} \mathrm{C}$-HSQC. Los núcleos que son detectados se indican en fucsia mientras que en azul se señalan aquellos a través de los cuales se transfiere la magnetización. Las flechas indican los caminos de transferencia de la magnetización. Las imágenes se tomaron y adaptaron de http://www.protein-nmr.org.uk/. 


\subsubsection{Asignación de cadenas alifáticas}

La asignación de las cadenas laterales alifáticas se realiza mediante experimentos que identifican resonancias alifáticas basadas en acoplamientos J que se dan a través de enlaces entre los núcleos de la cadena lateral de los aminoácidos.

Con el fin de sobrellevar el efecto de solapamiento de señales dado por el tamaño de la molécula y el gran número de lisinas presentes en Na-FAR-1, en una primera instancia se emplearon dos experimentos $\mathrm{HCC}(\mathrm{CO}) \mathrm{NH}$-TOCSY 3D: $(\mathrm{H}) \mathrm{C}(\mathrm{CCO}) \mathrm{NH}-\mathrm{TOCSY}$ y $\mathrm{H}(\mathrm{C})(\mathrm{CCO}) \mathrm{NH}-\mathrm{TOCSY}{ }^{77,78,79}$. En ambos experimentos la magnetización se transfiere entre los carbonos alifáticos de las cadenas laterales bajo mezclado isotrópico, y luego, vía el carbono carbonílico, a la resonancia amida del residuo siguiente (i+1). En el experimento $\mathrm{H}(\mathrm{C})(\mathrm{CCO}) \mathrm{NH}-\mathrm{TOCSY}$, la magnetización se deja evolucionar bajo la influencia de la resonancia del protón alifático. Este experimento correlaciona las resonancias amida del esqueleto carbonado con las resonancias de protones alifáticos de las cadenas laterales del residuo anterior (i-1). En el $(\mathrm{H}) \mathrm{C}(\mathrm{CCO}) \mathrm{NH}-\mathrm{TOCSY}$ la magnetización del protón alifático no se deja evolucionar y este espectro correlaciona las resonancias amida del esqueleto carbonado con las resonancias de carbonos alifáticos de las cadenas laterales del residuo anterior (i-1). En este trabajo se empleó un tiempo de mezclado de $12 \mathrm{~ms}$.

Como las asignaciones de secuencia y resonancia de la mayoría de las amidas de la cadena principal ya habían sido determinadas, las resonancias de las cadenas laterales se asignaron a cada residuo (figura 3.6). Los experimentos $\mathrm{HCC}(\mathrm{CO}) \mathrm{NH}-\mathrm{TOCSY}$ fueron también útiles para confirmar las asignaciones previas y permitieron asignar gran parte de las resonancias $C \delta$ y $C \gamma$ de la mayoría de los residuos. Debido a la naturaleza oscilatoria de la transferencia de magnetización durante el mezclado isotrópico, un solo tiempo de mezclado no produce una trasferencia homogénea de magnetización a lo largo de toda la cadena lateral y los picos son menos intensos para espines acoplados más distantes, esto dificultó completar la asignación de cadenas laterales. 


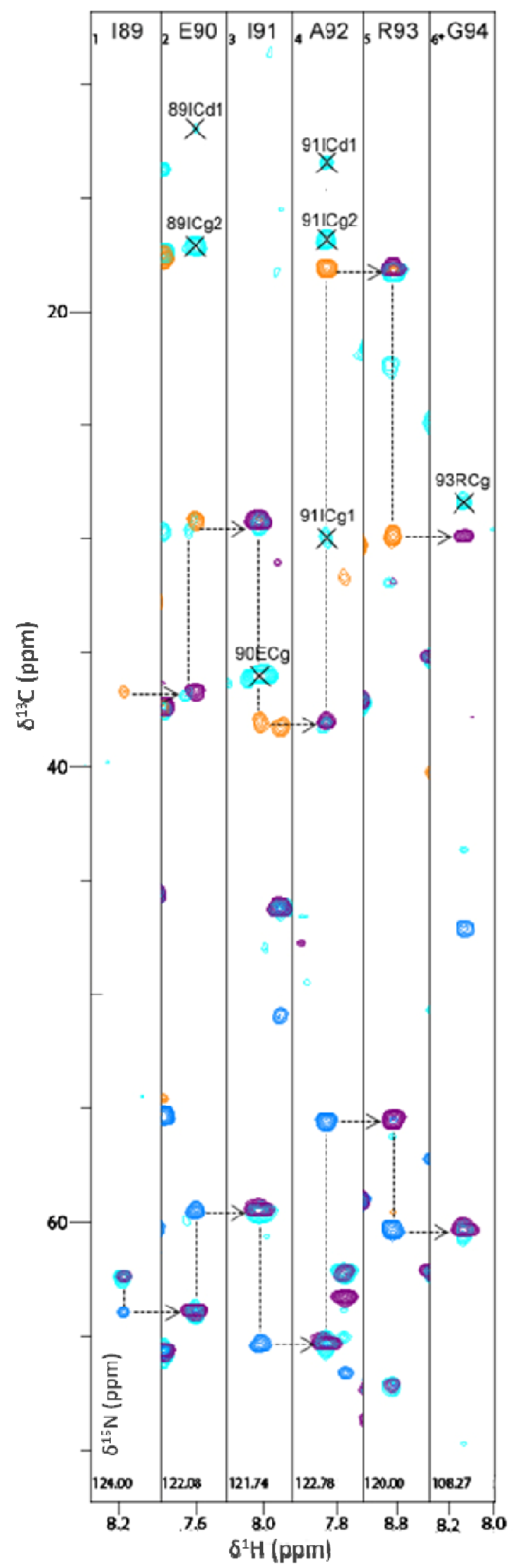

Fig.3.6. Bandas de espectros (H)C(CCO)NH que muestran los resultados de conectividad de secuencia. Bandas consecutivas de las resonancias amida de los residuos 89 al 94. El espectro $(\mathrm{H}) \mathrm{C}(\mathrm{CCO}) \mathrm{NH}$ se representa en turqueza y permite la asignación de resonancias de carbonos alifáticos de las cadenas laterales de residuos previos (i-1). También se representan espectros HNCACB y $\mathrm{HN}(\mathrm{CO}) \mathrm{CACB}$ que se emplearon en la asignación de la cadena principal. HNCACB presenta correlaciones de $C \beta$ (naranja) y $\mathrm{C} \alpha$ (azul) de residuo i y del residuo anterior (i-1) y $\mathrm{HN}(\mathrm{CO}) \mathrm{CACB}$ muestra correlaciones de $\mathrm{C} \beta$ y $\mathrm{C} \alpha$ del residuo previo (violeta). La conectividad de secuencia observada mediante estos espectros se indica con líneas punteadas. 
Para completar las asignaciones se empleó un experimento $\mathrm{HCCH}-\mathrm{COSY}$ (del inglés Correlation Spectroscopy) ${ }^{80}$ y dos tipos de HCCH-TOCSYs (del inglés Total Correlation Spectroscopy): $\mathrm{H}(\mathrm{C}) \mathrm{CH}-\mathrm{TOCSY}$ y $(\mathrm{H}) \mathrm{CCH}-\mathrm{TOCSY}^{81}$. En el HCCH-COSY cada banda de carbono presenta correlaciones con los hidrógenos alifáticos de carbonos contiguos, mientras que en el $\mathrm{H}(\mathrm{C}) \mathrm{CH}-\mathrm{TOCSY}$ se observan correlaciones con todos los hidrógenos alifáticos de la cadena lateral. En el (H)CCH-TOCSY se observan los desplazamientos químicos de todos los carbonos de la cadena lateral en la banda de hidrógeno.

En ambos experimentos HCCH-TOCSY la magnetización se transfiere desde los hidrógenos de la cadena lateral al carbono alifático unido. En el $\mathrm{H}(\mathrm{C}) \mathrm{CH}-\mathrm{TOCSY}$ la magnetización del protón alifático inicial se deja evolucionar, obteniéndose espectros con dimensiones indirectas ${ }^{1} \mathrm{H}$ y ${ }^{13} \mathrm{C}$ y una dimensión directa ${ }^{1} \mathrm{H}$, mientras que en (H)CCH-TOCSY el protón inicial sólo se usa para transferir la magnetización y se obtienen dos dimensiones de ${ }^{13} \mathrm{C}$ y la directa de ${ }^{1} \mathrm{H}$. La asignación se basó fundamentalmente en el $\mathrm{H}(\mathrm{C}) \mathrm{CH}-\mathrm{TOCSY}$, pero el experimento $(\mathrm{H}) \mathrm{CCH}$-TOCSY fue especialmente útil para asignar las resonancias de lisinas que presentaron gran solapamiento en el espectro anterior. Na-FAR-1 posee un gran número de lisinas (un total de 25) en su estructura primaria, residuos que debido a la carga presente en su cadena lateral se encuentran generalmente expuestos al solvente, censando un ambiente similar que redunda en un solapamiento de las señales. En el ejemplo de las figuras 3.7 y 3.8 se observan las correlaciones obtenidas a partir de estos experimentos TOCSY que permitieron completar la asignación de un residuo de lisina gracias a la complementación de $\mathrm{H}(\mathrm{C}) \mathrm{CH}-\mathrm{TOCSY}$ con $(\mathrm{H}) \mathrm{CCH}-\mathrm{TOCSY}$.

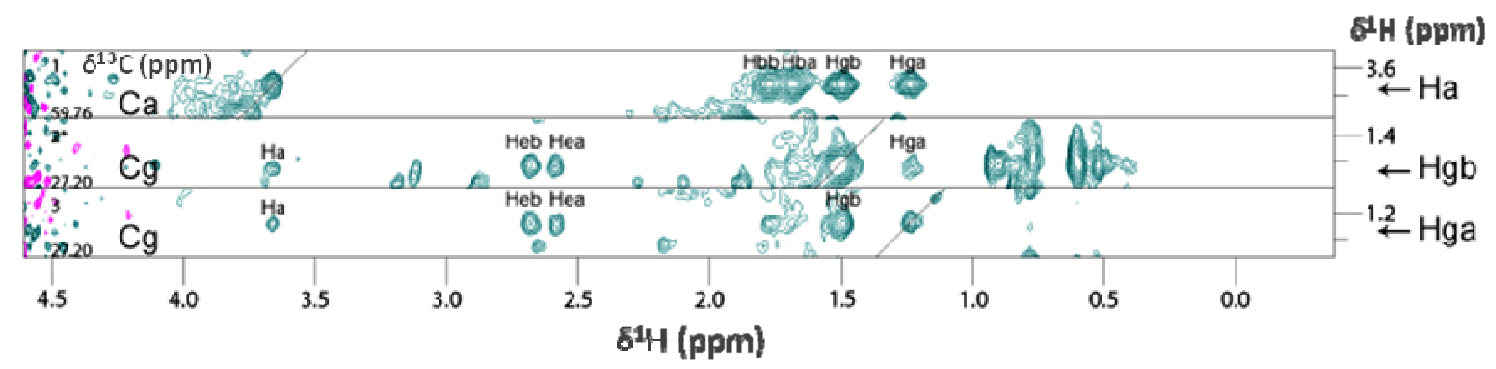

Fig.3.7. Bandas de espectros $\mathrm{H}(\mathrm{C}) \mathrm{CH}$-TOCSY. Se muestran las correlaciones ${ }^{13} \mathrm{C} \alpha$ y ${ }^{13} \mathrm{C} \gamma-{ }^{1} \mathrm{H}$ de Lys ${ }^{68}$. El pico correspondiente al $\mathrm{H} \varepsilon$ se detecta en la banda del $\mathrm{C} \gamma$ pero los desplazamientos químicos de $\mathrm{C} \delta$ y $\mathrm{C} \varepsilon$ son aún desconocidos. 


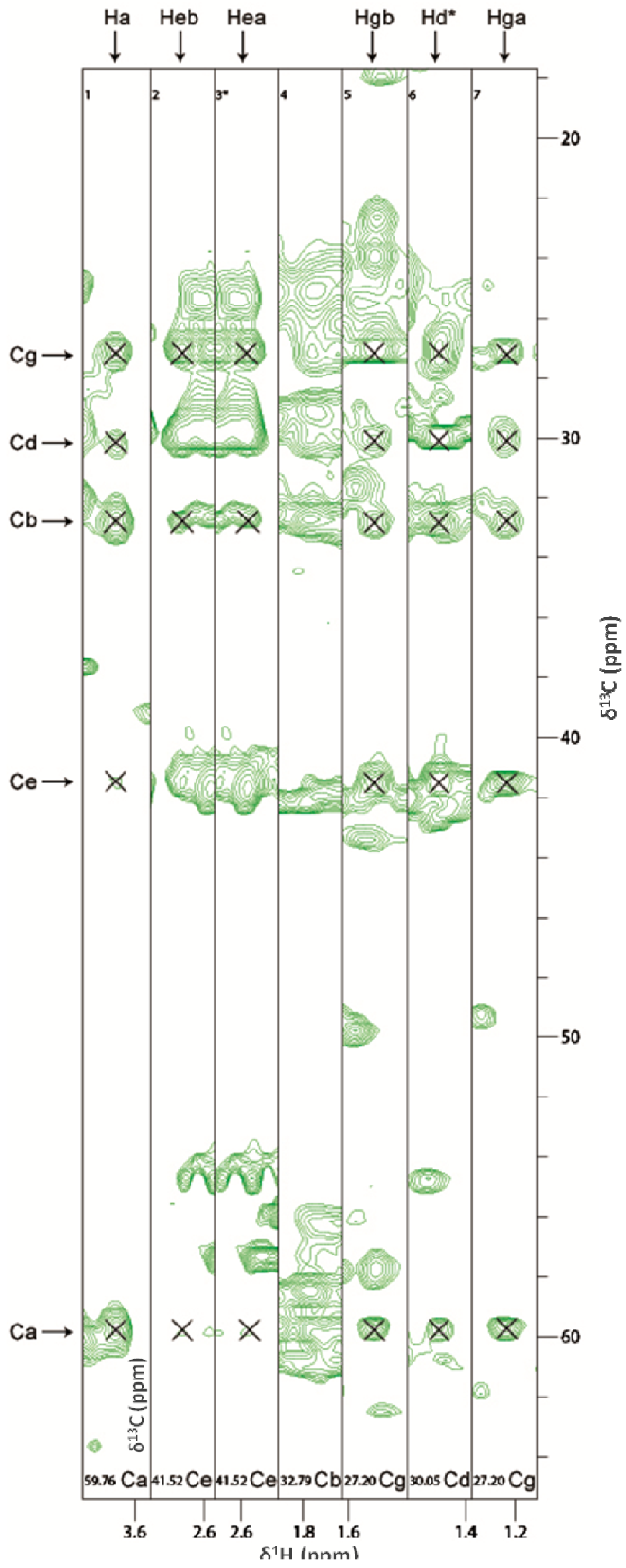

Fig 3.8. Bandas de espectros (H)CCH-TOCSY. Se muestran las correlaciones ${ }^{13} \mathrm{C}-{ }^{13} \mathrm{C}-{ }^{1} \mathrm{H}$ de lys 68. En la banda correspondiente a $\mathrm{C} \alpha$, se observan los picos correspondientes a todos los carbonos de la cadena lateral. Navegando hacia los desplazamientos químicos de $\mathrm{C} \delta$ y $C \varepsilon$, se reconocen las resonancias de los hidrógenos correspondientes. 


\subsubsection{Asignación de cadenas aromáticas}

La asignación de las cadenas laterales aromáticas se llevó a cabo con el aporte de los experimentos 2D ( $\mathrm{HB}) \mathrm{CB}(\mathrm{CGCD}) \mathrm{HD}$ y $(\mathrm{HB}) \mathrm{CB}(\mathrm{CGCDCE}) \mathrm{HE}$, dónde las resonancias $\mathrm{H} \delta$ y $\mathrm{H} \varepsilon$ se correlacionan con resonancias intra-residuo de $C \beta$ por la transferencia de magnetización a través de acoplamientos escalares ${ }^{82}$. Una vez identificados los desplazamientos químicos de $\mathrm{H} \delta$ y $\mathrm{H} \varepsilon$ se navegó en el espectro $2 \mathrm{D}{ }^{13} \mathrm{C}-\mathrm{HSQC}$, que presenta correlaciones ${ }^{13} \mathrm{C}-{ }^{1} \mathrm{H}$ para todos los átomos directamente unidos, independientemente de la identidad química, y se identificaron las resonancias $C \delta$ y $C \varepsilon$ de los residuos aromáticos correspondientes.

Dada la cantidad de residuos aromáticos en la secuencia de Na-FAR-1 (6 tirosinas y 9 fenilalaninas), los espectros 2D fueron suficientes para asignar la mayoría de los residuos, sin embargo, algunos presentaron solapamiento y las asignaciones restantes se realizaron mediante los espectros $3 \mathrm{D}{ }^{13} \mathrm{C}-\mathrm{NOESY}$.

\subsubsection{Asignación de espectros NOESY}

Todas las asignaciones se transfirieron a los espectros NOESY 3D: ${ }^{13} \mathrm{C}-\mathrm{NOESY}-\mathrm{HSQC}$ y ${ }^{15} \mathrm{~N}-\mathrm{NOESY}-\mathrm{HSQC}$ para generar restricciones a emplear en cálculos de estructura subsecuentes (figura 3.9).
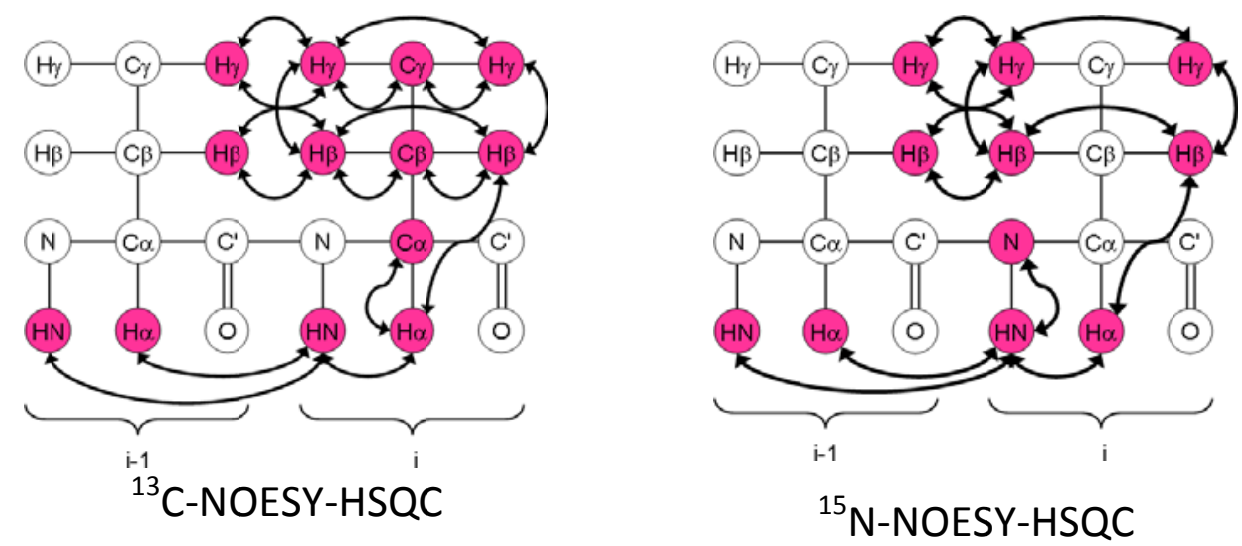

Fig.3.9. Esquemas de los experimentos NOESY. Los experimentos empleados fueron $3 D^{13} \mathrm{C}$-NOESYHSQC y $3 D^{15} \mathrm{~N}-\mathrm{NOESY}$-HSQC. Los núcleos que son detectados se indican en fucsia. Las flechas indican los caminos de transferencia de la magnetización. Las imágenes se tomaron de http://www.proteinnmr.org.uk/. 
Se asignaron las dimensiones directa de hidrógeno e indirecta del heteroátomo correspondiente $\left({ }^{15} \mathrm{~N}\right.$ en ${ }^{15} \mathrm{~N}$-NOESY y ${ }^{13} \mathrm{C}$ en ${ }^{13} \mathrm{C}$-NOESY). La asignación de la dimensión indirecta de hidrógeno solo se completó manualmente en casos donde existiera gran confianza. Los experimentos NOESY también permitieron la identificación de las resonancias no asignadas hasta ese momento: cadenas laterales de prolinas y argininas así como también amidas de las cadenas laterales.

\subsubsection{Compendio de asignación}

A partir de los experimentos descriptos se asignaron 157 de los 170 residuos de NaFAR-1 recombinante. Los residuos no asignados pertenecen a la secuencia de polihistidina $\mathrm{N}$-terminal de la proteína recombinante, que corresponde a una región de alta movilidad de acuerdo con los experimentos de dinámica expuestos en el capítulo siguiente. La totalidad de los residuos de la secuencia de la proteína nativa fue asignada, al menos parcialmente.

Un resumen de la asignación se muestra en la tabla 3.1.

\begin{tabular}{llll}
\hline Tipo de resonancia & Disponible & Asignado & \% Asignado \\
\hline Elemento C & 812 & 682 & 83.99 \\
Elemento H & 1014 & 927 & 91.42 \\
Elemento N & 229 & 156 & 68.12 \\
Amida & 331 & 294 & 88.82 \\
Cadena principal & 671 & 602 & 89.72 \\
Cadena principal no-H & 510 & 455 & 89.22 \\
Cadena lateral H & 853 & 780 & 91.44 \\
Cadena lateral no-H & 531 & 383 & 72.13 \\
\hline
\end{tabular}

Tabla 3.1. Resumen de la asignación de Na-FAR-1.

En la figura 3.10 se muestra el ${ }^{15} \mathrm{~N}-\mathrm{HSQC}$ asignado de Na-FAR-1. 


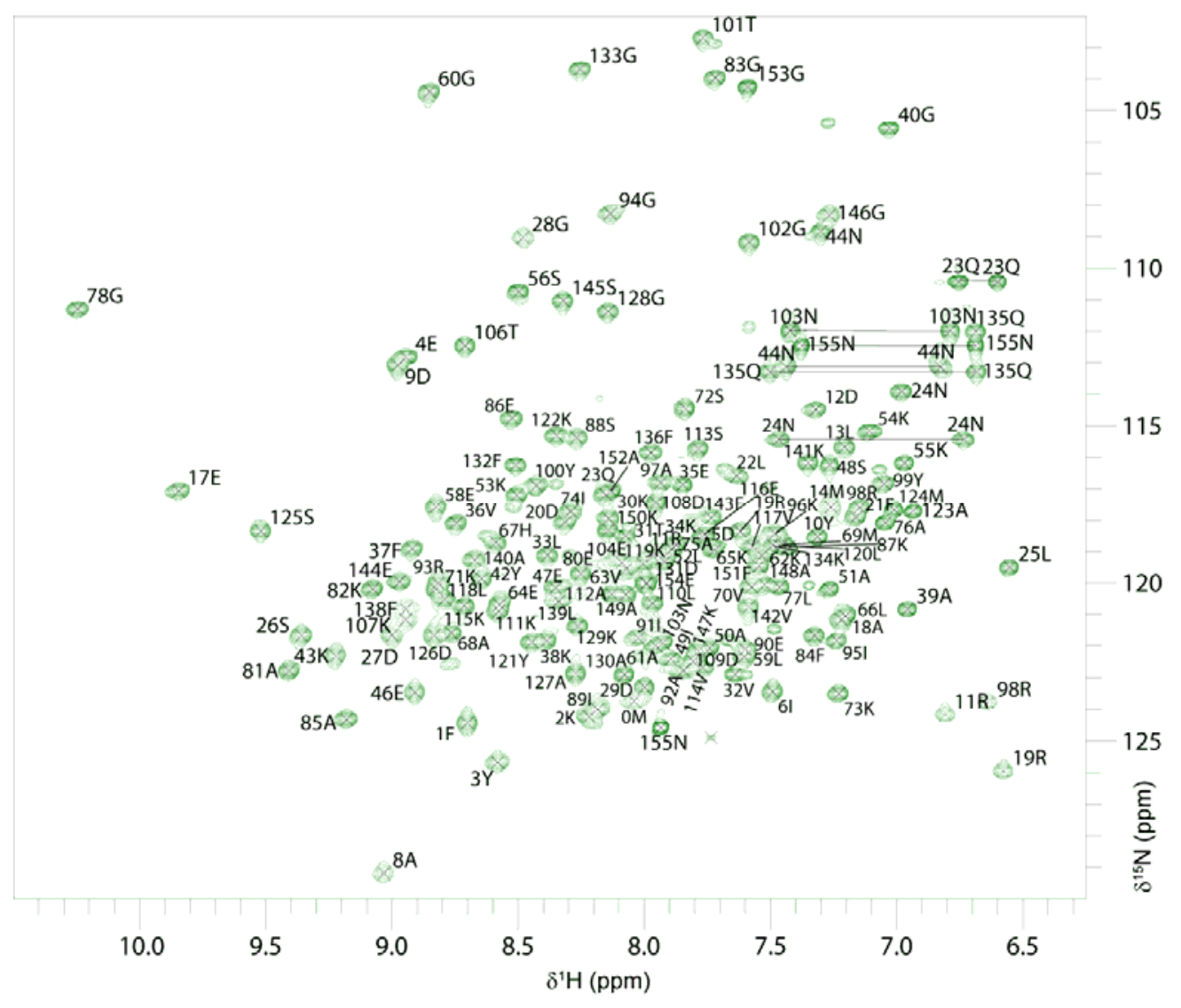

Fig.3.10. 15N-HSQC asignado de Na-FAR-1. Se muestran las correlaciones amida de Na-FAR-1. Los 155 aminoácidos de la proteína nativa fueron asignados total o parcialmente.

La gran mayoría de las resonancias asignadas presentó desplazamientos químicos dentro de los límites esperados para el tipo de átomo/residuo ${ }^{83}$. Sin embargo, hubo algunas excepciones con desplazamientos químicos inusuales (Tabla 3.2). Los datos que contenían estos desplazamientos químicos atípicos fueron verificados, y la asignación fue confirmada en cada caso.

El análisis posterior de la estructura de Na-FAR-1 permitió determinar que los desplazamientos químicos atípicos se correlacionan con la cercanía de estos núcleos a anillos de residuos aromáticos. 


\begin{tabular}{lcc}
\hline Resonancia & $\delta$ (ppm) & $\begin{array}{c}\text { Distribución } \boldsymbol{\delta} \text { de } \\
\text { referencia (ppm) }\end{array}$ \\
\hline 6 Ile Hg & -0.175 & $0.88-1.68$ \\
16 Pro Hdb & 2.273 & $3.30-4.00$ \\
40 Gly Hab & 2.739 & $3.60-4.34$ \\
48 Ser Ha & 2.873 & $4.08-4.88$ \\
73 Lys Hdb & 0.875 & $1.39-1.83$ \\
105 Pro Hdb & 2.171 & $3.30-4.00$ \\
121 Tyr Ha & 2.706 & $4.07-5.19$ \\
129 Lys Hg & 0.278 & $1.07-1.63$ \\
136 Phe Hb & 1.434 & $2.53-3.33$ \\
\hline
\end{tabular}

Tabla 3.2. Desplazamientos químicos atípicos de Na-FAR-1. Los datos de referencia fueron extraídos de las distribuciones de desplazamientos químicos presentes en CCPNanalysis basados en la base de datos $\operatorname{RefDB}^{83}$.

\subsection{Restricciones para el cálculo de estructura}

Muchos de los parámetros que pueden ser medidos por espectroscopía de RMN son sensibles a la conformación molecular. Mediante el conjunto de restricciones generadas a partir de estos parámetros se puede determinar la estructura tridimensional y son estas restricciones la base de la determinación estructural por RMN. En este trabajo se emplearon restricciones espaciales derivadas de experimentos NOESY, restricciones de ángulos diedros y, para el refinamiento, se incluyeron restricciones derivadas de acoplamientos residuales dipolares (RDCs, por sus siglas en inglés).

\subsubsection{Restricciones NOE}

Las restricciones más comúnmente usadas en la determinación estructural de proteínas son las $\mathrm{NOE}$, que contienen conectividades internucleares espaciales independientes de enlace. Las restricciones NOE se crean como consecuencia del efecto nuclear Overhauser (NOE) entre espines. Como se mencionó previamente, el efecto nuclear Overhauser proviene de los procesos de relajación cruzada de núcleos 
dipolarmente acoplados que están a distancias cercanas en el espacio. Por perturbaciones en la distribución de poblaciones entre estados de un núcleo, los procesos de relajación cruzada inducen un cambio en la distribución de poblaciones de otro núcleo dipolarmente acoplado que se observa como un cambio en la intensidad de señal. La proporción de relajación cruzada $(\sigma)$ entre un par de núcleos aislados A y $B$ puede describirse como:

$\sigma_{A B}=\zeta r_{A B}{ }^{-6}$

Donde $r_{A B}$ es la distancia internuclear y $\zeta$ es la función de correlación que depende del tiempo de correlación rotacional, $\tau_{c}$ del vector internuclear. Luego de la perturbación del equilibrio de un núcleo dado y un tiempo subsiguiente $\tau_{\text {mezcla, donde se permite }}$ que ocurran los procesos de relajación cruzada, la magnetización se transfiere al núcleo vecino. La ecuación 3.1 describe que la eficiencia con que ocurre esta transferencia de magnetización es proporcional a la inversa de la sexta potencia de la distancia internuclear. De este modo, la intensidad de los picos resultantes se puede usar para estimar la distancia entre dos núcleos, pudiéndose identificar los núcleos en un rango de hasta $5 \AA$ para NOEs entre ${ }^{1} \mathrm{H}-{ }^{1} \mathrm{H}$.

Un experimento 2D ${ }^{1} \mathrm{H}$ NOESY incluye una serie de tres pulsos de $90^{\circ}$ en protón con dos tiempos distintos entre ellos (figura 3.11). El primer pulso transfiere la magnetización al plano-xy donde el tiempo incrementado $\tau_{1}$ se emplea para codificar el desplazamiento químico del protón excitado en la dimensión indirecta. El segundo pulso retorna la magnetización al eje z. Durante el tiempo de mezclado del NOE, $\tau_{\text {mezcla, }}$ ocurre un proceso de relajación cruzada entre los núcleos dipolarmente acoplados de manera dependiente de la distancia. El pulso final transfiere la magnetización del protón al plano xy para su detección.

La configuración espacial de los protones forma una red que establece caminos alternativos para la transferencia de magnetización indirecta, proceso que se conoce como difusión de espín. Si el $\tau_{\text {mezcla }}$ es demasiado grande, se permite la difusión de espín afectando las intensidades NOE observadas y produciendo una subestimación de las distancias entre hidrógenos al aplicar la aproximación del par de espines aislados. 


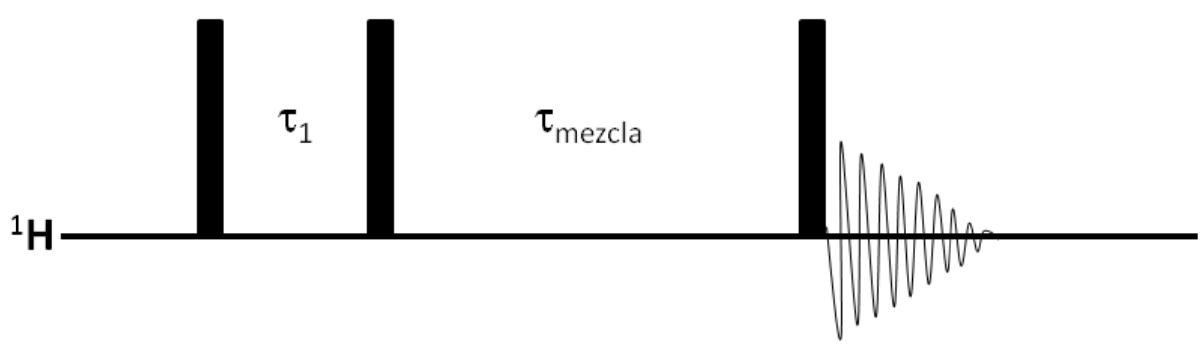

Fig. 3.11. Secuencia de pulsos básica de un experimento NOESY. Los pulsos de radiofrecuencia de $90^{\circ}$ se representan con rectángulos. Los primeros dos pulsos están separados por un tiempo de evolución $\tau_{1}$. Seguidamente hay un tiempo $\tau_{\text {mezcla }}$ donde transcurren los procesos de relajación cruzada. El pulso final transfiere la magnetización al plano xy para su detección.

En este trabajo se generaron restricciones NOE a partir de experimentos $3 \mathrm{D}{ }^{13} \mathrm{C}$ NOESY-HSQC y $3 D^{15} \mathrm{~N}$-NOESY-HSQC ${ }^{84}$. Estos experimentos contienen esencialmente una secuencia de pulsos NOESY como la de la figura 3.11 seguida de una secuencia HSQC para transferir magnetización al heteronúcleo unido que sea relevante. Ambos experimentos se realizaron con un tiempo de mezclado de $100 \mathrm{~ms}$ para generar intensidades razonables de picos con una difusión de espín tolerable para una molécula del tamaño de Na-FAR-1 ${ }^{85}$.

Las restricciones de distancia NOE se generaron con el programa CCPNAnalysis ${ }^{73}$ por conversión de la altura observada para cada pico en una distancia internuclear restringida usando la opción de compartimientos de distancia "Distance Bins", con tolerancias de asignación que se seleccionaron teniendo en cuenta el ancho de línea de los picos NOE. Los valores de tolerancia para el protón, carbono y nitrógeno fueron 0.05 ppm, 0.20 ppm y 0.40 ppm respectivamente.

La ventaja del método de compartimientos de distancia sobre el uso de valores definidos calculados a partir de $" 1 / r^{6}$ intensity distance mapping" reside en que no es necesario calibrar el valor de referencia basado en una distancia conocida.

Entonces, en lugar de dar a un pico un valor de distancia específico, se restringe a rangos de distancia permitidos. Se definen distintas clases de intensidades de picos, (por ejemplo, fuerte, medio, débil, muy débil) cada una de las cuales está asociada a una distancia comprendida entre límites de distancia que a su vez presentan un error 
asociado. Cada pico NOE se normaliza con respecto a la intensidad media de todos los picos NOE y de acuerdo a esto se agrupa dentro de una clase de distancia dada.

Las clases de distancia NOE empleadas en la generación de restricciones para las etapas finales del cálculo se detallan en la tabla 3.3.

\begin{tabular}{cc}
\hline Intensidad NOE mínima normalizada & Distancia máxima \\
\hline 3 & 2.8 \\
1 & 3.2 \\
0.25 & 4 \\
0.1 & 5 \\
0 & 6 \\
\hline
\end{tabular}

Tabla 3.3. Compartimientos de distancia empleados en la generación de restricciones NOE.

Las restricciones generadas en CCPNAnalysis son importadas a ARIA para el cálculo de estructura preservando la información de las intensidades de los picos. Allí a partir de las restricciones inicialemente compartimentalizadas, se calculan valores definidos de distancia con un error asociado, que son sometidos a procesos de recalibración mediante la relación de intensidad de la aproximación del par de espines con $1 / r^{6}$ y en base a las estructuras calculadas a lo largo de las iteraciones.

El error asociado a los valores de distancia que son recalibrados por $A R I A$, originalmente establecido en \pm 0.12 , se moduló en \pm 0.15 en las etapas finales del cálculo, lo cual disminuyó considerablemente la energía de las estructuras calculadas.

\subsubsection{Restricciones de ángulos diedros}

Las restricciones de ángulos diedros, aunque agregan poca información adicional a estructuras bien definidas por otros datos, pueden proporcionar información estructural valiosa en zonas donde los datos experimentales son escasos o donde las restricciones espaciales son ambiguas, y ayudan a la convergencia en los cálculos de estructura ${ }^{86}$. 
Los ángulos diedros de la cadena principal se predijeron empleando la herramienta DANGLE (Dihedral Angles from Global Likelihood Estimates) ${ }^{86}$, contenida en el programa CCPNAnalysis. DANGLE predice los ángulos $\varphi$ y $\psi$ de la cadena principal y la estructura secundaria de la proteína, basándose en datos de secuencia y de desplazamiento químico del esqueleto de la proteína. Cada residuo es evaluado en el contexto de los dos aminoácidos que lo preceden y los dos siguientes. Los datos de secuencia y de desplazamiento químico son analizados en secciones de cinco aminoácidos, contra una base de datos con información de fragmentos de cinco residuos de estructuras de proteínas en solución, para encontrar las diez coincidencias más cercanas. Este análisis se usa en combinación con rangos predefinidos basados en tipos específicos de residuos (glicinas, prolinas, residuos previos a prolinas), para predecir los ángulos $\varphi$ y $\psi$ y la estructura secundaria.

\subsubsection{Restricciones RDCs}

Las mediciones de NOEs proveen información semicuantitativa de la distancia entre pares de núcleos de hidrógeno próximos en el espacio $(<5 \AA$ ) dentro de la proteína. Si estas restricciones de corto alcance no son complementadas con información de largo alcance puede producirse una importante acumulación de errores a lo largo de toda la molécula. Para prevenir esto, se puede emplear información obtenida a partir de acoplamientos residuales dipolares (RDCs) que definen la orientación relativa de enlaces específicos dentro de la proteína con respecto a un marco de referencia en la molécula. Los RDCs brindan restricciones espaciales de largo alcance y ayudan a definir la orientación entre diferentes dominios de la proteína, donde la información de corto alcance sea escasa o nula, o que se encuentren en regiones remotas de la molécula, y de este modo contribuyen a mejorar la calidad de las estructuras calculadas ${ }^{87}$.

El acoplamiento dipolar entre dos núcleos puede definirse como:

$D_{A B}(\theta)=D_{0}\left(1-3 \cos ^{2} \theta\right)$

Donde $\theta$ es el ángulo entre el enlace internuclear $A-B$ y el campo magnético, $D_{0}$ depende de la distancia entre ambos núcleos y de sus constantes giromagnéticas. La 
molécula en solución rota y gira aleatoriamente, tomando todas las orientaciones posibles de $\theta$, como resultado, $D_{A B}$ se promedia a cero. Este efecto es aprovechado en la mayoría de los experimentos de RMN porque aumenta la sensibilidad y reduce la complejidad de los espectros, pero resulta en la pérdida de toda la información estructural contenida en los acoplamientos dipolares. Para poder usar esa información valiosa para el cálculo de estructura se puede evitar la pérdida de los acoplamientos dipolares influyendo sobre el movimiento aleatorio de la molécula, induciendo una pequeña preferencia por una orientación particular con respecto al campo magnético. Esto se puede lograr empleando un medio anisotrópico como bicelas, fagos filamentosos o geles comprimidos, dónde la molécula se orienta de un modo particular debido a interacciones electrostáticas o estéricas, pero aún puede moverse aleatoriamente para producir espectros bien resueltos.

Para dos núcleos $\mathrm{A}$ y $\mathrm{B}$ dipolarmente acoplados dentro de una molécula que se mueve aleatoriamente en solución anisotrópica, el acoplamiento dipolar observado $D_{A B}$, se puede escribir como ${ }^{88}$ :

$D_{A B}(\theta, \varphi)=A_{a}^{A B}\left\{(3 \cos 2 \theta-1)+3 / 2 R\left(\operatorname{sen}^{2} \theta \cos 2 \phi\right\}\right.$

Donde $A_{a}{ }^{A B}$ y $R$ son los componentes axial y rómbico, respectivamente, del tensor de alineamiento $\mathbf{A}$. A contiene los componentes principales $A_{x x}, A_{y y}$ y $A_{z z}$. Con $A_{a}, A_{r}$ y $R$ definidas como:

$$
A_{a}=\frac{1}{3} \frac{\left[A_{z z}^{A B}-A_{x x}^{A B}+A_{y y}^{A B}\right]}{2} \quad A_{r}=\frac{1}{3}\left[A_{x x}^{A B}-A_{y y}^{A B}\right] \quad R=\frac{A_{r}^{A B}}{A_{a}^{A B}}
$$

$\theta$ es el ángulo entre el vector del enlace A-B y el eje $z$ del tensor de alineación. $\phi$ es el ángulo entre la proyección del vector internuclear $A-B$ entre el plano xy y el eje $x$. $A_{a}{ }^{A B}$ es igual a:

$$
A_{a}^{A B}=-\left(\frac{\mu_{0} h}{16 \pi^{3}}\right) S_{\gamma A \gamma B}\left\langle r_{A B}^{-3}\right\rangle A_{a}
$$

Donde $\mu_{0}$ es la permeabilidad al vacío, $h$ es la constante de Plank, $S$ es el parámetro de orden, $\gamma_{A}$ y $\gamma_{B}$ son las constantes giromagnéticas de los núcleos $A$ y $B$ respectivamente y $A_{a}$ es la parte axial del tensor de 
alineamiento. Cuando se observa un solo tipo de acoplamiento dipolar, casi todos los valores se mantienen constantes, siendo los ángulos $\theta$ y $\phi$ los únicos que afectan los RDC.

En el presente trabajo se empleó una solución de fagos filamentosos PF1 (ASLAbiotech, Japón) como medio de alineamiento. En presencia del campo magnético, los fagos alargados (60尺̊ de ancho y $20000 \AA$ de largo) se alinean paralelos al campo magnético, debido a que presentan una suceptibilidad magnética anisotrópica, y forman de manera cooperativa un medio homogéneo pero anisotrópico, restringiendo los movimientos brownianos de las moléculas cercanas ${ }^{87}$. Una ventaja que presenta el empleo soluciones diluidas de cristales líquidos como fagos o bicelas, es que la magnitud de alineamiento se puede regular mediante la concentración de los mismos. Como Na-FAR-1, es una proteína de unión a ligandos hidrofóbicos, las bicelas no resultan apropaiadas para este sistema y la elección del medio de alineamiento recayó en los fagos.

La magnitud de alineamiento se estimó a través de la separación de bandas del deuterio. Los núcleos cuadrupolares como el deuterio, tienen una distribución de cargas no esférica dentro del núcleo, que es anisotrópica con respecto al campo magnético externo. En un medio isotrópico la interacción cuadrupolar, así como ocurre con los acoplamientos dipolares, se promedia a cero, pero puede observarse en un medio anisotrópico. La separación cuadrupolar en el espectro unidimensional de deuterio, se correlaciona de un modo aproximadamente lineal con la concentración de fagos $^{89}$.

Además de la concentración del medio de alineamiento se deben tener en cuenta otros factores que influyen sobre el nivel de orden en la muestra cuando se usa un medio eléctricamente cargado como los fagos, como por ejemplo, la carga neta y la distribución de cargas de la proteína ${ }^{90}$. Una proteína positivamente cargada interactúa fuertemente con los fagos llevando a un ensanchamiento de las señales y pérdida de resolución.

En una primera instancia se empleó una concentración de $18 \mathrm{mg} / \mathrm{ml}$ de fagos PF1 que produjo un alineamiento débil satisfactorio con una separación cercana a los $9 \mathrm{~Hz}$ en el 
espectro de deuterio. Sin embargo, en estas condiciones, las señales de Na-FAR-1 desaparecieron y se ensancharon en el espectro ${ }^{15} \mathrm{~N}-\mathrm{HSQC}$.

Debido al alto punto isoeléctrico de rNa-FAR-1, estimado en 9.6 (EMBL Gateway to Isoelectric Point Service, http://www.embl-heidelberg.de/cgi/pi-wrapper.pl), la proteína positivamente cargada, estaría interactuando fuertemente con las partículas de bacteriófago con carga superficial negativa ( $\mathrm{pl} \sim 4.0$ ) en las condiciones de trabajo a pH 7.4. La muestra se diluyó y la concentración de sal se incrementó para disminuir interacciones electrostáticas y censar las mejores condiciones de interacción entre la proteína y el bacteriófago, que a su vez permitieran un grado de alineamiento suficiente.

Los experimentos de RDCs se midieron a una concentración final $300 \mathrm{mM}$ de $\mathrm{NaCl}, 9$ $\mathrm{mg} / \mathrm{ml}$ de fagos PF1 y $300 \mu \mathrm{M}$ de Na-FAR-1 con $1.2 \% \mathrm{D}_{2} \mathrm{O}$. En las condiciones de trabajo empleadas se observó una separación de $4.07 \mathrm{~Hz}$ para el HDO (figura 3.12).

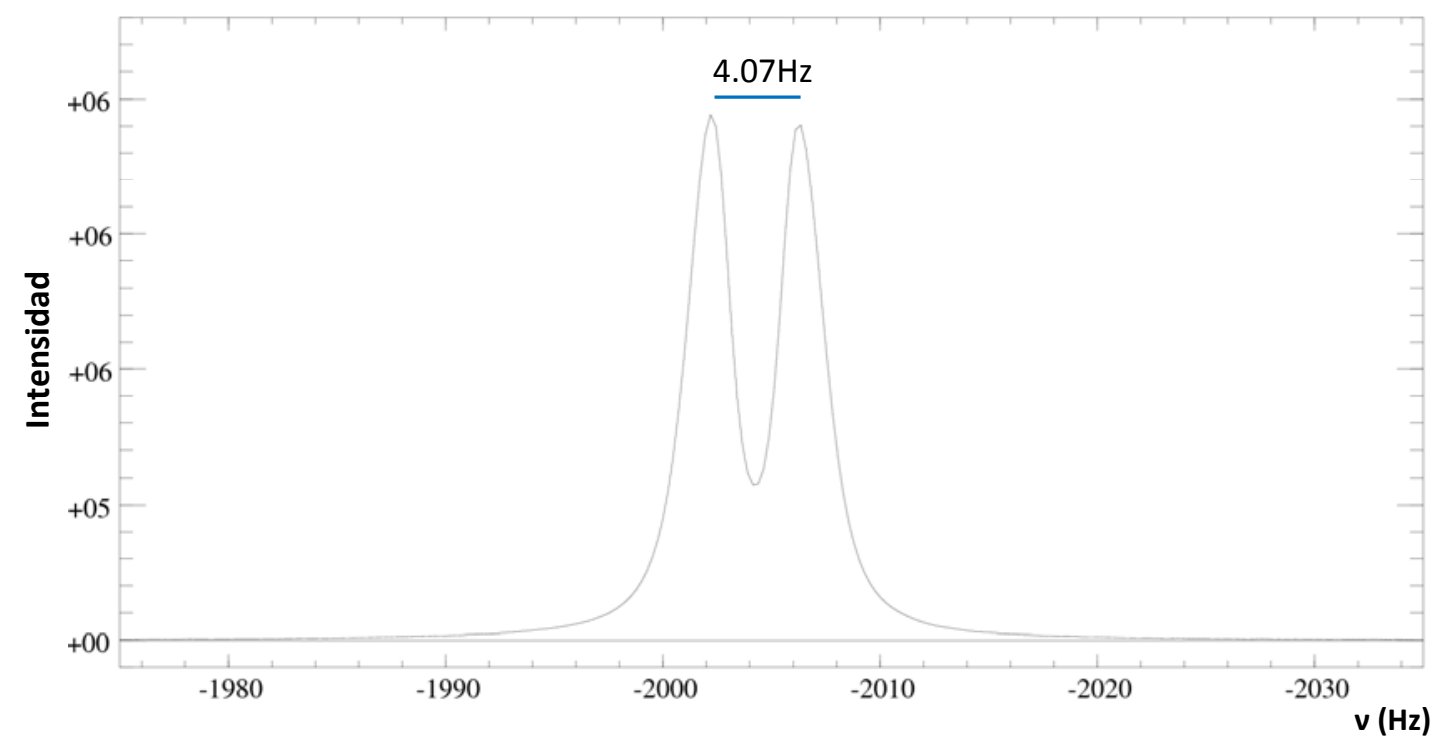

Fig.3.12. Separación cuadrupolar de deuterio de HDO en $9 \mathrm{mg} / \mathrm{ml}$ de fagos a 311K. La separación es proporcional al grado de alineamiento de la muestra.

Para la adquisición de espectros se utilizaron esquemas HSQC modificados basados en frecuencia, donde los acoplamientos se observan como una diferencia de posiciones de dos picos en un doblete. 
Se obtuvo información angular de acoplamientos dipolares ${ }^{1} \mathrm{H}^{15} \mathrm{~N}^{91} \mathrm{y}{ }^{1} \mathrm{H}_{-}{ }^{13} \mathrm{C} \alpha{ }^{92}$ con métodos en fase y anti fase IPAP (del inglés in phase anti phase). En ambos casos los espectros se adquierieron en fase y antifase, y luego se combinaron por adición o substracción a modo de obtener espectros que contengan únicamente los picos campo arriba o campo abajo en la dimensión de ${ }^{15} \mathrm{~N}^{91}$. Los experimentos se realizaron en condiciones isotrópicas (muestras no alineadas) y anisotrópicas (alineadas en presencia de fagos) desde donde se extrajeron acoplamientos escalares $(\mathrm{J}$ ) y residuales dipolares $(J+D)$, respectivamente. Los valores de $\mathrm{J}$ y $\mathrm{J}+\mathrm{D}$ se midieron usando el macro para cálculo de RDC, RDC_Calculator (Dr. Graham Ball, University of Edinburgh) en el programa CCPNAnalysis para picos resueltos con el objeto de calcular D (figura 3.13). Se llevaron a cabo duplicados para realizar una estimación del error de medida de los acoplamientos. Se obtuvieron 102 restricciones ${ }^{1} \mathrm{D}_{\mathrm{NH}}$ con un error de $1.98 \mathrm{~Hz}$ y 76 restricciones ${ }^{1} D_{\mathrm{H \alpha C} \alpha}$ con un error de $0.84 \mathrm{~Hz}$.

Para estimar el tensor de alineamiento se empleó el programa PALES (del inglés Prediction of Aligment from structure) ${ }^{93}$ (http://spin.niddk.nih.gov/bax/software/ PALES/). En base a las estructuras calculadas a partir de restricciones NOE y ángulos diedros, se extrajeron mediante PALES los componentes axial y rómbico para cada clase de RDC empleada en este trabajo. Para el tensor de alineamiento ${ }^{1} D_{\mathrm{NH}}$ se estimó $A a=3.96 \mathrm{~Hz}$ y $R=0.651$, mientras que para ${ }^{1} D_{H \alpha C \alpha}$ se estimó $A a=7.93 \mathrm{~Hz}$ y $R=0.651$. Este programa permitió evaluar el factor $Q$, que es una medida de cuán bien satisfacen las estructuras calculadas a las restricciones RDC. El factor Q obtenido fue de 0.549 lo cual indica que las restricciones provenientes de acoplamientos residuales dipolares pueden emplearse para el refinamiento de la estructura. Un total de 178 restricciones de acoplamientos dipolares, se incorporaron al cálculo de estructura via potencial SANI 94 


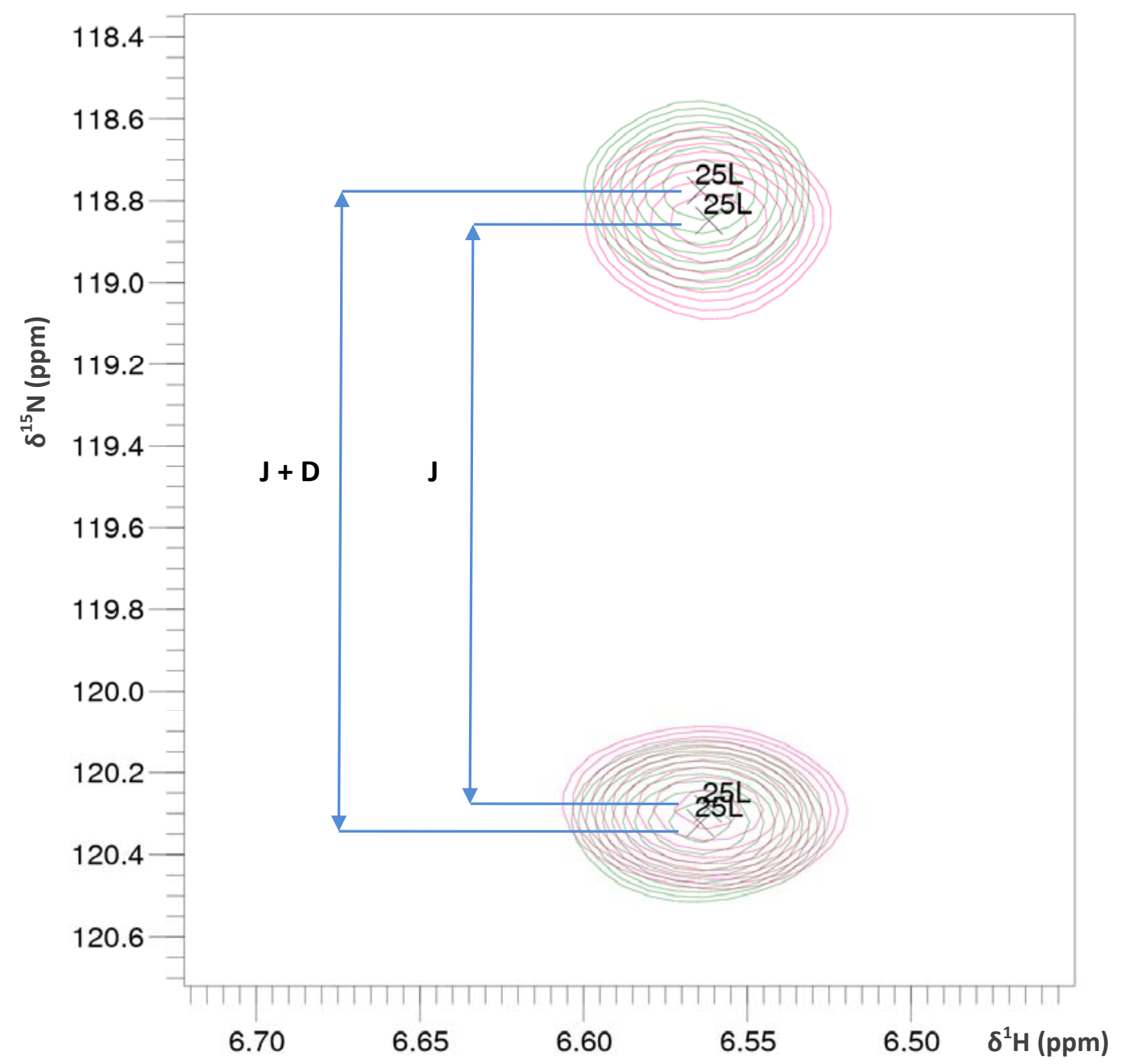

Fig.3.13. Separación escalar y residual dipolar en ${ }^{15} \mathbf{N}$ de un grupo amida de Na-FAR-1. La separación escalar (J) fue medida para una muestra en condiciones isotrópicas. El incremento en la separación (J+D) de una muestra alineada se usó para medir el RDC (D).

\subsection{Cálculo de estructura}

El objetivo del cálculo de estructura es encontrar las conformaciones que satisfagan las restricciones experimentales dentro del marco de las restricciones empíricas de geometrías de enlaces permitidas. Se empleó el programa ARIA 2.3 (del inglés Ambiguous Restraints for Iterative Assignment) para el cálculo de la estructura ${ }^{95}$. ARIA presenta un protocolo automático que puede manejar un gran número de restricciones. A continuación se intentará describir el protocolo seguido en ARIA durante el cálculo de la estructura de Na-FAR-1. 


\subsubsection{Dinámica molecular restringida y annealing simulado}

ARIA usa dinámica molecular restringida o rMD (del inglés Restrained molecular dynamics) y annealing simulado para producir múltiples estructuras compatibles con las restricciones y la información empírica. Emplea CNS (Crystallography and NMR System) ${ }^{96}$ como maquinaria de cálculo de estructura usando campos de fuerza y dinámica de ángulos de torsión.

La dinámica molecular restringida calcula la estructura monitoreando cambios en la energía potencial de la molécula bajo la influencia de términos empíricos que describen las interacciones covalentes y no covalentes conocidas entre átomos y los datos experimentales, durante una simulación de dinámica molecular ${ }^{84}$. Se usa un campo de fuerza para calcular la energía que se impone a cada átomo:

$E_{\text {total }}=E_{\text {covalente }}+E_{\text {no-covalente }}+E_{\text {experimental }}$

Donde $E_{\text {covalente }}=E_{\text {enlace }}+E_{\text {ángulo }}+E_{\text {diedro }}+E_{\text {impropio }}$ y $E_{\text {no-covalente }}=E_{\text {van der waals }}$

$E_{\text {impropio }}$ representa términos para imponer la quiralidad de centros quirales y planaridad de anillos aromáticos.

Los términos covalente y no covalente restringen los movimientos atómicos respecto a los valores ideales de geometría molecular. En este caso el campo de fuerza empleado es el PARALLHDG-5.3 ${ }^{97}$. El término experimental restringe los movimientos moleculares a modo de que la estructura satisfaga las observaciones experimentales.

Durante el proceso denominado annealing simulado (simulated annealing) se parte de una conformación inicial al azar y en primer lugar se eleva la temperatura del sistema. En esta etapa, los términos de fuerza potencial se suavizan y la energía cinética domina el sistema, permitiendo a la molécula explorar múltiples conformaciones y superar barreras de plegamiento. El sistema luego se enfría lentamente, reduciéndose la energía cinética al mismo tiempo que va creciendo el peso de los términos de energía potencial. Para evitar mínimos locales, el enfriamiento se realiza muy lentamente en condición de pseudoequilibrio. El propósito de la simulación es encontrar conjuntos de coordenadas que satisfagan los datos experimentales del mejor modo posible de modo que las estructuras calculadas tengan la menor energía potencial. 
Las condiciones del proceso de annealing simulado se adaptaron para mejorar la convergencia de las estructuras calculadas, principalmente se incrementó el número de pasos en cada etapa (Tabla 3.3).

\begin{tabular}{lll}
\hline Etapa & Temperatura (K) & Pasos \\
\hline Alta temperatura & 10000 & 20000 \\
Refinamiento & 2000 & 10000 \\
Enfriamiento 1 & 1000 & 5000 \\
Enfriamiento 2 & 50 & 4000 \\
\hline
\end{tabular}

Tabla 3.4. Resumen de las condiciones de annealing simulado.

\subsubsection{Restricciones en ARIA}

Las principales restricciones que se usan en RMN para el cálculo de la estructura son las generadas a partir de los espectros NOESY. Debido al gran número de hidrógenos presentes en la proteína, hay ciertos casos en que sus desplazamientos químicos se asemejan mucho y no es posible asignar todos los picos NOE de un modo no ambiguo.

Los picos NOE de Na-FAR-1 se asignaron manualmente en instancias donde esto podía llevarse a cabo con certeza, sin embargo, en la mayoría de los casos, la dimensión indirecta de hidrógeno permaneció sin asignarse. A este tipo de restricciones, donde existe más de una posible asignación para la dimensión indirecta de hidrógeno, se las denomina restricciones ambiguas.

En CCPNAnalysis se generan restricciones, ambiguas y no ambiguas que son importadas a $A R I A$. Las restricciones se importan junto a una lista de asignaciones posibles según los rangos de tolerancia en el desplazamiento químico establecidos en CCPNAnalysis durante la generación de las restricciones. Todas las resonancias que caen dentro de esos rangos de tolerancia son consideradas en ARIA como posibles asignaciones para el pico en cuestión. Cada pico NOESY es tomado como una superposición de señales proveniente de cada una de las posibles asignaciones, usando un peso relativo proporcional a la inversa de la sexta potencia de la distancia 
interatómica correspondiente. El punto de corte es establecido $\mathrm{p}$

El cálculo de la estructura se lleva a cabo empleando las restricciones de distancia ambiguas mediante la combinación de todas las posibles asignaciones de un pico NOE dentro de una restricción ${ }^{95}$.

Un caso especial son los grupos proquirales en la proteína, especialmente los grupos metilo de leucinas y valinas, pueden ser difíciles de asignar estereoespecíficamente, y cualquier mala asignación puede aparejar errores en las estructuras calculadas. ARIA puede trabajar con grupos proquirales ambiguos permitiendo la asignación no degenerada a ambos miembros del par proquiral y cambiando sus asignaciones durante el cálculo ${ }^{98}$. La conformación de menor energía es la que resulta seleccionada para cada centro proquiral.

\subsubsection{Esquema iterativo de cálculo}

$A R I A$ emplea una estrategia iterativa para el cálculo de la estructura ${ }^{98}$. La estrategia iterativa seguida por ARIA puede resumirse del siguiente modo: (i) Análisis del conjunto de estructuras, calibración de intensidades, detección de inconsistencias en las restricciones. (ii) Creación de un conjunto de restricciones con menos posibilidades de asignación y cálculo de un nuevo conjunto de estructuras.

Esto se repite un número definido de veces para lograr aumentar el número de restricciones no ambiguas con el fin de obtener estructuras bien definidas con menor energía.

El esquema usado para el cálculo de la estructura de Na-FAR-1 se indica en la tabla 3.4.

En la iteración 0 , se realiza un cálculo de annealing simulado usando todas las restricciones no ambiguas y ambiguas asignadas manualmente, partiendo desde una estructura al azar. La iteración 1 comienza analizando un número de estructuras definido seleccionado de la iteración 0 empleando como criterio la menor energía total del sistema. Durante el cálculo, las restricciones de distancia se analizan en base a las estructuras generadas para identificar violaciones, que pueden deberse a asignaciones incorrectas o artefactos de ruido y caen fuera del margen de tolerancia. A medida que transcurren las iteraciones se establecen límites cada vez más estrictos de tolerancia a 
las violaciones y en el filtro de asignación parcial. Este último establece un punto de corte en la intensidad de los picos que son considerados como contribución a la asignación.

De este modo se van filtrando las asignaciones logrando en algunos casos desambiguar las restricciones. El nuevo conjunto de restricciones con menos posibilidades de asignación se emplea en la siguiente iteración para el cálculo partiendo de las estructuras seleccionadas.

\begin{tabular}{|c|c|c|c|c|c|c|c|c|}
\hline It & $\begin{array}{c}\text { Restricciones } \\
\text { de distancia }\end{array}$ & $\begin{array}{c}\mathbf{N}^{\circ} \text { de } \\
\text { estructuras } \\
\text { calculadas }\end{array}$ & $\begin{array}{c}\mathbf{N}^{\circ} \text { de } \\
\text { estructuras } \\
\text { seleccionadas }\end{array}$ & $\begin{array}{c}\text { Punto de } \\
\text { corte de } \\
\text { distancia (Å) }\end{array}$ & $\begin{array}{c}\text { Tolerancia de } \\
\text { violación (Å) }\end{array}$ & $\begin{array}{c}\text { Umbral de } \\
\text { violación }\end{array}$ & $\begin{array}{c}\text { Punto de corte } \\
\text { de signación } \\
\text { parcial }\end{array}$ & $\begin{array}{c}\text { Otras } \\
\text { restricciones }\end{array}$ \\
\hline 0 & todas & 40 & 10 & 7 & 1000 & 0.5 & 1.0 & Ángulos diedros \\
\hline 1 & $\begin{array}{c}\text { chequeadas } \\
\text { de it 0 }\end{array}$ & 40 & 10 & 7 & 5.0 & 0.5 & 0.9999 & $\begin{array}{c}\text { Ángulos diedros } \\
\text { RDC }\end{array}$ \\
\hline 2 & $\begin{array}{c}\text { chequeadas } \\
\text { de it 1 }\end{array}$ & 40 & 10 & 7 & 3.0 & 0.5 & 0.999 & $\begin{array}{c}\text { Ángulos diedros } \\
\text { RDC }\end{array}$ \\
\hline 3 & $\begin{array}{c}\text { chequeadas } \\
\text { de it 2 }\end{array}$ & 40 & 10 & 7 & 1.0 & 0.5 & 0.999 & $\begin{array}{c}\text { Ángulos diedros } \\
\text { RDC }\end{array}$ \\
\hline 4 & $\begin{array}{c}\text { chequeadas } \\
\text { de it 3 }\end{array}$ & 40 & 10 & 7 & 1.0 & 0.5 & 0.99 & $\begin{array}{c}\text { Ángulos diedros } \\
\text { RDC }\end{array}$ \\
\hline 5 & $\begin{array}{c}\text { chequeadas } \\
\text { de it 4 }\end{array}$ & 40 & 10 & 7 & 1.0 & 0.5 & 0.98 & $\begin{array}{c}\text { Ángulos diedros } \\
\text { RDC }\end{array}$ \\
\hline 6 & $\begin{array}{c}\text { chequeadas } \\
\text { de it 5 }\end{array}$ & 40 & 10 & 7 & 0.5 & 0.5 & 0.95 & $\begin{array}{c}\text { Ángulos diedros } \\
\text { RDC }\end{array}$ \\
\hline 7 & $\begin{array}{c}\text { chequeadas } \\
\text { de it 6 }\end{array}$ & 100 & 20 & 7 & 0.5 & 0.5 & 0.95 & $\begin{array}{c}\text { Ángulos diedros } \\
\text { RDC }\end{array}$ \\
\hline 8 & $\begin{array}{c}\text { chequeadas } \\
\text { de it 7 }\end{array}$ & 100 & 20 & 7 & 0.5 & 0.5 & 0.95 & $\begin{array}{c}\text { Ángulos diedros } \\
\text { RDC }\end{array}$ \\
\hline
\end{tabular}

Tabla 3.4. Esquema iterativo usado en ARIA para el cálculo de la estructura de Na-FAR-1.

Debe mencionarse que como los ángulos diedros calculados con DANGLE se basan en ángulos diedros tomados desde una base de datos de estructuras conocidas, la exactitud del resultado depende de cuan representativa sea la base de datos, en lugar de recaer exclusivamente en los datos experimentales. Esto podría entonces trasladar errores al cálculo de la estructura. Para prevenir estos efectos, las restricciones de ángulos diedros sólo se emplean en pasos de alta temperatura del proceso de simulación de annealing para favorecer la convergencia. En los pasos finales de enfriamiento se omiten estas restricciones angulares, haciendo cero la constante de fuerza, previniendo desviaciones en las estructuras calculadas. Las restricciones de 
ángulos diedros se quitaron en la etapa final de todas las iteraciones, haciendo cero la constante de fuerza en la etapa de enfriamiento 2 .

\subsubsection{Refinamiento en agua}

Para una mayor eficiencia, las estructuras se calculan en el vacío con interacciones simplificadas de van der Waals y sin término electrostático en el campo de fuerza. Sin embargo, este procedimiento puede llevar a la aparición de artefactos en la estructura

final ${ }^{99}$. Es por ello que se empleó un paso de refinamiento donde un número definido de estructuras del último paso de iteración se encapsularon en una capa fina de moléculas de agua explícita, y se refinaron contra un campo de fuerza empírico que incluye una representación más completa de van der Waals y términos electrostáticos. Para que el refinamiento en agua no fuerce a una desviación de los datos experimentales, el campo de fuerza se parametrizó de acuerdo a las estructuras calculadas in vacuo. El refinamiento en agua se llevó a cabo en las 20 estructuras de menor energía de la iteración número 8 , siguiendo el procedimiento publicado por Linge y col $^{99}$.

\subsubsection{Análisis de las restricciones}

Luego de cada ronda de cálculo, las restricciones rechazadas por ARIA como violaciones se analizaron con CCPNAnalysis. Se eliminaron los picos provenientes de ruido y las asignaciones incorrectas se corrigieron. Las violaciones para las cuales no se encontró razón válida para desechar se mantuvieron en los cálculos subsiguientes. Este proceso se repitió hasta que las estructuras calculadas mostraron buena convergencia y baja energía.

\subsection{Validación de estructuras}

Las estructuras calculadas proveen modelos generados para representar del mejor modo posible los datos experimentales. La calidad de estos modelos depende de la calidad de los datos y de la manera en que estos datos son interpretados en una 
estructura tridimensional ${ }^{100}$. Por ello es importante tener alguna medida referente a la calidad de la estructura calculada y de algún modo saber cuán representativa es en relación a la proteína de interés.

\subsubsection{Selección del conjunto de estructuras}

En RMN las restricciones definen rangos de distancias y de ángulos permitidos y no valores discretos, es por esto que son múltiples estructuras las que representan los datos experimentales.

En la iteración final in vacuo de Na-FAR-1 se seleccionaron los 20 modelos que mostraron la menor energía experimental (NOE+RDC) (figura 3.14). Este conjunto de estructuras se sometió a refinamiento en agua y los 20 modelos refinados se tomaron como conjunto de estructuras de Na-FAR-1.

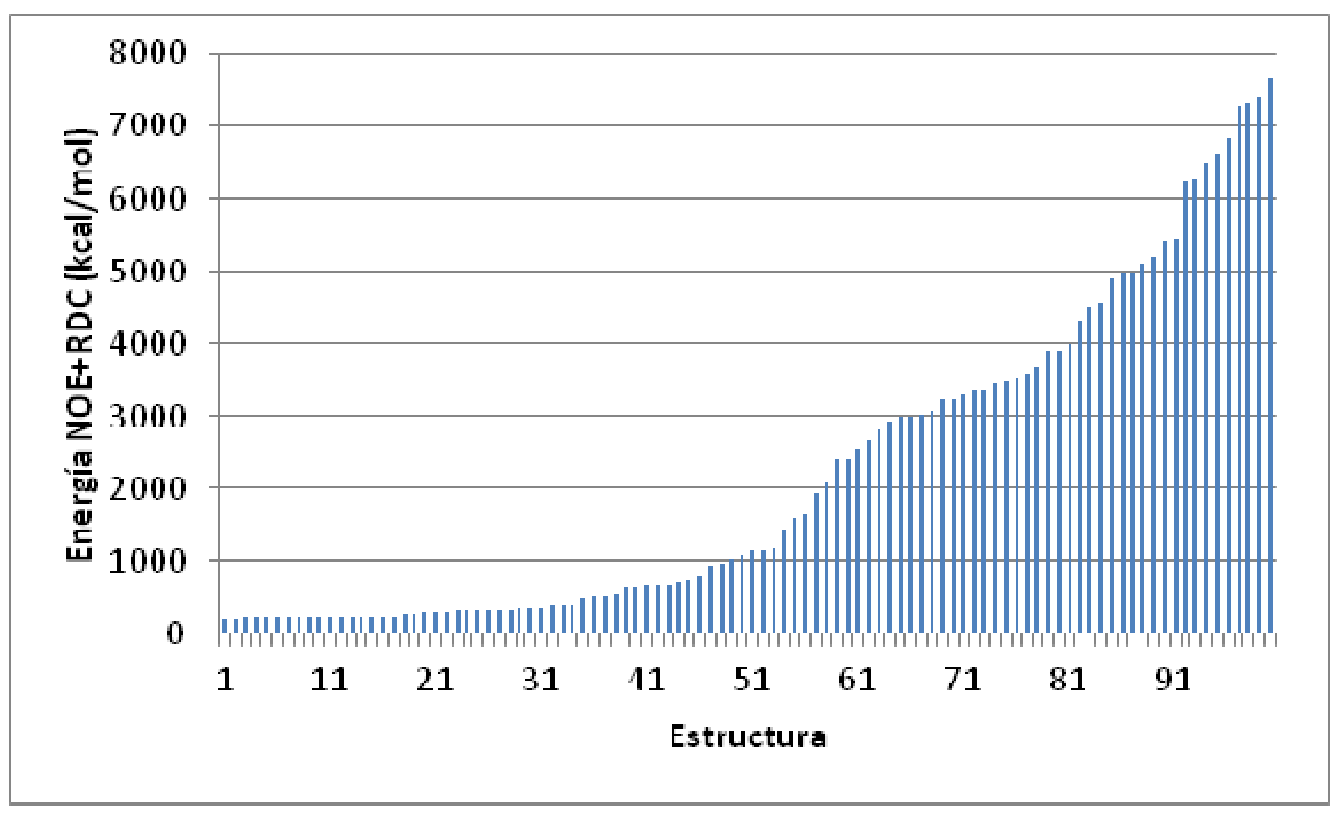

Fig.3.14. Energía total de las 100 estructuras de Na-FAR-1 generadas en la iteración 8 del cálculo. 


\subsubsection{Evaluación de la calidad de las estructuras}

Un modo de evaluar la calidad de las estructuras calculadas es mediante el análisis de las restricciones empleadas. La precisión está directamente relacionada con la cantidad de restricciones empleadas durante el cálculo. Cuantas más restricciones son incluidas mejor es la resolución de la estructura calculada ${ }^{100}$.

Las estadísticas de las restricciones experimentales, calculadas a partir de las 20 estructuras refinadas en agua, se detallan en la Tabla 3.5. Es pertinente destacar que no se observaron violaciones consistentes mayores a $0.3 \AA$.

La precisión de las estructuras calculadas da una idea de cuán bien se correlacionan las estructuras con las restricciones experimentales empleadas. Sin embargo, esto no implica que una estructura muy precisa sea la más representativa.

\begin{tabular}{lc}
\hline Restricciones de distancia NOE & \\
\hline NOE totales & 7097 \\
Ambiguas & 3443 \\
No ambiguas & 3654 \\
$\quad$ Intra-residuo & 1548 \\
$\quad$ Inter-residuo & 2106 \\
$\quad$ Secuenciales $(\mathrm{i}-\mathrm{j}=1)$ & 833 \\
$\quad$ Corto alcance $(\mathrm{i}-\mathrm{j}<5)$ & 756 \\
$\quad$ Largo alcance $(\mathrm{i}-\mathrm{j}>5)$ & 517 \\
Violaciones por estructura $>0.5 \AA$ & 0.3 \\
Violaciones por estructura $>0.3 \AA$ & 1.6 \\
RMSD restricciones de distancia & $0.016 \AA$ \\
\hline RDCs & \\
\hline${ }^{1} \mathrm{D}_{\mathrm{NH}}$ & 102 \\
${ }^{1} \mathrm{D}_{\mathrm{C} \alpha \mathrm{H} \alpha}$ & 76 \\
Factor Q & 0.164 \\
\hline Ángulos diedros & 312 \\
\hline
\end{tabular}

Tabla.3.5. Estadística de las restricciones experimentales empleadas en el cálculo. 
Mediante la inspección visual de una imagen generada con pymol (www.pymol.org) se puede tener una idea de la precisión del conjunto de estructuras (figura 3.15). Los 20 modelos de Na-FAR-1 son muy similares debido al alto número de restricciones que están representadas. Las regiones terminales y las regiones lazo (especialmente la región del lazo 4) están menos definidas que el resto de la proteína debido al menor número de restricciones presentes y esto podría ser una consecuencia de procesos dinámicos que experimentan esas zonas.
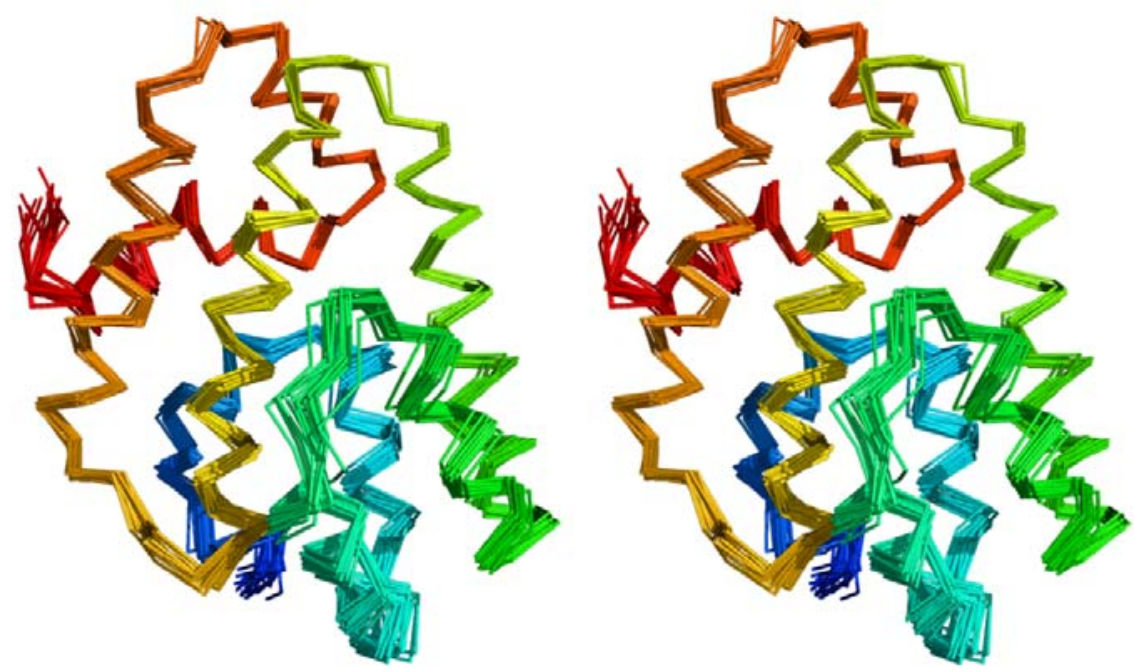

Fig.3.15. Representación estereoscópica de las 20 estructuras finales calculadas de Na-FAR-1 superpuestas. La coloración es de azul en el extremo N-terminal a rojo en el C-terminal.

La calidad de los modelos se puede evaluar de una forma más cuantitativa mediante el cálculo de la desviación cuadrática media (RMSD) entre las coordenadas atómicas de cada modelo y una estructura promedio generada a partir del conjunto de estructuras.

La estructura promedio se generó empleando el programa UWMN (M. Hartshorn y L. Caves, University of York). Este programa crea una matriz de la distancia entre los átomos de todos los modelos del conjunto de estructuras. La matriz de distancia se proyecta hacia el espacio tridimensional para producir la estructura promedio.

EI RMSD se calculó para la molécula entera y para las regiones estructuradas que fueron determinadas a partir de datos de relajación presentados en el capítulo siguiente. Se seleccionaron los residuos que se hallaban en las regiones de estructura 
secundaria definida, excluyendo lazos y las regiones móviles de los extremos N- y Cterminal (tabla 3.6).

\begin{tabular}{lcc}
\hline & \multicolumn{2}{c}{ RMSD con respecto a la estructura promedio $(\AA)$} \\
& Molécula completa & Regiones estructuradas \\
\hline Átomos pesados & 1.012 & 0.944 \\
Cadena principal & 0.597 & 0.504 \\
$\mathrm{C} \alpha$ & 0.611 & 0.523 \\
\hline
\end{tabular}

Tabla 3.6. RMSD calculado con UWMN para regiones estructuradas y totales.

En la figura 3.16 se observa que existe una buena distribución de restricciones espaciales a lo lago de la molécula. Esto resulta en que la mayoría de los residuos presente un RMSD bastante similar a la media, indicando que la estructura se encuentra bien definida. Los residuos con mayores valores de RMSD se encuentran en regiones lazos y en los extremos de la proteína.

La presencia de restricciones RDCs a lo largo de la molécula asegura la existencia de información orientacional entre las distintas zonas y elementos de estructura secundaria. 

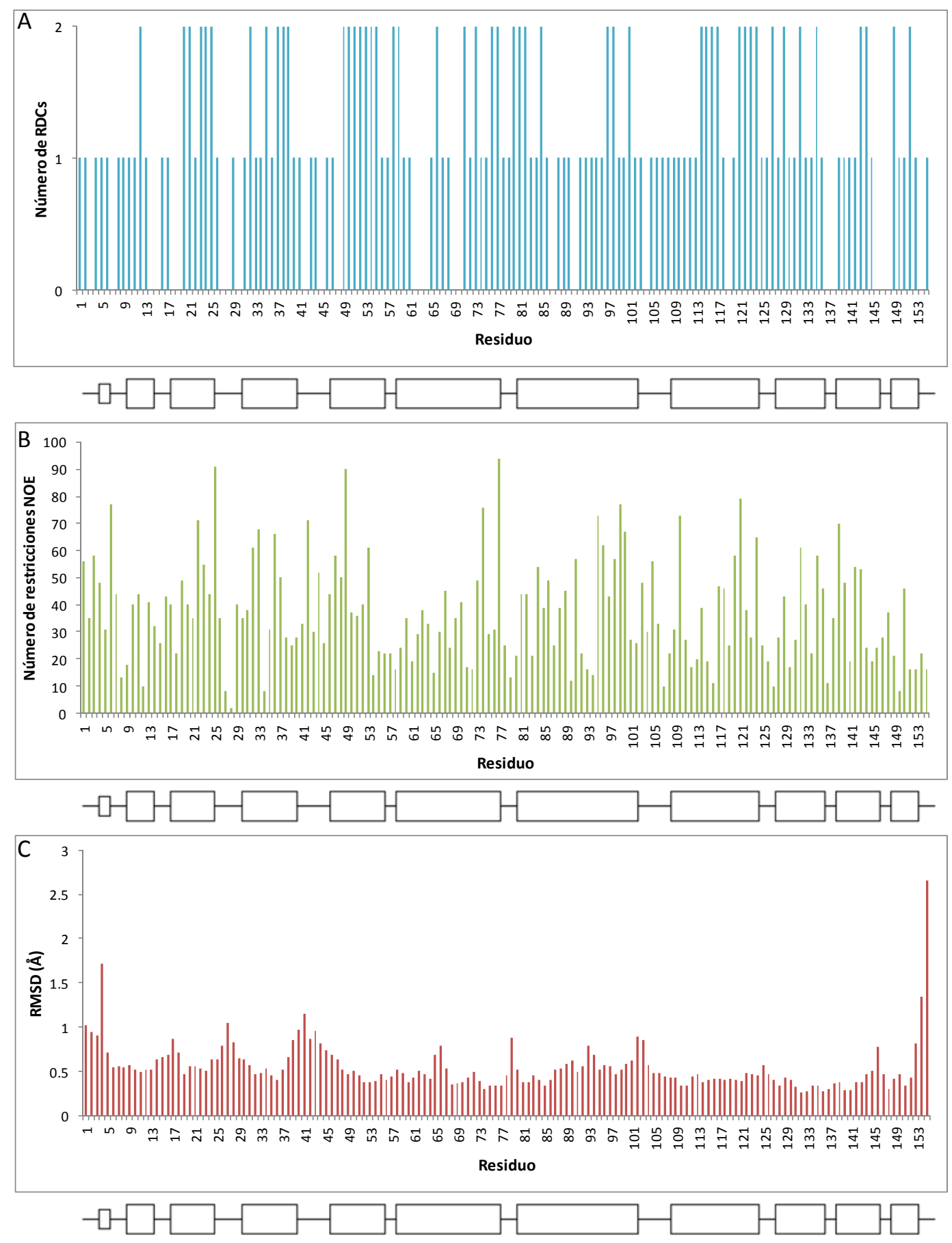

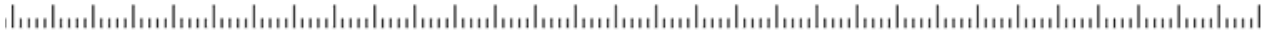
$\begin{array}{llllllllllllllll}0 & 10 & 20 & 30 & 40 & 50 & 60 & 70 & 80 & 90 & 100 & 110 & 120 & 130 & 140 & 150\end{array}$

Fig.3.16. Correlación entre restricciones espaciales y el RMSD por residuo en la estructura de Na-FAR1. En (A) se indica el número de restricciones de acoplamientos dipolares, en (B) el número de restricciones NOE, empleadas durante el cálculo de la estructura y en (C) se indica el RMSD, estimado mediante UWMN, para los $\mathrm{C} \alpha$ de cada residuo en las estructuras resultantes. 


\subsubsection{Calidad geométrica del conjunto de estructuras de NA-FAR-1}

En cristalografía de rayos $\mathrm{X}$, la determinación estructural se realiza exclusivamente a partir de datos experimentales y no requiere de la incorporación de datos empíricos o del empleo de campos de fuerza como ocurre en RMN. Mediante la comparación con los datos estándar provenientes de estructuras determinadas por cristalografía de rayos $\mathrm{X}$ se puede evaluar la calidad geométrica de las estructuras determinadas por RMN. En la tabla 3.7 se incluye la desviación promedio del conjunto de estructuras de Na-FAR-1 con respecto a los valores geométricos ideales.

\begin{tabular}{lc}
\hline RMSD respecto de la geometría ideal \\
\hline Longitud de enlace $(\AA)$ & $0.03 \pm 0.00$ \\
Angulo de enlace $\left(^{\circ}\right)$ & $0.59 \pm 0.02$ \\
Angulo impropio $\left(^{\circ}\right)$ & $1.57 \pm 0.07$
\end{tabular}

Tabla 3.7. RMSD del conjunto de estructuras de Na-FAR-1 con respecto a valores empíricos.

La calidad geométrica de las estructuras puede ser evaluadas por la distribución de los ángulos de torsión de la cadena principal $\left(\varphi\right.$ y $\psi$ ) y de las cadenas laterales $\left(\chi_{1}\right)^{101}$.

La calidad del conjunto de estructuras de Na-FAR-1 se evaluó empleando Procheck$N M R^{102}$ y los resultados se incluyen en el Apéndice B. Esta información se graficó para el conjunto de estructuras de Na-FAR-1 (figura 3.17). Las estadísticas de Ramachandran para todos los residuos (excluyendo las prolinas, glicinas y los residuos $\mathrm{N}$-terminales del tag de polihistidina) del conjunto de estructuras de Na-FAR-1 se resumen en la tabla 3.8 .

Más del $90 \%$ de los residuos cae en las regiones más favorables del gráfico de Ramachandran. Si se tienen en cuenta las regiones permitidas adicionales el porcentaje de residuos se encuentra cerca del 99\%, lo cual es consistente con estructuras de buena geometría y alta calidad. 
Al analizar los gráficos de Ramachandran para los residuos individuales, se comprobó que aquellos localizados en hélices $\alpha$ se localizaron en regiones favorables o cerca de estas. Para los residuos que se encuentran en lazos o en los extremos de la proteína, la variabilidad en los ángulos $\phi$ y $\psi$ fue mayor, lo cual puede deberse a la falta de restricciones que definieran esas zonas.

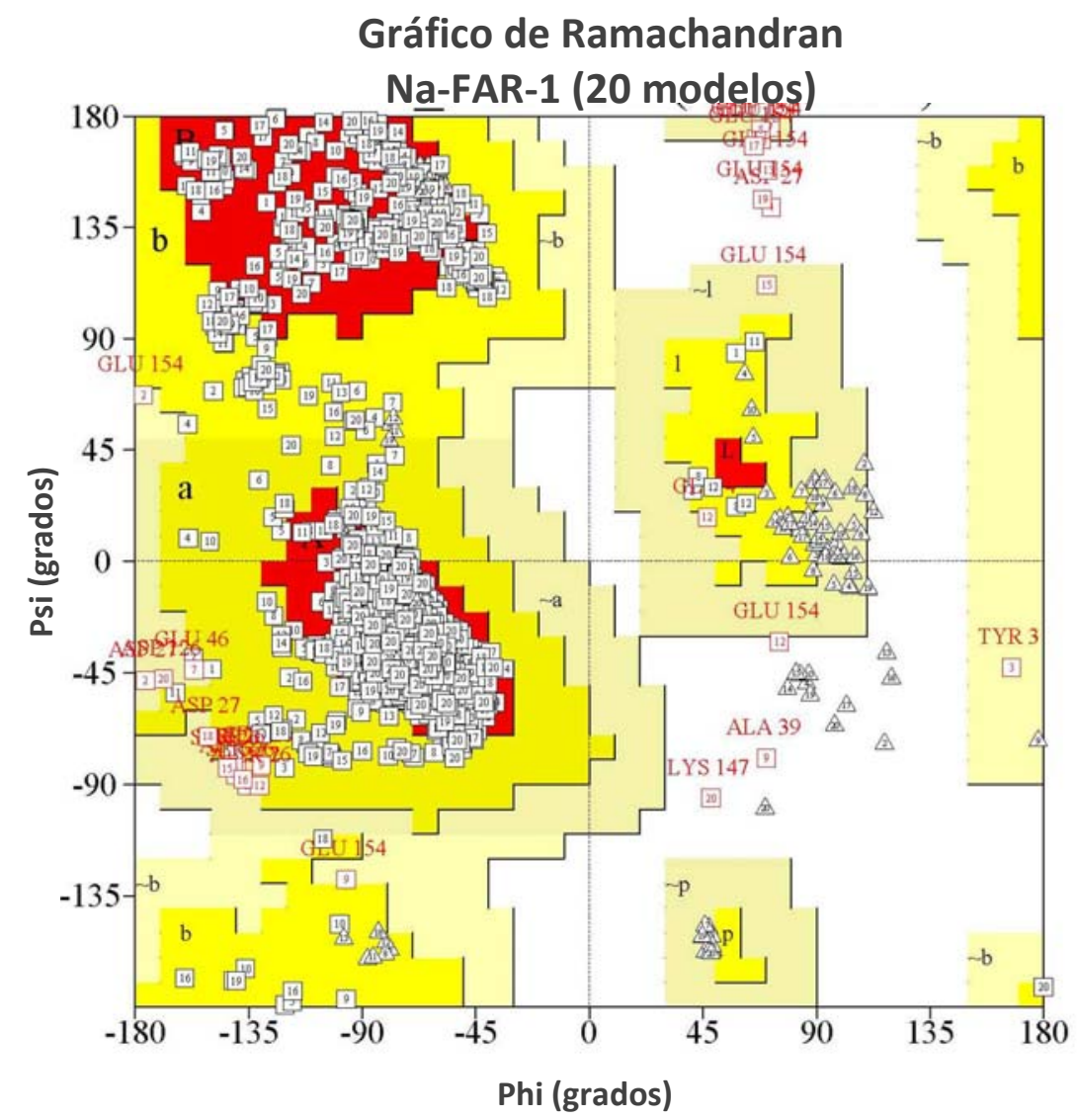

Fig.3.17. Gráfico Ramachandran para el conjunto de estructuras de Na-FAR-1 generado con PROCHECK_NMR. Los cuadrados blancos representan residuos en regiones favorables, los triángulos representan residuos de glicina y los cuadrados rojos indican residuos en regiones no favorables.

\begin{tabular}{lrr}
\hline Regiones & $\mathrm{N}^{\circ}$ residuos & \% residuos \\
\hline Muy favorables & 2490 & 92,9 \\
Permitidas adicionales & 162 & 6,0 \\
Permitidas generosamente & 21 & 0,8 \\
No permitidas & 7 & 0,3
\end{tabular}

Tabla 3.8. Resumen de las estadísticas Ramachandran determinadas con Procheck-NMR para el conjunto de estructuras de Na-FAR-1. 
La distribución de los ángulos de torsión de las cadenas laterales, $\chi_{1}$, es otro indicador de la calidad geométrica de las estructuras calculadas. La distribución de $\chi_{1}$ por residuo en las estructuras indica cuán bien definida esta la posición de la cadena lateral. Las posiciones de la mayoría de las cadenas laterales de Na-FAR-1 están relativamente bien definidas dado que ningún residuo cae en regiones no favorables para $\chi_{1}$ (Apéndice B).

\subsection{Estructura de Na-FAR-1}

La estructura de apo Na-FAR-1 resuelta en solución mediante espectroscopía de RMN se muestra en la figura 3.18 .
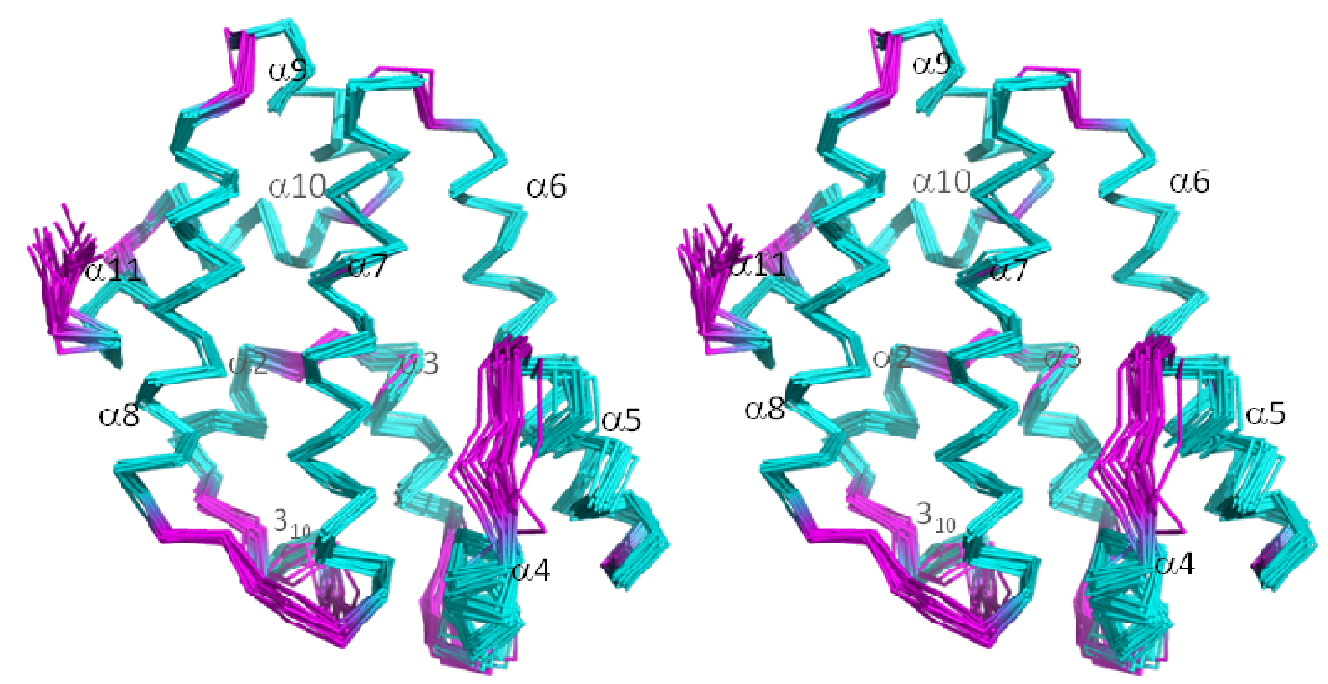

Fig.3.18. Representación estereoscópica de la estructura de Na-FAR-1. Coloreada según estructura secundaria, con $\alpha$-hélices en turquesa y lazos en violeta. La imagen se generó con pymol a partir de las 20 estructuras calculadas. En la representación se eliminó el tag de polihistidina.

La estructura secundaria estimada con el algoritmo dss de pymol se esquematiza en la figura 3.19.

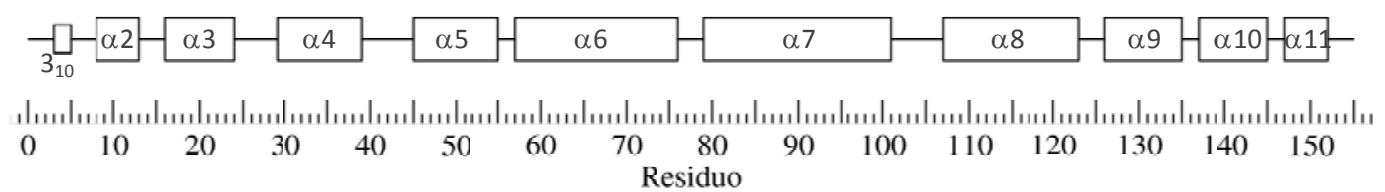

Fig.3.19. Diagrama de la distribución de elementos de estructura secundaria regular de Na-FAR-1. Las hélices se representan como rectángulos. 
Na-FAR-1 presenta una estructura aplanada cuya forma es semejante a un elipsoide, con ejes de unos 40, 30 y $17 \AA ̊$ (figura 3.20). Está compuesta por 11 hélices de distintas longitudes, unidas por regiones lazo también de longitud variable y dispuestas formando una cavidad interna. En el extremo $\mathrm{N}$-terminal presenta un giro del tipo $3_{10}$ de tres aminoácidos de longitud, mientras que las 10 hélices restantes son hélices $\alpha$.

Las hélices de la región $\mathrm{N}$-terminal de la proteína, $3_{10}$ (conformada por los residuos 3 a 5), $\alpha 2(8-11)$ y $\alpha 3(16-24)$ son relativamente cortas y coplanares entre sí y con las hélices de la región C-terminal de la proteína $\alpha 9$ (126-135) y $\alpha 10$ (137-144) también de menor tamaño, y con una de las hélices mayores, la hélice $\alpha 6$ (57-75). Las otras dos hélices de mayor tamaño de Na-FAR-1, $\alpha 7$ (79-99) y $\alpha 8$ (107-122) son a su vez relativamente coplanares entre sí y con la hélice $\alpha 5$ (45-55). Estos dos grandes semielipsoides paralelos se enfrentan delineando la cavidad interna, que se cierra en un extremo por la hélice $\alpha 4$ (29-37) y en otro extremo por la hélice $\alpha 11$ (147-152) que se ubican casi perpendiculares a los dos planos.
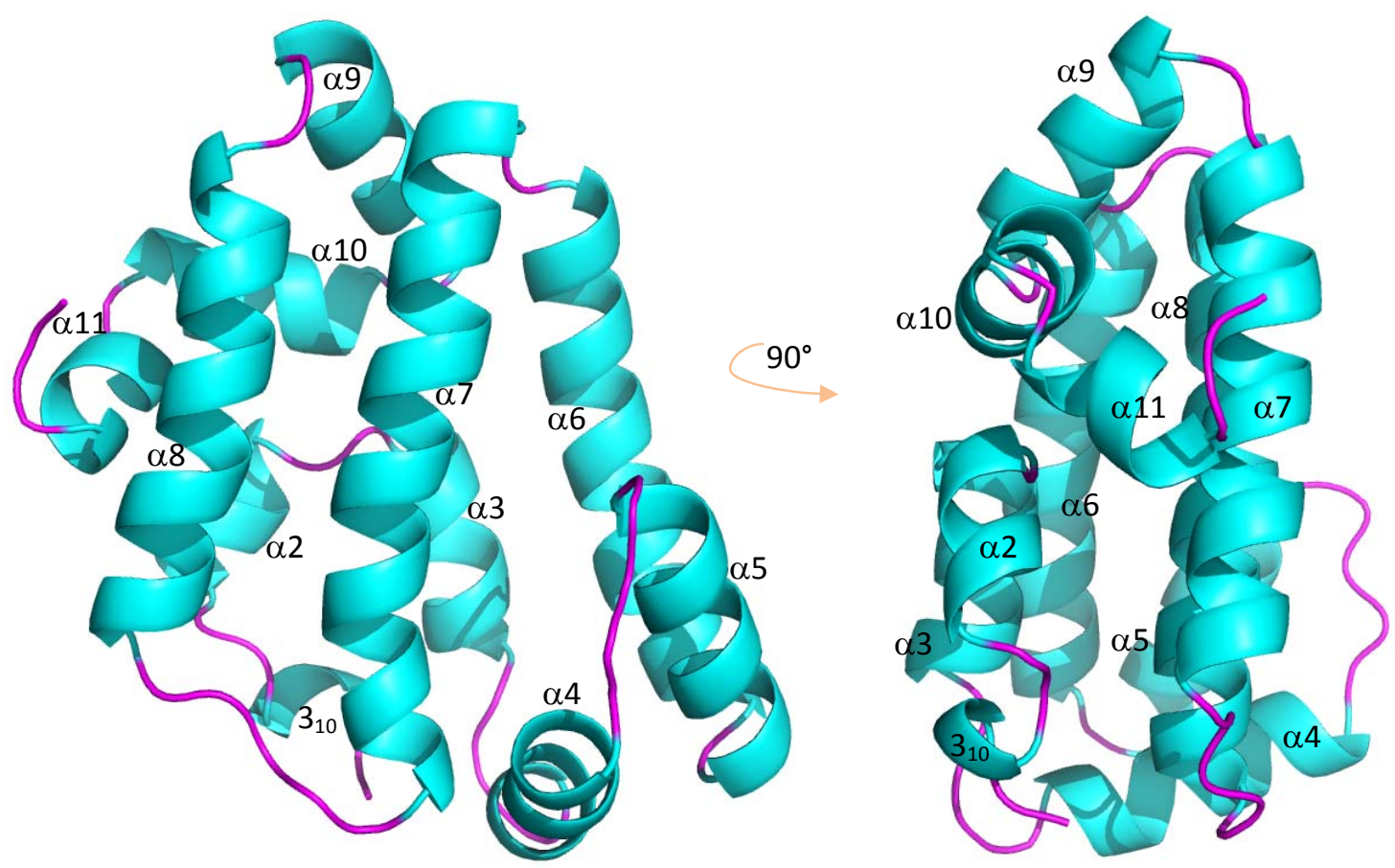

Fig.3.20. Representación de la estructura de Na-FAR-1 girada en $90^{\circ}$ sobre el eje mayor. La imagen se generó a partir de la estructura más cercana a la media y se coloreó según estructura secundaria, con $\alpha$ hélices en turquesa y lazos en violeta. Se puede apreciar la estructura alargada y aplanada de Na-FAR-1, comparable a un elipsoide. 


\subsection{Conclusiones}

Se determinó la estructura tridimensional de Na-FAR-1 en solución por espectroscopía de resonancia magnética nuclear con buena calidad.

Habiéndose asignado al menos parcialmente la totalidad de los residuos de Na-FAR-1, incluyendo más del 90\% de los hidrógenos, las asignaciones se transfirieron a experimentos NOESY para la generación de restricciones. Se emplearon para el cálculo de estructura un total de 7289 restricciones espaciales derivadas de experimentos NOE (2670 N-NOESY y 4619 C-NOESY) y 312 restricciones de ángulos diedros. Durante etapas más avanzadas del cálculo estas restricciones se complementaron con aquellas derivadas de 178 RDCs (102 ${ }^{1} \mathrm{D}_{\mathrm{NH}}$ y $\left.76{ }^{1} \mathrm{D}_{\mathrm{CaHa}}\right)$ obtenidas de una muestra parcialmente alineada con fagos PF1.

Na-FAR-R presentó una estructura elipsoidal compuesta por 11 hélices que se disponen formando una cavidad central. Con la información dinámica de Na-FAR-1 descripta en el siguiente capítulo se intentará complementar el análisis estructural. 


\section{Dinámica de Na-FAR-1}

Las proteínas son moléculas muy dinámicas que presentan movimientos internos que a menudo son inherentes a sus funciones biológicas. Los movimientos de este tipo de macromoléculas pueden ocurrir en escalas de tiempo que van desde los movimientos locales en orden de los picosegundos hasta los movimientos concertados de dominios grandes durante segundos. Las medidas por RMN son sensibles al movimiento en muchas de estas escalas de tiempo lo cual hace de esta técnica una herramienta poderosa para caracterizar dinámica estructuralmente relevante desde el punto de vista funcional.

\subsection{Procesos de relajación}

En un sistema en estado de equilibrio existe una completa falta de coherencia, con un pequeño exceso de población en el estado de menor energía y una pequeña deficiencia de población en el estado de alta energía, según la distribución de Boltzmann. Si el equilibrio es perturbado, se induce un cambio en la distribución de poblaciones y el sistema retorna al estado de equilibrio mediante un proceso de relajación.

Desde el punto de vista macroscópico, la resultante de la sumatoria de espines individuales equivale a la magnetización. El proceso por el cual la magnetización vuelve a la distribución de poblaciones de Boltzmann se denomina relajación longitudinal. La energía involucrada en el regreso de la magnetización al estado de baja energía, y por ende al equilibrio, se disipa en los alrededores y por eso se denomina relajación espínentorno. La relajación longitudinal se caracteriza por el tiempo $T_{1}$ y la velocidad $R_{1}$ asociados $\left(R_{1}=1 / T_{1}\right)$.

Un núcleo aislado no se puede reorientar por sí mismo dado que este proceso requiere una transferencia de energía hacia el entorno, y el tiempo que tarda en relajarse depende de interacciones entre el núcleo perturbado y sus alrededores. El tiempo de relajación $T_{1}$, está relacionado con la fluctuación del campo magnético local percibida por el núcleo como consecuencia de núcleos vecinos, tanto en la misma molécula 
como en el solvente circundante. Los valores de $T_{1}$ dependen de cuán rápido se mueve aleatoriamente o rota en solución la molécula que contiene al núcleo.

La relajación también puede ocurrir mediante una pérdida de coherencia en el plano xy, proceso que se describe como relajación transversal. La relajación transversal está relacionada con la interacción entre espines, por lo que se conoce como relajación espín-espín y se caracteriza por el tiempo de relajación $T_{2}$ y la velocidad $R_{2}\left(R_{2}=1 / T_{2}\right)$. Este es un efecto mecánico cuántico que no lleva a una transferencia de energía hacia los alrededores, sino a una transferencia de magnetización hacia un núcleo cercano. Así, se obtiene un ensanchamiento en la línea espectral, de modo que el ancho $(\Delta v)$ es aproximadamente igual a $1 / T_{2}$. La relajación espín-espín tiende a ser más eficiente $\left(T_{2}\right.$ es menor) para moléculas con movimientos aleatorios lentos, que es el caso de proteínas y otras macromoléculas de gran tamaño, y lleva a un ensanchamiento y solapamiento significativo de las señales.

Otro mecanismo de relajación es el NOE, que ocurre entre dos núcleos dipolarmente acoplados. Para un par de núcleos dipolarmente acoplados hay seis caminos de relajación. Cuatro son procesos de intercambio de espín que corresponden a los mecanismos de relajación longitudinal previamente mencionados. Los otros dos son procesos de relajación cruzada donde ambos núcleos se relajan juntos, correspondientes a las transiciones cuánticas cero y cuántica doble. En estos dos procesos de relajación cruzada se origina el NOE (figura 4.1).

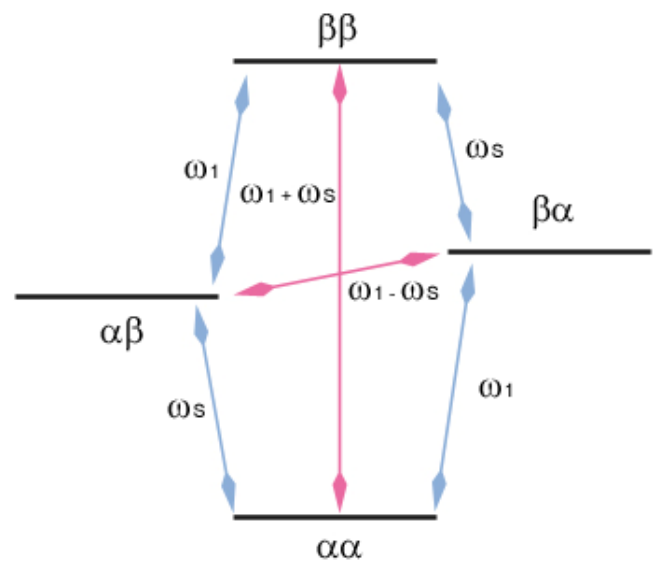

Fig.4.1. Niveles de energía y transiciones asociadas en un sistema homonuclear de dos espines. Las transiciones cuánticas simples se indican en azul, las transiciones prohibidas, cero y doble cuántica se indican en magenta. 
Las oscilaciones en el campo magnético que dan lugar a la relajación son generadas por la difusión rotacional de las moléculas en la muestra. El modo en que los movimientos internos de diferentes amplitudes y diferentes escalas de tiempo afectan las velocidades de relajación de un núcleo particular depende de las fluctuaciones del campo magnético causadas por el movimiento y por el número de movimientos relativos de los núcleos magnéticamente activos cercanos.

Para núcleos ${ }^{15} \mathrm{~N}$ de la cadena principal el principal compañero de relajación es el protón covalentemente unido. Y como la distancia entre ambos está fija por medio del enlace, los procesos involucrados en la reorientación del vector internuclear dan una noción directa del movimiento de la cadena principal. Para un núcleo ${ }^{15} \mathrm{~N}$ amida hay dos mecanismos dominantes que llevan a oscilaciones en el campo local efectivo. Las fluctuaciones causadas por mecanismos de anisotropía de desplazamientos químicos, producidas por variaciones en el apantallamiento electrónico que censa el núcleo ${ }^{15} \mathrm{~N}$ en el campo aplicado, a medida que la orientación del vector internuclear $\mathrm{NH}$ cambia con el movimiento molecular. El segundo mecanismo es la interacción dipolo-dipolo, donde las fluctuaciones son causadas por los dipolos de núcleos vecinos (en este caso H amida).

La distribución de frecuencias de oscilación del campo magnético local generada por el movimiento molecular depende del tiempo de correlación rotacional de la molécula $\left(\tau_{\mathrm{m}}\right)$.

El término $\tau_{c}$ se emplea para los vectores individuales, mientras que $\tau_{m}$ y $\tau_{c}$ son equivalentes si la molécula presenta movimientos isotrópicos. La relación entre tiempos de correlación y relajación puede emplearse para analizar la dinámica molecular. Los núcleos de residuos involucrados en movimientos internos de la molécula, tienen $\tau_{c}$ efectivos bajos debido a que el movimiento interno tiene un tiempo de correlación adicional asociado.

La relajación es más eficiente cuando las frecuencias de las oscilaciones coinciden con las diferencias de energía entre estados de espín. Para la relajación longitudinal $T_{1}$, esto corresponde a frecuencias cercanas a las frecuencias de Larmor de los núcleos ${ }^{15} \mathrm{~N}$ $y^{1} \mathrm{H}$. Para NOE, la diferencia de energías en el doble cuántico y el cuántico cero corresponde a la suma y la resta de ambas frecuencias de Larmor respectivamente. En 
el caso de la relajación transversal, al igual que para $T_{1}$, corresponde a frecuencias cercanas a las de Larmor de los núcleos involucrados, pero también depende de fluctuaciones de frecuencia cercanas a cero. Es por esto que $T_{2}$ no alcanza un mínimo cuando $\tau_{c}$ crece, sino que continúa cayendo (figura 4.2).

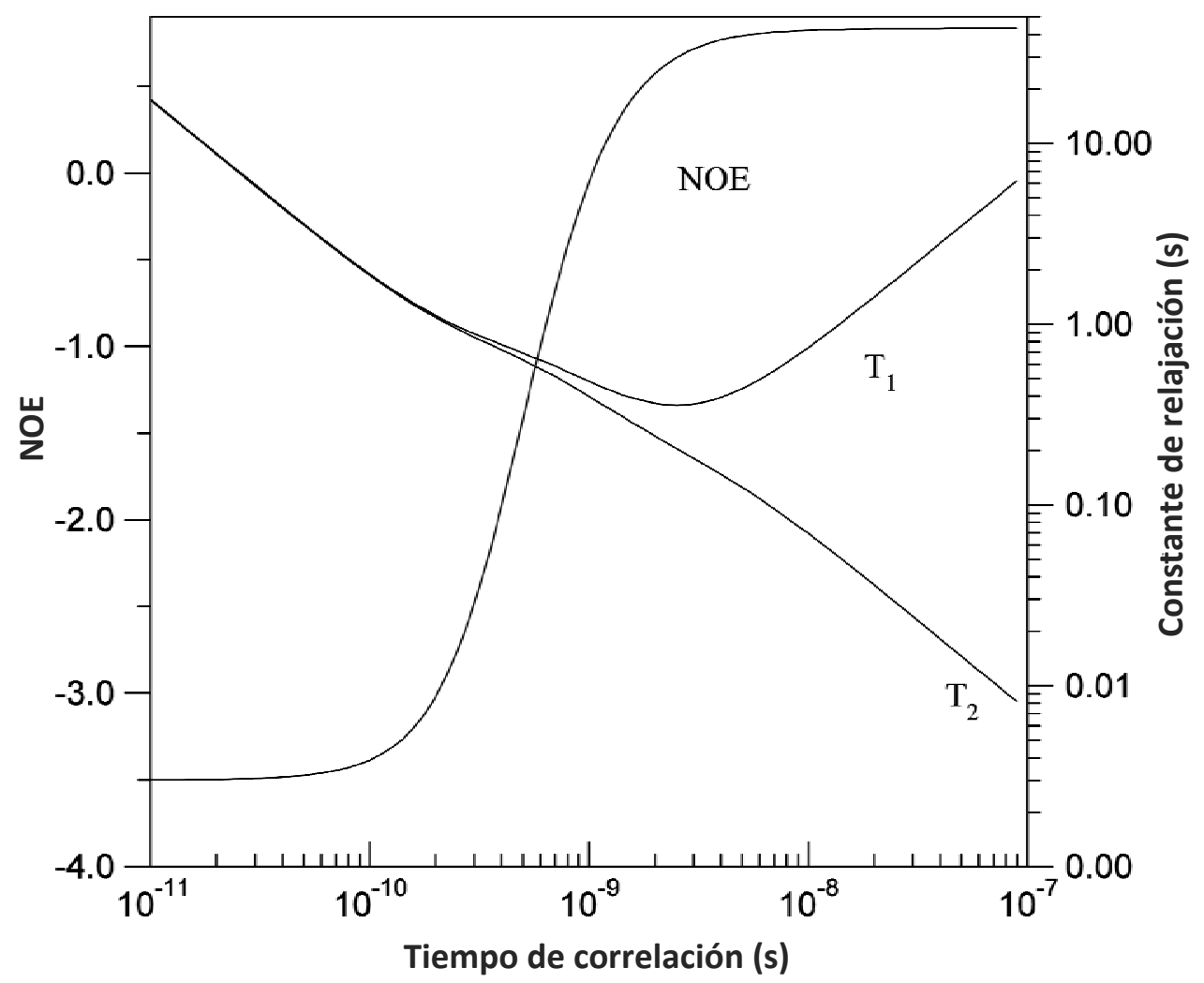

Fig.4.2. Relación entre $\mathrm{T} 1, \mathrm{~T} 2, \mathrm{NOE}{ }^{15} \mathrm{~N}$ y tiempo de correlación. Los datos fueron cedidos por el Dr. Brian Smith.

En este trabajo se analizaron las propiedades de relajación de las amidas de la cadena principal de Na-FAR-1. Habiendo asignado los desplazamientos químicos de los átomos ${ }^{1} \mathrm{H}$ y ${ }^{15} \mathrm{~N}$, la información dinámica de los vectores $\mathrm{NH}$ de la cadena principal se puede obtener mediante el estudio de las velocidades de relajación ${ }^{15} \mathrm{~N}$. Se midieron los tiempos de relajación longitudinal $\mathrm{T}_{1}, \mathrm{y}$ transversal $\mathrm{T}_{2}, \mathrm{y}$ los NOE heteronucleares.

La relajación de las amidas se puede describir en términos de funciones de densidad espectral ${ }^{103}$ : 


$$
\begin{aligned}
& \frac{1}{T_{1}}=\frac{d^{2}}{4}\left[J\left(\omega_{H}-\omega_{N}\right)+3 J\left(\omega_{N}\right)+6 J\left(\omega_{H}+\omega_{N}\right)+c^{2} J\left(\omega_{N}\right)\right] \\
& \frac{1}{T_{2}}=\frac{d^{2}}{8}\left[4 J(0)+J\left(\omega_{H}-\omega_{N}\right)+3 J\left(\omega_{N}\right)+6 J\left(\omega_{H}\right)+6 J\left(\omega_{H}+\omega_{N}\right)\right]+\frac{c^{2}}{6}\left[4 J(0)+3 J\left(\omega_{N}\right)\right]+R_{e x}
\end{aligned}
$$

$N O E=1+\frac{d^{2}}{4 R_{1}}\left(\frac{\gamma_{N}}{\gamma_{H}}\right)\left[6 J\left(\omega_{H}+\omega_{N}\right)-J\left(\omega_{H}-\omega_{N}\right)\right]$

Donde $d=\frac{\mu_{0} h \gamma_{N} \gamma_{H}\left\langle r_{N H}^{-3}\right\rangle}{8 \pi^{2}}, c=\frac{\omega_{N} \Delta \sigma}{\sqrt{3}}, \mu 0$ es la permeabilidad al vacío, $\mathrm{h}$ es la constante de Planck, $\omega \mathrm{H}$ y $\omega \mathrm{N}$ son las frecuencias de Larmor de los espines ${ }^{1} \mathrm{H}$ y ${ }^{15} \mathrm{~N}$ respectivamente, $\gamma_{\mathrm{H}}$ y $\gamma_{\mathrm{N}}$ son las constantes giromagnéticas de los espines ${ }^{1} \mathrm{H}$ y ${ }^{15} \mathrm{~N}, \Delta \sigma$ es la anisotropía de desplazamiento químico del espín ${ }^{15} \mathrm{~N}$ colinear con el vector de enlace $\mathrm{NH}$. El término $\mathrm{R}_{\mathrm{ex}}$ incluye los procesos de intercambio químico que contribuyen al decaimiento de la magnetización transversal.

$J(i)$ representa la probabilidad de oscilaciones en i generadas por la reorientación del vector $\mathrm{NH}$ con un tiempo de correlación dado y es una función de densidad espectral de la forma $J(i)=\frac{\tau_{c}}{1+2\left(i \tau_{c}\right)}$.

\subsection{Medida de $T_{1}, T_{2}$ y NOE heteronuclear}

Los espectros $T_{1}$ y $T_{2}$ se basan en experimentos ${ }^{15} \mathrm{~N}$ HSQC realizados con formato pseudo 3D, con ciertos puntos de tiempo seleccionados en la dimensión extra ${ }^{104}$. En ambos experimentos la magnetización se transfiere entre los núcleos ${ }^{1} \mathrm{H}$ y ${ }^{15} \mathrm{~N}$ empleando secuencias de pulsos INEPT e INEPT reversa reenfocadas. La magnetización se genera y se detecta en los protones amida para obtener una máxima sensibilidad.

En el caso de T1, La magnetización transversal producida con la secuencia INEPT inicial se convierte en magnetización longitudinal mediante un pulso de $90^{\circ}$ y luego se deja relajar durante un tempo (delay). La magnetización retorna al plano transversal mediante un segundo pulso de $90^{\circ}$ que imprime el desplazamiento químico de ${ }^{15} \mathrm{~N}$ 
antes del INEPT reverso. La altura del pico en el espectro resultante es proporcional a la magnetización z presente inmediatamente antes del pulso de $90^{\circ}$. Se repite el experimento con diferentes tiempos de espera entre los dos pulsos de $90^{\circ}$ y esto permite evaluar la vuelta al equilibrio de la magnetización z y calcular $T_{1}$ mediante el ajuste de los datos a una función exponencial. Los tiempos de espera usados fueron 0.1011 s, 0.6011 s, 1.011 s y 1.4011 s y se realizaron duplicados de los tiempos $0.1011 \mathrm{~s}$ y 1.011 s para una estimación del error.

Para medir $T_{2}$, se emplea una serie de pulsos CPMG (Carr-Purcell-Meimboom-Gill) 105106 que elimina las contribuciones de inhomogeneidad de la muestra y evolución de desplazamiento químico, dado que brinda un decaimiento de la señal proporcional a la relajación $T_{2}$ pura. El experimento comienza con una secuencia INEPT reenfocada que produce magnetización ${ }^{15} \mathrm{~N}$ en fase en el plano transversal. En el tiempo de espera se coloca la secuencia de pulsos CPMG, seguida del marcado en el desplazamiento químico de ${ }^{15} \mathrm{~N}$ y finalmente un INEPT lleva la magnetización a los protones para la adquisición. Los tiempos usados fueron 16.96 ms, 33.92 ms, 67.84 ms, 101.76 ms, y 135.68 ms, con duplicados en 33.92 ms y 101.67 ms para el cálculo del error.

Los valores NOE ${ }^{1} \mathrm{H}^{15}{ }^{15}$ en estado estacionario se obtuvieron mediante espectros ${ }^{15} \mathrm{~N}$ HSQC con magnetización inicial ${ }^{15} \mathrm{~N}$, en presencia de saturación ${ }^{1} \mathrm{H}$ (NOEsat) y ausencia de saturación ${ }^{1} \mathrm{H}$ (NOEinsat) aplicadas entes de iniciar el experimento. Mediante la saturación de los protones el equilibrio se restablece a través de las transiciones prohibidas cero y doble cuántica que origina el NOE (NOEsat). En un sistema en equilibrio térmico sin saturación (NOEinsat), se dan todas las transiciones cuánticas posibles y se obtiene un experimento de referencia. La relación de intensidades de los picos resultantes permitió realizar una estimación de la contribución NOE a la relajación. Ambos experimentos se realizaron por duplicado para la estimación del error.

\subsubsection{Análisis de Datos}

Los datos se procesaron con los programas Azara (W Boucher, www.ccpn.ac.uk/azara). Los scripts iniciales se crearon desde los archivos Bruker mediante el programa 
ReferenceB escrito por la Dra. Krystyna Bromek. Los espectros procesados se cargaron en el programa CCPNAnalysis. Los datos de $\mathrm{T}_{1}$ y $\mathrm{T}_{2}$ se incluyeron como series experimentales con sus respectivos tiempos de delay. La asignación de los espectros se transfirió desde los experimentos ${ }^{15} \mathrm{~N}-\mathrm{HSQC}$ previos para cada amida de la cadena polipeptídica que presentara una resolución aceptable para producir datos confiables. Para los experimentos $T_{1}$ y $T_{2}$, el tiempo de relajación y error asociados se calcularon para cada pico aplicando una función de ajuste exponencial $\left(\mathrm{I}=\mathrm{A} \mathrm{e}^{-\mathrm{Bt}}\right)$ a la intensidad del pico, graficando la altura (I) en función del tiempo de delay (t). Esto se llevó a cabo mediante la herramienta "follow intensity changes" dentro de CCPNAnalysis ${ }^{73}$. El error del ajuste se calculó usando el método de covarianza de error ${ }^{107}$. La altura de los picos de los espectros NOEsat y NOEinsat se exportó desde CCPNAnalysis y se obtuvo una estimación del error con la relación señal ruido de los experimentos duplicados empleando el script snratio_nmr (A. G. Palmer III, www.palmer.hs. columbia. edu/software.html). Las alturas de los picos y los errores asociados se usaron para calcular los NOE ${ }^{1} \mathrm{H}_{-}{ }^{15} \mathrm{~N}$ empleando el script noecalc_nmr (A. G. Palmer III, www.palmer.hs.columbia. edu/software.html).

\subsubsection{Resultados}

Los valores calculados para $T_{1}, T_{2}$ y NOE se graficaron en función de la secuencia de aminoácidos (Figura 4.3).

El análisis de la dinámica ${ }^{15} \mathrm{~N}$ de la cadena principal indica que hay pocas regiones intrínsecamente flexibles en la proteína, como se manifiesta a través del perfil aplanado de las constantes de relajación $\mathrm{T}_{1}, \mathrm{~T}_{2}$ y de los datos de ${ }^{1} \mathrm{H}-{ }^{15} \mathrm{~N}$ NOE.

Sólo las regiones terminales de la proteína y unos pocos residuos en regiones de lazos o que se encuentran muy expuestos se desvían de los valores promedio, de un modo consistente con movimientos en las escalas de tiempo de nanosegundos y picosegundos. La metionina 14 ubicada en el lazo 2, presenta un valor $\mathrm{T}_{2}$ menor que la media, típico de movimientos en las escalas de microsegundos y milisegundos. 


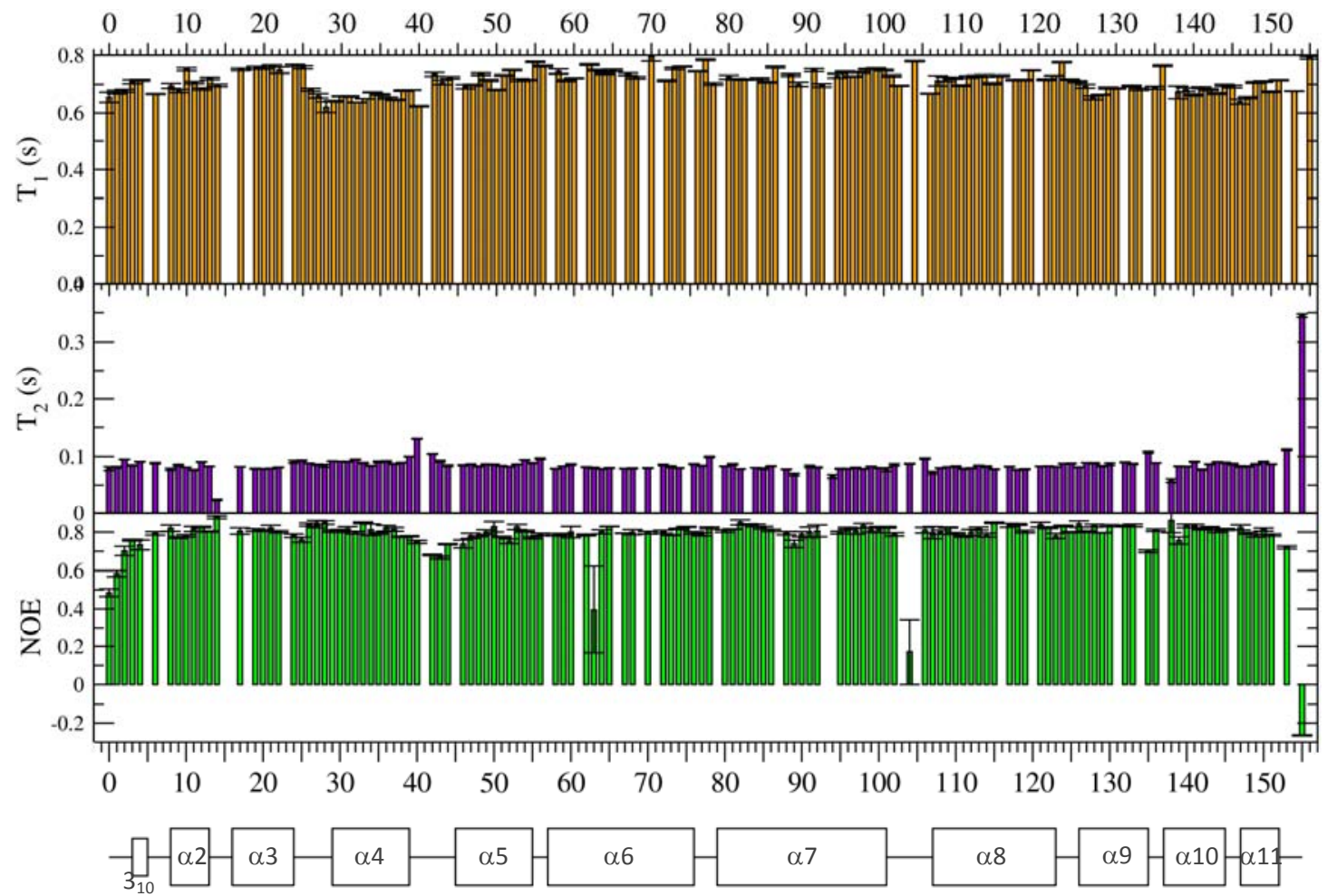

Residuo

Figura 4.3. Valores de $\mathrm{T1}, \mathrm{T} 2, \mathrm{NOE}$ heteronuclear ${ }^{15} \mathrm{~N}$ para cada pico amida de la cadena principal de Na-FAR-1 a $60.8 \mathrm{MHz}\left({ }^{15} \mathrm{~N}\right)$ y $311 \mathrm{~K}$. Se esquematiza la estructura secundaria de la proteína en bloques (hélices $\alpha$ ) y líneas (lazos).

A partir de los valores medios de los tiempos de relajación obtenidos para cada elemento de estructura secundaria se observan tendencias que indican que la proteína muestra un comportamiento anisotrópico (tabla 4.1).

Como consecuencia del movimiento molecular anisotrópico, las hélices $\alpha 4$ y $\alpha 11$, que se encuentran perpendiculares al eje mayor de la molécula, presentan bajos valores de $\mathrm{T}_{1}$ y elevados valores de $\mathrm{T}_{2}$.

Los vectores NH alineados con el eje largo del tensor de difusión, en las hélices $\alpha 3, \alpha 6$, $\alpha 7$ y $\alpha 8$, tienen mayores $T_{1}$ y menores $T_{2}$. 


\begin{tabular}{ccc}
\hline Estructura secundaria & $\mathrm{T}_{1}$ promedio $(\mathrm{ms})$ & $\mathrm{T}_{2}$ promedio $(\mathrm{ms})$ \\
\hline Hélice 1 & $712 \pm 5$ & $87.7 \pm 0.7$ \\
Hélice 2 & $706 \pm 5$ & $82.3 \pm 0.9$ \\
Hélice 3 & $756 \pm 5$ & $81.7 \pm 0.9$ \\
Hélice 4 & $658 \pm 2$ & $90.5 \pm 0.8$ \\
Hélice 5 & $720 \pm 3$ & $86.1 \pm 0.7$ \\
Hélice 6 & $740 \pm 4$ & $81.1 \pm 0.7$ \\
Hélice 7 & $730 \pm 4$ & $79.0 \pm 1.1$ \\
Hélice 8 & $724 \pm 4$ & $80.2 \pm 0.8$ \\
Hélice 9 & $681 \pm 4$ & $89.2 \pm 1.1$ \\
Hélice 10 & $681 \pm 6$ & $82.1 \pm 1.0$ \\
Hélice 11 & $692 \pm 3$ & $85.9 \pm 0.8$ \\
\hline
\end{tabular}

Tabla 4.1. Valores promedio T1 y T2 para residuos en regiones de estructura secundaria regular. Existen diferencias en los valores de cada región, que dependen de la orientación relativa con respecto al tensor de difusión de la molécula, denotando un comportamiento anisotrópico.

\subsection{Estimación de los tiempos de correlación y del tensor de difusión rotacional}

Para determinar la contribución de los movimientos internos a la relajación, se deben determinar los tiempos de correlación de cada uno de los vectores amida individuales y el de toda la molécula. El tiempo de correlación $\tau_{c}$ se puede estimar residuo a residuo mediante el cociente $T_{1} / T_{2}$ cuya relación se describe en la ecuación de Key y col. ${ }^{108}$. El gráfico de $T_{1}$ en función de $T_{2}$ para cada aminoácido permite la estimación del tiempo de correlación rotacional de toda la molécula (figura 4.4). 


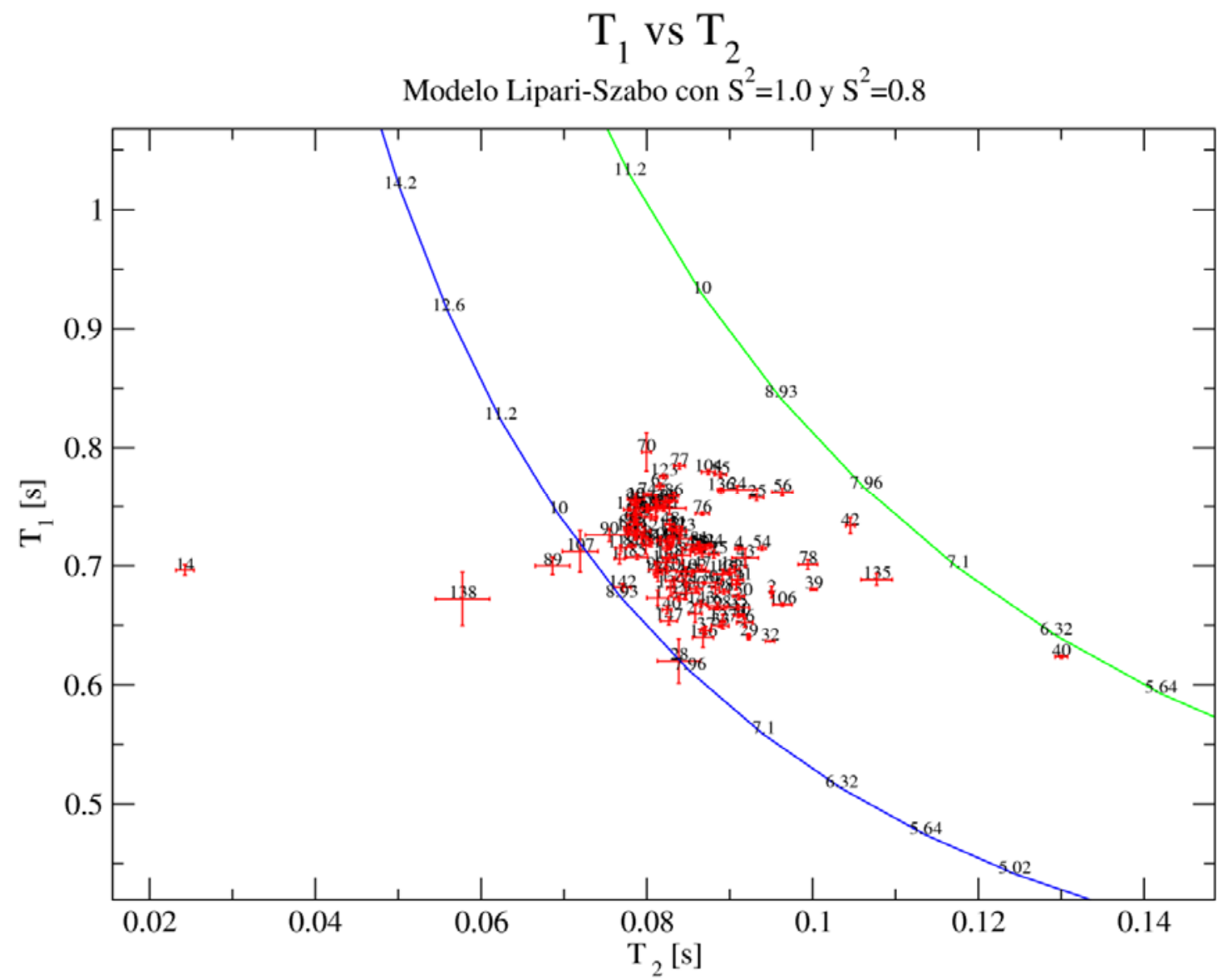

Fig.4.4. 15N T1 en función de T2 para Na-FAR-1 a $60.8 \mathrm{MHz}(15 \mathrm{~N})$ and 311K. Modelo Lipari Szabo con $\mathrm{S}^{2}=1$ (curva azul) y $\mathrm{S}^{2}=0.8$ (curva verde). Los números a lo largo de las curvas indican los valores esperados de T1/T2 que corresponden al tiempo de correlación para movimientos isotrópicos.

La mayoría de los residuos están dispersos de forma paralela a los contornos modelo de $S^{2}$, en un rango de tiempos de correlación entre 7.96 y 10 ns. Esta variabilidad en los tiempos de correlación estaría indicando el comportamiento anisotrópico de la proteína. La mayoría de los puntos se localizan entre las dos líneas del modelo, más cercanos al contorno de $\mathrm{S}^{2}=1.0$, corresponden a residuos en regiones de estructura tridimensional relativamente bien definida y con poca movilidad. No se observan puntos hacia la derecha de $S^{2}=0.8$ que suelen corresponder a residuos con gran movilidad en las regiones lazo o C-terminal de las proteínas. Los residuos más cercanos a la zona derecha del gráfico se localizan en lazos y presentan bajos valores de NOE, lo cual indicaría que están en regiones flexibles. 
Teóricamente ningún residuo podría tener un valor de $S^{2}$ mayor que 1.0, sin embargo, el comportamiento de los residuos ubicados a la izquierda de $S^{2}=1.0$ se puede explicar por la presencia de intercambio químico, $R_{e x}$, que disminuye $T_{2}$ y desplaza los puntos hacia la izquierda del gráfico. La mayoría de los residuos presentes en esta zona del gráfico se hallan en regiones lazo de Na-FAR-1.

La ecuación de Kay permite obtener una estimación de $\tau_{\mathrm{c}}$ para cada residuo ${ }^{108}$. Esto se llevó a cabo mediante el script r2r1_tm (A. G. Palmer III, www.palmer.hs.columbia.edu /software.html), que calcula $\tau_{c}$ a partir del cociente R2/R1. Para obtener una estimación más precisa de $\tau_{c}$, los residuos con un valor de NOE $<0.6$ y aquellos con un cociente $R_{1} / R_{2}$ desviado de la media en más de una desviación estándar, se eliminaron para el cálculo. Los valores de $\tau_{c}$ calculados se muestran en la figura 4.5 .

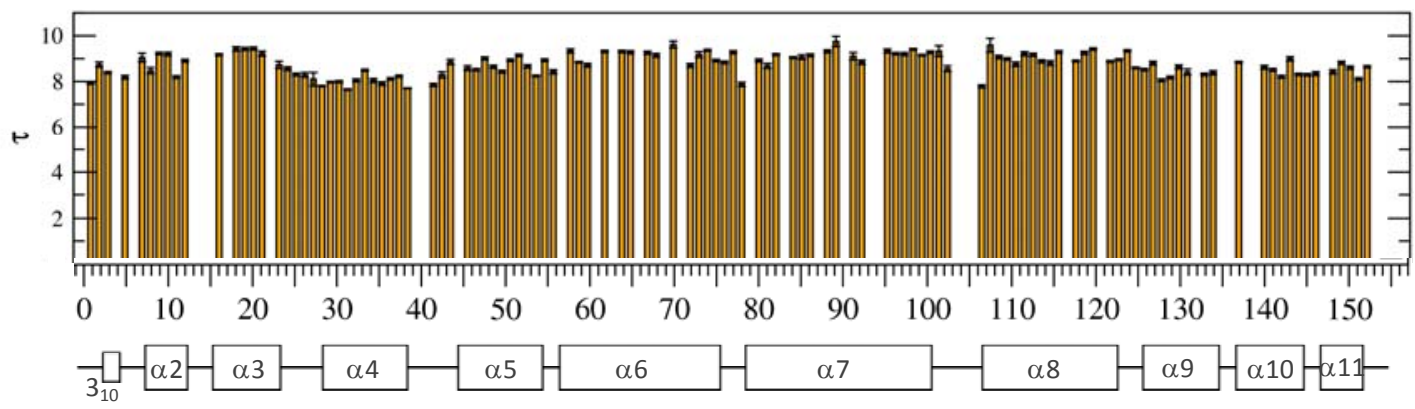

Fig.4.5. $\tau$ c de la cadena principal de Na-FAR-1. Se esquematiza la estructura secundaria de la proteína en bloques (hélices) y líneas (lazos). Existen diferencias en los valores de $\tau c$ individales que dependen de la orientación relativa con respecto al tensor de difusión de la molécula, denotando un comportamiento anisotrópico.

Existen diferentes zonas cuyos residuos presentan valores de $\tau_{c}$ alejados de la media como el caso de la hélice $\alpha 4$ cuyos bajos valores evidencian el comportamiento anisotrópico de la molécula. A partir del promedio de los $\tau_{\mathrm{c}}$ individuales se estimó un $\tau_{m}$ de $8.75 \pm 0.08$ ns para la molécula. El $\tau_{m}$ teórico de Na-FAR-1 calculado mediante una aproximación esférica con $\tau=0.6 \times \mathrm{MW}$ (a partir del peso molecular considerando la doble marca), resultó ser de 10.82 ns. La diferencia observada entre el valor teórico 
y el experimental probablemente se deba a que el comportamiento isotrópico no es el que mejor describe al movimiento de Na-FAR-1.

El análisis de los datos de relajación sumado a la naturaleza elipsoidal aplanada de la estructura calculada de Na-FAR-1 sugiere que la proteína presenta una difusión rotacional anisotrópica en lugar de isotrópica. La factibilidad de los modelos de rotación difusional y los parámetros del tensor de rotación difusional de Na-FAR-1 se determinaron usando la representación cuadrática propuesta por Brushweiler y Lee 109,110

Los datos experimentales se pueden ajustar a tres modelos de difusión diferentes: isotrópico, axialmente simétrico o completamente anisotrópico. El modelo isotrópico explica el movimiento global de la molécula con un solo parámetro, el coeficiente de difusión de la proteína, $\mathrm{D}_{\text {iso, }}$, relacionado directamente con el tiempo de correlación de la proteína, $D_{\text {iso }}=\left(6 \times \tau_{m}\right)^{-1}$. Para moléculas no esféricas el análisis de los movimientos intramoleculares es más complejo. Si la molécula presenta anisotropía rotacional, los tiempos de correlación de los vectores ${ }^{15} \mathrm{~N}-{ }^{1} \mathrm{H}$ individuales van a diferir de acuerdo a su posición relativa con respecto al tensor de difusión molecular. El modelo axialmente asimétrico utiliza, además del parámetro $D_{\|}$(equivalente al $D_{\text {iso }}$ ), un parámetro de difusión anisotrópico $D_{\perp}$ y dos ángulos, $\theta$ y $\phi$ que definen la orientación del vector $\mathrm{N}-\mathrm{H}$ con respecto al tensor de difusión ${ }^{111,112,113}$. En el modelo rómbico (totalmente anisotrópico), los parámetros del ajuste son en total seis, $D_{i s o}, 2 D_{z z} /\left(D_{x x}+D_{y y}\right), D_{x x} / D_{y y}, y$ los tres ángulos $\theta, \phi$ y $\psi$ que definen la orientación del vector $\mathrm{N}-\mathrm{H}$ con respecto a las tres coordenadas principales del tensor de difusión ${ }^{114,115}$.

Los valores de $\tau_{c}$ calculados y la estructura de Na-FAR-1 más cercana a la media del conjunto de estructuras se utilizaron como punto de partida en el programa quadric_diffusion (A. G. Palmer III, www.palmer.hs.columbia.edu/software.html). Las estadísticas para el cálculo del tensor isotrópico, de simetría axial y de asimetría total rómbica arrojaron valores $\chi^{2}$ de 10439.3262, 2467.61157 y 1429.95715 respectivamente. El resultado obtenido indicaría que el tensor rómbico es el más adecuado para la estructura de Na-FAR-1. 


\subsection{Análisis libre de modelo (Model Free Analysis)}

El formalismo libre de modelo, que hace mínimas suposiciones previas con respecto al movimiento molecular, fue descripto por Lipari y Szabo ${ }^{116,117}$ y posteriormente ampliado por Clore y col. ${ }^{118}$, y se puede emplear para analizar los datos a modo de determinar escalas de tiempo y amplitudes de los movimientos intramoleculares. La función de densidad espectral, para una molécula isotrópica, se define como:

$$
J(\omega)=\frac{2}{5}\left[\frac{S^{2} \tau_{m}}{1+\left(\omega \tau_{m}\right)^{2}}+\frac{\left(S_{f}^{2}-S^{2}\right) \tau}{1+(\omega \tau)^{2}}\right]
$$

Donde $\tau=\tau_{\mathrm{e}} \tau_{\mathrm{m}} /\left(\tau_{\mathrm{e}}+\tau_{\mathrm{m}}\right), \tau_{\mathrm{m}}$ es el tiempo de correlación rotacional isotrópico de la molécula, $\tau_{\mathrm{e}}$ es el tiempo de correlación efectivo de los movimientos internos, $S^{2}=S_{f}^{2} S_{s}^{2}$ es el cuadrado del parámetro de orden generalizado caracterizando la amplitud de los movimientos internos, definido por valores que van entre 1, para un sistema totalmente restringido, y 0 para un sistema con rotación libre. $S_{f}^{2}$ y $S_{s}^{2}$ son los cuadrados de los parámetros de orden para los movimientos internos en las escalas de tiempo lenta y rápida respectivamente. En el caso de moléculas anisotrópicas, se obtienen funciones de densidad espectral más complejas expresadas en función de los parámetros difusionales y de los ángulos mencionados en el apartado anterior.

Los movimientos internos de la cadena principal de Na-FAR-1 se modelaron con el programa FASTModelFree (P. Loria, Yale University, http://xbeams.chem.yale.edu/ loria/software.php) ${ }^{119}$ que interactúa con el programa ModelFree (A. G. Palmer III, http://www.palmer.hs.columbia.edu/software/modelfree.html). El programa ModelFree optimiza los parámetros "Lipari-Szabo model free" para datos de relajación de heteronúcleos y automatiza el proceso de selección de modelo y optimización de tensores. Sin embargo, este programa aún no contempla el modelo de rotación difusional de anisotropía total del tipo rómbico, por lo que se empleó el modelo axialmente simétrico, a modo de aproximación con un $D_{\|} / D_{\perp}=1.34394 \pm 0.00415$ estimado mediante quadric_diffusion. Se modelaron los tres parámetros de relajación, $R_{1}, R_{2}$ y NOE heteronuclear, sus errores asociados, el $\tau_{m}$ estimado y el tensor de difusión calculado. 
Se emplearon cinco modelos posibles con no más de tres parámetros libres de modelo: Modelo $1\left(S^{2}\right)$, modelo $2\left(S^{2}, \tau_{e}\right)$, modelo $3\left(S^{2}, R_{e x}\right)$, modelo $4\left(S^{2}, \tau_{e}, R_{e x}\right)$ y modelo 5 $\left(S^{2}, \tau_{e}, S_{f}^{2}\right)$.

El criterio de selección automatizada de los modelos se basa en el protocolo de Mandel ${ }^{120}$ con modificaciones sugeridas por Chen ${ }^{121}$. En la tabla 4.2 se resume la asignación de los 5 modelos a los residuos.

\begin{tabular}{|c|c|c|}
\hline Modelo & Cantidad & Residuos \\
\hline $1\left(S^{2}\right)$ & 11 & $4,8,34,50,80,114,124,130,133,142,145$ \\
\hline $2\left(S^{2}, \tau_{e}\right)$ & 3 & $24,25,102$ \\
\hline $3\left(S^{2}, R_{e x}\right)$ & 31 & $\begin{array}{l}11,17,19,21,49,53,60,63,64,68,74,85,86, \\
91,92,96,97,98,99,100,101,107,108,112, \\
113,117,121,122,126,136,138\end{array}$ \\
\hline $4\left(S^{2}, \tau_{\mathrm{e}}, \mathrm{R}_{\mathrm{ex}}\right)$ & 16 & $\begin{array}{l}0,1,3,44,47,48,51,52,55,73,76,89,111,123, \\
129,146\end{array}$ \\
\hline $5\left(S^{2}, \tau_{e}, S_{f}^{2}\right)$ & 8 & $9,29,32,38,42,43,135,144$ \\
\hline No ajustado & 62 & $\begin{array}{l}2,6,10,12,13,14,20,22,26,27,28,30,31,33, \\
35,36,37,39,40,46,54,56,58,59,62,65,67, \\
70,72,75,77,78,81,82,83,84,88,90,94,95, \\
104,106,109,110,115,118,119,125,127,128, \\
132,139,140,141,143,147,148,149,150,151, \\
153,155\end{array}$ \\
\hline No incluido & 24 & $\begin{array}{l}5,7,15,16,18,23,41,45,57,61,66,69,71,79, \\
87,93,103,105,116,120,131,134,137,154\end{array}$ \\
\hline
\end{tabular}

Tabla 4.2. Asignación libre de modelo de las resonancias amida de Na-FAR-1. Los residuos no incluidos en el análisis fueron las prolinas, los residuos cuyo grupo amida no pudo ser asignado y aquellos que no estaban resueltos a modo de producir datos confiables. La mayoría de los residuos no ajusta ningún modelo.

La mayoría de los residuos no se ajusta a ninguno de los modelos debido a que la anisotropía rotacional axial no describe adecuadamente el comportamiento dinámico en solución de Na-FAR-1. 


\subsection{Conclusiones}

Los parámetros de relajación medidos indican que la molécula presenta movimientos anisotrópicos. Los tiempos de correlación individuales varían en distintas zonas de la proteína lo cual es consistente con anisotropía rotacional.

Mediante el análisis de los movimientos internos se identificó que toda la molécula es apreciablemente rígida, especialmente los elementos de estructura secundaria regular $\alpha$-helicoidales y que contiene lazos donde existe apreciable intercambio químico.

La región dónde se observó una movilidad apreciable comprende el lazo 4, entre las hélices $\alpha 4$ y $\alpha 5$. Esa alta movilidad sería la causa por la cual esta región se encuentra menos definida en la estructura de Na-FAR-1.

El análisis libre de modelo asumiendo un modelo isotrópico o una anisotropía de simetría axial no fue satisfactorio para modelar el comportamiento de Na-FAR-1. Se requiere ampliar el análisis mediante la incorporación de un modelo de anisotropía total del tipo rómbico que es incorporado por el programa Relax ${ }^{114,115}$. Estos cálculos se están llevando a cabo, pero han sido dejados fuera del presente trabajo de tesis por limitaciones de tiempo. 


\section{Análisis estructural de Na-FAR-1}

\subsection{Estructura secundaria}

Na-FAR-1 presenta un muy alto contenido de hélices en su estructura secundaria y una total ausencia de regiones $\beta$. La proporción helicoidal de la estructura secundaria de la proteína estimada con el porgrama Procheck-nmr alcanza el $75 \%$. Si se tiene en cuenta la región $\mathrm{N}$-terminal de polihistidinas de la proteína recombinante empleada en los experimentos, este porcentaje baja al 69\%, valor similar al determinado mediante discroísmo circular.

\begin{tabular}{lccc}
\cline { 2 - 4 } & \multicolumn{2}{l}{ Estructura secundaria \% } & \\
\cline { 2 - 4 } & CD & rNa-FAR-1 & nNa-FAR-1 \\
\hline Hélice & 62 & 69 & 75 \\
Hoja- $\beta$ & 3 & - & - \\
Otros & 35 & 31 & 25 \\
\hline
\end{tabular}

Tabla 5.1- Estructura secundaria de Na-FAR-1. Estructura secundaria estimada mediante Procheck-nmr considerando la proteína recombinante en su totalidad ( $r$-Na-FAR-1) y tomando solo los resultados para porción nativa sin el tag (nNa-FAR-1)

La hélice $\mathrm{N}$-terminal está compuesta por 3 aminoácidos y es del tipo $3_{10}$. Los residuos se encuentran a una distancia tal que el grupo $\mathrm{NH}$ del residuo E5 se encuentra formando un puente $\mathrm{H}$ con el grupo carbonilo del residuo $\mathrm{Y} 3$. El giro $3_{10}$ está presente en la mayoría las estructuras del conjunto de NMR (figura 5.1), según predicho por Prochek_nmr.

Otras proteínas de unión a lípidos también presentan giros $3_{10}$ en sus estructuras. Las lipocalinas y las FABP de tipo 4, exhiben una hélice corta del tipo $3_{10}$ en la región $\mathrm{N}$ terminal, que ayuda a cerrar un extremo del barril- $\beta$ presente en sus estructuras ${ }^{122}$. En las nsLTP, que son exclusivamente $\alpha$-helicoidales, también se ha encontrado este tipo de estructura secundaria. Un giro $3_{10}$ se encuentra bien definido en el extremo Cterminal de la estructura cristalográfica de la proteína nsLTP de maíz ${ }^{123}$, mientras que en la estructura determinada por $\mathrm{RMN}$ el extremo C-terminal de esta proteína es menos estructurado y la hélice $3_{10}$ no se encuentra definida ${ }^{124}$. 


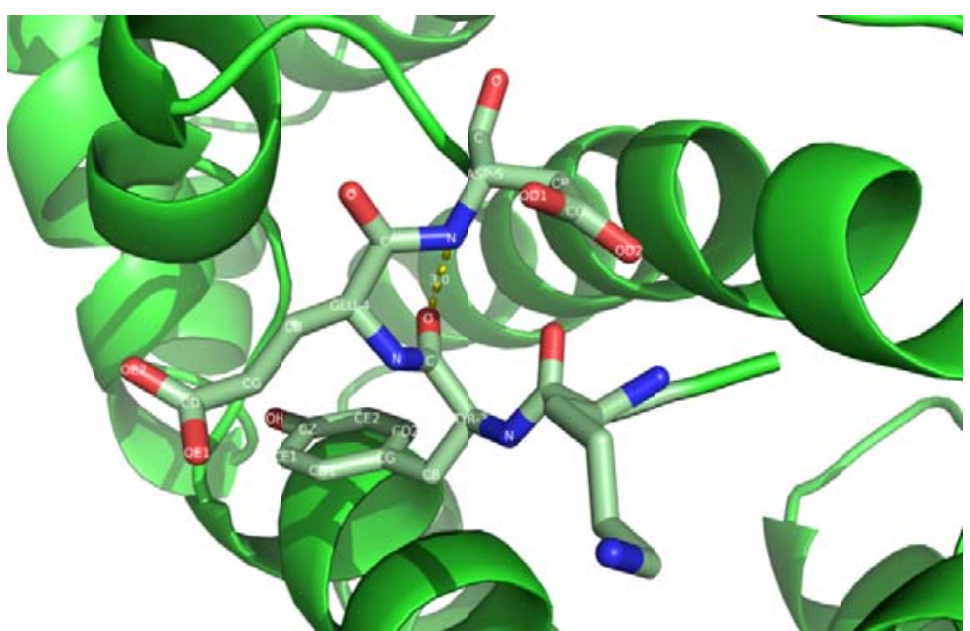

Fig. 5.1. Hélice $3_{10}$ en el extremo $\mathbf{N}$-terminal de Na-FAR-1. El grupo NH del residuo E5 se encuentra formando un puente $\mathrm{H}$ con el grupo carbonilo del residuo $\mathrm{Y} 3$, separados por una distancia de $2.5 \AA$.

La orientación relativa y la regularidad de las 10 hélices de Na-FAR-1 se evaluó mediante el programa QHELIX ${ }^{125}$.

\begin{tabular}{lc}
\hline Irregularidad de hélice & \\
\hline Hélice1 (3-5) & - \\
Hélice2 (8-13) & $0.1213 \AA$ \\
Hélice3 (16-24) & $0.2114 \AA$ \\
Hélice4 (29-39) & $0.1968 \AA$ \\
Hélice5 (45-55) & $0.0636 \AA$ \\
Hélice6 (57-76) & $0.5834 \AA$ \\
Hélice7 (79-101) & $0.6028 \AA$ \\
Hélice8 (107-123) & $0.3314 \AA$ \\
Hélice9 (126-135) & $0.1087 \AA$ \\
Hélice10 (137-145) & $0.1639 \AA$ \\
Hélice11 (147-152) & $0.0582 \AA$ \\
\hline
\end{tabular}

Tabla 5.2- Análisis de la regularidad de hélices de Na-FAR-1 mediante QHELIX. El valor típico para una hélice regular según el método de Kahn es de $0.23 \AA^{125}$. Las hélices de Na-FAR-1 presentan mínimas desviaciones con respecto a ese valor.

Todas las hélices presentan una geometría regular (tabla 5.2). La hélice que más se desvía de la idealidad es $\alpha 7$, que es la más larga de la estructura. 
En la tabla 5.3 se indican los ángulos presentes entre las distintas hélices de la proteína.

\begin{tabular}{|c|c|c|c|c|c|c|c|c|c|c|}
\hline \multicolumn{11}{|c|}{ Ángulos entre hélices $\left({ }^{\circ}\right)$} \\
\hline & $3_{10}$ & $\alpha 2$ & $\alpha 3$ & $\alpha 4$ & $\alpha 5$ & $\alpha 6$ & $\alpha 7$ & $\alpha 8$ & $\alpha 9$ & $\alpha 10$ \\
\hline \multicolumn{11}{|l|}{$3_{10}$} \\
\hline$\alpha 2$ & 126.4 & & & & & & & & & \\
\hline$\alpha 3$ & 89.1 & -139.8 & & & & & & & & \\
\hline$\alpha 4$ & 80.2 & 64.4 & 111.5 & & & & & & & \\
\hline$\alpha 5$ & 99.5 & -132.7 & -13.5 & 121.5 & & & & & & \\
\hline$\alpha 6$ & -89.9 & 42.1 & -177.5 & -70.6 & 165.6 & & & & & \\
\hline$\alpha 7$ & 66.6 & -160.8 & -22.9 & 109.1 & -33.3 & 155.7 & & & & \\
\hline$\alpha 8$ & -118.9 & 12.8 & 151.0 & -69.5 & 141.6 & -30.6 & -173.4 & & & \\
\hline$\alpha 9$ & 117.1 & -116.4 & 34.2 & 131.9 & 20.8 & -145.3 & 53.0 & -122.8 & & \\
\hline$\alpha 10$ & -28.2 & -103.0 & 115.8 & -79.4 & 124.3 & -62.8 & 93.0 & -93.1 & 137.1 & \\
\hline$\alpha 11$ & 53.0 & -109.7 & 74.7 & -45.5 & 87.9 & -106.4 & 64.9 & -114.7 & 107.3 & -72.2 \\
\hline
\end{tabular}

Tabla 5.3- Ángulos entre hélices de Na-FAR-1 determinados mediante QHELIX. Los ángulos se evaluaron mediante el algoritmo de Chou ${ }^{125}$, para las 11 hélices presentes en Na-FAR-1.

Para evaluar la orientación relativa entre las hélices de Na-FAR-1 se graficó la distribución de ángulos agrupados de a 15 grados en forma de histograma (figura 5.3). Para hélices que se encuentren en una disposición ortogonal respecto al resto, la mayoría de los ángulos presentes con respecto a otras hélices tomarán valores cercanos a $90^{\circ}$ y no tendrán ángulos cercanos a cero ni a $180^{\circ}$. La distribución de ángulos obtenida mostró que las hélices $\alpha 4$ y $\alpha 11$ se encuentran perpendiculares al resto de las hélices. 

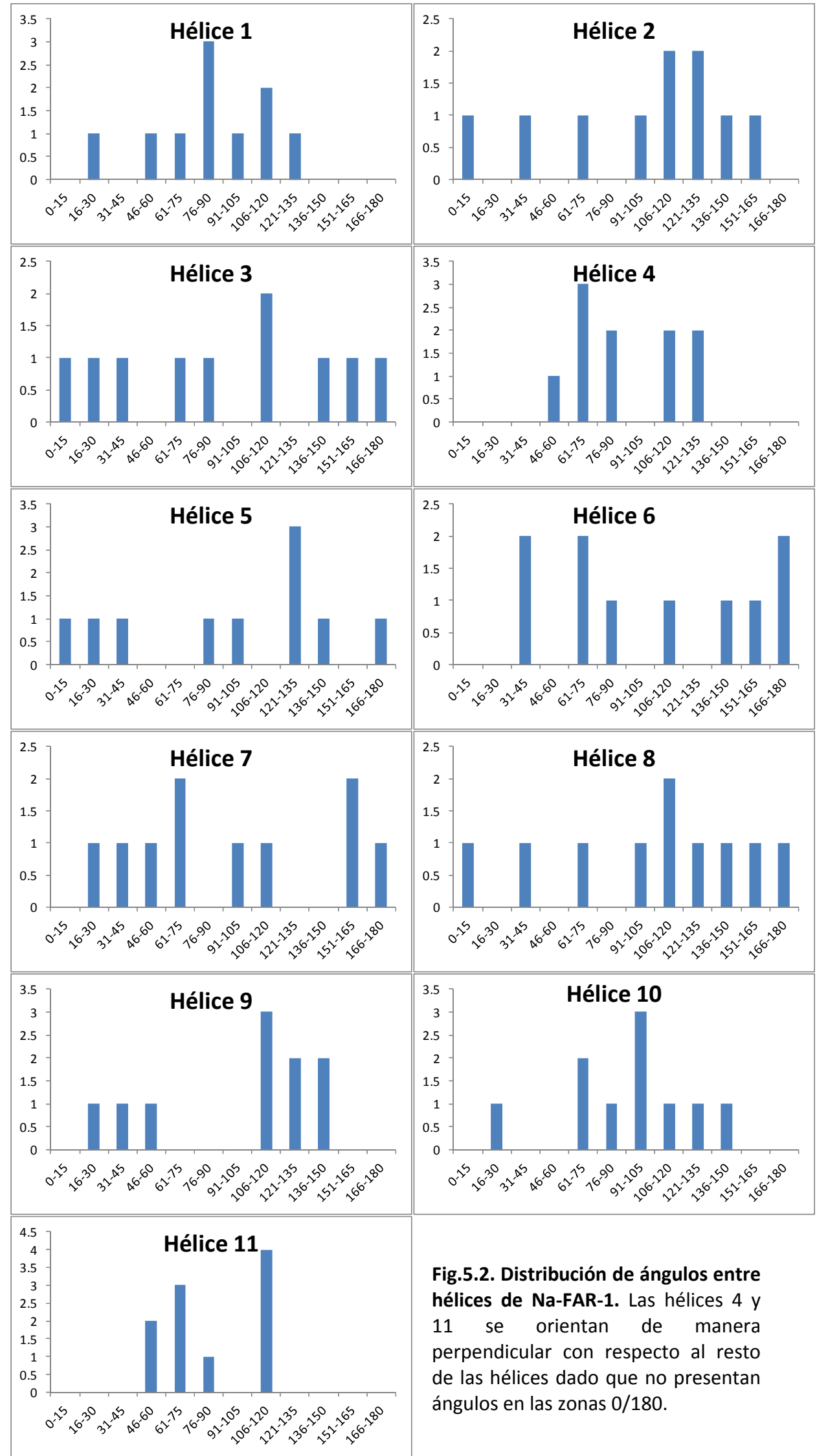

Fig.5.2. Distribución de ángulos entre hélices de Na-FAR-1. Las hélices 4 y 11 se orientan de manera perpendicular con respecto al resto de las hélices dado que no presentan ángulos en las zonas 0/180. 


\subsection{Distribución de residuos}

La naturaleza de las hélices de Na-FAR-1 se evaluó a través del análisis de la distribución los diferentes residuos que las componen.

\subsubsection{Residuos hidrofóbicos}

La gran mayoría de los residuos hidrofóbicos se ubican en la región interna de las hélices con sus cadenas laterales apuntando hacia la cavidad interna de la proteína (figura 5.3). Sólo unos pocos residuos hidrofóbicos aislados se encuentran en regiones superficiales en contacto con el solvente.

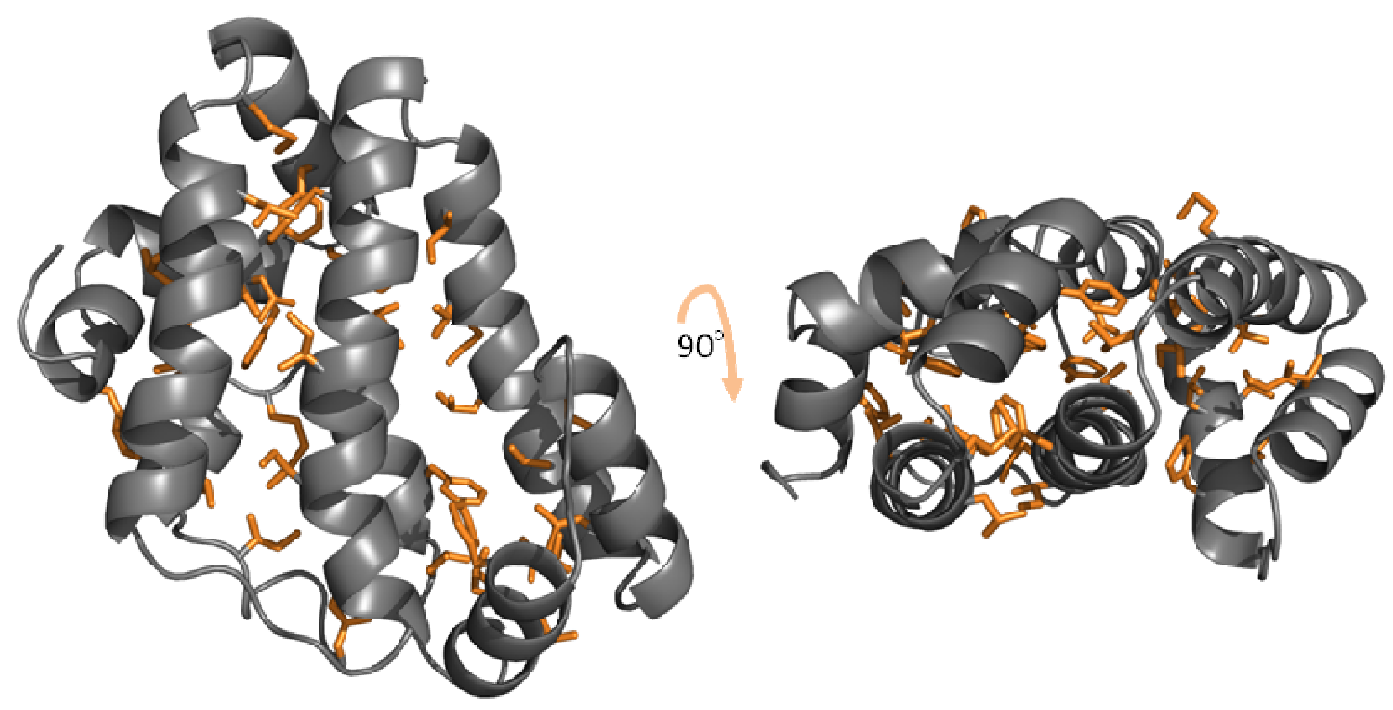

Fig.5.3. Representación de residuos hidrofóbicos en la estructura de Na-FAR-1. Las cadenas laterales de los residuos hidrofóbicos (leu, ile, val, met, phe) se esquematizan en color anaranjado.

\subsubsection{Residuos aromáticos}

Na-FAR-1 posee 6 tirosinas, 9 fenilalaninas y no presenta triptofanos en su estructura primaria. Los residuos aromáticos se localizan mayoritariamente en el interior de la proteína, excepto F38 que está expuesta al solvente (figura 5.4). 

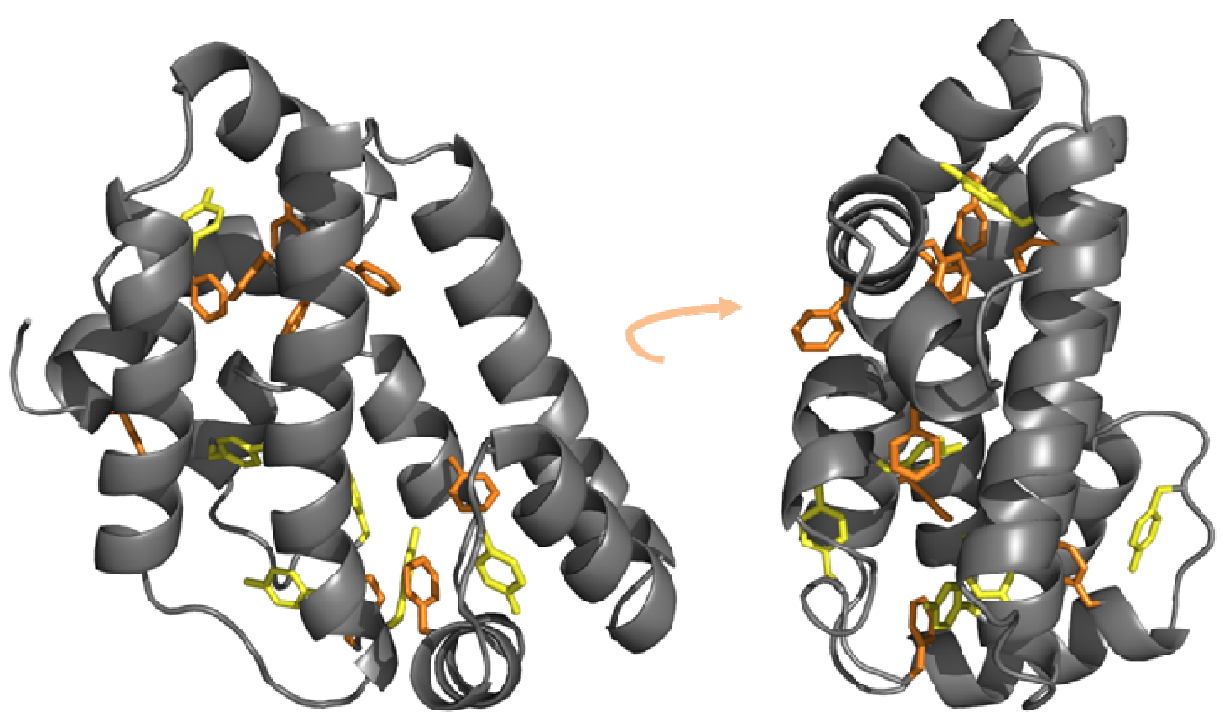

Figura 5.4. Representación de residuos aromáticos en la estructura de Na-FAR-1. Las cadenas laterales de los residuos de tyr se esquematizan en color amarillo y phe en anaranjado.

\subsubsection{Residuos polares}

La distribución de residuos es la esperada para una proteína globular, con los residuos polares y cargados ubicados preferencialmente en la superficie externa de la molécula generando una superficie hidrofílica (figura 5.5).

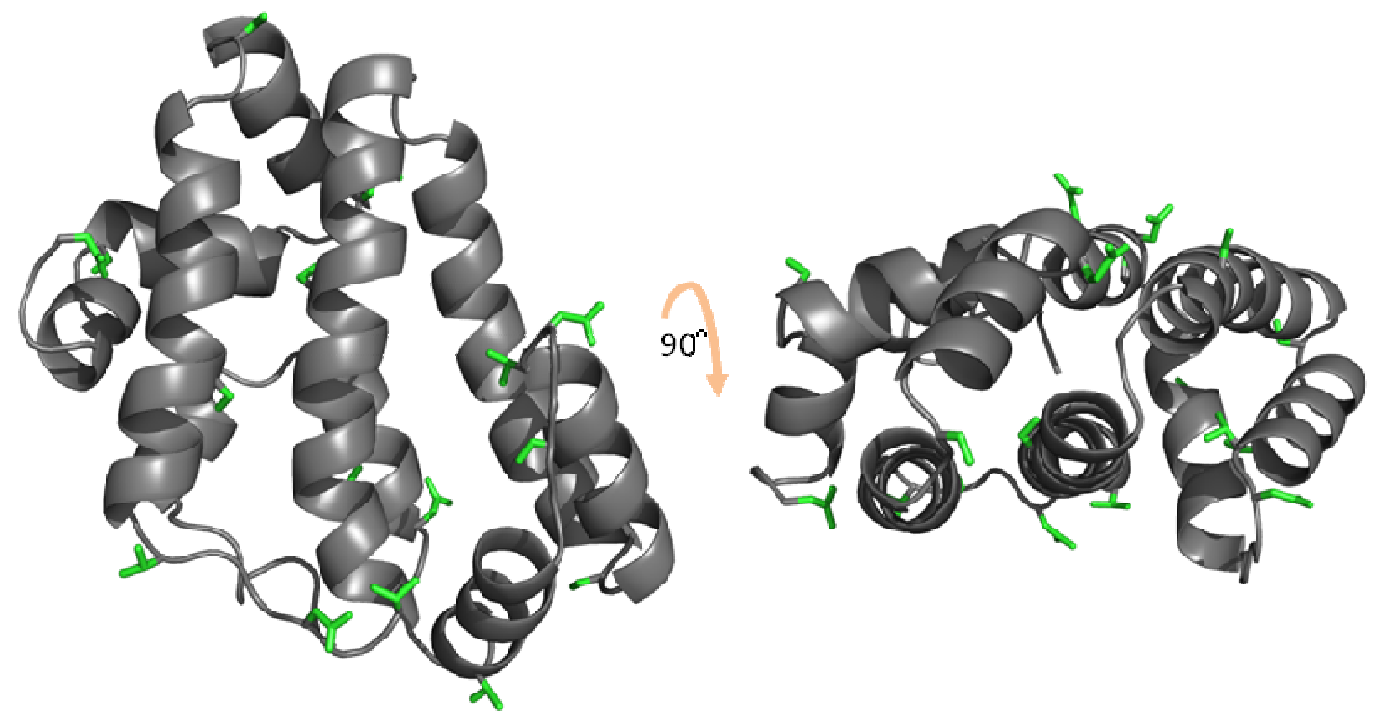

Figura 5.5. Representación de residuos polares en la estructura de Na-FAR-1. Las cadenas laterales de los residuos polares sin carga (thr, ser, gln, asn) se esquematizan en color verde. 
La mayoría de los residuos polares no cargados se encuentra en la superficie de la proteína en regiones lazo o extremos de hélices. A excepción de la serina 88 que se localiza en la cavidad interna.

Na-FAR-1 presenta un elevado número de lisinas cuyas cadenas laterales positivamente cargadas están en contacto con el solvente estabilizando la molécula en solución (figura 5.6). Un único residuo de lisina (K96) se encuentra en el interior de la cavidad. Otros dos residuos positivamente cargados presentan cadenas laterales en la cavidad interna, H67 y R97.

Los residuos negativos se ubican en la superficie de la molécula, en su totalidad (figura 5.6).

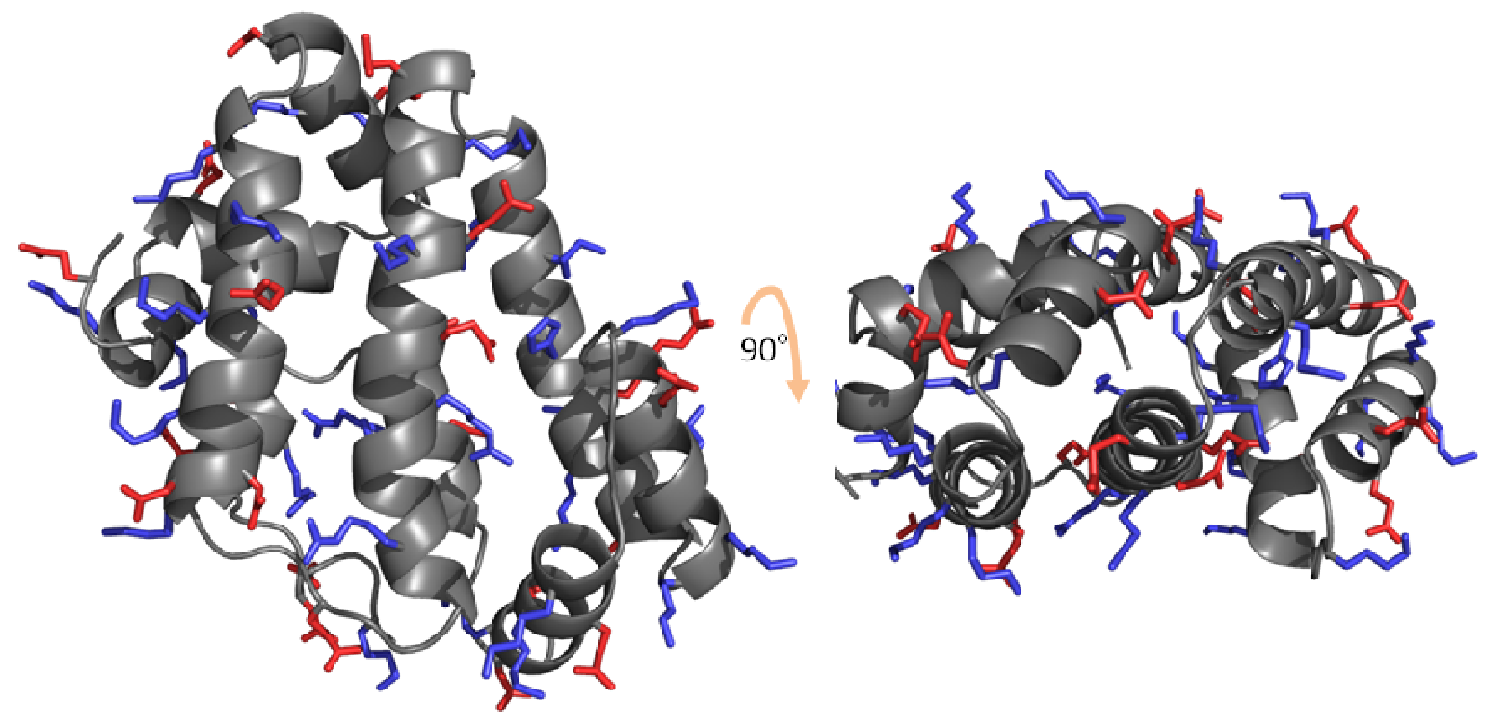

Figura 5.6. Representación de residuos cargados en la estructura de Na-FAR-1. Las cadenas laterales de residuos cargados se esquematizan en azul (arg, his, lys) y rojo (asp, glu).

La distribución de carga en la superficie de Na-FAR-1 es bastante uniforme, con una preponderancia de carga positiva (figura 5.7). Debido a la mayor cantidad de lisinas, argininas e histidinas en comparación con glutamatos y aspartatos. 

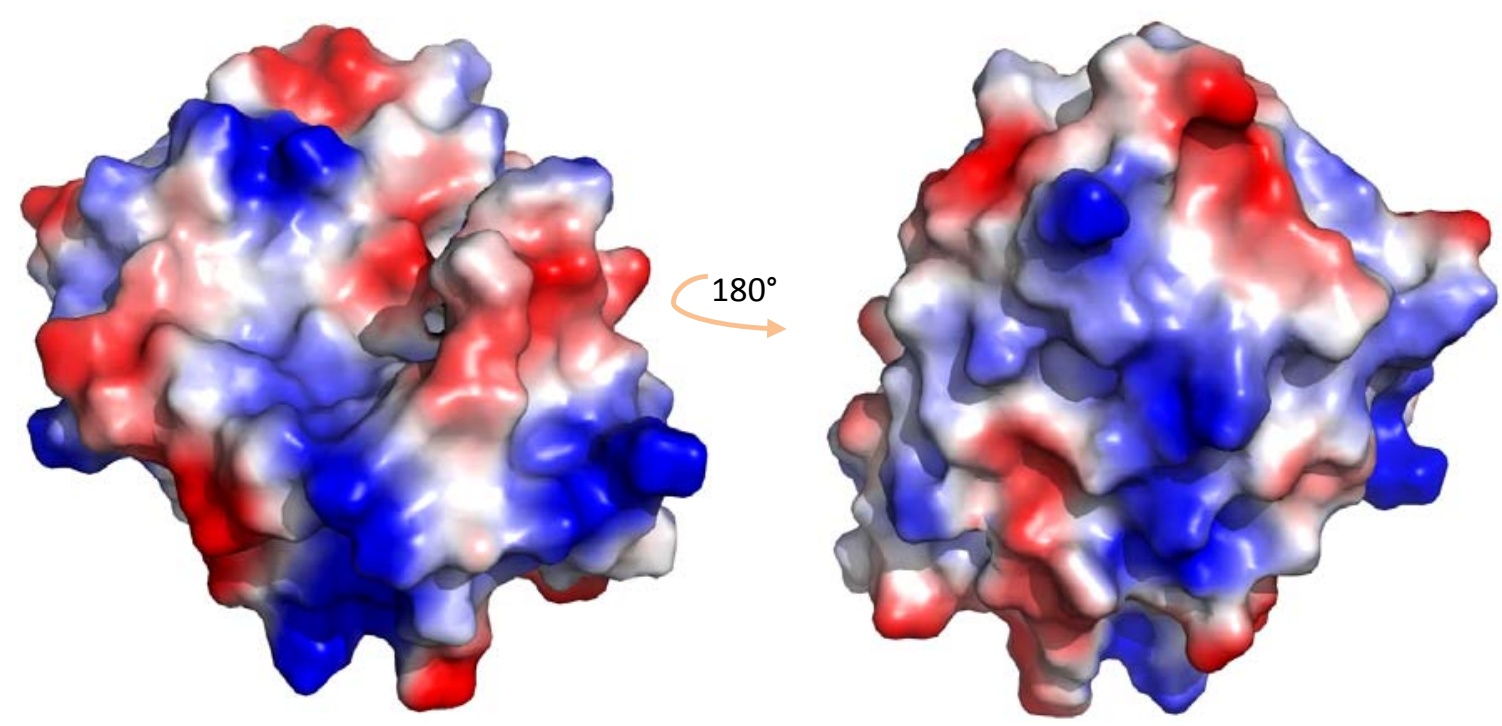

Figura 5.7. Representación de la carga superficial en la estructura de Na-FAR-1. Las cargas superficiales se generaron en pymol con la función de potencial electrostático en el vacío. Las cargas positivas se representan en azul, las cargas negativas en rojo y las zonas sin carga en gris.

\subsection{Estructura cristalográfica de Na-FAR-1}

La cristalografía de rayos $X$ es una técnica bien establecida para la determinación de estructuras de macromoléculas, que es complementaria a la de RMN $^{126}$.

A raíz de una colaboración con el Dr. Mads Gabrielsen del laboratorio de cristalografía del "Instituto de Infecciones, Immunidad e Inflammación", en la Universidad de Glasgow, surgió la posibilidad de cristalizar la proteína Na-FAR-1 para desarrollar estudios mediante cristalografía de rayos $X$, en paralelo a los de $R M N$, para la determinación de la estructura de Na-FAR-1 mediante esta técnica.

La proteína Na-FAR-1 purificada en nuestro laboratorio (sin deslipidizar por rp-HPLC) se envió al robot de cristalización del laboratorio de Mads Gabrielsen, donde se obtuvieron cristales en dos tipos de isoformas diferentes ${ }^{127}$, se recolectaron los datos y empleando la estructura de Ce-FAR-7 se intentó realizar el reemplazo molecular sin éxito.

Como estrategia para solucionar el problema de fase, Kate Griffiths, en el laboratorio del Dr. Brian Smith de la Universidad de Glasgow, expresó y cristalizó la proteína 
sustituida con selenometionina. Se seleccionó la forma cristalina cúbica que presentó mejor resolución (grupo espacial P432) y se difractó en el sincrotrón Diamond Light Source, estación 104 (Oxford, Reino Unido), con una resolución de 2.14 Å. Los datos se procesaron y la estructura se resolvió obteniéndose una buena concordancia entre el modelo y los datos experimentales con un $\mathrm{R}=19.9$ y un $\mathrm{R}_{\text {libre }}=22.5$ luego del refinamiento. EI RMSD de longitud de enlace fue de $0.01 \AA$ y el de ángulos de $0.990^{\circ}$. Se detectó densidad electrónica compatible con una molécula de palmitato en la cavidad interna de la proteína y un total de 174 moléculas de agua.

En la figura 5.8 se presenta la estructura cristalográfica de Na-FAR-1 en su forma holo.
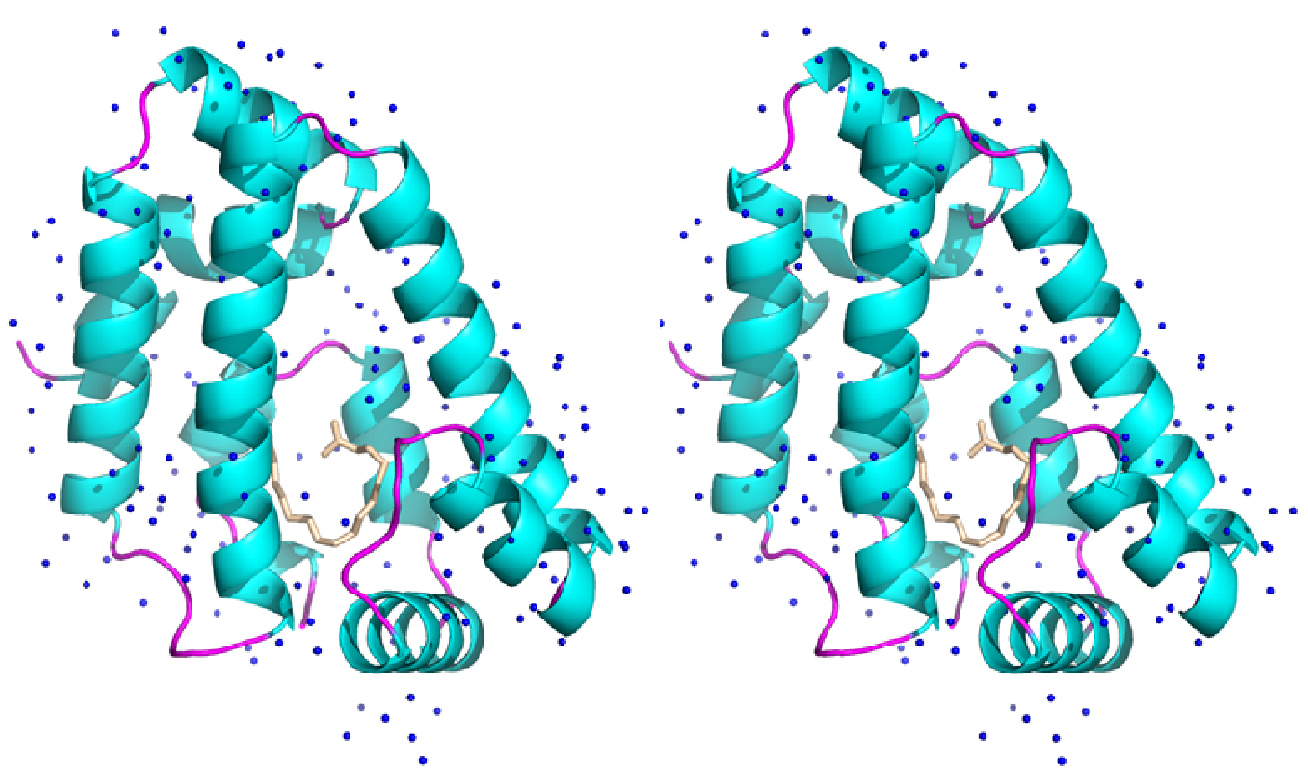

Fig.5.8. Representación estereoscópica de la estructura de Na-FAR-1 determinada mediante cristalografía de rayos $X$ coloreada según estructura secundaria. Con $\alpha$-hélices en turquesa y lazos en violeta. En el interior de la cavidad se localiza una molécula de ácido palmítico, en azul se señalan las moléculas de agua.

La estructura cristalográfica de Na-FAR-1 se determinó con cristales producidos a partir de proteína no deslipidizada por HPLC en fase reversa. El cristal presentó densidad electrónica satisfactoria para la asignación de una molécula de palmitato, pero se detectaron otras zonas con presencia de densidad electrónica no tan bien definidas, posiblemente ocupadas por poblaciones heterogéneas de ligandos. Es por esto que la 
forma holo de Na-FAR-1, determinada por cristalografía de rayos $X$, no corresponde a una estequiometria real 1:1 Na-FAR-1:palmitato.

\subsection{Comparación entre las formas apo y holo}

Las estructuras de Na-FAR-1 en su forma apo y holo se determinaron mediante RMN y cristalografía de rayos $X$, respectivamente. Si bien mediante ambas técnicas se obtuvieron estructuras de buena calidad geométrica, al realizar una comparación se debe tener en cuenta que las diferencias observadas pueden deberse a condiciones inherentes a las distintas metodologías y no únicamente a las diferencias presentes en la estructura de la proteína, por hallarse libre de ligando, o formando complejo ${ }^{128}$.

El contenido de estructura secundaria es muy similar a la proteína apo, presentando la forma holo un $70 \%$ de $\alpha$-hélices y un $30 \%$ de lazos. Asimismo, el giro $3_{10}$ se encuentra bien definido en la estructura cristalográfica.

El plegamiento general de las estructuras, complejada con palmitato (holo) y sin ligando (apo) es muy similar, siendo ambas estructuras prácticamente superponibles (figura 5.9). Una comparación de las estructuras da una diferencia RMSD de $1.814 \AA$ (con un total de 1082 átomos alineados). Para los átomos de la cadena principal la comparación entre ambas estructuras presenta un RMSD de 1.579 Å (con 583 átomos).

Una inspección visual de la proteína permite distinguir que si bien el plegamiento general es muy similar, la estructura de la forma apo es más compacta, las hélices se disponen delineando una cavidad interna de menor tamaño, mientras que en la estructura cristalográfica esta cavidad está más expandida (figura 5.9).

La incorporación de los acoplamientos residuales dipolares en el refinamiento de la estructura por RMN permite validar el modelo obtenido para la forma apo. Las restricciones de largo alcance evitan que la posición de las hélices se deba a una limitación en la cantidad y calidad de datos disponibles para el cálculo de estructura a partir de restricciones de corta distancia. 

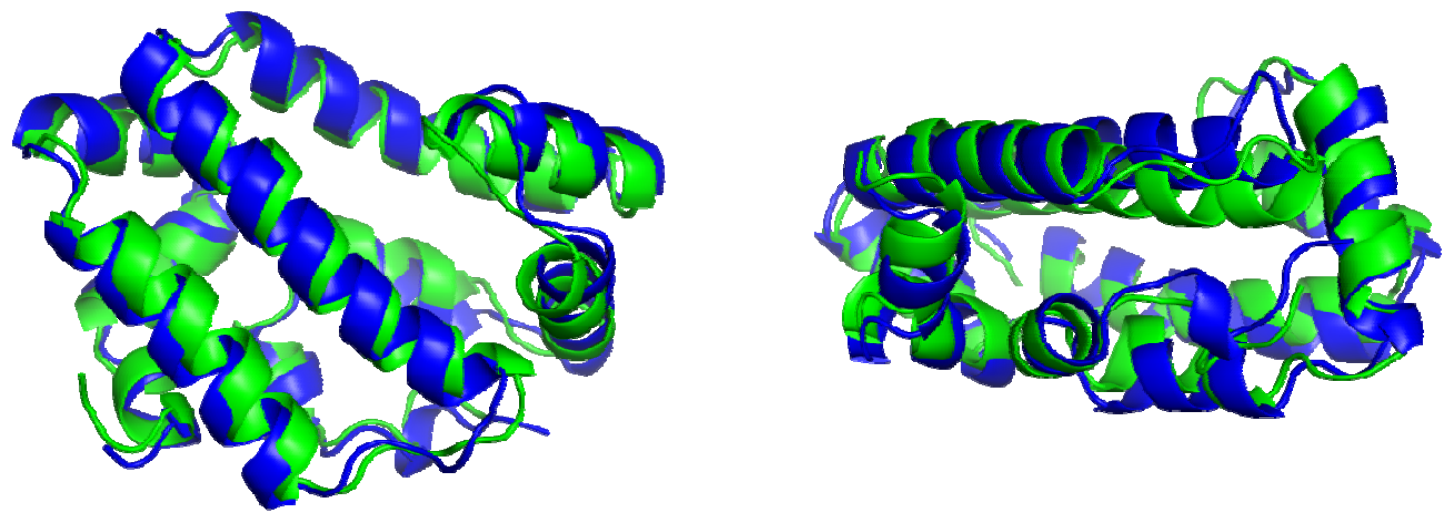

Fig. 5.9. Superposición de las estructuras apo (verde) y holo (azul) de Na-FAR-1. Ambas estructuras presentan una disposición muy similar de hélices, sin embargo, puede apreciarse que la estructura de la forma apo es más compacta.

\subsubsection{Cavidad hidrofóbica}

Na-FAR-1 posee una cavidad hidrofóbica central que adopta diferentes características en presencia o ausencia de ligando (figura 5.10).
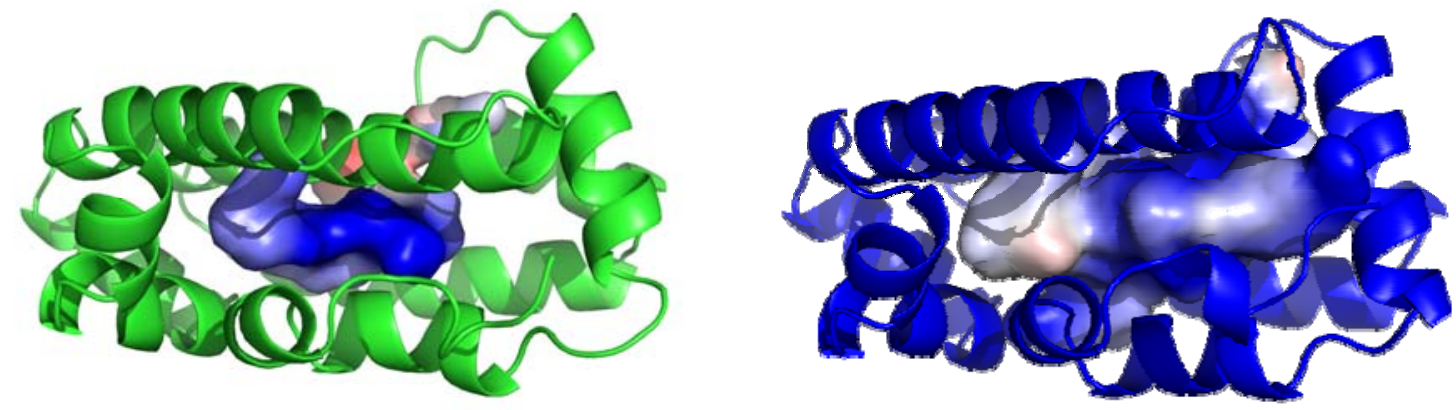

Fig. 5.10. Cavidad interna de las estructuras apo (verde) y holo (azul) de Na-FAR-1. La cavidad en la forma holo es apreciablemente mayor que en la forma apo. La imagen de las cavidades internas se generó mediante pymol.

El volumen de las cavidades de ambas estructuras se calculó con el programa CASTp ${ }^{129}$. Para poder comparar las estructuras determinadas por las diferentes técnicas, se eliminaron los hidrógenos de la estructura calculada por RMN.

La estructura de apo Na-FAR-1 calculada por RMN presenta una cavidad hidrofóbica central con un volumen de $1222.9 \AA^{3}$ accesible a una sonda de $1.4 \AA$ (tamaño 
equivalente al de una molécula de agua) que se reduce a $938.9 \AA^{3}$ si se trata del volumen accesible para una sonda de $1.925 \AA$ (equivalente a un grupo $\mathrm{CH}_{2}$ ).

En cuanto a la estructura cristalográfica de Na-FAR-1, en la forma holo, el volumen de la cavidad accesible a una molécula de agua es dos veces mayor que en la forma apo, alcanzando los $2567.7 \AA^{3}$, mientras que para una sonda de $1.925 \AA$ se encuentra en el mismo orden de magnitud $2169.3 \AA^{3}$.

La apertura de la cavidad también se modifica en cada modelo, siendo de mayor tamaño en la forma holo (figura 5.11).
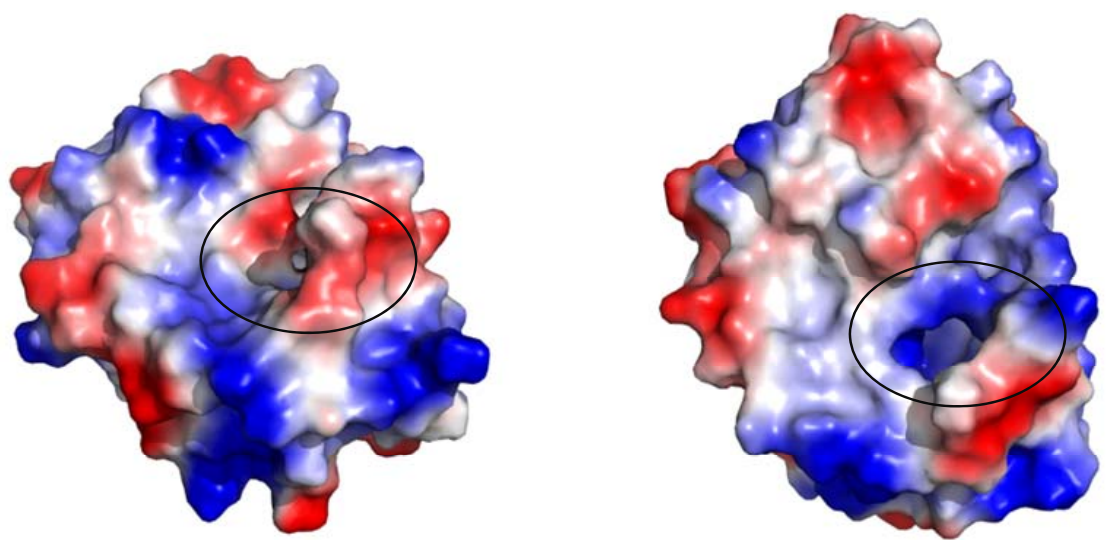

Fig. 5.11. Superficie de Na-FAR-1 en su forma apo y holo. Las cargas superficiales se generaron en pymol con la función de potencial electrostático en el vacío. Las cargas positivas se representan en azul, las cargas negativas en rojo y las zonas sin carga en gris. La cavidad se encuentra más abierta en la proteína unida a ligando.

La región que comunicaría la cavidad interior con el seno de la solución está comprendida por las hélices $\alpha 6, \alpha 7$, el lazo 4, que presenta una alta movilidad de acuerdo a los estudios de dinámica, y las hélices $\alpha 4$ y $\alpha 5$. Los cambios en la apertura de la cavidad, que es mayor en la forma holo, están fundamentalmente modulados por cambios en la región del lazo 4. Un Puente salino entre K71 y E86 mantiene la orientación de las hélices $\alpha 6$ y $\alpha 7$ en la proteína apo. En la forma holo, E46 que se localiza a un extremo de $\alpha 5$ forma un puente salino con $\mathrm{K} 71$ restringiendo la orientación de $\alpha 5$ y $\alpha 6$ y abriendo el portal. En el extremo más distante a la cavidad, $\alpha 5$ se acerca a $\alpha 4$ en la forma holo, donde E35 y K55 forman un puente salino, la orientación de $\alpha 4$ y $\alpha 5$ también contribuye a la apertura de la entrada a la cavidad. A 
su vez, la hélice $\alpha 5$ es dos aminoácidos más corta que en la forma apo y el lazo 4, es por lo tanto más largo y se dobla abriendo la entrada de la cavidad.

Los residuos adoptan posiciones diferentes y la cavidad queda definida por diferentes residuos en cada caso (figura 5.12).

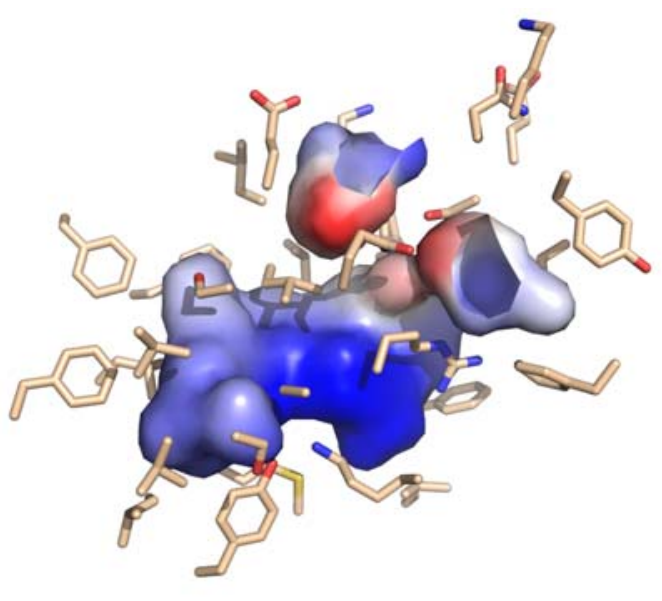

$-60.874 \quad 60.874$

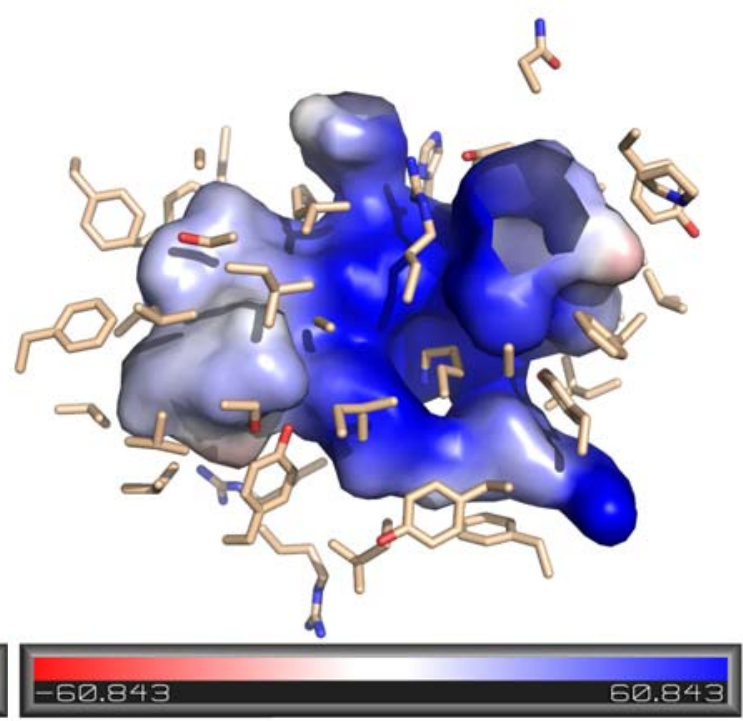

60.843

Fig. 5.12. Cavidad interna de Na-FAR-1 en su forma apo, libre de ligando, y holo, unida a palmitato. Se esquematizan las cadenas laterales de los residuos que delimitan la cavidad. Las cargas superficiales de ambas cavidades se generaron en pymol con la función de potencial electrostático en el vacío. Las cargas positivas se representan en azul, las cargas negativas en rojo y las zonas sin carga en gris.

\subsubsection{Cavidad de la forma Apo}

Los bordes de la cavidad próximos al solvente están decorados con tres aminoácidos positivos H67, K71 en la hélice $\alpha 6$ y K43 localizada en la posición más externa del lazo 5 y también los residuos negativamente cargados (E90, E46, E86), así como un residuo polar N44. La entrada a la cavidad está rodeada por residuos hidrofóbicos F37, G94, A97 e 189, en una posición más profunda, y de naturalezas dual Y42 y polar (T45, S48).

La cavidad se encuentra inmersa dentro de la proteína con un volumen más accesible delimitado por las cadenas laterales de residuos hidrofóbicos (A18, 189, V70, F21, L22, V63, L66, 174), polares (T45, S48) y también positivamente cargados (R93, K96). El 
volumen más inaccesible se localiza detrás de $\mathrm{K} 96$ y de dos residuos polares ( $\mathrm{P} 15, \mathrm{~S} 88)$, y está delimitado por residuos hidrofóbicos M14, L13, Y10, V114, V117, L139, F143, A92, F136 y F132 (figura 5.13).
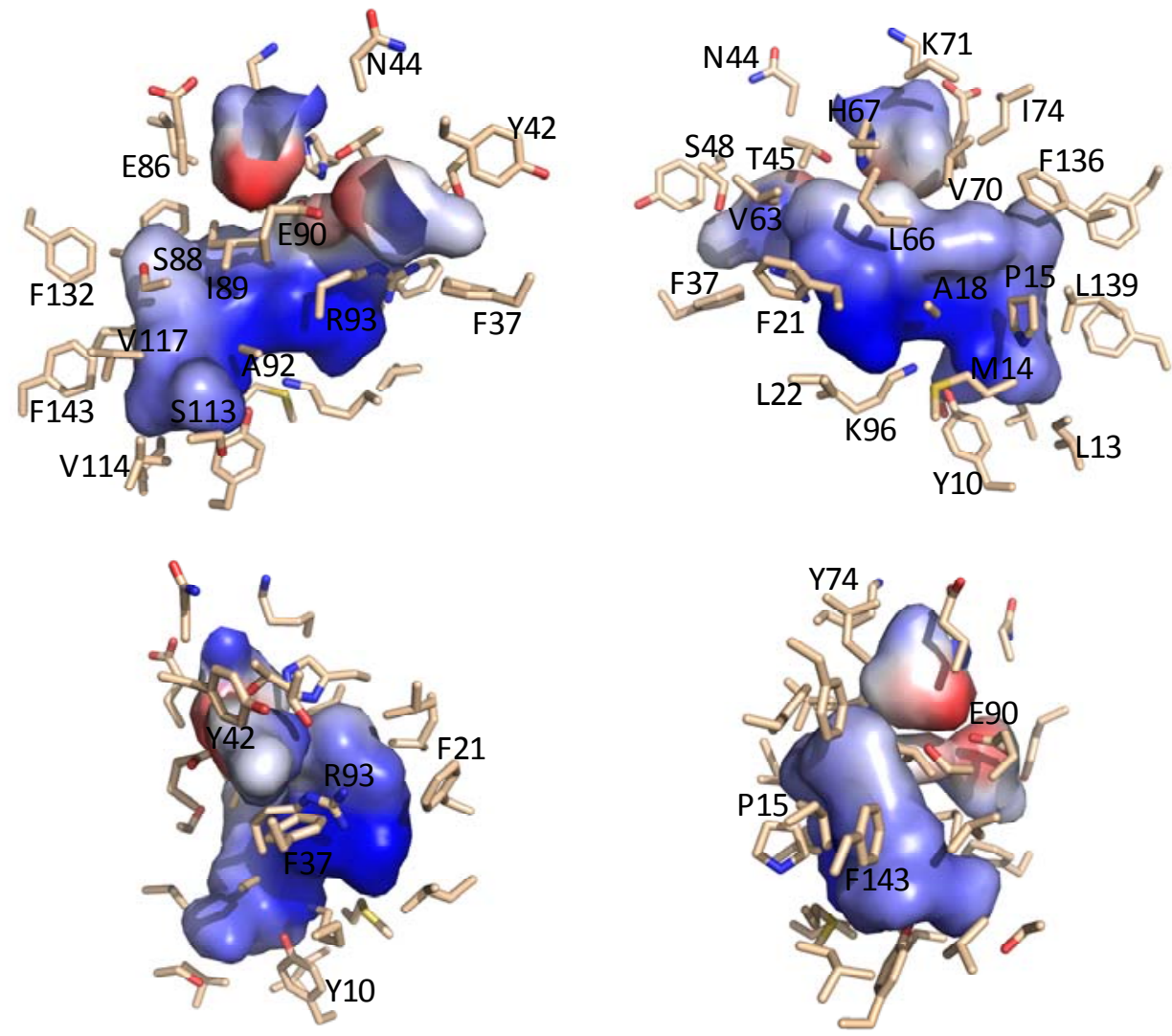

Fig.5.13. Cavidad interna de Na-FAR-1 en su forma libre de ligando. Se esquematizan las cadenas laterales de los residuos que delimitan la cavidad.

\subsubsection{Forma holo}

En la estructura cristalográfica la cavidad está principalmente delineada por residuos hidrofóbicos (F132, F136, L139, V142, F143, M14, L13, V114, V117, Y10, V70, 189, I91, A92, 195, A97, A18, A97, Y99, Y100, F21, L22, L25, L33, V36, F1, I6, F37, Y42, I49, L52, V63, L66, M69). Residuos positivamente cargados como K43, R93 y H67 están localizados en la entrada de la cavidad en contacto con el solvente donde también se localizan residuos polares (N44, T45, S48). E46 está presente en dos confórmeros 
diferentes, uno de los cuales forma un puente salino ya sea con K71 o con H67, residuos también localizados en la entrada (figura 5.14).
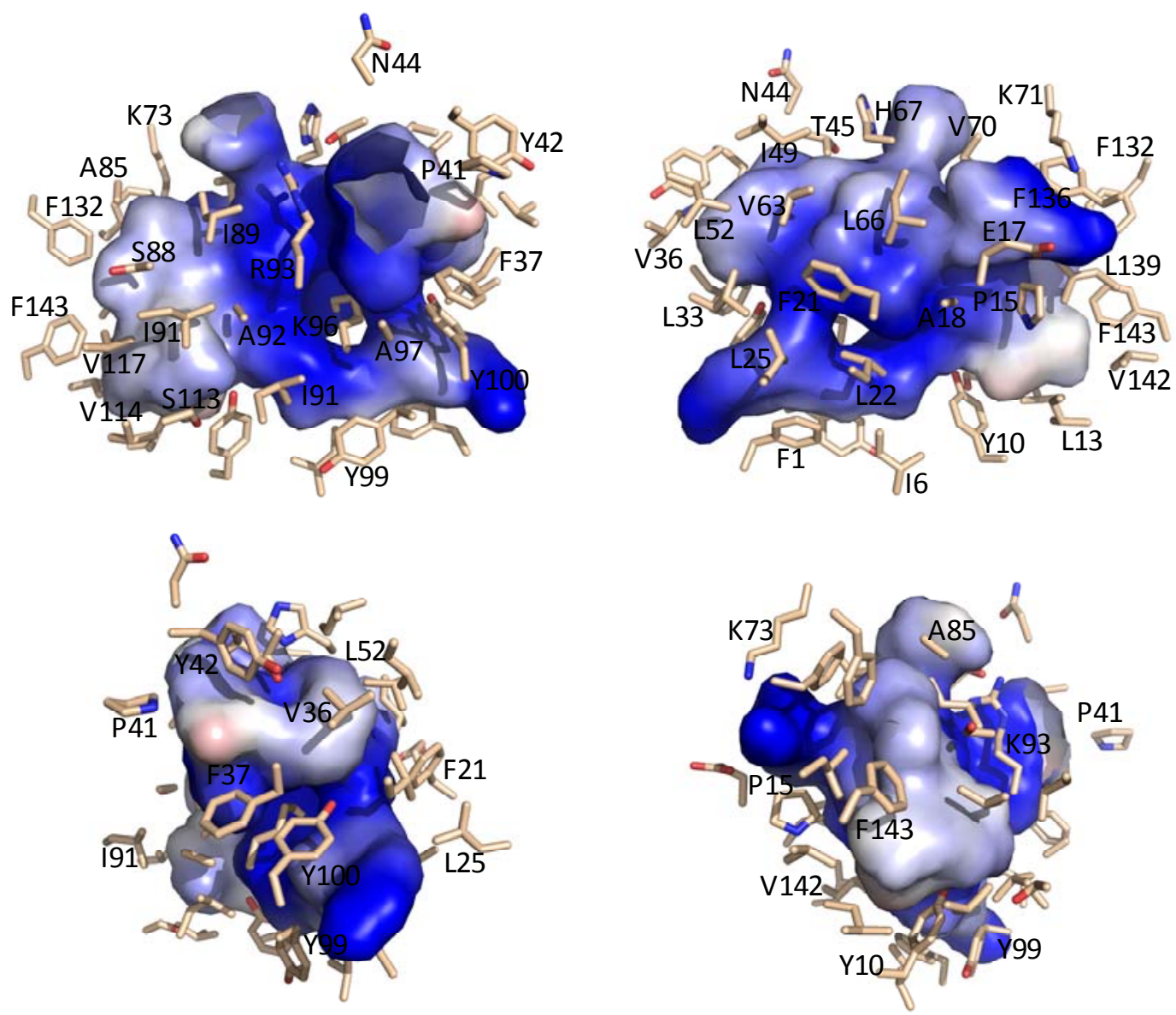

Fig.5.14. Cavidad interna de Na-FAR-1 en su forma unida a ligando. Se esquematizan las cadenas laterales de los residuos que delimitan la cavidad.

Dentro de la cavidad, el palmitato se localiza en una zona media, rodeado por las cadenas laterales de los residuos hidrofóbicos (A18, F21, L22, L33, V63, L66, A92, M14, 195, L25). Hay cinco residuos aromáticos en proximidad del ligando, 3 tirosinas (Y10, Y99, Y100) y dos fenilalaninas (F1, F21). El grupo cargado del palmitato se encuentra estabilizado por la cadena lateral de K96 (figuras 5.15 y 5.16 ). 


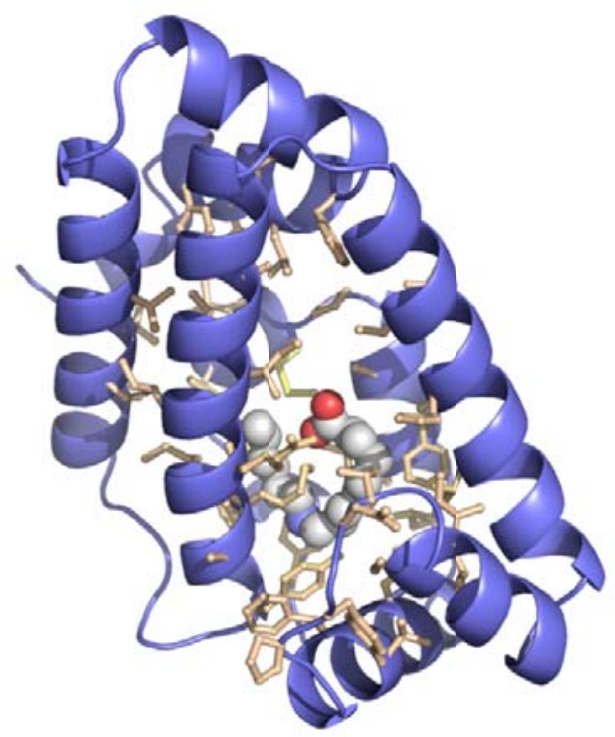

Fig.5.15. Cavidad interna de Na-FAR-1 unida a palmitato. Se esquematizan las cadenas laterales de los residuos que delimitan la cavidad.
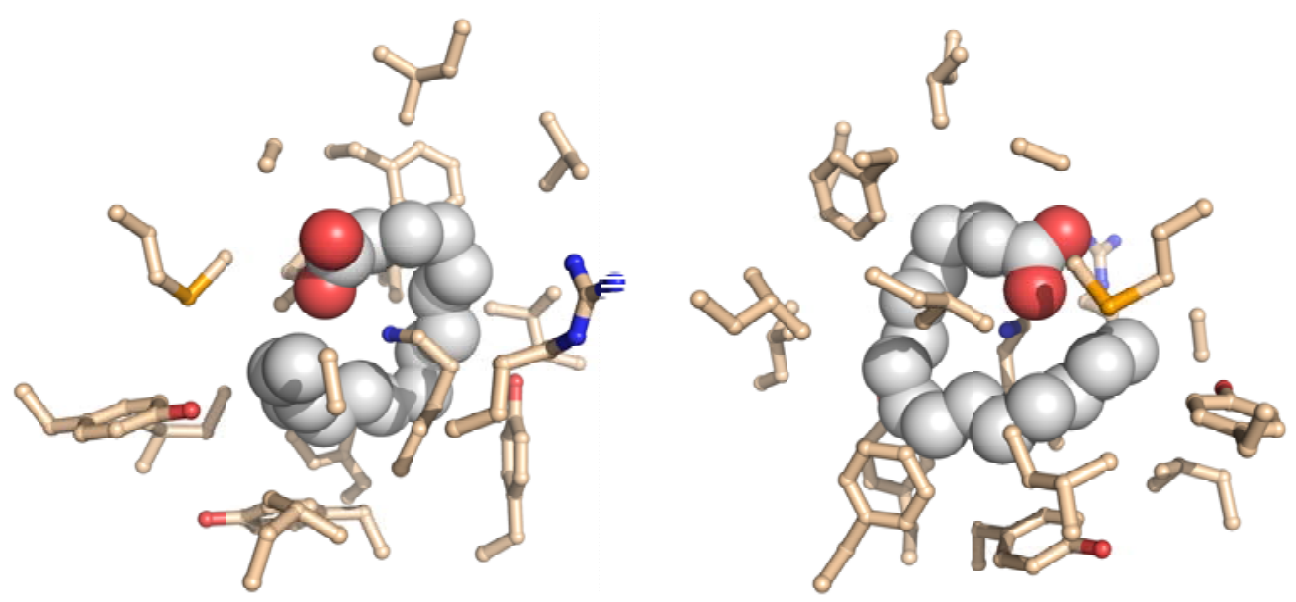

Fig.5.16. Residuos de Na-FAR-1 em contacto con palmitato. Se esquematizan las cadenas laterales de los residuos que delimitan la cavidad y la molécula de palmitato en su interior.

\subsection{Comparación con otras estructuras}

Una comparación geométrica con las estructuras disponibles en bases de datos realizada mediante alineamiento de matrices de distancia con el programa $D A L{ }^{130}$, reveló que no existen estructuras similares a la de Na-FAR-1, a excepción de Ce-FAR-7. Algunas estructuras candidatas fueron seleccionadas por el programa con un RMSD>3.7Å (PDB ID: 2ip6-A, 1x8z-A, 1x91-A, 3kav-D, 1x8z-B). Una inspección de la superposición generada con estas estructuras permitió comprobar que correspondía a 
una similitud en la orientación de segmentos de ciertas hélices más que a una similitud de plegamiento general.

La estructura de Na-FAR-1 constituye el segundo ejemplo de estructura determinada conteniendo un nuevo patrón de plegamiento, descripto por primera vez en Ce-FAR-7 50 .

\subsubsection{Análisis comparativo con Ce-FAR-7}

La estructura de Ce-FAR-7 en forma apo se determinó mediante cristalografía de rayos $X$ PDB ID: $29 W Y^{50}$.

La proteína Ce-FAR-7 presenta diferencias en la estructura primaria con respecto a NaFAR-1. Como se ha mencionado previamente, el transcripto primario de Ce-FAR-1 carece de señal de secreción. La proteína madura presenta 138 aminoácidos entre los que se encuentran dos residuos de cisteína mientras que Na-FAR-1, con 155 residuos, carece de este tipo de aminoácido.

Mediante el programa jalview ${ }^{53}$ se realizó un alineamiento de secuencias corregido en base a la estructura de ambas proteínas (figura 5.17). El alineamiento generado permite observar que 32 residuos se encuentran conservados. Entre los residuos conservados se encuentran residuos hidrofóbicos, L77 y A81 (L78 y A82 en Ce-FAR-7) que ayudan a determinar el ángulo entre $\alpha 6$ y $\alpha 7$. L33, L59 (L60 en Ce-FAR-7) y L52 (que es sustituida por otro residuo hidrofóbico, V53) que están involucrados en mantener la orientación entre $\alpha 6$ y las hélices $\alpha 4$ y $\alpha 5$. También está conservado el puente salino entre E35 y K55 (K56 en Ce-FAR-7) que ayuda a mantener la orientación de $\alpha 4$ y $\alpha 5$. Otro puente salino conservado, entre K73 (R74 en Ce-FAR-7) y E17 ayuda a mantener la orientación entre $\alpha 6$ y $\alpha 3$.

Na-FAR-1 presenta una inserción de 4 residuos en la posición 107 en el extremo Nterminal de $\alpha 8$ que resultan en una mayor longitud de esta hélice.

Ce-FAR-7 tiene una inserción de un residuo de histidina en la posición 40 ubicada en el lazo 4. A su vez, es 14 residuos más corta en la región C-terminal por lo que carece de 
las dos hélices, $\alpha 10$ y $\alpha 11$ presentes en Na-FAR-1 y posiblemente en otros miembros de esta familia de proteínas de mayor longitud de secuencia.

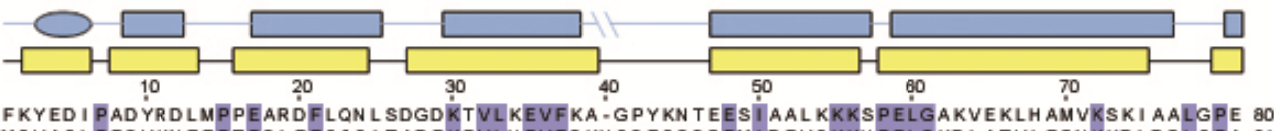
$\begin{array}{ll}\text { NG-FAR-1 } & \text { 1 FKYED I PADYRDLMPPEARDFLQNL SDGD KTVLKEVFKA-GPYKN TEESIIAALKKKSPELGAKVEKLHAMVIKSKI AALGPE BO } \\ \text { CO-FAR-7 } & \text { 1 MSVASLPECVKN FFPTEQLEFSSSITADEKPVLHEVFQKH SCFSQCGEMIDEVSKKH PELGKRLATVLEGNKKRLDGLSPA 81 }\end{array}$

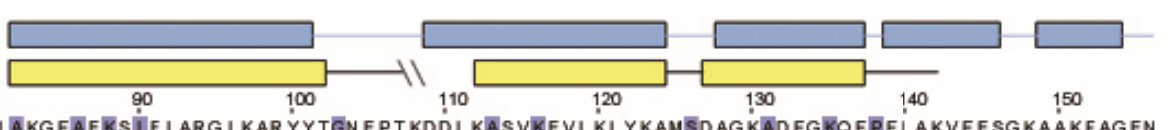

Na-FAR-1 81 AKGFAEKSIEI ARG I KARYYTGN EPT KDDL KASVKEVL KLYKAMSD AG KAD FG KGFPFLAKVFESGKAAKFAGEN

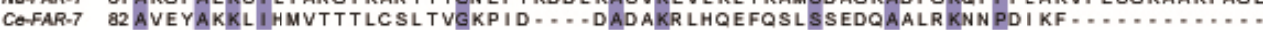

Fig. 5.17. Alineamiento de secuencias basado en estructura de Na-FAR-1 y Ce-FAR-7. Los elementos de estructura secundaria se esquematizan como rectángulos ( $\alpha$-hélices) y líneas (lazos) en color celeste para Na-FAR-1 y en amarillo Ce-FAR-7.

Las prolinas al inicio de las hélices P7 en $\alpha 2$, P15 $\alpha 3$, P79 $\alpha 7$, P137 en $\alpha 10$ (que se corresponden con P7, P15, P80 y P134 en Ce-FAR-7) se encuentran altamente conservadas en estas proteínas y entre los miembros de la familia FAR.

En la región N-terminal, Ce-FAR-7 presenta una hélice $\alpha$ de 5 residuos de longitud, en lugar del giro $3_{10}$ de tres aminoácidos.

Una comparación de las estructuras con pymol da un RMSD de $1.711 \AA$ (con un total de 636 átomos alineados) con la forma apo y de $1.646 \AA ̊$ (para 608 átomos alineados) con la forma holo. En la figura 5.18 se muestra una superposición de las tres estructuras.
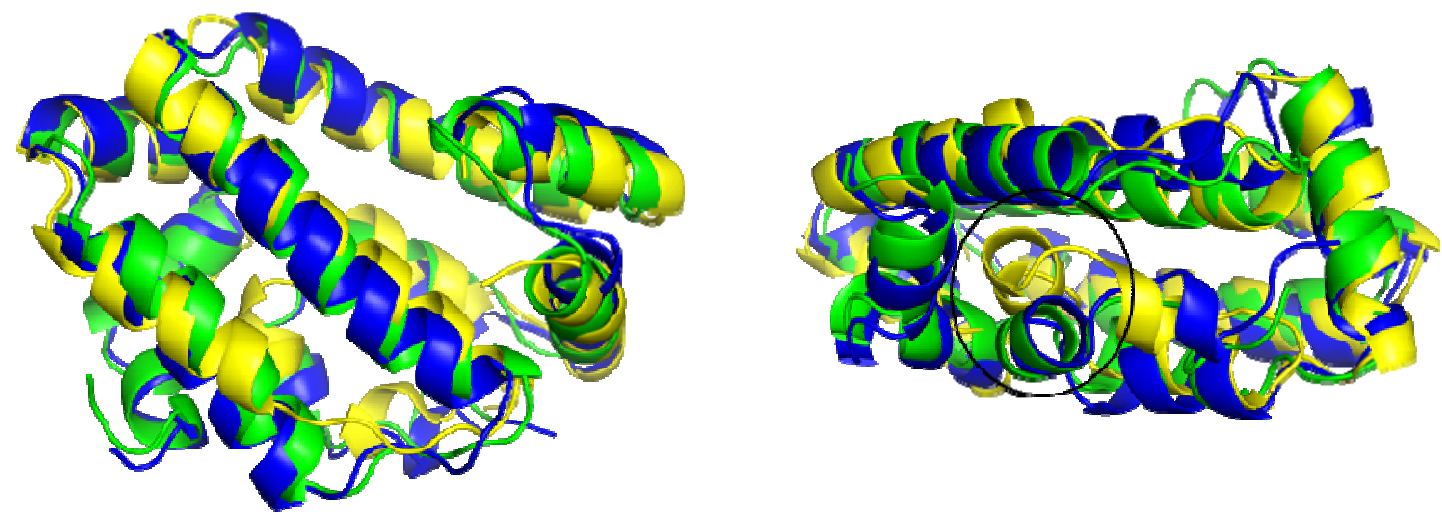

Fig. 5.18. Superposición de las estructuras apo (verde) y holo (azul) de Na-FAR-1 con Ce-FAR-7 (amarillo). Las estructuras presentan una disposición muy similar de hélices, sin embargo, puede apreciarse que en Ce-FAR-7 las hélices $\alpha 2$ y $\alpha 3$ (delimitadas con un círculo) se acercan hacia el centro disminuyendo el tamaño la cavidad. 


\subsubsection{Cavidad interna}

La región comprendida por el lazo 4, que constituye la entrada a la cavidad, no fue modelada en la estructura de Ce-FAR-7 por presentar densidad electrónica insuficiente. Es probable que la falta de buena definición en esta región se deba a los procesos dinámicos que ocurren en el lazo 4, como se ha determinado para Na-FAR-1.

La cavidad estimada para Ce-FAR-1 con CASTp presenta un tamaño mucho menor que para ambas formas de Na-FAR-1, con un volumen de $687.7 \AA^{3}$ accesible a una sonda equivalente al de una molécula de agua que se reduce a $390.0 \AA^{3}$ si se trata del volumen accesible para una sonda equivalente a un grupo $\mathrm{CH}_{2}$.

Las hélices $\alpha 2$ y $\alpha 3$ se acercan hacia las hélices $\alpha 7$ y $\alpha 8$ disminuyendo el volumen de la cavidad. Por este motivo, los autores distinguen dos zonas o bolsillos hidrofóbicos a las que denominaron P1 y P2 en Ce-FAR-7 (figura 5.19) ${ }^{50}$.
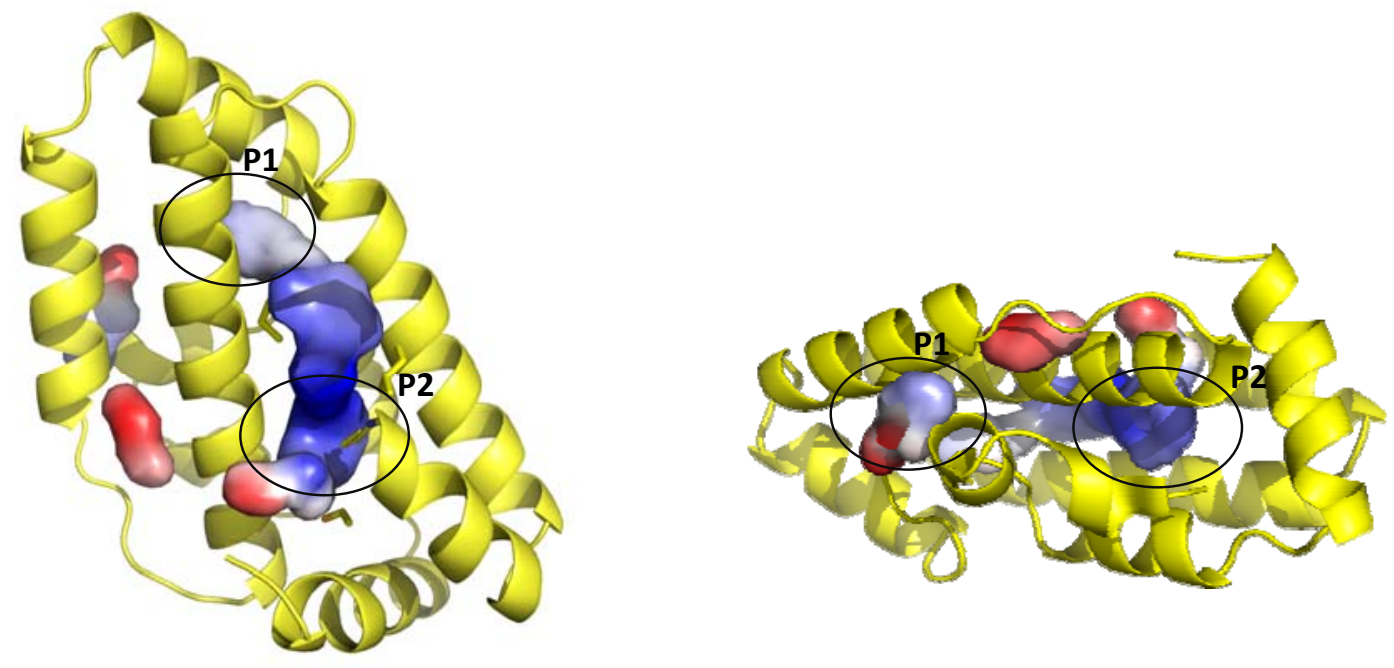

Fig. 5.19. Estructura de Ce-FAR-7 con la cavidad interna. Las imágenes se generaron en pymol, se señalan ambos bolsillos hidrofóbicos P1 y P2. Las cargas superficiales de lambas cavidades se generaron en pymol con la función de potencial electrostático en el vacío. Las cargas positivas se representan en azul, las cargas negativas en rojo y las zonas sin carga en gris.

Ciertos residuos que delinean las cavidades de las proteínas tienen un alto grado de conservación, pero en otros casos se producen cambios por aminoácidos de características similares que mantienen el perfil hidrofóbico. A85, 189 que en Ce-FAR-7 son A86, 190 forman parte del bolsillo P1, junto con 174, F84, F132, L139 que son 
sustituidos en Ce-FAR-7 por los residuos L75, Y85, L129, I136. Los residuos F21, L33, F37 que corresponden al bolsillo P2 también se encuentran conservados. Además, en este segundo bolsillo hidrofóbico, L25, V63 y L66 son sustituidos por los residuos de la misma naturaleza I25, L64, V67 en Ce-FAR-7.

En otros casos existe una sustitución por residuos de diferente naturaleza dentro de la cavidad. Se sustituye un aminoácido polar por uno hidrofóbico como S88 por L89, y los residuos positivamente cargados $\mathrm{K} 96$ y $\mathrm{R} 93$ son sustituidos por un residuo hidrofóbico y uno polar, L97 y T94 respectivamente, en Ce-FAR-7.

Las diferencias en el tamaño y características de la cavidad interna de ambas proteínas podrían estar relacionadas con diferentes funciones biológicas y se traducen a su vez en diferencias en la unión a ligandos como se discute en el capítulo 6 de análisis de unión a ligando.

\subsubsection{Sitios de fosforilación}

Se ha mencionado que todas las FAR presentan una secuencia consenso de fosforilación para caseína quinasa tipo Il cuya posición se encuentra muy conservada, a pesar del alto grado de diversidad de secuencia que presentan estas proteínas. No existe evidencia que indique que este sitio esté fosforilado naturalmente, pero experimentos in vitro con Ce-FAR-7 muestran que mediante la fosforilación artificial se

produce una alteración en la unión de ligando ${ }^{50}$. En este estudio muestran que la fosforilación mediada por la caseína quinasa tipo II inestabiliza la proteína Sin embargo, simulan la fosforilación por sustitución de la treonina 26 por ácido aspartico, y esto trae aparejado un aumento en la afinidad de la proteína por retinol.

Tanto en Na-FAR-1 como en Ce-FAR-7 la cadena lateral que resultaría modificada (de S26 y T26 respectivamente) reside en la región lazo entre las hélices $\alpha 3$ y $\alpha 4$ en un extremo de la molécula (figura 5.20). 

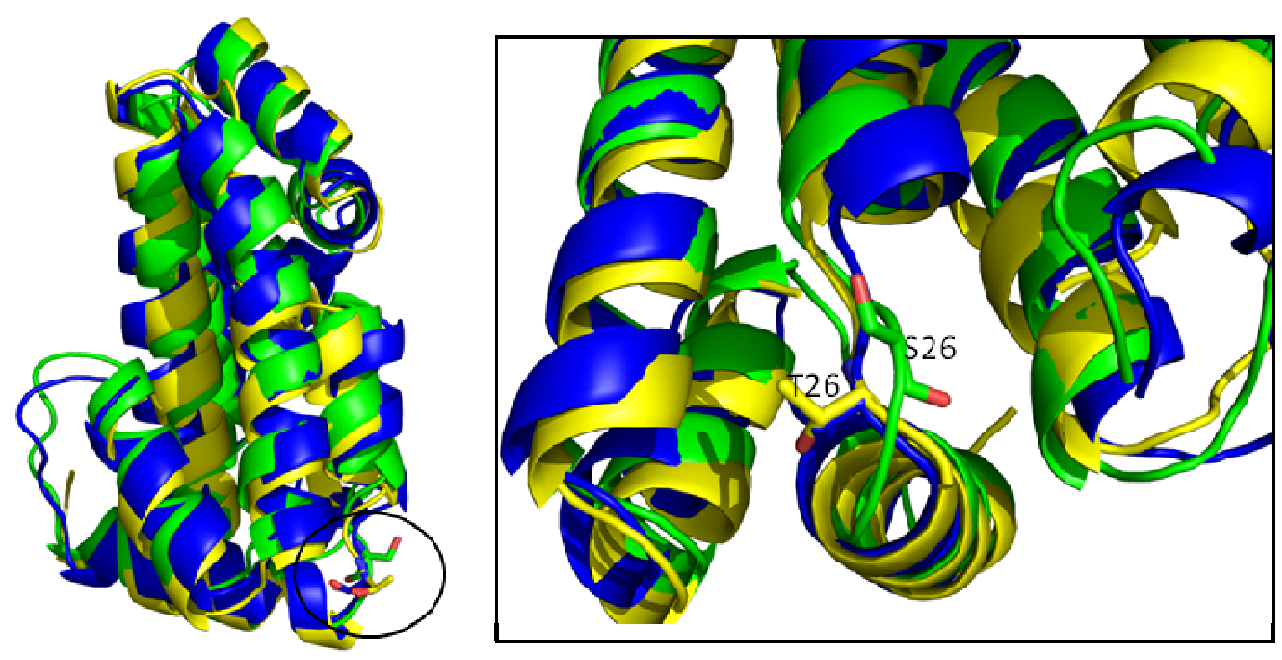

Fig.5.20. Sitio de fosforilación de Na-FAR-1 y Ce-FAR-7. Se esquematizan las estructuras de Ce-FAR-7 (amarillo) y Na-FAR-1 apo (verde) y holo (azul).

Es posible que la fosforilación afecte la unión a ligando a través de un cambio conformacional que modifique el ángulo entre estas hélices y module la apertura de la región portal.

\subsection{Conclusiones}

La estructura tridimensional de Na-FAR-1 en sus formas apo y holo, resuelta por RMN y cristalografía de rayos $\mathrm{X}$ respectivamente, revela la presencia de una cavidad interna que adopta diferentes características dependiendo de la presencia o ausencia del ligando. La cavidad resultante es mucho mayor para holo Na-FAR-1, mientras que el arreglo helicoidal y los ángulos que forman no se modifican drásticamente en comparación con la forma apo. La región del lazo 4 de alta movilidad podría funcionar a modo de portal para la salida y entrada de ligandos presentando una disposición más cerrada en la forma apo.

Parece existir un elevado grado de conservación en las estructuras de miembros distantes de la familia FAR de proteínas. Pese a las diferencias existentes en la 
secuencia de las dos proteínas con estructura resuelta en la actualidad, Ce-FAR-7 y NaFAR-1 presentan el mismo patrón de plegamiento.

Sin embargo, también exhiben diferencias en cuanto a longitud de ciertas hélices, y orientación entre hélices que determinan diferencias en la cavidad hidrofóbica de las proteínas. Las diferencias podrían estar asociadas a los distintos roles que podrían cumplir estas proteínas, que no sólo provienen de organismos diferentes, un nematodo de vida libre y un nematodo parásito intestinal, sino que también presentarían diferencias en cuanto a la su localización (Ce-FAR-7 no posee señal de secreción). 


\section{Análisis de interacción con ligandos}

Existen muchos aspectos de la interacción proteína-ligando que pueden ser caracterizados, entre estos: la identidad de él o los ligandos unidos, la afinidad y la especificidad de unión, identificar cuáles son los residuos que intervienen y que definen los sitios de unión, así como evidenciar los cambios estructurales producidos a raíz de la interacción.

En este trabajo se analizó la interacción de Na-FAR-1 con ligandos mediante espectroscopía de fluorescencia y de resonancia magnética nuclear, con la finalidad de estimar la estequiometria de los complejos formados y las constantes de disociación correspondientes, así como también los cambios estructurales producidos. Asimismo, se analizó la preferencia por ácidos grasos de distinta longitud de cadena mediante ensayos de desplazamiento. Por último, se analizó la partición de equilibrio con membranas artificiales como medida relativa de la afinidad por ligandos. A su vez, se evidenció la variedad de ligandos que es capaz unir Na-FAR-1 en el entorno de E. coli, mediante cromatografía en capa fina y gaseosa.

\subsection{Caracterización de la composición lipídica}

Como se ha mencionado previamente, ciertas proteínas FAR han sido caracterizadas desde el punto de vista bioquímico y se ha encontrado que son capaces de unir ácidos grasos y retinol. Sin embargo, no se ha establecido previamente con certeza si su especificidad se limita a ligandos de esa naturaleza o son capaces de unir otros tipos de lípidos. Como estrategia para comenzar a estudiar las preferencias de unión a ligandos de Na-FAR-1, se realizó una extracción de la fracción lipídica unida a la proteína recombinante purificada desde E. coli y su posterior análisis. Teniendo en cuenta que el citoplasma bacteriano no es el ambiente natural de la proteína esta estrategia sirve como una primera aproximación para determinar la identidad de los componentes lipídicos unidos a Na-FAR-1 en su ambiente natural. 


\subsubsection{Extracción de lípidos de rNa-FAR-1}

Se realizó una extracción de lípidos basada en su solubilidad en solventes orgánicos y la desnaturalización de la proteína. En primer lugar, los lípidos se solubilizaron en una mezcla de solventes. Luego, mediante la utilización de un sistema de partición y posterior centrifugación, se separaron de otros compuestos.

Siguiendo los protocolos descriptos en el capítulo de Producción de proteína, se purificó la proteína recombinante desde E. coli. Se realizaron los pasos de cromatografía de afinidad y cromatografía de exclusión molecular, pero sin incluir en este caso la deslipidización por HPLC. Se extrajeron lípidos de 15mg de proteína NaFAR-1, no deslipidizada por HPLC, y se realizó también la extracción a proteína apo (deslipidizada por HPLC) como control. Asimismo, se realizó la extracción de $3 \mathrm{ml}$ de cultivo de la cepa de expresión E. coli BL21 ( $\lambda \mathrm{DE} 3$ ), lisado por sonicado. Como control de contaminantes lipídicos en las soluciones empleadas, se extrajo igual volumen de buffer en paralelo.

Para la extracción de lípidos de Na-FAR-1 se siguió la metodología descripta por Folch ${ }^{131}$ y modificada por Obal y col ${ }^{32}$. Cada muestra se mezcló con $15 \mathrm{ml}$ de solución $\mathrm{CHCl}_{3}: \mathrm{CH}_{3} \mathrm{OH}$ (2:1), se agitó en vórtex durante 15 min en baño de hielo y se filtró. El filtrado se lavó con $250 \mu \mathrm{l}$ de solución acuosa de $\mathrm{NaCl} 2.9 \%$ y se agitó. El sistema de solventes resultante (metanol/cloroformo/agua con $\mathrm{NaCl}$ ) asegura una buena extracción debido a que es lo suficientemente apolar como para que los lípidos se disuelvan en el mismo y, al mismo tiempo, tan polar y con la fuerza iónica necesaria como para vencer las fuertes fuerzas de asociación entre los lípidos y otros constituyentes celulares como las proteínas.

Se logró la separación de fases por centrifugación a 1000 rpm durante $10 \mathrm{~min}$. La fase acuosa se descartó y la fase orgánica inferior que contiene los lípidos se secó bajo corriente de $\mathrm{N}_{2}$ gaseoso. La fracción lipídica se redisolvió en $\mathrm{CHCl}_{3}$ y se almacenó a $20^{\circ} \mathrm{C}$ bajo atmósfera de $\mathrm{N}_{2}$ hasta su análisis. 


\subsubsection{Cromatografía en capa fina}

La separación de los componentes lipídicos unidos a Na-FAR-1 se realizó mediante cromatografía en capa fina (TLC, del inglés thin layer chromatography) que se basa en la propiedad física de adsorción. Los lípidos se aplican sobre un gel de sílice que forma una fina capa (fase estacionaria) sobre un soporte sólido. La mezcla de solventes (fase móvil) se desplaza sobre la sílica por capilaridad, arrastrando los lípidos. Los grupos polares de los lípidos interactúan con la fase estacionaria y favorecen su retención mientras que las cadenas hidrofóbicas favorecen su solubilización y arrastre por la fase móvil. De esta manera, empleando una composición adecuada en la fase móvil, se logra una separación de los lípidos que se habrán desplazado de forma diferencial respondiendo a su partición entre ambas fases.

Las muestras lipídicas obtenidas de lisados de E. coli, holo Na-FAR-1, los controles apo Na-FAR-1, y de solventes y los estándares se sembraron manualmente con jeringa Hamilton en placas de TLC de Silica Gel, Si250 (J.T.Baker) de $20 \times 20 \mathrm{~cm}$ previamente activadas a $100^{\circ} \mathrm{C}$ por $30 \mathrm{~min}$. Se emplearon en la corrida condiciones que permitieron separar las diferentes clases de lípidos, siguiendo la metodología y sistema de solventes descripto por Obal y col. ${ }^{32}$. Para la resolución de lípidos polares (PL) se empleó una fase móvil con la siguiente composición: acetato de metilo / isopropanol / cloroformo / metanol / 0.25\% KCl (25:25:25:10:9, v/v/v/v/v). Para la separación de lípidos neutros (NL), el sistema de solventes empleado fue: hexano /dietil-éter / ácido acético (80:20:1, v/v/v). Las bandas de lípidos se visualizaron por pulverización de las placas con $\mathrm{CuSO}_{4} 8 \%(\mathrm{~m} / \mathrm{v})$ en solución acuosa de $\mathrm{H}_{3} \mathrm{PO}_{4} 10 \%(\mathrm{v} / \mathrm{v})$ y calentamiento a $140^{\circ} \mathrm{C}$. La identificación de los componentes lipídicos se llevó a cabo mediante la comparación con patrones sembrados en la misma placa. Todo el procedimiento se realizó por duplicado. Las placas se muestran en la figura 6.1.

En la corrida se incluyeron los siguientes controles: Extracción en blanco que sirve para verificar la ausencia de lípidos en los reactivos y solventes empleados (Ctl); muestra de una extracción realizada a proteína deslipidizada por HPLC que sirve a su vez para evidenciar el desempeño de este paso de purificación (Apo); muestra de una extracción realizada al cultivo de $E$. coli dónde quedará evidenciado el entorno lipídico 
en contacto con la proteína (Ec). Asimismo se agregó a modo de estándar una muestra de homogenato de hígado de rata cuya composición es conocida (Est).
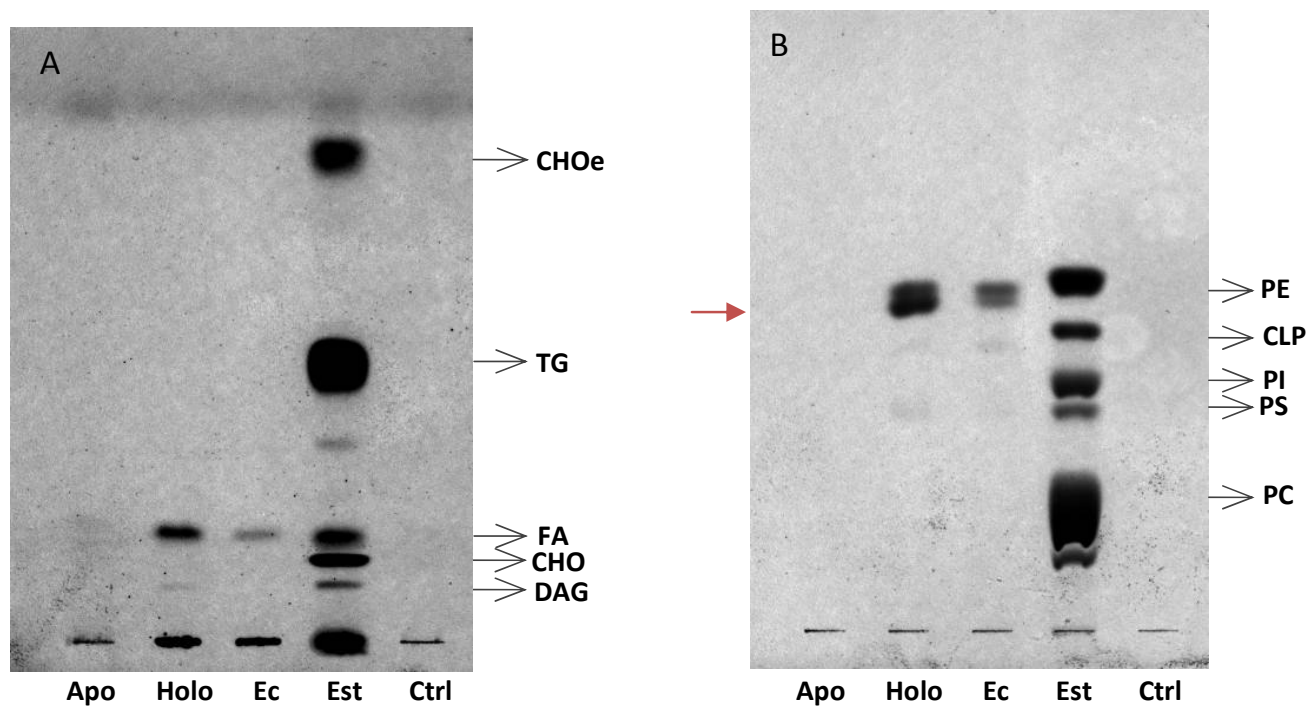

Fig. 6.1. Fracciones lipídicas unidas a Na-FAR-1 evidenciadas por TLC. Las fracciones lipídicas se analizaron mediante TLC en condiciones optimizadas para resolver por separado clases de lípidos neutros (A) y polares (B). Los estándares y las muestras (aproximadamente entre 2 y $10 \mathrm{mg}$ ) se sembraron manualmente en placas de TLC. Apo: extracción de NaFAR purificada por HPLC; Holo: extracción de NaFAR sin HPLC; Ec: extracción de cultivo de E.coli; Est: estándar de homogenato de hígado de rata; Ctrl: extracción sin muestra. DAG: diacilglicéridos; CHO: colesterol; FA: ácidos grasos; TG: triglicéridos; $\mathrm{CHOe}$ : ésteres de colesterol; PC: fosfatidilcolina; PS: fosfatidilserina; PI: fosfatidilinositol; CLP: cardiolipina; PE: fosfatidiletanolamina.

En la placa correspondiente a lípidos neutros (figura 6.1. panel A), para la muestra extraída de la proteína (Holo) se observa la presencia de una gran proporción de ácidos grasos y, en menor medida, de diacilglicéridos. Esto implica que Na-FAR-1 es capaz de unir ácidos grasos y diacilglicéridos.

En cuanto a los lípidos neutros extraídos de E. coli, se observa únicamente la presencia de ácidos grasos. No se observa la banda correspondiente a los diacilglicéridos, lo cuál podría deberse a que la proteína presente una cierta preferencia por este tipo de ligandos y sea capaz de concentrarlos.

En la placa dónde se resolvieron los lípidos polares (figura 6. 1. panel B), se observa que en la fracción lipídica unida a Na-FAR-1 está presente fundamentalmente 
fosfatidiletanolamina, y en menor medida fosfatidilserina y cardiolopina. En consecuencia, Na-FAR-1 es capaz de unir distintas clases de fosfolípidos.

El entorno celular de lípidos de E. coli parece contener las mismas clases de compuestos hidrofóbicos aunque en una proporción diferente. En este caso, si se compara la intensidad de las bandas de fosfatidilserina y cardiolipina, la proporción de estos lípidos se invierte con respecto a la proteína, donde la de fosfatidilserina es más intensa mientras que la de cardiolipina es menor. Si bien la diferencia es sutil, la proteína podría presentar una preferencia por el primer ligando frente al segundo.

Las clases lipídicas presentes en $E$. coli han sido extensamente estudiadas por muchos autores quienes han determinado que sus constituyentes principales son fosfatidiletanolamina, fosfatidilglicerol y cardiolipina ${ }^{132}$. Teniendo esto en cuenta, la banda presente en las calles de extracto de proteína holo y de $E$. coli, cuya movilidad no se corresponde con ningún marcador del estándar (señalada con una flecha roja) podría corresponder a fosfatidilglicerol.

No se observa la presencia de bandas en las calles pertenecientes a los controles tanto de deslipidización (extracción de proteína apo) como el de solventes. El control de apo Na-FAR-1 sirve para constatar la correcta remoción de los ligandos copurificantes, que resulta fundamental para su análisis biofísico y estudio por RMN.

Según se desprende de los resultados mostrados en la figura 6.1, la fracción lipídica unida a Na-FAR-1 exhibe un contenido de lípidos heterogéneo. Dado que estudios previos han demostrado que otros miembros de la familia de las FAR unen retinol, ácidos grasos y sus análogos fluorescentes, el presente análisis revela que Na-FAR-1 une estos compuestos pero también una amplia variedad de clases lipídicas. Une lípidos neutros como ácidos grasos y DAG y lípidos polares como PE, PS, PG y CLP.

Esta proteína FAR es capaz de unir todos los lípidos presentes en el ambiente celular bacteriano. Si bien la unión de ácidos grasos, PE, PG es notoria, ya que son abundantes en el entorno. Podría inferirse que tiene cierta preferencia por DAG y PS cuyas bandas son casi imperceptibles en $E$. coli. 


\subsubsection{Saponificación y esterificación de ácidos grasos}

Muchos lípidos simples y complejos son muy polares o de muy alto peso molecular como para ser sometidos a técnicas cromatográficas como la cromatografía gaseosa. Además, en ciertos casos es necesario hidrolizarlos para analizar sus constituyentes. Los ácidos grasos componentes de los lípidos acilados pueden ser obtenidos por saponificación, proceso durante el cual se produce la hidrólisis de los enlaces éster que los unen.

Los lípidos extraídos se hidrolizaron en una solución de $\mathrm{KOH} 10 \%$ p/v en etanol bajo atmósfera nitrogenada, a $80^{\circ} \mathrm{C}$ durante $45 \mathrm{~min}$. Se realizó una partición de la mezcla mediante el agregado de éter de petróleo para remover la fracción insaponificable. Los ácidos grasos libres se protonaron con el agregado de $\mathrm{HCl}$ fumante y se solubilizaron en éter de petróleo luego de una segunda partición.

Para obtener los ésteres metílicos derivados de los ácidos grasos, se agregaron $2 \mathrm{ml}$ de $\mathrm{BF}_{3} 10 \%$ en metanol, y se incubaron en atmósfera nitrogenada a $64^{\circ} \mathrm{C}$ durante $1 \mathrm{~h}$. Los ésteres metílicos se obtuvieron por derivatización con $\mathrm{CH}_{3} \mathrm{OH}-\mathrm{BF}_{3}$ de acuerdo al método descripto ${ }^{133}$.

\subsubsection{Cromatografía gaseosa}

La composición de ácidos grasos de la fracción lipídica se analizó mediante cromatografía gaseosa (GC) de sus ésteres metílicos. Dicha técnica cromatográfica se basa en el principio de partición entre dos fases de diferente hidrofobicidad, una móvil y una estacionaria. Un líquido de alto punto de ebullición, empaquetado en una columna capilar sobre un soporte sólido, forma la fase estacionaria y los lípidos son arrastrados por un flujo gaseoso que constituye la fase móvil.

Los ésteres metílicos se obtuvieron por derivatización con $\mathrm{CH}_{3} \mathrm{OH}-\mathrm{BF}_{3}$ de acuerdo al método descripto por ${ }^{133}$. Para la corrida se utilizó un equipo HP 6890 (Hewlett Packard). Los picos individuales de los ésteres metílicos de ácidos grasos se identificaron por comparación de sus tiempos de retención con los de estándares.

Los cromatogramas obtenidos se muestran en las figuras 6.2. y 6.3. 


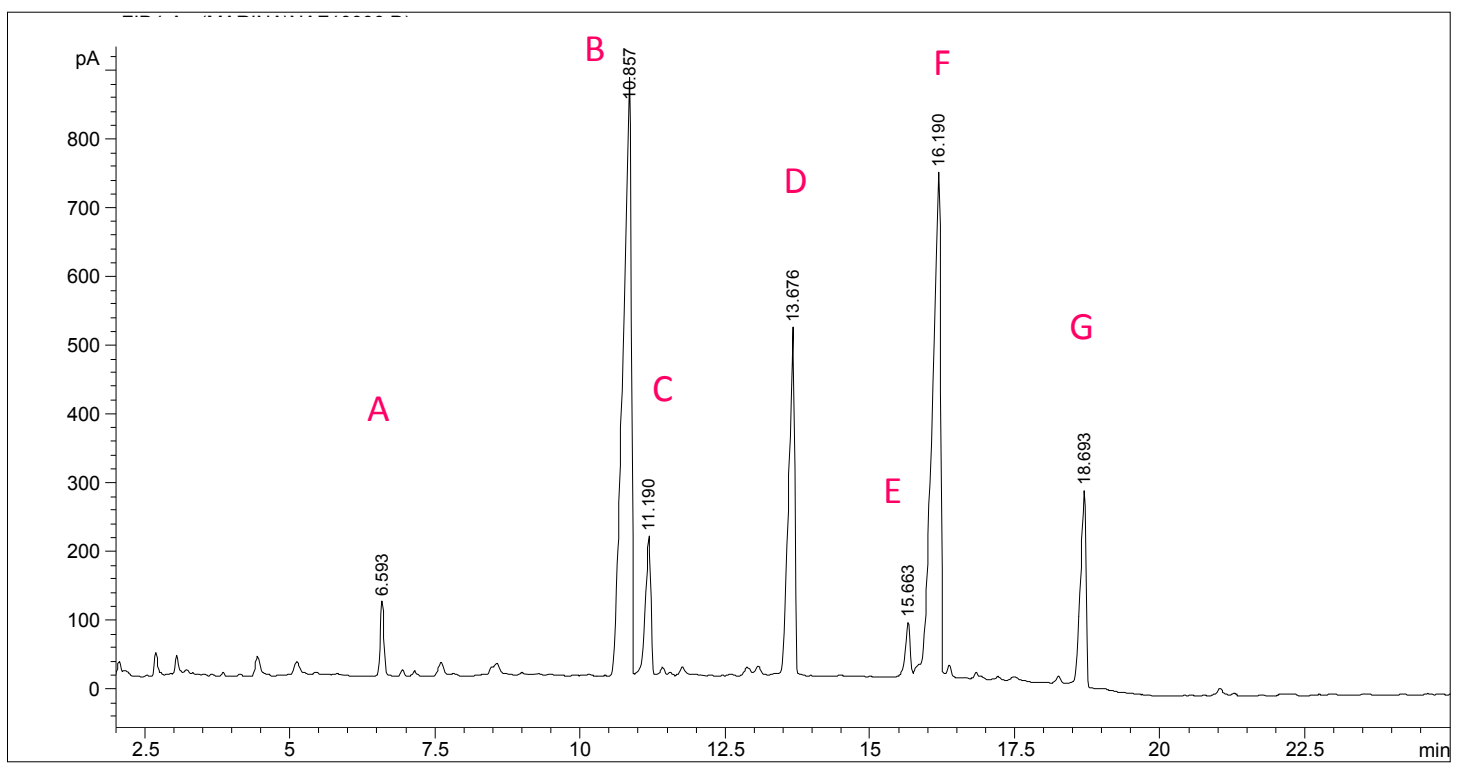

Fig. 6.2. Cromatograma de los ácidos grasos unidos a Na-FAR-1 analizados por GC. Cromatogramas resultantes de los FAs asociados a Na-FAR-1 recombinante. Los ácidos grasos detectados fueron: $A$, ácido mirístico (14:0); B, palmítico (16:0); C, hexadecenoico (16:1); D, metilenhexadecanoico (17:1); $E$, esteárico (18:0); F, octadecenoico (18:1); G, $\beta$-hidroximirístico.

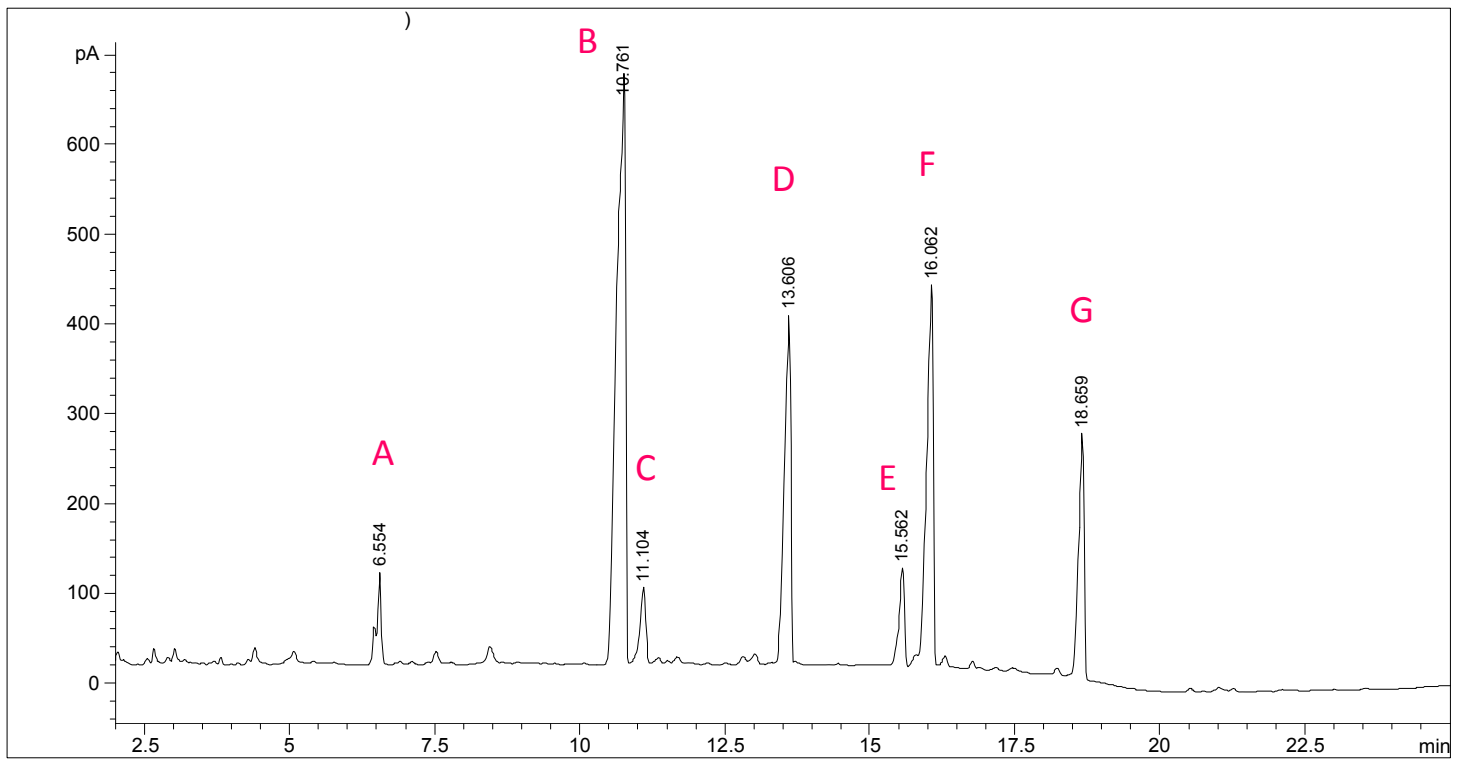

Fig. 6.3. Cromatograma de los ácidos grasos de cultivo bacteriano analizados por GC. Cromatograma resultante de los FAs extraídos cultivos de $E$. coli. Los ácidos grasos detectados fueron: $A$, ácido mirístico (14:0); B, palmítico (16:0); C, hexadecenoico (16:1); D, metilenhexadecanoico (17:1); E, esteárico (18:0); $\mathrm{F}$, octadecenoico (18:1); G, $\beta$-hidroximirístico. 
Los ácidos grasos detectados fueron: ácido mirístico (14:0), ácido palmítico (16:0), ácido hexadecenoico (16:1), ácido metilenhexadecanoico (17:1), ácido esteárico (18:0), ácido octadecenoico (18:1), ácido $\beta$-hidroximirístico.

Los picos individuales de los ésteres metílicos de ácidos grasos se identificaron por comparación de sus tiempos de retención con los de estándares. Los FAs, metilenhexadecanoico (17:1) y $\beta$-hidroximirístico que no estaban presentes entre los estándares se identificaron por comparación con la bibliografía ${ }^{134}$. En el trabajo citado se describe en E. coli, la presencia de los ácidos mirístico (14:0), palmítico (16:0), hexadecenoico (16:1), metilenhexadecanoico (17:1), octadecenoico (18:1) y $\beta$ hidroximirístico. La presencia y proporción de FAs depende de la cepa bacteriana, el medio de cultivo y la temperatura, pero dado que las condiciones empleadas en el presente trabajo son muy similares a las descriptas en literatura, los resultados están en concordancia.

Mediante el análisis de los FAs unidos a la proteína se desprende que los ácidos grasos saturados presentan una abundancia relativa del $57 \%$ mientras que el $43 \%$ restante comprendería FAs insaturados (tabla 6.1 y figura 6.4). El ácido graso saturado 16:0 resultó ser el componente mayoritario.

\begin{tabular}{lll}
\cline { 2 - 3 } & \multicolumn{2}{l}{ Abundancia relativa (\%) } \\
\hline Ácido graso & Na-FAR-1 & E. coli \\
\hline $14: 0$ & $2.75 \pm 0.88$ & $2.52 \pm 0.04$ \\
$16: 0$ & $37.82 \pm 1.38$ & $39.9 \pm 1.78$ \\
$16: 1$ & $4.70 \pm 0.67$ & $3.61 \pm 0.07$ \\
$17: 1$ & $14.47 \pm 0.50$ & $17.39 \pm 0.97$ \\
$18: 0$ & $8.82 \pm 6.60$ & $4.26 \pm 0.27$ \\
$18: 1$ & $24.11 \pm 7.55$ & $22.6 \pm 1.62$ \\
$\beta-\mathrm{OH}$ & $7.33 \pm 0.14$ & $9.72 \pm 0.51$ \\
\hline
\end{tabular}

Tabla 6.1. Abundancia relativa de ácidos grasos. 


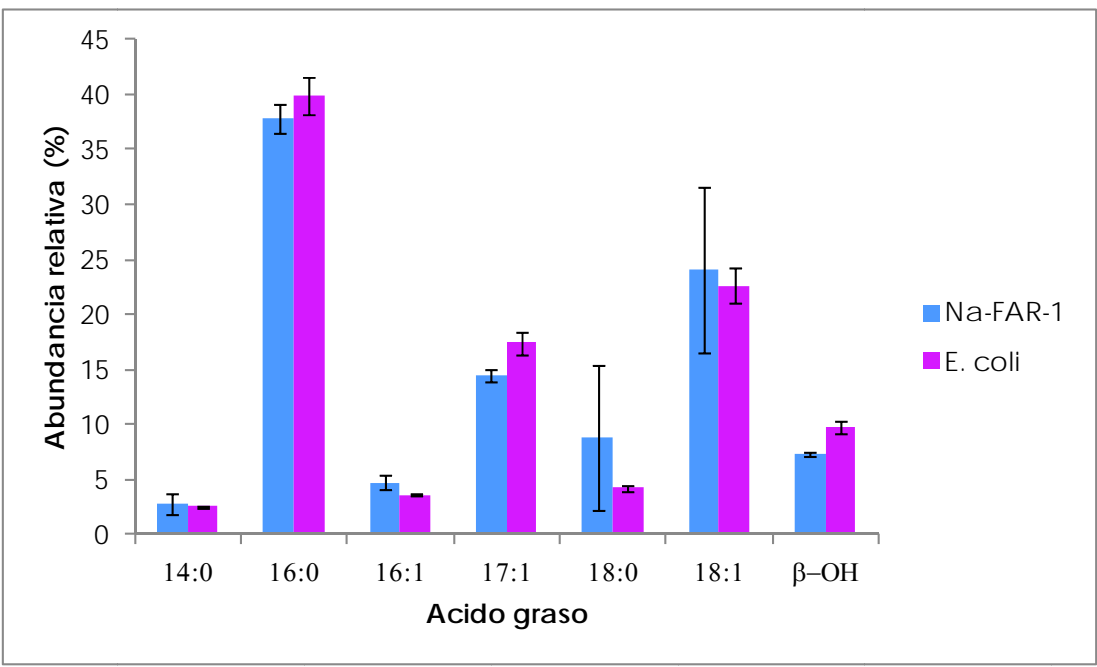

Fig. 6.4. Abundancia relativa de ácidos grasos unidos a Na-FAR-1 detectados por GC. Análisis por GC de FAs asociados a Na-FAR-1 recombinante (azul) y extraídos de E. coli (violeta). Na-FAR-1 presenta una composición de ácidos grasos similar a la del entorno. Se muestra el promedio de dos extracciones independientes \pm SD.

La composición de FAs presentes en Na-FAR-1 y los derivados de E. coli mostraron alta similitud. Esta correlación implica que Na-FAR-1 es capaz de unir los lípidos cuya composición en ácidos grasos es semejante a la presente en el ambiente bacteriano, pero no da una idea acerca de cómo se unen (residuos involucrados en la interacción), cuál es la especificidad de unión o la afinidad con que se forman los complejos. Para abordar estas cuestiones se realizaron estudios por fluorescencia y RMN.

\subsection{Análisis de interacción con ligandos por RMN}

La interacción de un ligando con una proteína tiene como resultado la formación de un complejo que está en equilibrio con las formas libres de ambas moléculas:

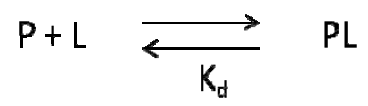

donde $\mathrm{P}$ se refiere a la proteína, $\mathrm{L}$ al ligando y $\mathrm{PL}$ al complejo que forman.

La afinidad provee una medida de la fuerza con que se establece la interacción y puede ser representada mediante la constante de disociación $\mathrm{K}_{\mathrm{d}}$ del complejo, definida como: 


$$
K d=\frac{[P][L]}{[P L]}
$$

El que se describe es el caso de un sistema simple, donde una proteína une un único ligando, pero existen sistemas más complejos dónde la proteína une múltiples ligandos y entran en juego más equilibrios con sus respectivas constantes.

Con la formación de un complejo PL se produce la estabilización de conformaciones diferentes a las que se encuentran para las estructuras más abundantes de ambas especies P y L libres en solución.

Las diferencias conformacionales entre las especies libres y las del complejo, tienen como resultado un cambio en los parámetros de $\mathrm{RMN}$, como por ejemplo, los desplazamientos químicos, los parámetros de relajación ( $T_{1}, T_{2}$ y NOEs), los parámetros dinámicos y los coeficientes de difusión. En consecuencia, la interacción proteínaligando puede estudiarse mediante diferentes experimentos que evalúen estos parámetros ${ }^{135}$. En estos experimentos se distinguen dos estrategias diferentes, se pueden observar cambios producidos en señales del ligando o en señales de la proteína.

El análisis de los desplazamientos químicos permite evaluar la afinidad de un ligando por la proteína debido a que la naturaleza dinámica del proceso de unión afecta la apariencia de los espectros. Se puede establecer si la interacción corresponde a un intercambio lento o rápido en la escala de tiempo de RMN y evaluar de este modo la constante de afinidad para la formación del complejo (figura 6.5).

La ecuación 6.1 se puede expresar de forma alternativa, con $\mathrm{Kd}$ en términos de las velocidades de asociación $\left(\mathrm{k}_{+1}\right)$ y disociación $\left(\mathrm{k}_{-1}\right)$ del complejo PL:

$$
K d=\frac{[P][L]}{[P L]}=\frac{K_{-1}}{K_{+1}}
$$

Si el proceso de disociación del complejo es lento ( $k_{-1}$ es baja) en comparación con la diferencia de desplazamientos químicos entre los dos estados (en unidades de frecuencia), se observaran dos conjuntos de resonancias para la proteína, correspondientes a la conformación libre y a la conformación en el complejo. 
Esta es la situación de intercambio lento característica de una alta afinidad por el ligando con una constante de disociación submicromolar $\left(\mathrm{K}_{\mathrm{d}}<\mu \mathrm{M}\right)$.

En una situación de intercambio rápido, donde la afinidad por el ligando es baja, el complejo se forma y disocia con mayor rapidez que la escala de tiempo de los desplazamientos químicos en $\mathrm{RMN}\left(\mathrm{k}_{-1}\right.$ es alta). Es por ello que se observa un único conjunto de señales que resuenan a un promedio pesado de los desplazamientos químicos correspondientes a $\mathrm{P}$ libre y a $\mathrm{P}$ unida. En este caso la constante de disociación del complejo es mayor al orden micromolar $\left(K_{d}>\mu M\right)$.

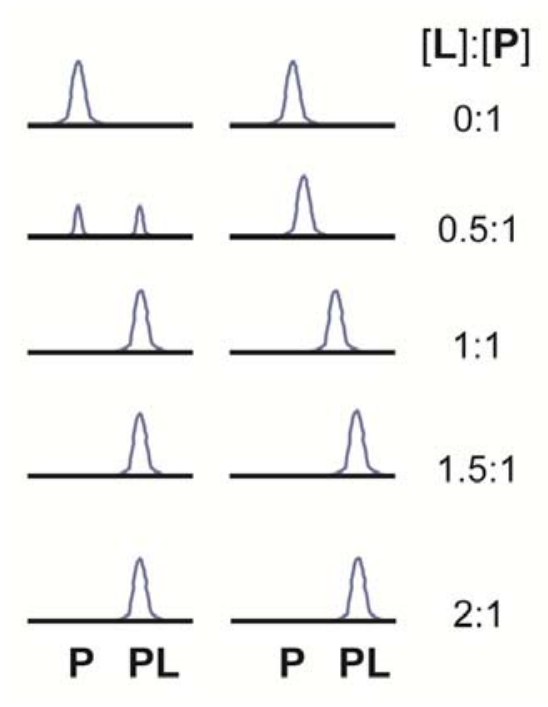

Fig. 6.5. Representación esquemática de los desplazamientos químicos registrados para la proteína en la formación de un complejo PL. A la izquierda se representa un equilibrio de intercambio rápido, a la derecha se representa un equilibrio de intercambio lento. Se parte de $\mathrm{P}$ libre en solución y se van agregando cantidades crecientes de L. En este ejemplo sólo la proteína presenta marca, por lo que no se observan desplazamientos químicos para L.

Cuando $\mathrm{k}_{-1}$ es del mismo orden de magnitud que la diferencia en los desplazamientos químicos en unidades de frecuencia, se produce el fenómeno de coalescencia. En estas situaciones de intercambio intermedio las señales se ensanchan y se pierden, dificultando el análisis de esos complejos mediante RMN.

En general, una unión se considera fuerte cuando $\mathrm{K}_{\mathrm{d}}$ es menor a $10^{-8} \mathrm{M}$ (intercambio lento), moderado entre $10^{-6}$ y $10^{-8} \mathrm{M}$ (intercambio intermedio) y débil cuando $\mathrm{K}_{\mathrm{d}}$ es mayor a $10^{-5} \mathrm{M}$ (intercambio rápido) ${ }^{136}$. 


\subsubsection{Titulación}

El experimento clave para estudiar la afinidad por ligandos a través de los desplazamientos químicos es el espectro ${ }^{15} \mathrm{~N}-\mathrm{HSQC}$. Para caracterizar las propiedades de unión a ligando mediante $\mathrm{RMN}$, se analizaron los cambios en las señales introducidos en espectros ${ }^{15} \mathrm{~N}-\mathrm{HSQC}$ de Na-FAR-1, por el agregado de cantidades crecientes de ligando.

Na-FAR-1 recombinante doblemente marcada $\operatorname{con}{ }^{13} \mathrm{C}-{ }^{15} \mathrm{~N}$ a una concentración de $430 \mu \mathrm{M}$, se tituló por adición secuencial de solución acuosa de oleato de sodio 100 $\mathrm{mM}$ sin $\operatorname{marca}{ }^{137}$ (figura 6.6). Se agregaron 0.5, 1, 2, 3, 4, 5, 6, 7, 8, 9 y 10 equivalentes de oleato de sodio. La titulación se llevó a cabo hasta lograr un exceso de ligando, observándose la precipitación de oleato de sodio a una relación proteína:ligando de 1:10. Luego de cada agregado, se incubó durante 15 minutos y se registraron los espectros ${ }^{15} \mathrm{~N}$-HSQC. Asimismo, se realizaron a modo de control espectros de difusión $\mathrm{T}_{2}$ a fin de evaluar posibles cambios en las propiedades de relajación, para cada punto de la titulación.

Asimismo se registraron experimentos de triple resonancia en distintos puntos de la titulación (a una relación proteína ligando 1:4 y 1:7) para poder asignar los picos desplazados y confirmar su identidad a lo largo de la titulación.

En la figura 6.6.A se muestran los espectros correspondientes a distintos puntos de la titulación superpuestos. En los espectros se observa que los cambios en los desplazamientos químicos no se reducen a zonas específicas que podrían estar en contacto con el ligando, si no que se producen a lo largo de toda la proteína. Este comportamiento estaría indicando la presencia de cambios globales en la estructura de la proteína al formar el complejo.

Algunas zonas ampliadas del espectro se muestran en las figuras 6.6.B y C para evidenciar las diferencias observadas a lo largo de la titulación. G78, por ejemplo, se desplaza a frecuencias mayores mientras que A46 lo hace hacia frecuencias menores, observándose un ensanchamiento del pico a partir del punto 1:4 de la titulación. 


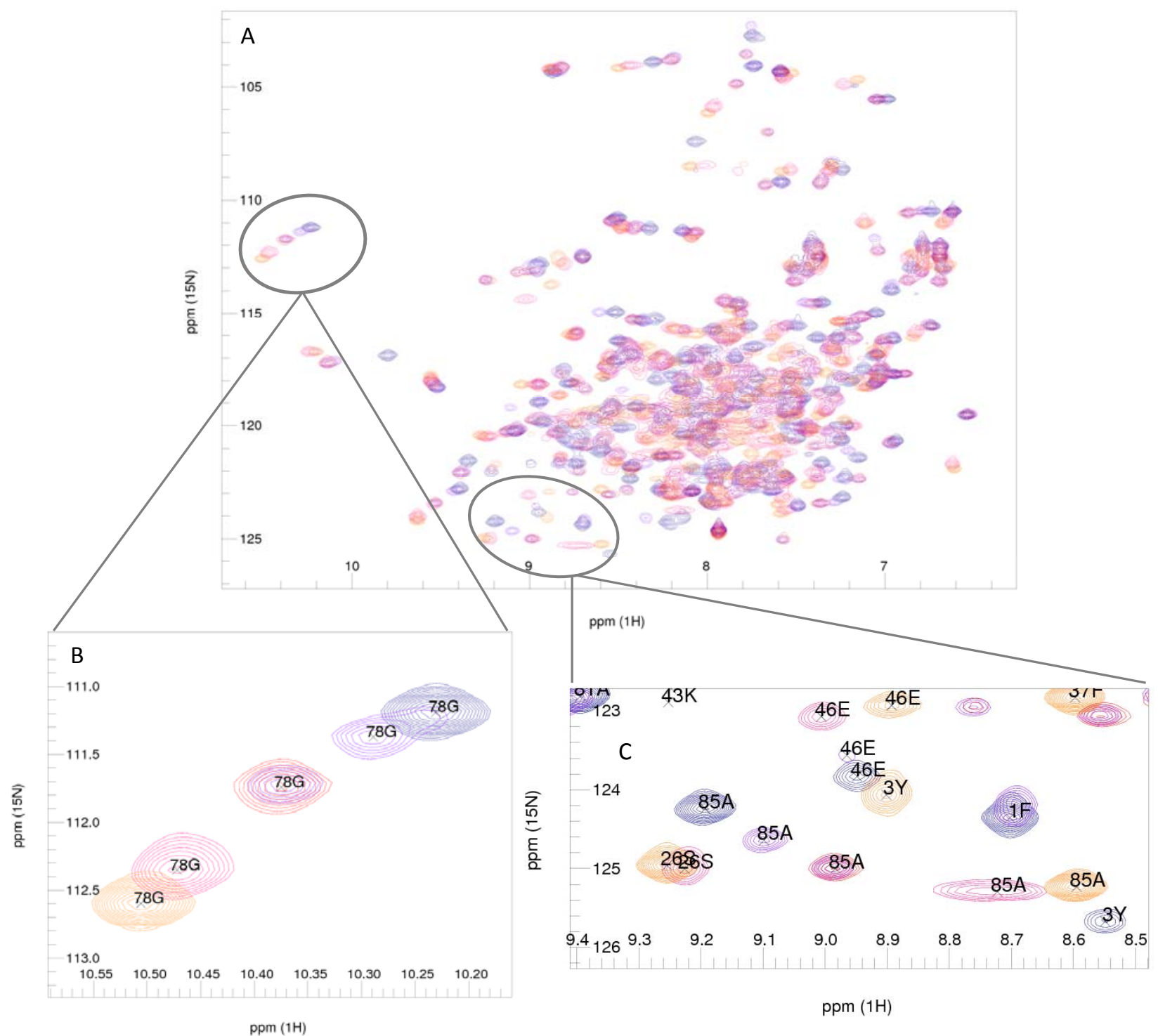

Fig. 6.6. (A) Espectros ${ }^{15} \mathrm{~N}$ HSQC secuenciales de Na-FAR-1 titulada con oleato de sodio. El espectro de la proteína apo se muestra en azul, relación 1:1 proteína ligando en violeta, 1:2 en rojo, 1:4 en rosa y 1:7 en naranja. Los picos de intercambio lento aparecen al inicio de la titulación, seguidos de un comportamiento de intercambio rápido desde una relación 1:4 de proteína:ligando (rosa). La titulación se finalizó por aparición de ligando precipitado a una relación proteína:ligando de 1:10. (B) (C) Regiones ampliadas del espectro ${ }^{1} \mathrm{H}-{ }^{15} \mathrm{~N}$ HSQC para los pasos de titulación de Na-FAR-1 con residuos experimentando distintos comportamientos.

La titulación se comenzó por adición de 0.5 equivalentes de ligando. En este punto se observaron dos picos provenientes de cada grupo amida desplazado, uno correspondiente a la forma apo de Na-FAR-1 permaneció en la posición original, y otro pico con un desplazamiento químico diferente, resultante de la conformación de la proteína en presencia de una molécula de ligando. 
En puntos subsiguientes de la titulación se observaron más cambios de desplazamiento químico, en cada caso resultando en la aparición de un nuevo pico sumada a la disminución de la intensidad del pico original. El proceso de unión a ligando exhibió por ende, un comportamiento de intercambio lento para la adición de $0.5,1,2$ y 3 equivalentes de oleato, lo que sugeriría que la proteína une tres ligandos con alta afinidad.

Este comportamiento fue sucedido por un proceso de intercambio rápido, dónde sólo un pico se observó por cada grupo amida desde una relación proteína:ligando 1:4 hasta una relación 1:10. En el punto de la titulación 1:4 proteína:ligando se observó un ensanchamiento de gran cantidad de picos indicativo de un comportamiento de intercambio intermedio.

A modo de ejemplo, en la figura 6.7 se muestran los espectros individuales de cada punto de la titulación y en la figura 6.8 superpuestos, para el residuo de glicina en posición 78.

Los resultados sugieren que Na-FAR-1 une hasta cuatro moléculas de oleato de sodio por molécula de proteína, tres de las cuales se unen con alta afinidad (con $K_{d}$ en el orden sub micromolar) y un cuarto ligando se uniría con baja afinidad. Los desplazamientos químicos correspondientes a las cuatro conformaciones de los complejos formados por Na-FAR-1 y a la forma libre de ligando se indican en la figura 6.8 .

A causa del aumento en la complejidad de los espectros producido por el incremento en el número de picos por grupo amida, se produjo un considerable solapamiento de señales en la situación de intercambio lento que dificultó la asignación de los espectros. El ensanchamiento de muchas señales por la transición a un régimen de intercambio intermedio, también dificultó la asignación de los espectros. 

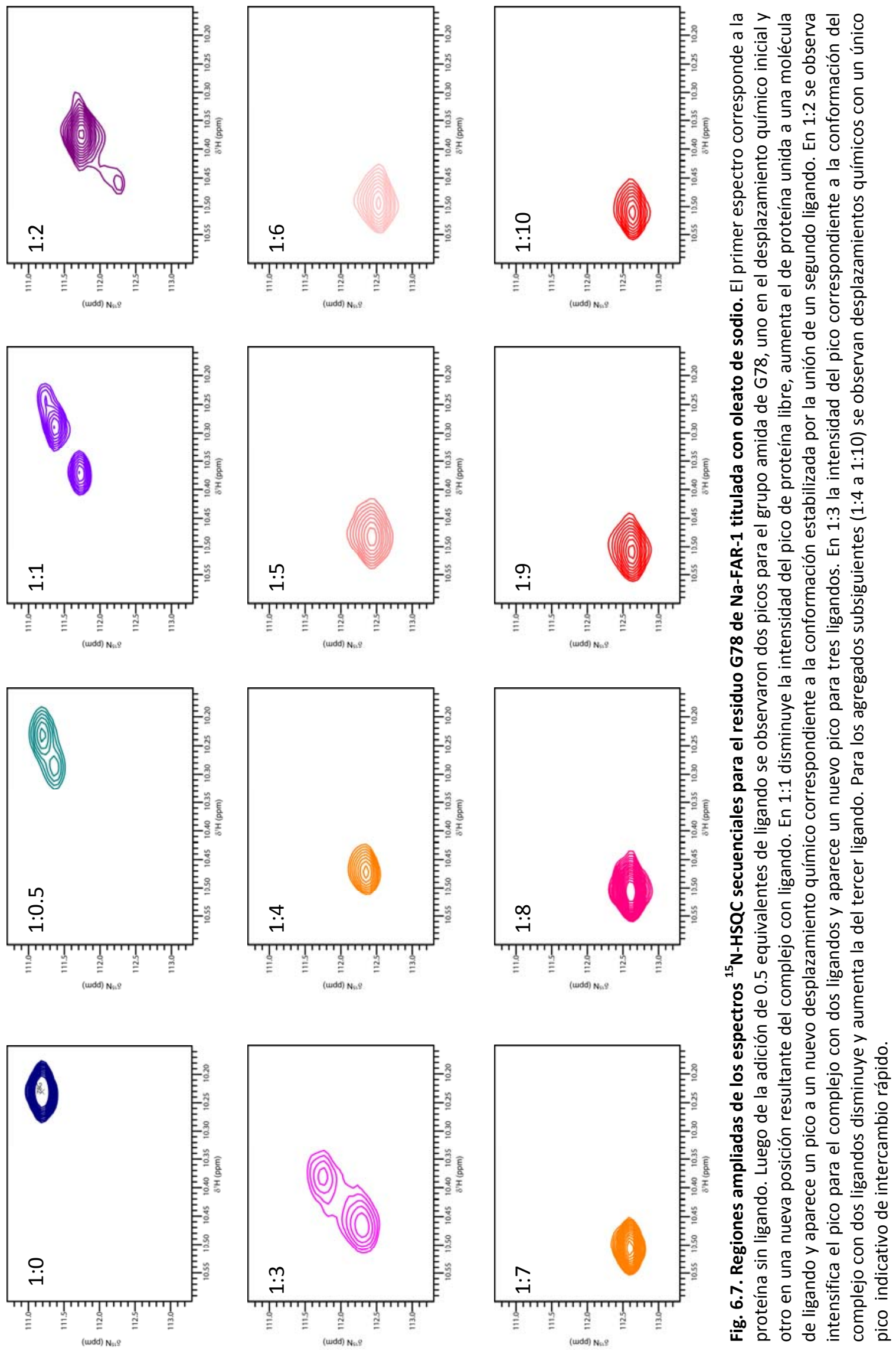


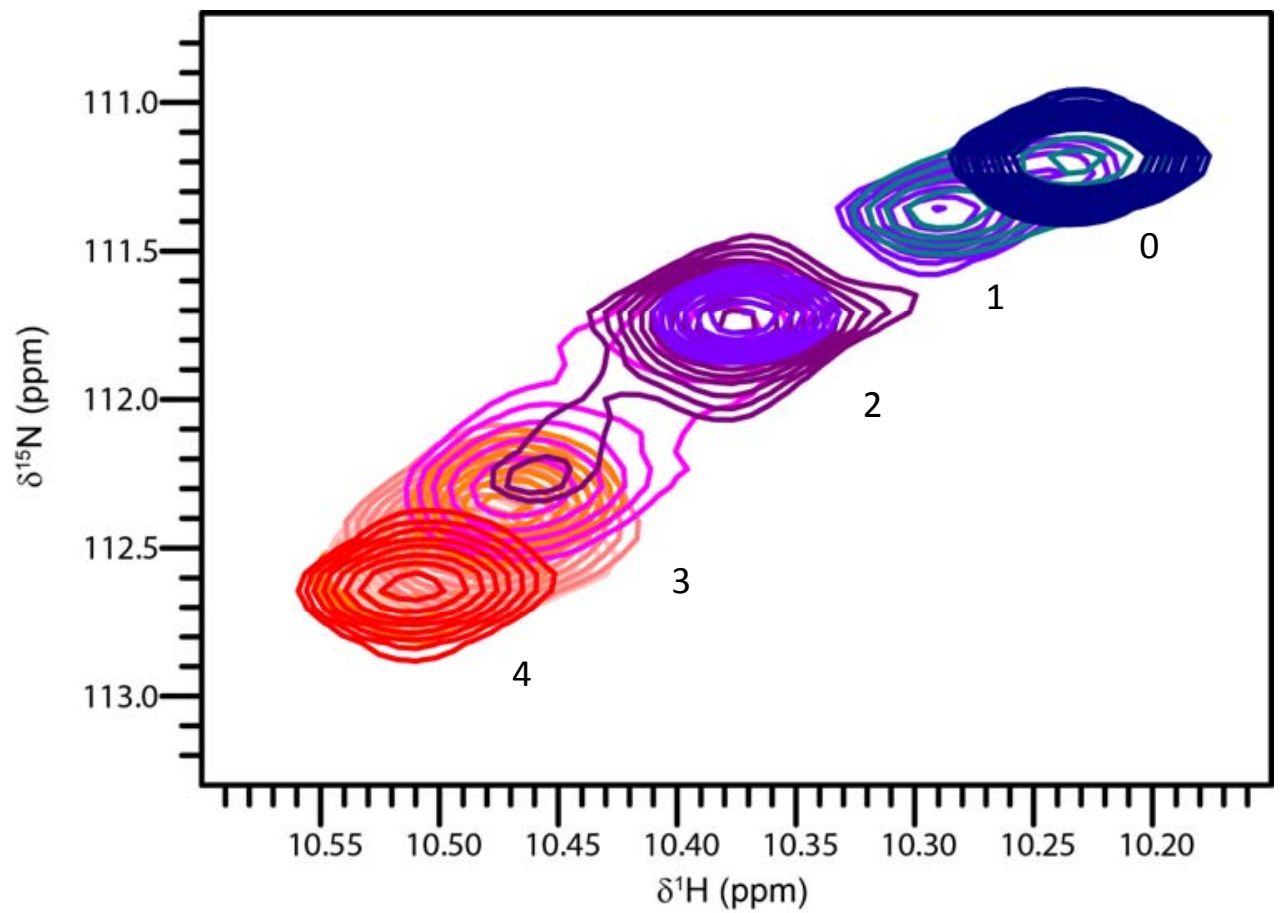

Fig. 6.8. Regiones ampliadas de los espectros ${ }^{15} \mathrm{~N}-\mathrm{HSQC}$ secuenciales para el residuo G78 de Na-FAR-1 titulada con oleato de sodio. Mediante la superposición de los espectros se identifican los desplazamientos químicos correspondientes a la proteína apo (indicada con 0) y los distintos complejos uniendo 1, 2, 3 y hasta 4 moléculas de ligando.

El complejo comportamiento demostrado por Na-FAR-1 en el proceso de unión a ligando, dado tanto por el número de ligandos unidos como por la afinidad de unión a los mismos, sumado a la complejidad adicional de los espectros, resultante de los cambios conformacionales globales en la estructura de la proteína, dificultó el análisis subsiguiente y el ajuste de los datos para la determinación de las constantes de disociación.

Si bien la concentración de oleato de sodio alcanzada durante los ensayos superó el valor estipulado para su concentración micelar crítica $(C M C){ }^{138}$, es importante destacar que las propiedades de relajación longitudinal de Na-FAR-1 no cambiaron a lo largo de la titulación. Esto indicaría que los cambios observados durante la titulación responden a la formación de los complejos y no a interacciones de la proteína con las micelas presentes. 


\subsubsection{Perturbación en los desplazamientos químicos}

La perturbación en los desplazamientos químicos, CSP (del inglés Chemical shift perturbation), se puede emplear para caracterizar el sitio de unión e identificar los residuos involucrados en la interacción con el ligando ${ }^{139}$. CSP se evaluó mediante la ecuación:

$$
\Delta \delta_{N H}=\sqrt{\left(\Delta \delta_{H}^{2}+\alpha \Delta \delta_{N}^{2}\right)}
$$

Con $\delta$ expresado en ppm y el factor de escala $\alpha=0.15$.

Habiéndose asignado la mayoría de los desplazamientos químicos para una relación 1:7 proetína:ligando se calculó el CSP. Para otros puntos de la titulación en los que se observaron multiplicidad de conformaciones o ensanchamiento de señales, la asignación fue insuficiente y no se pudo evaluar la CSP.

Los resultados obtenidos para una relación 1:7 de proteína:ligando se representaron en forma de histograma en la figura 6.9.

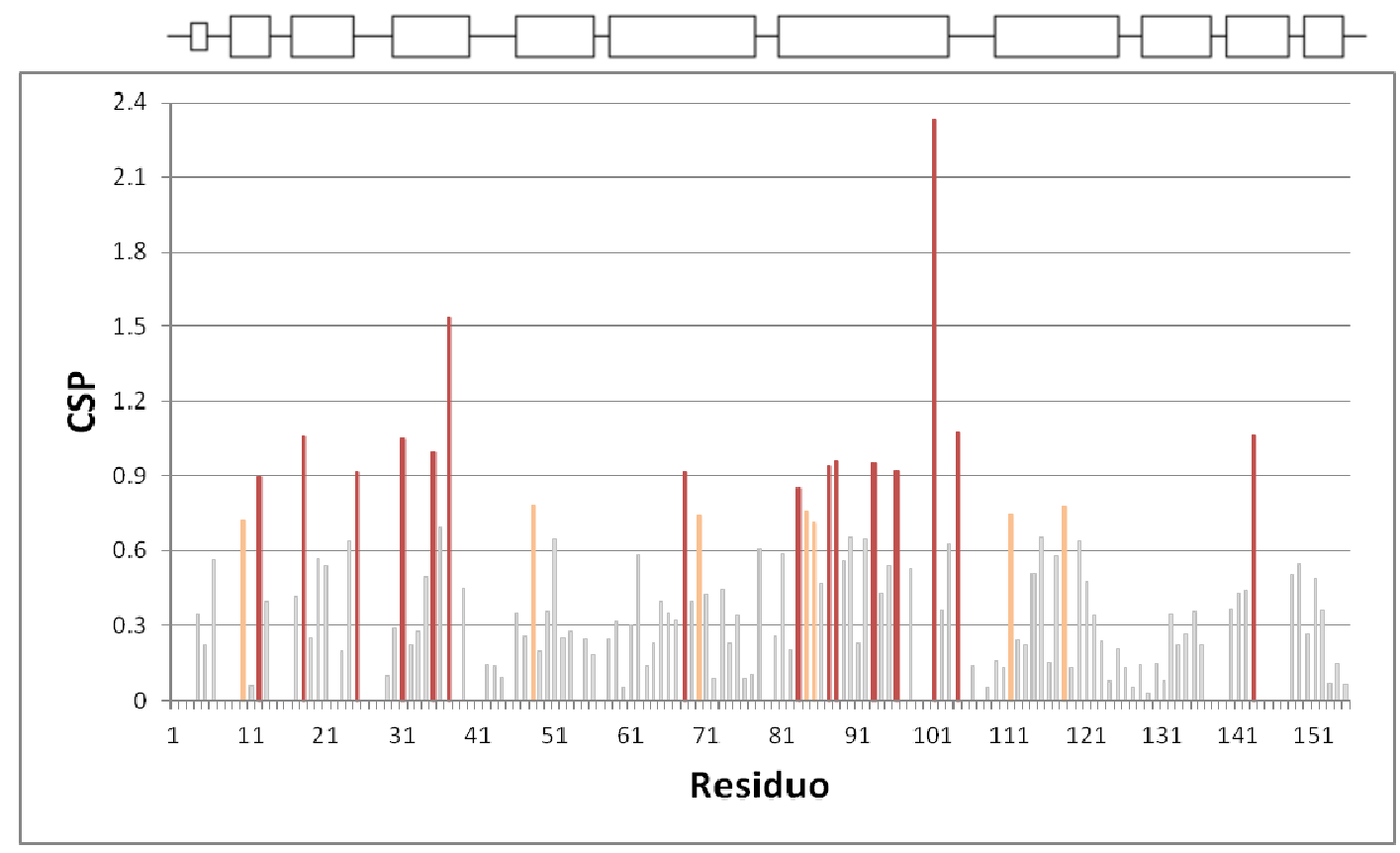

Fig. 6.9. Histograma de perturbación de desplazamientos químicos (CSP) a una relación proteína ligando 1:7. Las barras naranjas y rojas representan valores mayores a 0.7 y 0.8 respectivamente. En la zona superior del gráfico se esquematiza la estructura secundaria de Na-FAR-1. 
En dicho histograma se observa que los residuos que muestran un elevado CSP se distribuyen a lo largo de toda la proteína, pero se concentran en las hélices 2,3 y 4 de la región $\mathrm{N}$-terminal, también en la hélice 6 y, fundamentalmente, en la hélice 7. Estos residuos pueden presentar un corrimiento en sus desplazamientos químicos debido a una interacción con el oleato o pueden estar censando un entorno diferente a raíz de los cambios conformacionales de orden global que se producen en Na-FAR-1. Los residuos con CSP mayor a 0.7 se indican coloreados en la estructura de Na-FAR-1 en la figura 6.10.
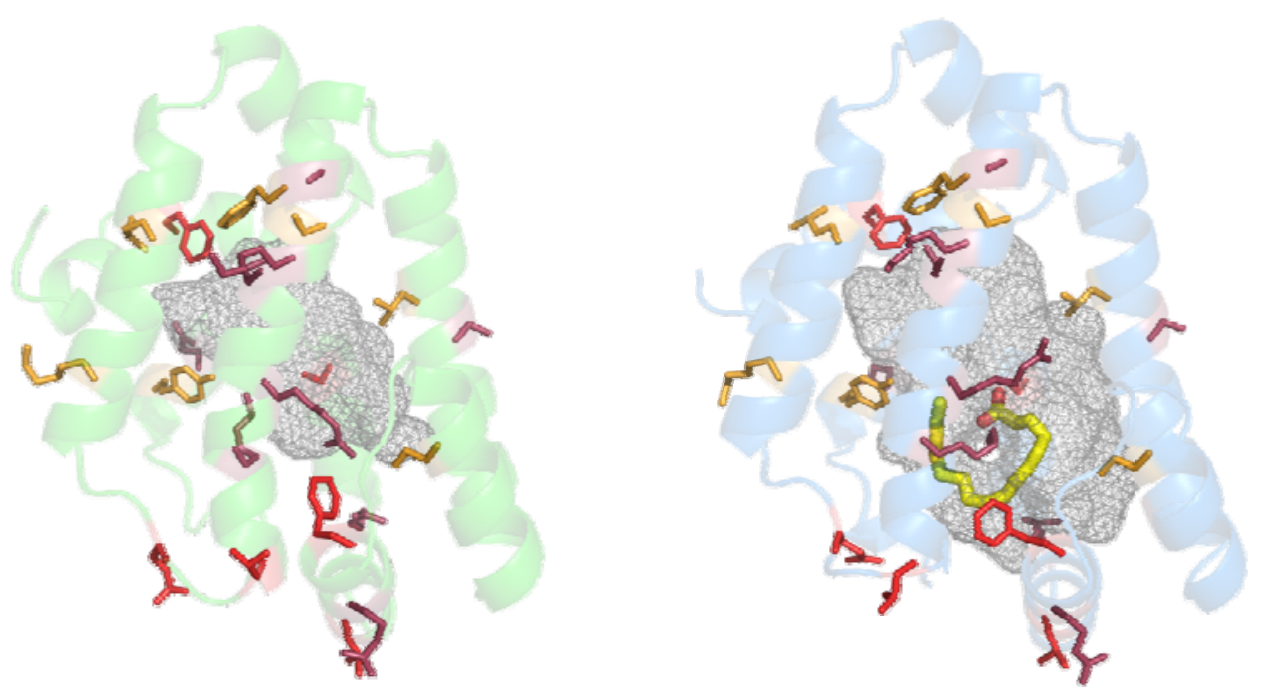

Fig. 6.10. Los residuos con altos valores de CSP se indican en la estructura de Na-FAR-1 apo (verde) y holo (azul). Perturbación de desplazamientos químicos (CSP) a una relación proteína ligando 1:7. Los residuos naranjas y rojos representan valores mayores a 0.7 y 0.8 respectivamente.

Entre los residuos que presentan elevado CSP se encuentran residuos que conforman la cavidad interna R96, K93, A85 (localizados en $\alpha 7$ ), A18 (en $\alpha 2$ ), L25 (en $\alpha 4$ ), F37 (en

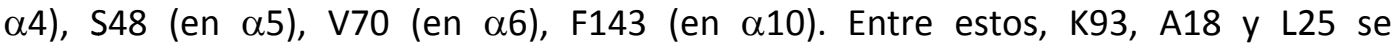
encuentran en contacto con el oleato presente en la estructura cristalográfica, los otros residuos podrían estar comprometidos en la interacción con otras moléculas de ligando. L25 a su vez se encuentra en el extremo de la hélice 3, dentro del posible sitio de fosforilación.

Otros residuos se encuentran en las regiones donde se observan las mayores diferencias entre la forma apo y holo, las hélices $\alpha 4$ (T31, E35) y $\alpha 7$ (G83, F84, K87, 
T101) y las regiones lazo 3 y 6, que cambian su orientación para una mayor apertura de la cavidad.

\subsection{Análisis de interacción con ligandos por espectroscopía de fluorescencia}

La fluorescencia es una técnica espectroscópica ampliamente empleada para estudiar interacciones de biomoléculas ${ }^{140}$. Es un caso particular de luminiscencia en la que la excitación óptica de una molécula (fluoróforo) y la emisión de luz desde la misma, que es prácticamente instantánea, ocurre mientras haya un estímulo excitatorio y tiene lugar a través de transiciones de estados electrónicos singletes.

Los fluoróforos suelen estar constituidos por grupos aromáticos heterociclos con un sistema de enlaces- $\pi$ conjugado en su estructura (como los presentes en residuos como triptófano, tirosina y fenilalanina). En algunos casos es posible unir a la molécula de interés un fluoróforo extrínseco con el fin de dotarla de propiedades espectrales adecuadas (como es el caso del ácido11-(9-dansilamin)undecanoico, DAUDA, y los ácidos grasos antroiloxi derivados, AOFAs).

La intensidad de emisión fluorescente así como las longitudes de onda de excitación y emisión dependen no sólo de la estructura química del fluoróforo, sino también del solvente, la temperatura, $\mathrm{pH}$, etc. La naturaleza del solvente (o el entorno donde se encuentra el fluoróforo) es uno de los factores principales que define la intensidad y longitudes de onda de emisión de fluorescencia de un compuesto en solución, y esta dependencia se explota para estudiar las interacciones proteína-ligando.

La capacidad de unión a distintos ligandos, tanto naturales como artificiales fluorescentes, que presentan otros miembros de la familia FAR ya ha sido estudiada mediante fluorescencia $37,41,42,45,46,50$. En la tabla 6.1 se presenta la información sobre la afinidad de proteínas FAR por diferentes ligandos disponible en literatura hasta la fecha.

Las distintas FAR unen DAUDA, cis-parinárico, retinol y ácidos caprílico, metilmirístico y oleico con afinidades $\left(K_{D}\right)$ que van desde el orden micromolar al picomolar. 


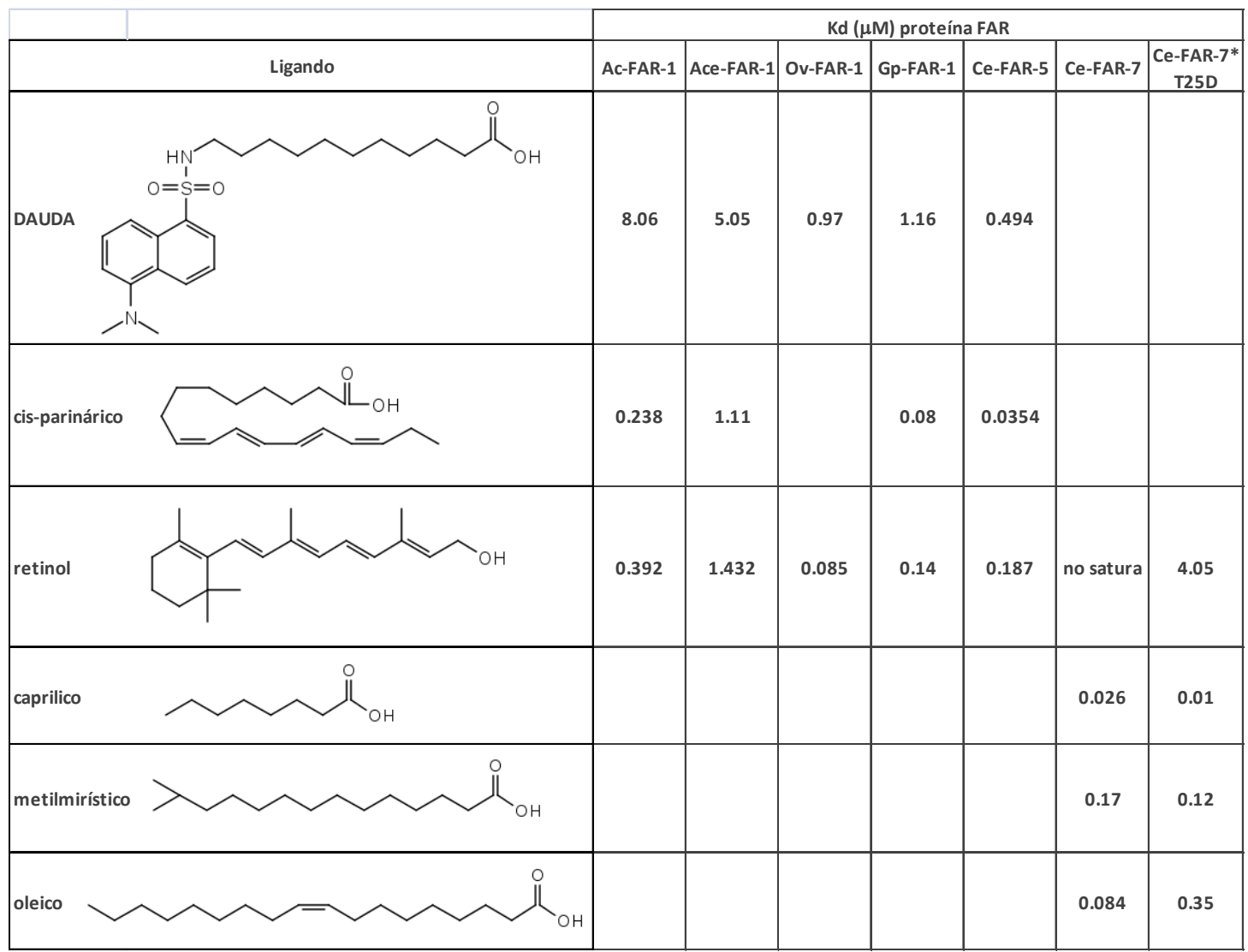

Tabla 6.1. Constantes de disociación de proteínas FAR con distintos ligandos. Las constantes de disociación son de FAR provenientes de los nematodos Ancylostom caninum (Ac-FAR-1) ${ }^{42}$, Ancylostoma Ceylanicum (Ace-FAR-1) ${ }^{45}$, Onchocerca volvulus (Ov-FAR-1) ${ }^{37}$, Globodera pallida (Gp-FAR-1) ${ }^{41}$, Caenorhabditis elegans (Ce-FAR-5 y Ce-FAR-7) ${ }^{46,50}$. Se presentan los datos de Ce-FAR-7 y un mutante indicado como Ce-FAR-7 ${ }^{*}$, donde se reemplazó el residuo de treonina 26 por glutámico a modo de simular la fosfrilación ${ }^{50}$. Los ligandos se representaron con el programa scketchEl (http://sketchel.sourceforge.net/).

A continuación se describirá la caracterización mediante espectroscopía de fluorescencia llevada a cabo para Na-FAR-1.

\subsubsection{Adquisición de espectros}

Los experimentos de fluorescencia se realizaron con un espectrofluorómetro Fluorolog-3 (Horiba-Jobin Yvon). Todas las medidas se hicieron por triplicado a una temperatura de $25^{\circ} \mathrm{C}$. En los ensayos las concentraciones de los compuestos hidrofóbicos se mantuvieron por debajo de su concentración micelar crítica (CMC). Se usaron blancos en buffer PBS para corregir por Raman y dispersión basal. 


\subsubsection{Evaluación de la preferencia por ácidos grasos de distinta longitud de cadena}

Para determinar la preferencia que tiene Na-FAR-1 por ácidos grasos saturados no fluorescentes de diferente longitud de cadena se realizaron ensayos de desplazamiento empleando el análogo fluorescente, ácido 11(dansilamino)undecanoico (DAUDA). Para los ensayos de desplazamiento, se preincubó la proteína con el DAUDA, luego de lo cual se agregó el acido graso a testear y se registró la disminución de intensidad de fluorescencia producida por el desplazamiento ${ }^{41}$. Según el procedimiento descripto por Prior y col. se preincubó la proteína con DAUDA y se detectaron los cambios en la fluorescencia producidos por el agregado de cantidades crecientes de ácidos grasos no fluorescentes ${ }^{41}$. Se empleó una concentración $1.5 \mu \mathrm{M}$ de Na-FAR-1 en la cubeta y la solución stock de DAUDA (SigmaAldrich) se diluyó 1:10000 en PBS para usar una concentración $1 \mu \mathrm{M}$ en los ensayos. Las soluciones de los ligandos no fluorescentes se prepararon $10 \mathrm{mM}$ en etanol y se diluyeron en PBS. Los ligandos empleados fueron ácidos grasos saturados de distinta longitud de cadena: ácido cáprico (c10), ácido undecanoico (c11), ácido dodecanoico (c12), ácido mirístico (c14), ácido pentadecanoico (c15), ácido palmítico (c16), ácido heptadecanoico (c17), ácido esteárico (c18), ácido nonadecanoico (c19).

La unión de DAUDA a la proteína provocó un desplazamiento hacia el azul (de 543 a $480 \mathrm{~nm}$ ) en su máximo de emisión, lo que, sumado a un marcado aumento en la intensidad de fluorescencia, indica que Na-FAR-1 posee un sitio de unión altamente apolar para el DAUDA (figura 6.11) tal como muestran otros miembros de la familia $\operatorname{FAR}^{42,37,46}$.

Se encontró que todos los ácidos grasos empleados desplazaron al DAUDA, lo cual sugiere que el sitio de unión es coincidente o presenta algún tipo de superposición con el de los ácidos grasos naturales. Según se observa en la figura 6.12, Na-FAR-1 une con mayor preferencia los ácidos grasos de cadena larga desde 14 a 19 carbonos, siendo el mirístico, de 14 carbonos de longitud el que produce mayor desplazamiento de DAUDA. 


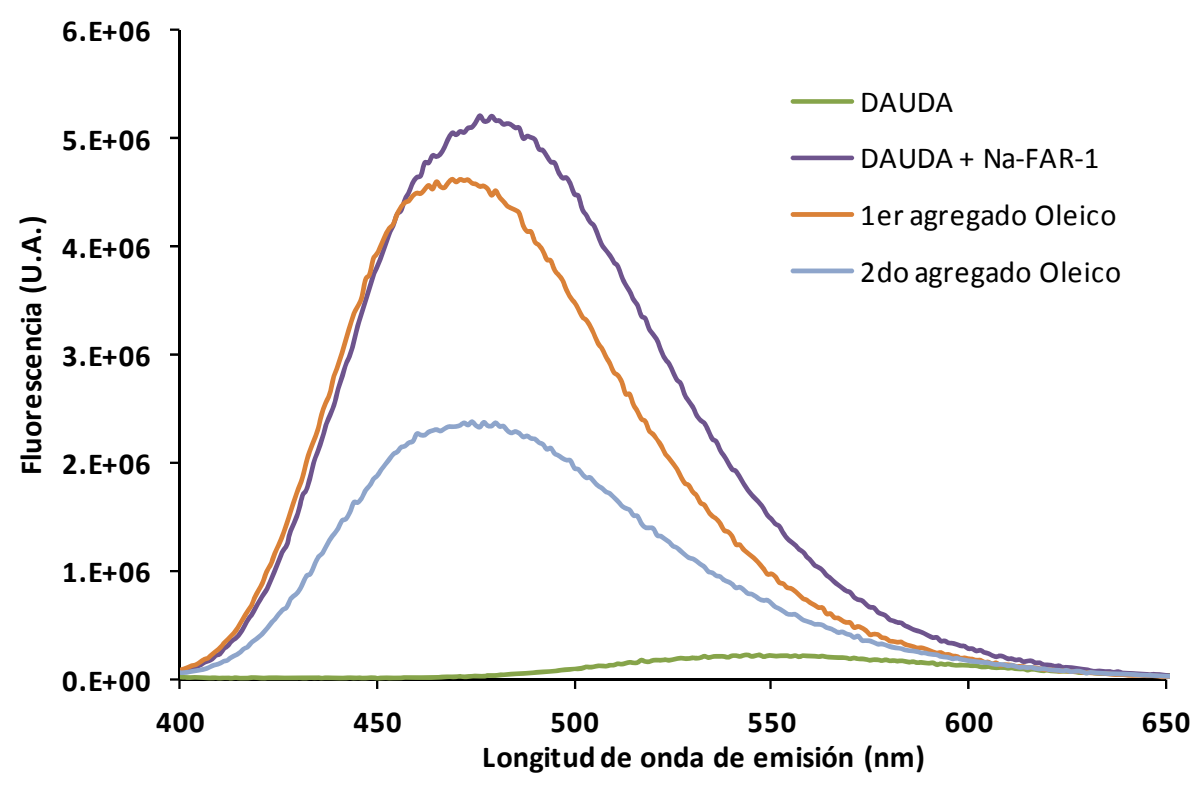

Fig. 6.11. Espectros de fluorescencia del complejo Na-FAR-1-DAUDA. Espectros de fluorescencia del DAUDA en solución, la fluorescencia se incrementa tras el agregado de Na-FAR-1 y luego disminuye mediante dos adiciones de ácido graso esteárico (18:0).

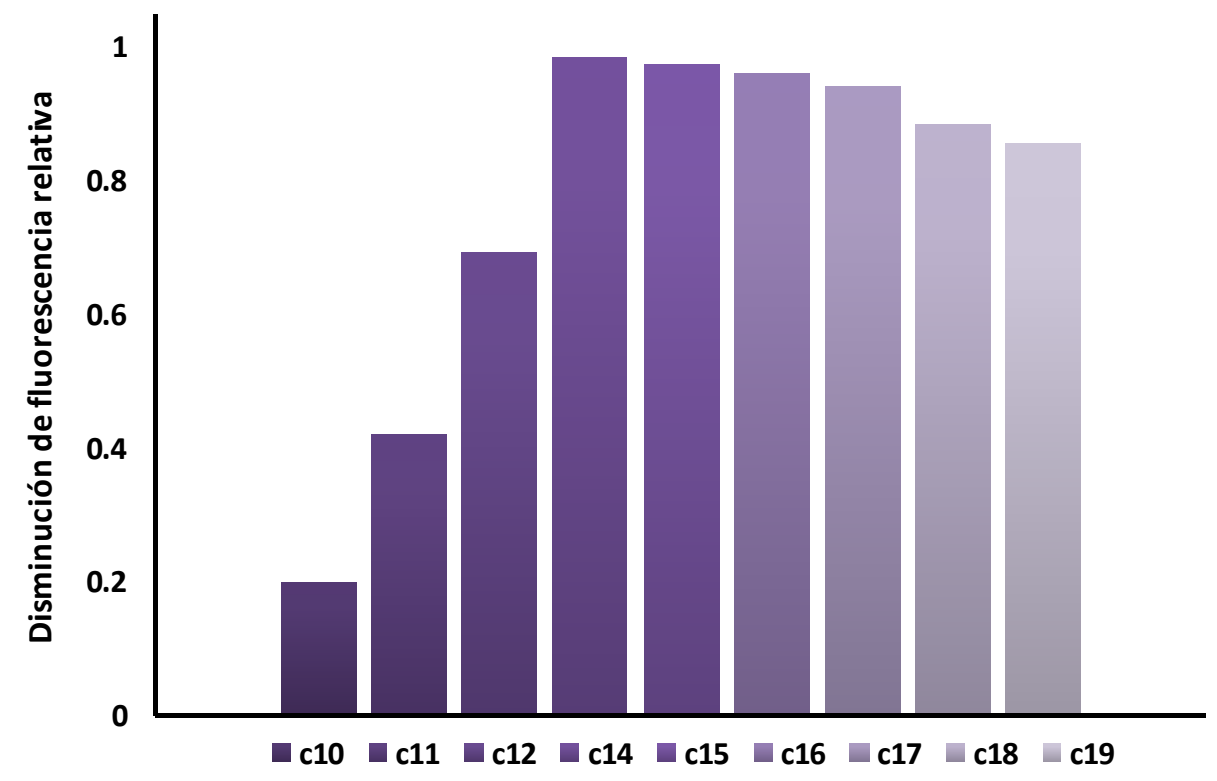

Fig. 6.12. Desplazamiento del DAUDA del complejo proteína-ligando por ácidos grasos de distinta longitud. Disminución en la fluorescencia relativa del DAUDA unido a Na-FAR-1 por el agregado de ácidos grasos de distinta longitud de cadena. 


\subsubsection{Titulaciones fluorimétricas y análisis de unión a ligandos}

Para evaluar la afinidad que presenta Na-FAR-1 por diferentes ligandos se estimó la constante de disociación $\left(K_{\mathrm{d}}\right)$ del complejo formado mediante titulaciones fluorimétricas. En ese sentido, se estudió la capacidad que presenta la proteína NaFAR-1 de unir dos análogos fluorescentes de ácidos grasos, el ácido oléico antroiloxiderivado (12AO) y el antroiloxi-derivado del palmitato (16AP), un compuesto hidrofóbico naturalmente fluorescente (retinol) y un ácido graso no fluorescente (ácido oleico) siguiendo la fluorescencia intrínseca de la proteína. Los datos se ajustaron con las siguientes ecuaciones.

Para estimar los valores de Kd se realizaron los ajustes presentes en el programa Sigma Plot (http://www.sigmaplot.com/) para regresión no lineal. Se emplearon las ecuaciones para unión a ligandos considerando uno y dos sitios con saturación.

La siguiente ecuación describe el ajuste teniendo en cuenta un único sitio de unión:

Frel $=\frac{F \max x[L]}{K d+[L]}+N s x[L]$

Donde Frel es la fluorescencia relativa del complejo proteína-ligando, Fmax es el máximo de fluorescencia, [L] es la concentración de ligando y Ns es una constante de ajuste que corrige la deriva en los datos en la saturación.

Si en cambio se suponen dos sitios de unión en la formación del complejo, se emplea la ecuación:

Frel $=\frac{F \max 1 x[L]}{\operatorname{Kd} 1+[L]}+\frac{F \max 2 x[L]}{\operatorname{Kd} 2+[L]}+N s x[L]$

Donde Fmax1 y Fmax2 son parámetros que utiliza el programa para simular la saturación del ligando unido al primer sitio y al segundo sitio, respectivamente.

Teniendo en cuenta que los resultados por RMN indicaron la existencia de sitios múltiples de unión para ácidos grasos, con la finalidad de estimar el número de sitios de unión para estos ligandos, se emplearon las ecuaciones para unión no cooperativa/hiperbólica estándar con n sitios del Dr. Alan Cooper, de la Universidad de Glasgow. 
Brevemente, la concentración del complejo proteína-ligando, se expresa en función de las concentraciones totales de proteína y ligando. Si hay $\mathrm{n}$ sitios de unión por mol de proteína, entonces el número total de sitios disponibles es igual a $\mathrm{n} \times \mathrm{Pe}$, dónde Pe es la concentración de proteína estimada, quedando:

$P L=\frac{(n P e+L o+K d)-\sqrt{(n P e+L o+K d)^{2}-4 n P e L o}}{2}$

La fracción de sitios ocupados $(\phi)$ para cualquier concentración de ligando está dada por: $\phi(L o)=\frac{P L}{n \cdot P e}$

$\phi(L o)=\frac{(n P e+L o+K d)-\sqrt{(n \cdot P e+L o+K d)^{2}-4 n P e L o}}{2 n P e}$

El valor de fluorescencia en cualquier punto es proporcional a la unión:

$F(L o)=F l+(F p l-F l) \phi(L o)$

Dónde $\mathrm{Fl}=$ Intensidad de fluorescencia en ausencia de proteína, y Fpl=Intensidad de fluorescencia en el estado totalmente unido.

En el caso de tratarse de un experimento en el que se sigue la fluorescencia intrínseca de la proteína, Fl se reemplaza por Fp en la ecuación (6.5).

En ambos casos los ajustes se realizaron empleando el módulo Solver de Excel MS Office para minimizar el error cuadrático medio entre los datos y la curva del modelo.

\subsubsection{Unión a antroiloxi-derivados de ácidos grasos}

Con el objetivo de conocer la afinidad de la proteína por distintos ligandos fluorescentes se estimó la constante de disociación del complejo proteína-ligando $\left(\mathrm{K}_{\mathrm{d}}\right)$ mediante titulación fluorimétrica según ${ }^{141}$. En esta técnica se monitorea el incremento de la fluorescencia de un ligando fluorescente como consecuencia del agregado de 
cantidades crecientes de proteína. Se preparó una dilución $0,5 \mu \mathrm{M}$ del ligando en buffer TBS en una cubeta de cuarzo. Se agregaron cantidades crecientes de la proteína en un rango de 0 a $10 \mu \mathrm{M}$ y se incubó por 3 minutos antes de cada medida. Se excitó a $383 \mathrm{~nm}$ y se midieron espectros de emisión entre 400-500 nm.

Se emplearon los siguientes derivados fluorescentes de ácidos grasos: Ácido 12-(9antroiloxi)oleico (12-AO), ácido 16-(9-antroiloxi)palmítico (16-AP) ambos adquiridos de Molecular Probes (USA).

La fluorescencia del grupo antroiloxi se incrementa marcadamente cuando se introduce en un entorno hidrofóbico como lo es el dominio de unión de Na-FAR-1. Este aumento en la fluorescencia es una medida directa de la unión del ligando a la proteína y permite el seguimiento de la formación del complejo FAR-ligando a medida que se agregan cantidades crecientes de proteína, para obtener de este modo el valor de $K_{d}$.

El ajuste de los datos experimentales de las titulaciones fluorimétricas de ambos análogos fluorescentes muestra la presencia de un solo sitio de unión con constantes de afinidad submicromolares. El valor de $\mathrm{K}_{\mathrm{d}}$ obtenido para el equilibrio entre el $12 \mathrm{AO} \mathrm{y}$ Na-FAR-1 fue de $0.10 \pm 0.05 \mu \mathrm{M}$ y para el $16 \mathrm{AP}$ de $0.2 \pm 0.1 \mu \mathrm{M}$.

En la figura 6.12 se muestran los espectros de un ensayo representativo para Na-FAR-1 con 12AO, y el ajuste no lineal para un sitio de unión por molécula de proteína realizado con la ecuación 6.1.
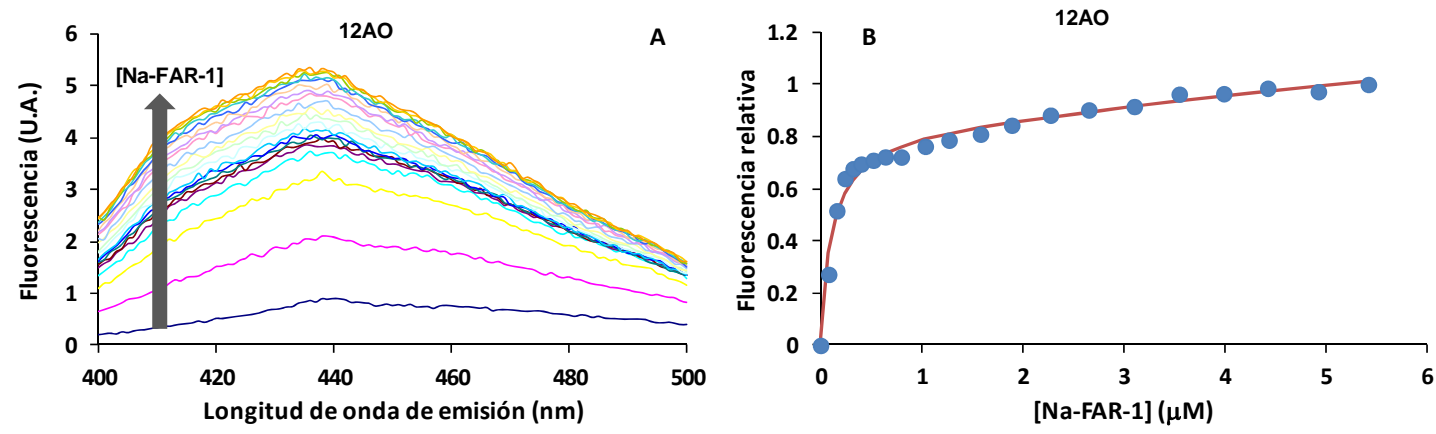

Fig. 6.12. Titulación fluorimétrica del 12 AO. (A) Aumento de la fluorescencia del $12 \mathrm{AO}$ con cada agregado de NaFAR. (B) La fluorescencia a $450 \mathrm{~nm}$ se empleó para calcular el $\mathrm{K}_{d}$ por el $12 \mathrm{AO}$. Se observa el ajuste no lineal que describe la unión del ligando a un solo sitio de la proteína Na-FAR-1 para $12 A O$. 


\subsubsection{Unión a ligandos naturales fluorescentes}

Para determinar el $\mathrm{K}_{d}$ de Na-FAR-1 por un ligando natural fluorescente como el retinol, se realizaron titulaciones fluorimétricas de la proteína ${ }^{37}$.

Se empleó una concentración $1.3 \mu \mathrm{M}$ de proteína en la cubeta en buffer PBS y se agregaron cantidades crecientes de retinol. Se preparó una solución stock $4,5 \mathrm{mg} / \mathrm{ml}$ de retinol y se realizaron diluciones en etanol que se agregaron directamente a la cubeta en los ensayos para evitar degradación en agua. Luego de cada agregado de retinol se incubó durante 3 minutos y se midió la fluorescencia en el rango 410-520 nm excitando a $350 \mathrm{~nm}$. Se realizó un blanco con los mismos agregados de retinol a la cubeta sin proteína que se sustrajo de los espectros para descontar la contribución a la fluorescencia del retinol libre.

La fluorescencia del retinol aumenta en presencia de un entorno hidrofóbico como el que presenta la cavidad interna de Na-FAR-1. De este modo se monitoreó la unión del retinol a la proteína y se estimó su afinidad.

En la figura 6.13 se muestran los espectros de un ensayo representativo para Na-FAR-1 con retinol $(A)$, y el ajuste no lineal para un sitio de unión por molécula de proteína empleando la ecuación 6.1 (B). El valor de $K_{d}$ obtenido para el retinol fue de $0.5 \pm 0.3$ $\mu \mathrm{M}$ para un único sitio de unión presente.
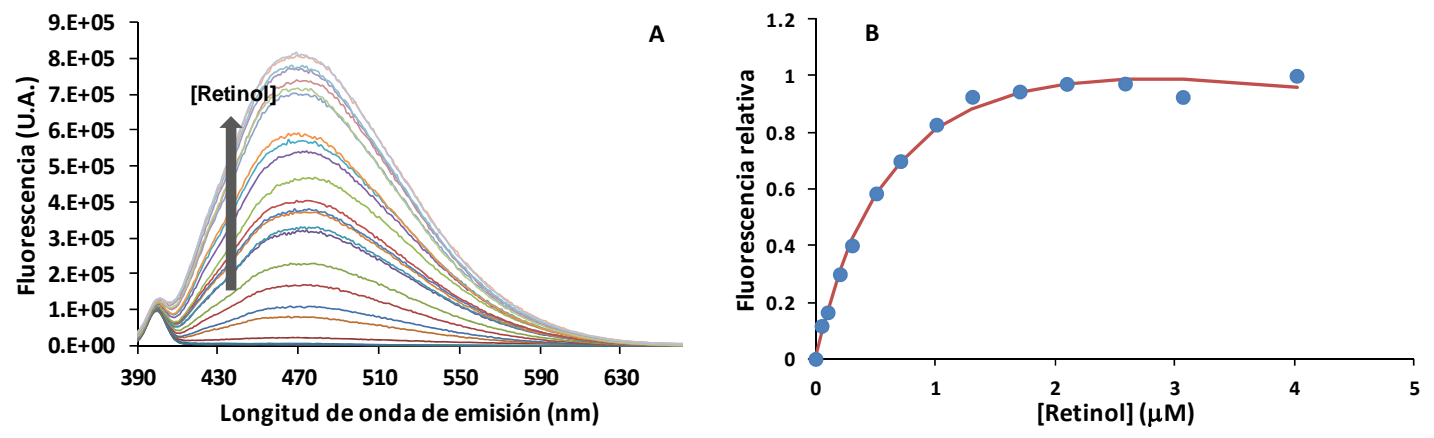

Fig. 6.13. Titulación fluorimétrica con retinol. (A) Aumento de la fluorescencia del retinol con cada agregado. (B) La fluorescencia a 470nm se empleó para calcular el $K_{d}$ para el retinol. Se observa el ajuste no lineal que describe la unión del ligando a un solo sitio de la proteína para retinol. 


\subsubsection{Unión a ácidos grasos naturales}

Para determinar la $K_{d}$ de Na-FAR-1 por un ligando natural no fluorescente como el ácido oleico, se realizaron titulaciones siguiendo la fluorescencia intrínseca de Tyr/Phe presentes en la proteína ${ }^{50}$. La fluorescencia intrínseca de estos residuos aromáticos es sensible a la presencia de ligando, viéndose un cambio en la intensidad de fluorescencia a medida que aumenta la concentración del ácido graso si los residuos están involucrados en el sitio de unión o se ven afectados por el cambio conformacional que sufre la proteína al unirlos.

Se preparó una dilución $1.5 \mu \mathrm{M}$ de la proteína en buffer PBS en una cubeta de cuarzo. Se agregaron cantidades crecientes de ligando en un rango de 0 a $12 \mu \mathrm{M}$, se incubó por 3 minutos y se midió la fluorescencia excitando a $275 \mathrm{~nm}$ y midiendo los espectros de emisión entre 290-390 nm. La intensidad de la fluorescencia intrínseca de Na-FAR-1 demostró ser sensible a la presencia de oleico, observándose una disminución en la intensidad de emisión fluorescente a $307 \mathrm{~nm}$ a medida que aumenta la concentración del ácido graso.

Al emplear las ecuaciones para unión no cooperativa/hiperbólica estándar con n sitios (ecuaciones. 6.4 y 6.5), el ajuste de los datos no presentó convergencia al permitir la variación del número de sitios $\mathrm{n}$. Consecuentemente no se pudo obtener información precisa acerca del número de sitios de unión presentes en Na-FAR-1 para el ácido oleico.

Para analizar el $K_{d}$ los datos experimentales se ajustaron con modelos no lineales de uno y de dos sitios de unión por molécula de proteína, mediante las ecuaciones 6.1 y 6.2 respectivamente.

Los datos experimentales fueron mejor representados con el modelos no lineal de dos sitios de unión por molécula de proteína con un valor $R^{2}$ de 0.9976 (figura 6.14). El ajuste empleando el modelo de un solo sitio de unión por proteína fue inconsistente con los datos experimentales. Los valores obtenidos para los Kd fueron de $0.10 \pm 0.07 \mathrm{y}$ $9 \pm 5 \mu \mathrm{M}$ para los dos sitios. 

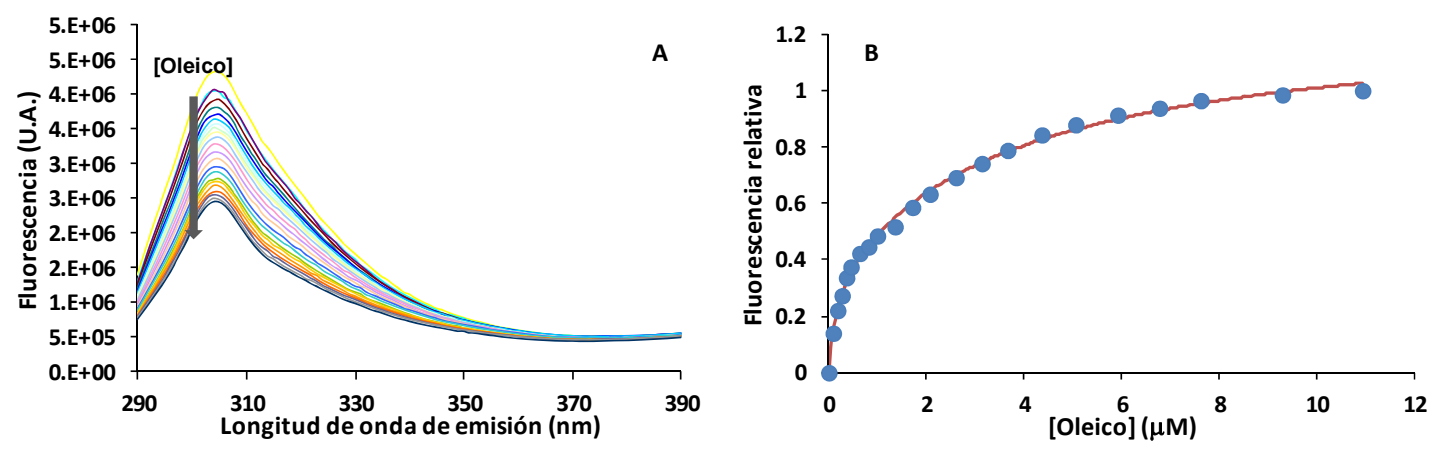

Fig. 6.14. Titulación fluorimétrica con oleico. Disminución de la intensidad de la fluorescencia intrínseca de Na-FAR-1 con cada agregado de oleico (A). La fluorescencia a $307 \mathrm{~nm}$ se empleó para calcular los Kds. En la figuras (B) se observa el ajuste no lineal que describe la unión del ligando a dos sitios de la proteína.

\subsubsection{Discusión titulaciones fluorimétricas}

Los resultados obtenidos por RMN sugieren que la proteína podría unir hasta cuatro moléculas de ligando. Sin embargo, basándose en los resultados de fluorescencia intrínseca, no es posible determinar con certeza el número de sitios. El ajuste de los datos experimentales parece corresponder a la presencia de dos sitios de unión para el ácido oleico. Esta discrepancia podría deberse a que los cambios en la fluorescencia intrínseca de Na-FAR-1 exhiben un comportamiento demasiado complejo.

La presencia de múltiples aminoácidos aromáticos complica la interpretación de la flurescencia de la proteína debido a que el ambiente de cada residuo es distinto y, por lo tanto, también sus propiedades espectrales. Na-FAR-1 presenta 6 residuos de tirosina y 9 fenilalaninas en su estructura y no posee triptófanos (figura 6.15).

Dos tirosinas y 5 fenilalaninas (Y10, Y100, F21, F84, F132, F136, F143) tienen contacto con la cavidad en la estructura apo, mientras que en la estructura más expandida de la proteína holo, un total de 13 residuos aromáticos pasan a delimitar la cavidad, 6 tirosinas y 7 fenilalaninas (Y3, Y42, Y99, Y121, F1, F37 y las anteriormente mencionadas para la forma apo). 

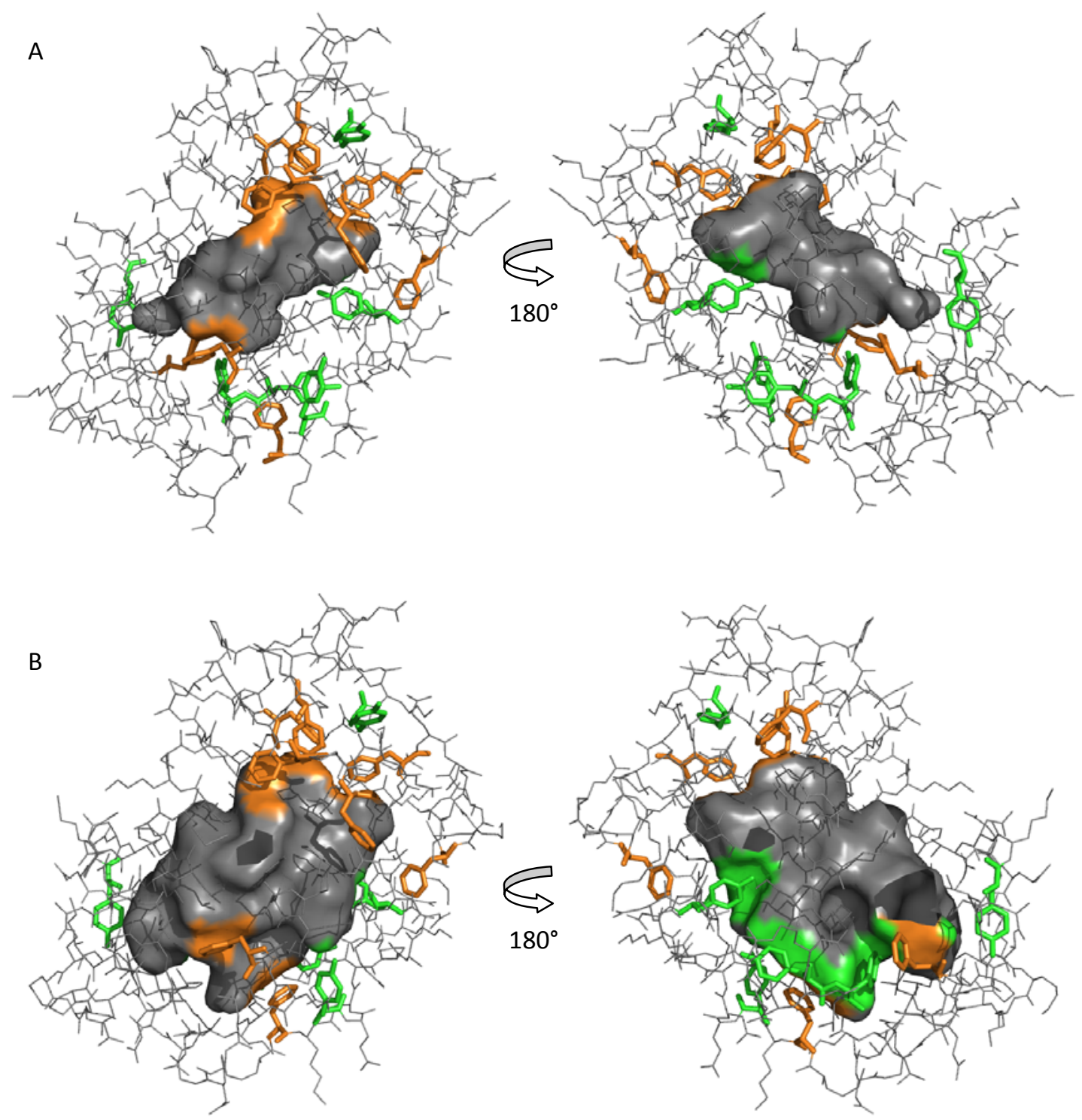

Fig. 6.15. Representación de los residuos aromáticos en la estructura de Na-FAR-1. (A) Estructura determinada mediante RMN (forma apo) y (B) mediante cristalografía de rayos $\mathrm{X}$ (forma holo). Se muestra una representación de la cavidad interna generada con pymol y los residuos aromáticos se colorearon en verde tirosinas y en naranja fenilalaninas.

Al excitar a $275 \mathrm{~nm}$ el espectro de emisión de la proteína está dominado por las tirosinas debido a que el máximo de absorción de las fenilalaninas ocurre a menores longitudes de onda (máximo a $260 \mathrm{~nm}$ ). Si bien el máximo de emisión de las tirosinas suele ser bastante insensible al ambiente (en la figura 6.14 se observa que la posición del máximo se mantiene durante la titulación), se producen cambios en la intensidad. 
Durante la titulación más de un residuo de la proteína puede estar censando la presencia de los ligandos o bien variando sus propiedades espectrales por los cambios estructurales producidos. A su vez, como existen regiones de la cavidad que no contactan residuos aromáticos la unión de una o más moléculas de oleico en estas zonas no producirían cambios en la fluorescencia intrínseca de la proteína. Posiblemente solo dos de los sitios sean sensibles a la presencia de ligando en Na-FAR1.

Por otro lado, los resultados obtenidos para los análogos fluorescentes y para el retinol muestran una estequiometria 1:1, posiblemente debido a impedimentos estéricos ocasionados por anillo aromático de la molécula de retinol o al voluminoso grupo antroiloxi en los AOFA que impediría la subsiguiente entrada de moléculas en la cavidad.

En la tabla 6.2 se resumen los valores de $K_{d}$ obtenidos para la formación de complejos de Na-FAR-1 con los diferentes ligandos.

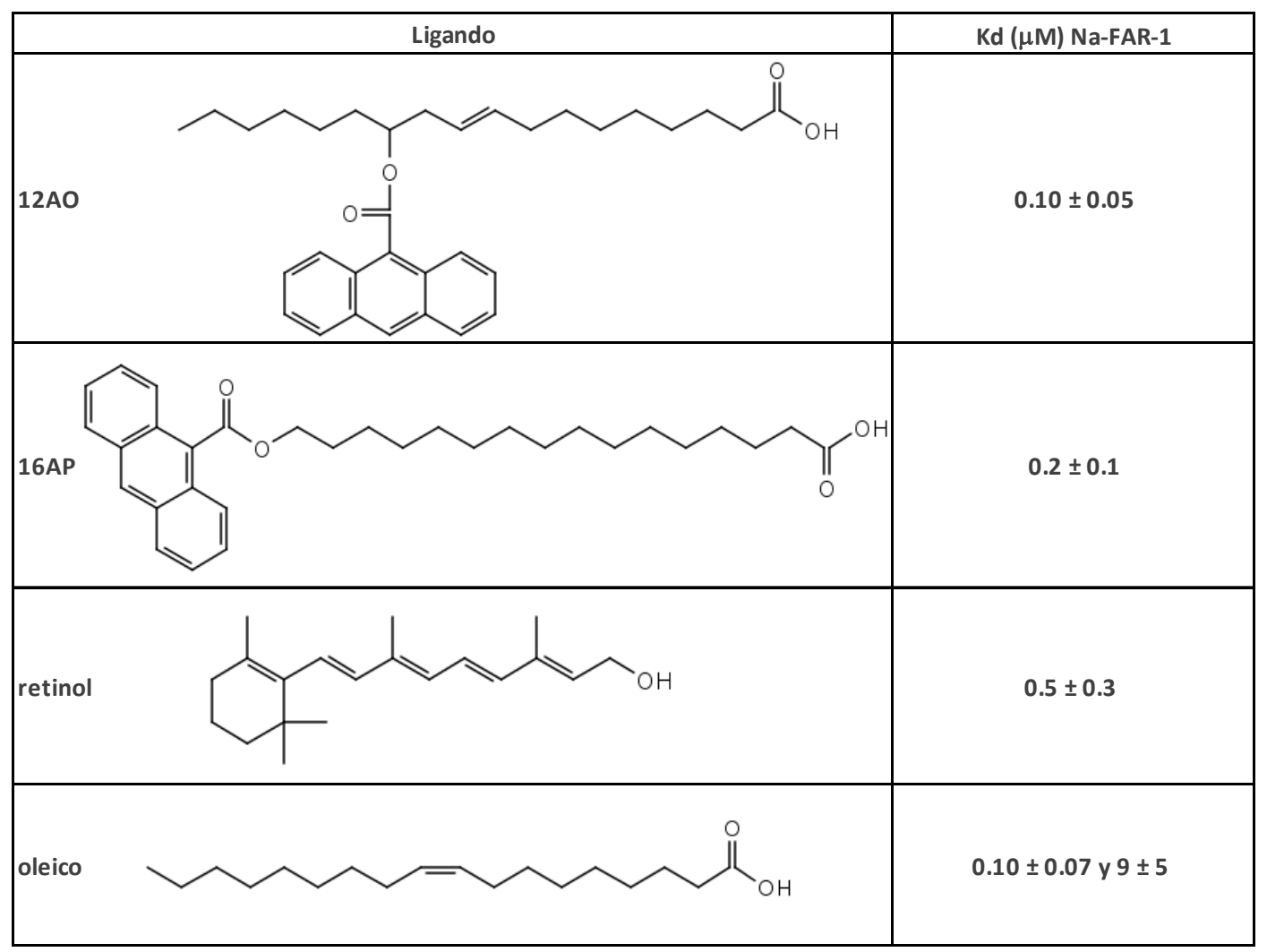

Tabla 6.2. Constantes de disociación de Na-FAR-1 con distintos ligandos hidrofóbicos. Los ligandos se representaron con el programa scketchEl (http://sketchel.sourceforge.net/). 


\subsubsection{Partición de equilibrio}

Las proteínas de unión a lípidos posiblemente deban interactuar con membranas celulares para cumplir sus funciones biológicas, ya sea para modificar el ambiente celular del huésped o bien para transferir lípidos dentro del parásito. El coeficiente de partición $\left(K_{p}\right)$ de un ligando brinda información de la afinidad relativa que tiene un soluto por dos fases, en este caso, de un ligando hidrofóbico antroiloxi-derivado de ácidos grasos por una proteína y una membrana fosfolipídica artificial de pequeño tamaño (SUV). El K $K_{p}$ se define como:

$K p=\frac{\frac{[F A R-A O F A]}{[F A R]}}{\frac{[S U V-A O F A]}{[S U V]}}$

donde [FAR-AOFA] y [SUV-AOFA] representan las concentraciones de ligando fluorescente unido a la proteína o a las vesículas, respectivamente.

El agregado de las vesículas conteniendo un quencher de la fluorescencia del AOFA, determinará una disminución de la fluorescencia inicial del ligando en presencia de la proteína. El decaimiento en la fluorescencia del AOFA luego de la titulación con SUVS puede ajustarse con la siguiente ecuación ${ }^{142}$ :

Frel $=\frac{a \times K p}{K p+\frac{[S U V]}{[F A R]}}-b x \frac{[\mathrm{SUV}]}{[F A R]}$

donde $F_{\text {rel }}$ es la fluorescencia relativa del AOFA con la proteína respecto al punto inicial de la titulación, a y b son parámetros de ajuste.

\subsubsection{Preparación de vesículas unilamelares pequeñas (SUV)}

Se prepararon vesículas unilamelares pequeñas de acuerdo a los trabajos de Huang y col. ${ }^{143}$ y Storch y col. ${ }^{144}$. Los lípidos en $\mathrm{CHCl}_{3}$ fueron mezclados, secados bajo corriente de $\mathrm{N}_{2}$ y resuspendidos en buffer TBS. La mezcla de fosfolípidos fue sonicada a $4^{\circ} \mathrm{C}$ bajo atmósfera de $\mathrm{N}_{2}$ gaseado hasta clarificar la suspensión (aproximadamente 45 minutos). 
Las vesículas se separaron por ultracentrifugación a 45.000 rpm durante 45 minutos y se conservaron sólo las SUV del sobrenadante a $4^{\circ} \mathrm{C}$ en una atmósfera de $\mathrm{N}_{2}$.

Se prepararon vesículas zwiteriónicas con una composición de $90 \mathrm{~mol} \%$ fosfatidilcolina de huevo (EPC) y $10 \mathrm{~mol} \% \mathrm{~N}$-(7-nitro-2,1,3-benzoxadiazol-4-yl) fosfatidilcolina (NBDPC) (Avanti Polar Lipids), que es un quencher de la fluorescencia de los antroiloxiderivados de ácidos grasos (AOFA).

La concentración de las SUV obtenidas se calculó en base al ensayo de cuantificación de fósforo inorgánico descripto por Gomori y col. ${ }^{145}$. La curva estándar se preparó empleando $\mathrm{NaH}_{2} \mathrm{PO}_{4} 1 \mathrm{mM}$. Las muestras y los estándares se prepararon por duplicado. Se agregaron $30 \mu \mathrm{l}$ de $\mathrm{Mg}\left(\mathrm{NO}_{3}\right)$ al $10 \%$ y se carbonizó bajo llama. A continuación se agregaron $400 \mu \mathrm{l}$ de $\mathrm{HCl}$ 0,5 $\mathrm{N}$ agitando en vortex. Los tubos se incubaron por 30 minutos en baño de agua hirviendo. Terminada la incubación, se agregó a cada tubo $930 \mu$ de una solución 1:6 (vol/vol) de ácido ascórbico (10\% peso/vol): ácido molíbdico. Las muestras se incubaron nuevamente durante 1 hora a $37^{\circ} \mathrm{C}$. Finalmente, se midió la absorbancia de las muestras a $820 \mathrm{~nm}$.

\subsubsection{Cálculo del coeficiente de partición}

El $K_{p}$ de un ligando fluorescente entre Na-FAR-1 y SUVs se determinó empleando la técnica de Massey y col. ${ }^{146}$. El Kp se calculó midiendo la fluorescencia de análogos fluorescentes de ácidos grasos (AOFA) luego del agregado de SUVs, compuestas por EPC más el quencher de transferencia de energía NBD-PC, a una solución conteniendo la proteína preincubada con el ligando fluorescente en una proporción 10:1 ( $\mu \mathrm{M})$ en buffer TBS (Tris $40 \mathrm{mM}, \mathrm{NaCl} 100 \mathrm{mM}, \mathrm{pH}=7,4$ ). Las medidas de fluorescencia se realizaron a una temperatura de $25^{\circ} \mathrm{C}$, con una longitud de onda de excitación $383 \mathrm{~nm}$ y se tomaron espectros de emisión entre $400-500$ nm.

El ajuste de los datos se realizó mediante la ecuación (6.10) empleando el módulo Solver de Excel MS Office, que minimiza el error cuadrático medio entre los datos y la curva del modelo. 


\subsubsection{Resultados coeficiente de partición}

En la figura 6.16 se muestra un ensayo representativo de la titulación del complejo Na-FAR-1-12AO preformado con cantidades crecientes de EPC-SUV conteniendo el quencher NBD-PC (panel A), y el ajuste empleado para el cálculo del valor de $K_{p}$ (panel B).
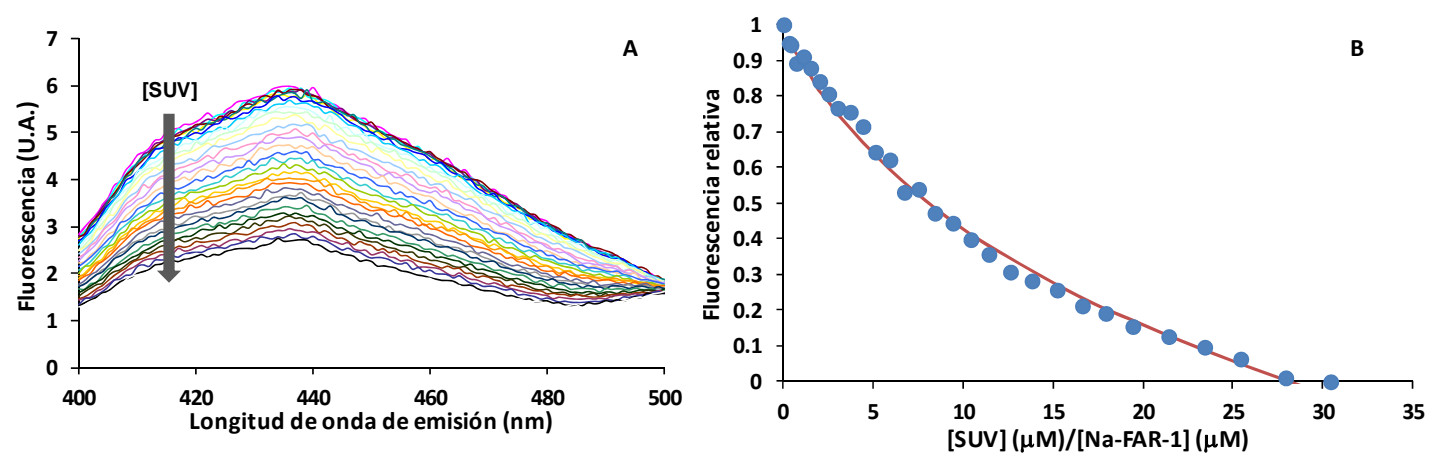

Fig. 6.16. Determinación de la constante de partición del $12 A O$ entre la proteína y EPC-NBD SUVs. (A) Titulación fluorimétrica del complejo Na-FAR-1-12AO con cantidades crecientes de EPC-SUV conteniendo un $10 \mathrm{~mol} \%$ de NBD-PC, que actúa como aceptor FRET del grupo antroiloxi. (B) La fluorescencia a $450 \mathrm{~nm}$ se empleó para calcular el Kp. En la figura se observa el ajuste de los datos experimentales.

El valor resultante de $K_{p}$ para el $12 \mathrm{AO}$ es de $11.8 \pm 1.5 \mu \mathrm{M}$ SUV/ $\mu \mathrm{M}$ Proteína, evidenciando una mayor preferencia relativa de este ligando por Na-FAR-1 en comparación con las membranas de EPC.

El resultado obtenido es muy similar al reportado para OV-FAR-1 en la partición de 2AP con SUVs, cuyo valor de $K_{p}$ promedio es $16^{47}$. El valor de $K_{d}$ de Ov-FAR-1 para este ligando es de $0.06 \mu \mathrm{M}$, muy cercano al de Na-FAR-1 por 12AO. En general se observa que se mantiene una relación entre la $K_{\mathrm{d}}$ y el $K_{\mathrm{p}}$ para el AOFA estudiado. A bajos valores de $K_{\mathrm{d}}$ altos valores del $K_{\mathrm{p}}$, lo que es lógico, ya que la tendencia a permanecer formando el complejo proteína-ligando refleja la mayor afinidad de la proteína por el ligando. 


\subsection{Conclusiones}

Na-FAR-1 parece ser capaz de unir todos las clases lipídicas presentes en E. coli demostrando una gran diversidad en la unión a ligando. Une lípidos neutros como ácidos grasos y DAG y lípidos polares como PE, PS, PG y CLP.

En consecuencia, mediante el análisis de los ligandos unidos a Na-FAR-1 se confirmó la presencia de ácidos grasos, que junto con el retinol (que no se detecta en estos estudios por su ausencia en $E$. coli) son los tipos de ligandos esperados para proteínas de la familia FAR. Sin embargo, también se encontró que Na-FAR-1 es capaz de unir diacilglicéridos y distintas clases de fosfolípidos, ligandos que no habían sido reportados previamente para estas proteínas.

En la titulación seguida por RMN de Na-FAR-1 con oleato de sodio se observa que se producen cambios en los desplazamientos químicos de la mayoría de los residuos, cuya magnitud (evaluada mediante CSP) es elevada en residuos distribuidos en toda la proteína, comportamiento indicativo de cambios globales en la estructura de Na-FAR1. Esto está en concordancia con las diferencias observadas en las estructuras apo y holo de Na-FAR-1, donde se aprecia una diferencia considerable en el tamaño de la cavidad central consecuencia de una estructura más expandida en la forma holo.

La CSP evaluada entre el punto de estequiometria 1:7 proteína ligando y la forma libre de ligando presenta valores elevados para los residuos K93, A18 y L25 que se encuentran en contacto con el palmitato en la estructura cristalográfica. A su vez, otros residuos que conforman la cavidad poseen una alta CSP, R96, A85, F37, S48, V70 y F143, por lo que potencialmente podrían contactar otras moléculas de ligando unidas.

Na-FAR-1 parece ser capaz de unir 4 moléculas de oleato de sodio por molécula de proteína. Tres de los sitios serían de alta afinidad exhibiendo un comportamiento de intercambio lento y en el cuarto sitio, que presenta un comportamiento de intercambio rápido, el oleato se uniría con baja afinidad.

El ajuste de los datos experimentales de las titulaciones fluorimétricas de los análogos fluorescentes y el retinol demuestran la presencia de un solo sitio de unión. En cambio, 
para el ácido oleico existiría más de un sitio de unión a ligando cuyo $n$ no pudo determinarse mediante el análisis realizado.

A pesar de que Na-FAR-1 presenta aparentemente múltiples sitios de unión para ácidos grasos, los resultados obtenidos para retinol y los análogos fluorescentes muestran una estequiometria 1:1, posiblemente debido a impedimentos estéricos ocasionados por el anillo aromático y el voluminoso grupo antroiloxi que presentan respectivamente, que impedirían la entrada de una segunda molécula de ligando.

Las constantes de afinidad obtenidas se hallan en el orden submicromolar para todos los ligandos testeados. El valor de $K_{d}$ obtenido para la formación de complejo en equilibrio entre Na-FAR-1 y el $12 \mathrm{AO}$ fue de $0.10 \pm 0.05 \mu \mathrm{M}$, para el 16AP fue de $0.2 \pm$ $0.1 \mu \mathrm{M}$, para el retinol fue de $0.5 \pm 0.3 \mu \mathrm{M}$ y para el oleico fue de $0.1 \pm 0.07$ y $9 \pm 5 \mu \mathrm{M}$ considerando dos sitios. Los valores de $K_{d}$ obtenidos para Na-FAR-1 con los distintos ligandos están dentro del rango de órdenes de magnitud hallados para otras FAR (ver tabla 6.1).

Na-FAR-1 presenta una preferencia por ácidos grasos de cadena larga (entre 14 y 19 carbonos), que es máxima para una longitud de 14 carbonos dentro del rango estudiado.

Asimismo, Na-FAR-1 es capaz de transferir ligandos a membranas, con un Kp de $11.8 \pm$ 1.5 para el $12 \mathrm{AO}$, lo cual indica una preferencia por la proteína. 


\section{Localización de Na-FAR-1}

En los capítulos precedentes se ha descripto la estructura de Na-FAR-1 y se han expuesto los resultados obtenidos en cuanto a la caracterización de unión a ligando desde el punto de vista biofísico y bioquímico. Para tratar de comprender el rol biológico que cumple esta proteína en la biología del parásito y en la patogénesis es fundamental conocer en que tejidos se expresa.

Como se ha mencionado previamente, la secuencia de mRNA codificante para la proteína Na-FAR-1 fue detectada por comparación con los genes de $C$. elegans en un análisis de transcriptómica. Daub y col. identificaron la presencia de mRNA codificante para una única proteína FAR, Na-FAR-1, en los estadios adulto y larval L4 del parásito Necator americanus ${ }^{51}$. Sin embargo, no existen a la fecha, reportes previos que acrediten la presencia del transcripto de NA-FAR-1.

Para determinar la presencia de Na-FAR-1 y su localización en los tejidos del parásito $N$. americanus se recurrió a una colaboración con el laboratorio del Dr. Bin Zahn en el Baylor College of Medicine, Texas, Estados Unidos. En N. americanus el desarrollo desde larva infectiva a adulto, para completar el ciclo de vida, requiere de un húesped humano. Para la mantención y propagación de este nematodo en el laboratorio se emplean modelos animales, específicamente en el laboratorio del Dr. Bin Zhan reproducen el ciclo de vida de $N$. americanus y obtienen estadios adultos del prásito en hamsters ${ }^{147}$.

El suero anti-Na-FAR-1 preparado en nuestro laboratorio con la proteína recombinante purificada y el suero control, se enviaron al laboratorio del Dr. Bin Zhan dónde se realizaron los ensayos de inmunolocalización que se describen a continuación. Los resultados obtenidos en los apartados 7.2 y 7.3 que corresponden a la detección e inmunolocalización de Na-FAR-1, fueron realizados por el Dr. Bin Zhan.

\subsection{Generación de antisuero}

Se obtuvo suero policlonal anti-NA-FAR-1 de conejo. Para ello, se inyectaron dos conejos de forma subcutánea con $0,7 \mathrm{mg}$ de Na-FAR-1 recombinante purificada, en 
buffer PBS:Adjuvante de Freund (1:1). Los niveles de anticuerpos en el suero del conejo se controlaron durante un período de cuatro meses mediante ensayos ELISA por extracción de sangre desde la oreja del animal. Al cabo de 4 meses, sin necesidad de una segunda dosis, los conejos se sangraron a blanco por degüello. Se extrajo suero de un animal no inmunizado como control. Para la obtención del suero la sangre se incubó a $37^{\circ} \mathrm{C}$ durante una hora, luego se mantuvo a $4^{\circ} \mathrm{C}$ por toda la noche. Se centrifugó a $3000 \mathrm{rpm}$ por $5 \mathrm{~min}$ a $4^{\circ} \mathrm{C}$ para separar el suero. El suero se fraccionó y se conservó a $-20^{\circ} \mathrm{C}$ hasta su uso.

\subsubsection{ELISA}

Se emplearon placas de 96 pocillos. Para sensibilizarlas se sembraron $100 \mu \mathrm{l}$ por pozo de solución de proteína $5 \mu \mathrm{g} / \mathrm{ml}$ en buffer PBS y se incubó toda la noche. Se bloqueó la placa con $200 \mu \mathrm{l}$ por pozo de PBS-leche $2 \%$ y se incubó $1 \mathrm{~h}$ a temperatura ambiente. Se lavó 3 veces con $300 \mu \mathrm{l}$ por pozo de PBS-Tween20 0.05\%. Se sembraron $100 \mu \mathrm{l}$ por pozo de diluciones seriadas del suero en PBS-leche $2 \%$ y se incubó $2 \mathrm{~h}$ a $37^{\circ} \mathrm{C}$. Se lavó 5 veces con $300 \mu \mathrm{l}$ por pozo de PBS-Tween20 0.05\%. Se agregaron $100 \mu \mathrm{l}$ por pozo de anticuerpo de cabra anti-IgG de conejo conjugado a peroxidasa de rábano picante HRP (del inglés horseradish peroxidase), dilución 1:5000 en PBS-leche 2\%. Se incubó $1 \mathrm{~h}$ a $37^{\circ} \mathrm{C}$. Se lavó 7 veces con $300 \mu \mathrm{l}$ por pozo de PBS-Tween20 0.05\%. Se agregaron $100 \mu \mathrm{l}$ por pozo de sustrato 3,3',5-tetrametilbenzina (TMB), $0.1 \mathrm{mg} / \mathrm{ml}, \mathrm{H}_{2} \mathrm{O}_{2} 0.03 \%$, en buffer fosfato/citrato, pH 5. Se incubó a temperatura ambiente 15 min. Se frenó la reacción mediante el agregado de $50 \mu \mathrm{l}$ por pozo de solución $\mathrm{H}_{2} \mathrm{SO}_{4} 2 \mathrm{~N}$. Los resultados se registraron en un lector de placas DTX 880 (Beckman Coulter) a una DO de $450 \mathrm{~nm}$ realizando una corrección 450-570 nm.

\subsection{Detección de Na-FAR-1}

Para determinar la existencia de proteína Na-FAR-1 nativa en el parásito, se realizó un análisis por western blot de extracto de N. americanus adulto. 
Las muestras se hirvieron en buffer de muestra con SDS y se separaron en gel de poliacrilamida en gradiente $4-20 \%$. Se sembraron $10 \mu \mathrm{l}$ de extracto de gusano adulto y 100 ng de proteínas FAR homólogas recombinantes como control. Seguidamente se transfirió a membrana PVDF (Millipore) por electro transferencia. El suero anti-NaFAR-1 se diluyó 1:5000 en PBS, pH 7.4 con Tween-20 0.05\% y se incubó con la membrana por $2 \mathrm{~h}$. Como anticuerpo secundario se utilizó IgG de cabra anti-lgG de conejo conjugada a HRP y para desarrollar la reacción se usó ECL (GE Healthcare).

\subsection{Inmunolocalización de Na-FAR-1}

Se prepararon nematodos $N$. americanus adultos como se describió previamente ${ }^{148}$. Brevemente, los gusanos adultos se recolectaron del intestino de hamsters que habían sido infectados con parásitos $N$. americanus en estadío larval L3, 45 días antes. Se fijaron con formaldehído $10 \%$ en solución acuosa. Los nematodos fijados se seccionaron y se montaron los preparados en portaobjetos de vidrio. Los sitios de unión inespecíficos se bloquearon con suero fetal bovino 5\% en PBS, 1 h de incubación. El suero de conejo anti-Na-FAR-1 se aplicó en dilución 1:500, a cada sección de tejido y se incubó durante $2 \mathrm{~h}$ en cámara húmeda a temperatura ambiente. El suero normal de conejo se usó en la misma dilución como control negativo. Las secciones histológicas se lavaron 6 veces por 5 min en PBS y se incubaron con anticuerpos IgG de cabra, antiIgG de conejo conjugados Cy3 (Rockland, Gilbertsville, PA). Para la visualización se empleó un microscopio invertido de fluorescencia Nikon TE-2000 con un filtro de excitación a $550 \mathrm{~nm}$ y una emisión de $565 \mathrm{~nm}$.

\subsection{Resultados}

El suero policlonal de conejo anti-NA-FAR-1 generado a partir de la proteína recombinante, se empleó para detectar la proteína Na-FAR-1 en un homogenato de parásito adulto Necator americanus, y se realizaron controles con suero normal de conejo y suero anti-Ac--FAR-1 (figura 7.1). 


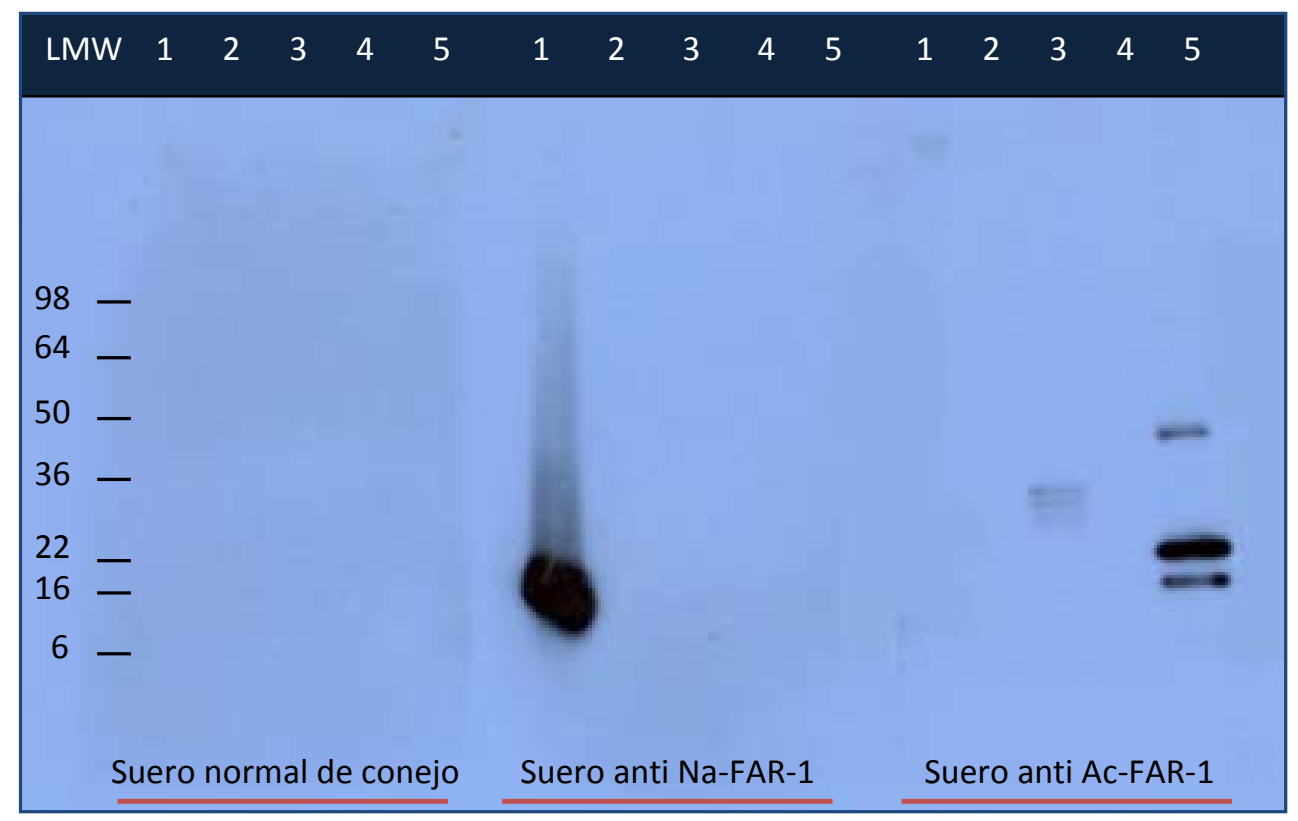

Fig.7.1. Western blot de extractos de $\mathbf{N}$. americanus con antisuero anti-Na-FAR-1. En el Western blot se observa que el suero anti-Na-FAR reconoce específicamente una banda intensa de alrededor de 17 kDa en el extracto de gusanos N. americanus adultos. Calles: LMW. Marcador de bajo peso molecular; 1. $10 \mu \mathrm{l}$ de extracto de gusanos adultos N. americanus; 2. Ac-API recombinante (100ng); 3. Bm-FAR-2 recombinante (100ng); 4. Bm-FAR-1 recombinante (100ng); 5. Ac-FAR-1 recombinante (100ng).

Según se observa en los resultados obtenidos por western blot, el suero anti-Na-FAR-1, reconoce específicamente una banda de aproximadamente 17 kDa en el extracto de gusanos adultos $N$. americanus y no se aprecia reacción cruzada con las proteínas homólogas de los nematodos Ancylostoma caninum (Ac-FAR-1) o Brugia malayi (BmFAR-1 y Bm-FAR-2), ni con una proteína no relacionada, el inhibidor de serina proteasa de A. caninum (Ac-SPI).

Las mismas muestras se sembraron a modo de control, incubadas con suero normal y suero anti Ac-FAR-1. En los controles realizados se comprobó que el suero control no reconoce ninguna proteína del extracto de Necator americanus y el suero anti Ac-FAR1 no presenta reactividad cruzada con el extracto del parásito en las diluciones estudiadas.

En el dendrograma presentado en la introducción (fugura 1.4) puede apreciarse que las FAR (Ac-FAR-1 y Bm-FAR-1) que no presentan reactividad cruzada con el sero antiNa-FAR-1 se agrupan en subgrupos diferentes al de Na-FAR-1 dentro del gran grupo de 
parásitos. En base a estos resultados podría esperarse que las FAR provenientes de $N$. americanus que se agrupan en subgrupos diferentes a Na-FAR-1, tampoco sean reconocidas por el antisuero.

Sin embargo, las proteínas NECAME_14206 y NECAME_04474, recientemente descubiertas al completarse el genoma de N. americanus, se agrupan junto a Na-FAR1, presentando un 67.31 y un $57.23 \%$ de identidad de secuencia, respectivamente. A su vez, poseen pesos moleculares teóricos muy similares a Na-FAR-1, con 156 aminoácidos NECAME_14206 tiene un peso molecular de 17780.19 Da y NECAME_04474, de 158 residuos presenta un peso molecular de 17455.66 Da. Consecuentemente la reactividad cruzada del antisuero con estas proteínas no puede descartarse, lo cual implica que la banda observada en el gel podría corresponder no sólo a Na-FAR-1 sino también a estas dos proteínas homólogas cercanas.

Tanto Na-FAR-1 como NECAME_14206 y NECAME_04474 presentan uno de los tres sitios de glicosilación conservados en las FAR, en la posición N29,L30,S31, los otros dos sitios estarían presentes en proteínas de filarias. Se ha reportado que los patrones de $\mathrm{N}$-glicosilaciones varían de una proteína a otra e incrementan el peso molecular en aproximadamente $2 \mathrm{kDa}{ }^{149}$. Esta variación en el peso molecular no permite descartar la presencia de estas modificaciones postraduccionales mediante el presente análisis.

Una vez comprobada la presencia de Na-FAR-1 y/o sus homólogas en el parásito, el suero anti-NAFAR-1 se empleó para la localización de las proteínas en secciones histológicas de nematodos adultos $N$. americanus. Los estudios de inmunolocalización mostraron que el suero anti-Na-FAR se unió fuertemente al intestino en especímenes de ambos sexos y a la apertura cloacal y a la bursa copulatoria de gusanos macho, revelando una ubicación interna de la o las proteínas en parásitos adultos (figura 7.2). No se puede afirmar si las 3 proteínas colocalizan o si en los distintos tejidos se presenta FAR diferentes pero cabe la posibilidad de que una/s cumplan funciones relacionadas a la reproducción y otra/s presenten funciones relacionadas a digestión. 

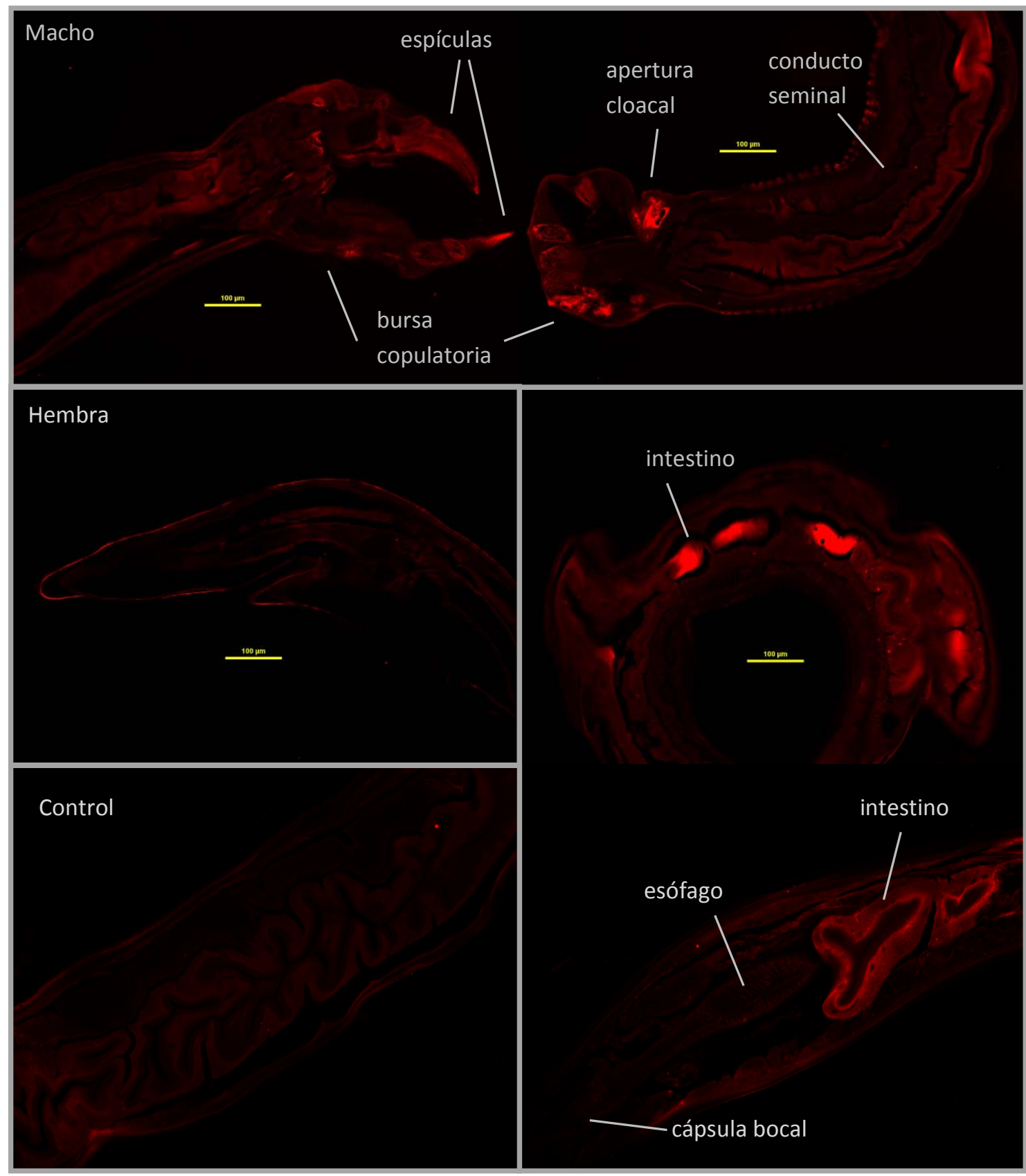

Fig.7.2. Localización tejido específica con suero anti-Na-FAR-1. La inmunolocalización con suero antiNa-FAR de conejo y anticuerpo secundario de cabra conjugado con Cy3, reveló que al menos una proteína FAR es reconocida en el intestino de $N$. americanus adulto de ambos sexos. También se detectó una proteína FAR en la bursa copulatoria y la apertura cloacal de gusanos macho, no así en la zona reproductiva femenina.

Las proteínas presentaron una localización diferencial en ambos sexos ya que fueron detectadas en el extremo posterior de gusanos macho, pero no así en las hembras. Se detectaron en el tracto reproductivo (espículas y bursa copulatoria) y apertura cloacal 
de machos pero no se observaron en la zona reproductiva femenina ni en el ano de parásitos hembra. Esto puede deberse a que en los machos el recto es una cloaca, que recibe también productos del sistema reproductivo conformado por los testículos, el conducto seminífero, las espículas y bursa copulatoria ${ }^{150}$. Esta localización podría estar sugiriendo un rol relacionado al transporte de lípidos con funciones reproductivas en machos.

Ciertas proteínas FAR también presentan una expresión diferencial de acuerdo al sexo en otros nematodos. Gp-FAR-1 del nematodo de plantas Golobdera pallida se detectó solo en hembras ${ }^{41}$, mientras que la proteína Ace-FAR-1 del nematodo Ancylostoma ceylanicum, cuyos huéspedes habituales son animales domésticos pero es capaz de infectar humanos, fue detectada en ovarios y útero de hembras adultas y en testículos en machos adultos ${ }^{45}$.

Las proteínas FAR han sido encontradas en los productos de Excresión/Secresión (ES) de parásitos adultos ${ }^{21,42,45}$ y si bien en este caso los productos de ES no fueron analizados la detección de las Na-FARs en la apertura cloacal sugiere que podrían ser secretadas. Los metabolitos presentes en los productos ES de los parásitos, ya sean los liberados mediante mecanismos activos de secreción o aquellos que puedan difundir a raíz de fugas o pérdidas desde el soma, pueden presentar actividad inmunomodulatoria y representan una interfaz de interacción entre el parásito y el hospedador ${ }^{34}$. Ov-FAR-1 fue descripta como el antígeno inmunodominante en la infección por esa filaria ${ }^{21}$, mientras que Ac-FAR-1 se detectó en productos ES de parásitos adultos ${ }^{42}$ y Ace-FAR-1 en los ES de hembras ${ }^{45}$.

La presencia de Na-FAR-1 o sus homólogas cercanas en el intestino podría estar indicando su participación en funciones metabólicas internas relacionadas al transporte de lípidos en los procesos digestivos. El tracto digestivo de los nematodos es complejo y posee regiones especializadas ${ }^{150}$. En la parte anterior del cuerpo se localiza la cavidad bucal conectada al esófago. El esófago es elongado y se subdivide en distintas regiones glandulares y musculares. Los músculos bombean alimentos desde la cápsula bucal al intestino, que está conectado al recto y este al ano en la superficie ventral del cuerpo. Las glándulas del esófago secretan enzimas digestivas en el lumen intestinal. La digestión inicial es extracelular y la digestión final intracelular ocurre en el 
intestino medio, donde se produce la absorción a través de la superficie de las microvellosidades de las células. Los nematodos son invertebrados pseudocelomados y no poseen estructuras circulatorias ni de intercambio de gases. Estas funciones se desarrollan por difusión y movimientos de los fluidos dentro de la cavidad corporal o pseudoceloma (producidos por los movimientos corporales), que están en contacto con los distintos tejidos y órganos (figura 7.3).

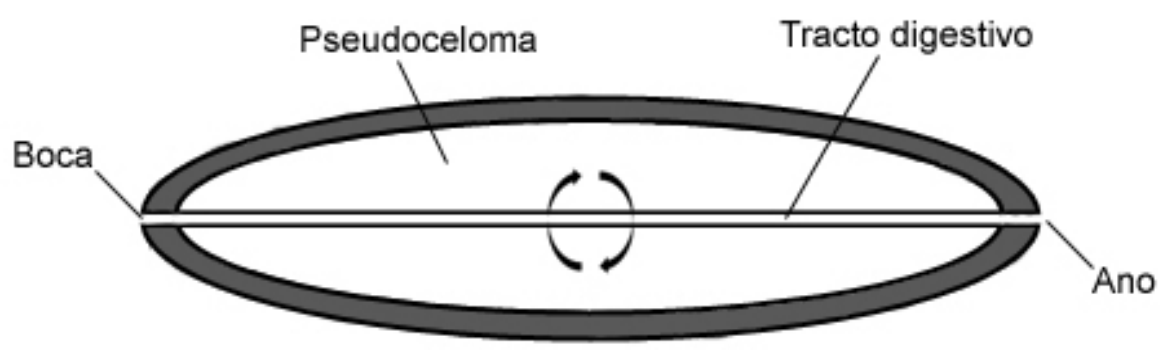

Nematodo

Fig.7.3. Representación esquemática del cuerpo de un nematodo. Los pseudocelomados o blastocelomados usan el fluido de la cavidad corporal para el transporte interno. Adaptado de ${ }^{150}$.

Aparentemente Na-FAR-1 y/o las FAR detectadas serían sintetizadas en las células del intestino, desde dónde podrían secretadas, dado que presentan péptido señal de secreción, hacia dos posibles regiones, la luz del intestino o la cavidad pseudocelómica. Sin embargo, no se detecta la presencia de Na-FARs en zonas extracelulares (figura 7.4).

Por limitaciones en la técnica de fijación empleada en el presente análisis, el contenido de las zonas extracelulares de los preparados podría perderse, debido a que para conservar su integridad se ha demostrado que se debe realizar una fijación en frío ${ }^{151}$.

El proceso de absorción de lípidos en la cara luminal del intestino requiere, al igual que en organismos superiores, de la emulsificación, lipólisis, y formación de micelas y puede producirse tanto por difusión simple como mediado por transportadores de membrana ${ }^{152}$. Luego, en las células intestinales los lípidos son procesados antes de ser activamente transportados al fluido pseudocelómico ${ }^{153}$. 


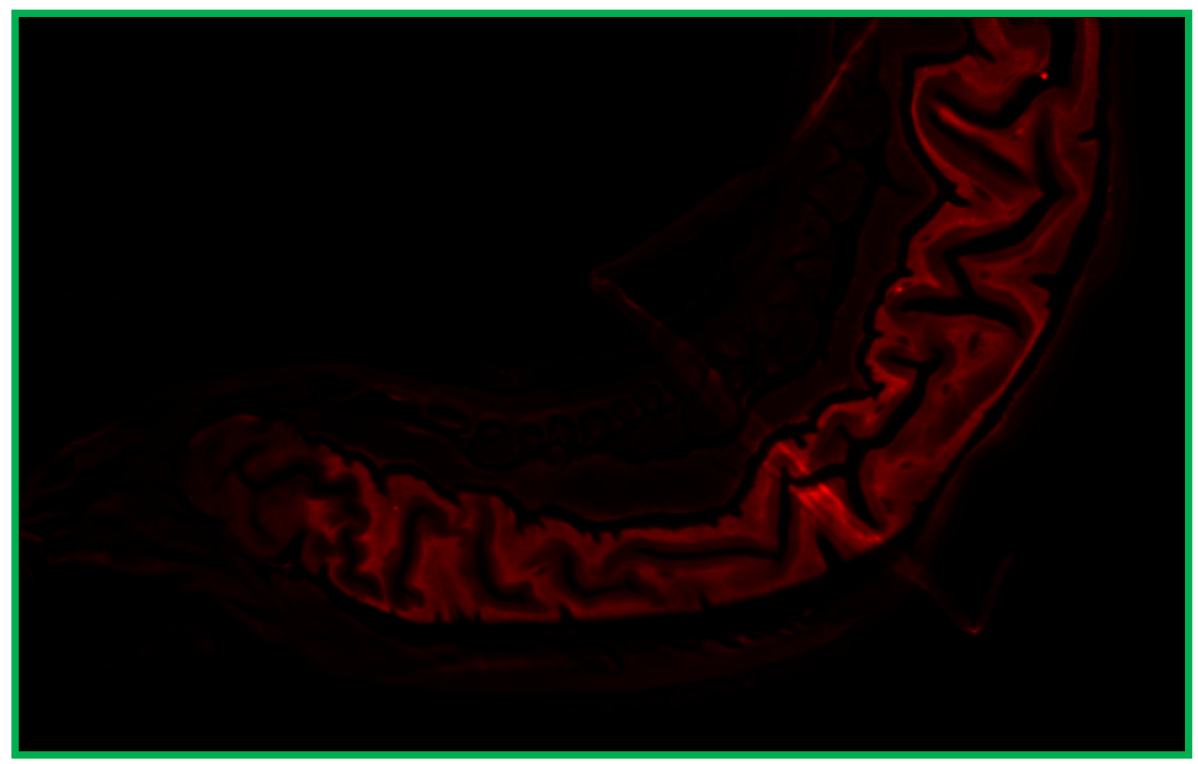

Fig.7.4. Localización intestinal de Na-FAR-1. La proteína es reconocida en el intestino de $N$. americanus adulto de ambos sexos. Pero no se detecta en las regiones extracelulares por limitaciones de la técnica empleada.

No está claro cuál sería el rol de la proteína Na-FAR-1 o sus homólogas en caso de ser liberadas hacia la luz del intestino pero podría especularse acerca de su función en caso mediarse su direccionamiento hacia el espacio pseudocelómico. Dado que los lípidos incorporados mediante la dieta deben ser enviados hacia otros tejidos, la o las FAR podrían estar participando en la solubilización de los distintos lípidos en el fluido de la cavidad corporal, para su distribución a los distintos tejidos del organismo.

La amplia diversidad de unión a ligando descripta para Na-FAR-1 en el capítulo precedente, sería funcional a la ubicación intestinal y esta capacidad de unión estaría en concordancia con su posible participación en la distribución de las distintas clases lipídicas absorbidas en el intestino.

Las FAR han sido detectadas en la hipodermis ${ }^{41,45,50}$, o pared corporal ${ }^{21}$ de otros nematodos adultos, sin embargo, Na-FAR-1 no se detectó en esta región (aunque esto puede deberse a las limitaciones antes mencionadas de la técnica). La luminiscencia observada en la figura 7.2, en zonas de la cutícula que recubre al parásito, correspondería a pegados inespecíficos.

La proteína de C. elegans, Ce-FAR-7, presenta una distribución tisular diferente a NaFAR-1. Esta proteína del nematodo de vida libre se localiza en la región de los labios y 
la cabeza, en la célula secretora y sus canales bilaterales y en la hipodermis ${ }^{50}$. La célula secretora (o célula de renette) ubicada en la zona anterior del cuerpo participa en la osmorregulación y excreción de metabolitos mientras que en la hipodermis se almacenan nutrientes de reserva. Las diferencias encontradas en cuanto a localización indicarían que ambas proteínas participarían en distintas funciones dentro de los nematodos.

\subsection{Conclusiones}

El suero anti Na-FAR-1 producido en conejo reconoce una banda de $17 \mathrm{kDa}$ en $\mathrm{N}$. americanus adulto y no reconoce las proteínas FAR homólogas de otros parásitos. Si bien el tamaño de la proteína detectada corresponde al esperado para Na-FAR-1, $N$. americanus produce otras proteínas FAR de secuencia y tamaño similares por lo que la presencia de reactividad cruzada del suero con estas proteínas no puede descartarse.

Na-FAR-1 y/o las Na-FARs homólogas estarían presentes en el intestino de parásitos adulto, y en la región posterior de machos adultos, específicamente en la bursa compulatoria y apertura cloacal.

La posible localización de Na-FAR-1, podría estar indicando roles relacionados al transporte de lípidos con funciones reproductivas en machos y en procesos digestivos en parásitos adultos de ambos sexos. Esta proteína, capaz de unir una gran diversidad de clases lipídicas podría participar en la solubilización y transporte pseudocelómico de compuestos hidrofóbicos. La presencia de diferentes proteínas FAR en un mismo organismo, como surge del reciente estudio del genoma completo de N. americanus, sugiere que podrían cumplir funciones complementarias. 


\section{Discusión general y conclusiones}

En el presente trabajo de tesis se optimizaron las condiciones para la obtención de la proteína Na-FAR-1 en cantidad y calidad necesarias para su análisis por biología estructural. Esto permitió la caracterización desde el punto de vista funcional y la determinación de la estructura tridimensional en solución por espectroscopía de resonancia magnética nuclear con alta calidad. Esta proteína no ha sido estudiada previamente por otros autores y constituye el primer ejemplo de estructura de una FAR procedente de nematodo parásito. Con anterioridad al presente trabajo, solo se contaba con la estructura cristalográfica de una FAR del nematodo de vida libre $C$. elegans (Ce-FAR-7).

Las proteínas transportadoras de lípidos más estudiadas son las de la familia de proteínas con estructuras barril- $\beta$ (FABP/P2/CRBP/CRABP). Estas proteínas son transportadores intracelulares de lípidos que están presentes en todo el phylum metazoa ${ }^{154}$ y tienen un tamaño menor al de las FAR. Los nematodos presentan el único ejemplo donde miembros de esta familia de proteínas, al igual que las FAR, son extracelulares $^{29}$.

Los nematodos también exhiben una segunda familia de proteínas de unión a lípidos ricas en $\alpha$-hélices de menor tamaño, las poliproteínas NPAs, cuya estructura ha sido determinada recientemente ${ }^{36}$. Las NPAs se sintetizan como precursores de gran tamaño que son clivados postraduccionalmente para generar las unidades funcionales capaces de unir ácidos grasos y retinol. Estas proteínas presentan también un plegamiento novedoso con dos cavidades internas discretas para la unión a ligandos. Ambas familias, NPAs y FARs, podrían representar un ejemplo de evolución convergente donde dos motivos de plegado fueron seleccionados para tener propiedades similares (afinidad por ligandos hidrofóbicos), pero aún no está esclarecido si poseen funciones únicas o si resultan un caso de redundancia funcional con ventajas adaptativas a la relación huésped-parásito.

Los parásitos helmintos, como Echinococcus granulosus, producen otro tipo de proteínas mayoritariamente alfa helicoidales, las HLBPs ${ }^{32}$. Estas proteínas poseen 
distintas subunidades de pequeño tamaño (8KDa) que se asocian entre sí y con una amplia variedad de lípidos, pero su estructura no ha sido aún determinada.

Entre las proteínas solubles de unión a lípidos cuya estructura secundaria, al igual que las FAR, es rica en hélices $\alpha$ se encuentran la seroalbúmina de vertebrados y las proteínas pequeñas de unión a lípidos no específicas de plantas, nsLTPs. La albúmina es una proteína de mayor tamaño que las FARs $(67 \mathrm{kDa})$ y es el transportador mayoritario de ácidos grasos en sangre en mamíferos, pero también es capaz de unir una amplia diversidad de ligandos ${ }^{155}$. Las nsLTP de plantas son proteínas transportadoras de lípidos pequeñas (7kDa aproximadamente) ricas en $\alpha$-hélices, involucradas en el transporte de estos compuestos para reservas y en la transmisión de señales y a su vez capaces de unir fosfolípidos ${ }^{156}$.

Sin embargo, la estructura de ninguna de estas familias de proteínas parece estar relacionada con la de las FAR. Na-FAR-1 presenta 11 hélices que se disponen formando una estructura elipsoidal con una cavidad central hidrofóbica. Mediante el análisis de dinámica estructural en solución se identificó que toda la molécula es apreciablemente rígida, especialmente los elementos de estructura secundaria regular $\alpha$-helicoidales y que presenta anisotriopía difusional en concordancia con la forma elipsoidal aplanada. La región dónde se observó una mayor movilidad comprende el lazo 4, entre las hélices $\alpha 4$ y $\alpha 5$. Esa alta movilidad sería la causa por la cual esta región se encuentra menos definida en la estructura de Na-FAR-1 y podría ser funcional a la entrada y salida de ligandos La estructura de la proteína presenta cambios globales asociados a la unión a ligando como una estructura más expandida y un tamaño de cavidad interna dos veces mayor en la proteína unida a ligando en comparación con la forma libre. Pese a estas diferencias notorias, el arreglo helicoidal y los ángulos que forman no se modifican drásticamente conservando el mismo plegamiento.

Pese a las diferencias existentes en la secuencia primaria de ambas proteínas, Ce-FAR7 y Na-FAR-1, presentan el mismo patrón de plegamiento. Las similitudes encontradas indican que existiría un elevado grado de conservación en las estructuras de miembros distantes de la familia de proteínas FAR. Sin embargo, también exhiben diferencias en cuanto a longitud y orientación de ciertas hélices que determinan cavidades hidrofóbicas características y que llevan aparejada una variación en las propiedades de 
unión a ligando. Estas observaciones podrían relacionarse con los distintos roles que podrían cumplir estas proteínas, que no sólo provienen de organismos diferentes, un nematodo de vida libre y un nematodo parásito intestinal, sino que también presentan diferencias en cuanto a la su localización tisular.

En cuanto a los compuestos hidrofóbicos que Na-FAR-1 es capaz de unir, su especificidad no se limita a ácidos grasos y retinol, sino que une también lípidos más voluminosos y polares como fosfolípidos y lípidos neutros como los diacilgliceridos. Frente a estos resultados, dado que la unión de las FAR a este tipo de compuestos no había sido estudiada previamente, se amplía el panorama en cuanto a la diversidad de ligandos que es capaz de unir esta familia de proteínas. En cuanto a la afinidad que presenta Na-FAR-1 por los distintos ligandos, la unión de ácidos grasos y retinol se encuentra en el orden submicromolar, comparable a valores reportados para otras FAR. La estequiometria de los complejos de Na-FAR-1 con retinol y análogos fluorescentes de ácidos grasos es 1:1 (proteína:ligando), pero sería capaz de unir cuatro moléculas de ácidos grasos por molécula de proteína. Asimismo, Na-FAR-1 es capaz de transferir ligandos a membranas artificiales. Si bien las funciones de Na-FAR-1 no están aún establecidas, estas características de alta afinidad y baja especificidad de unión podrían ser compatibles con una función de solubilización y transporte pseudocelómico de lípidos para funciones metabólicas y, posiblemente, asociadas a la reproducción dada la localización interna de la proteína en el parásito.

La presencia de diferentes proteínas FAR en un mismo organismo sugiere que podrían cumplir funciones complementarias, participando en el transporte de ligandos hidrofóbicos y manteniendo disponibles en solución cantidades significativas de lipidos para su metabolismo posterior en distintos tejidos del nematodo. 


\section{Apéndice $A$.}

\section{Asignación de los desplazamientos químicos de Na-FAR-1.}

Los desplazamientos químicos se indican en ppm.

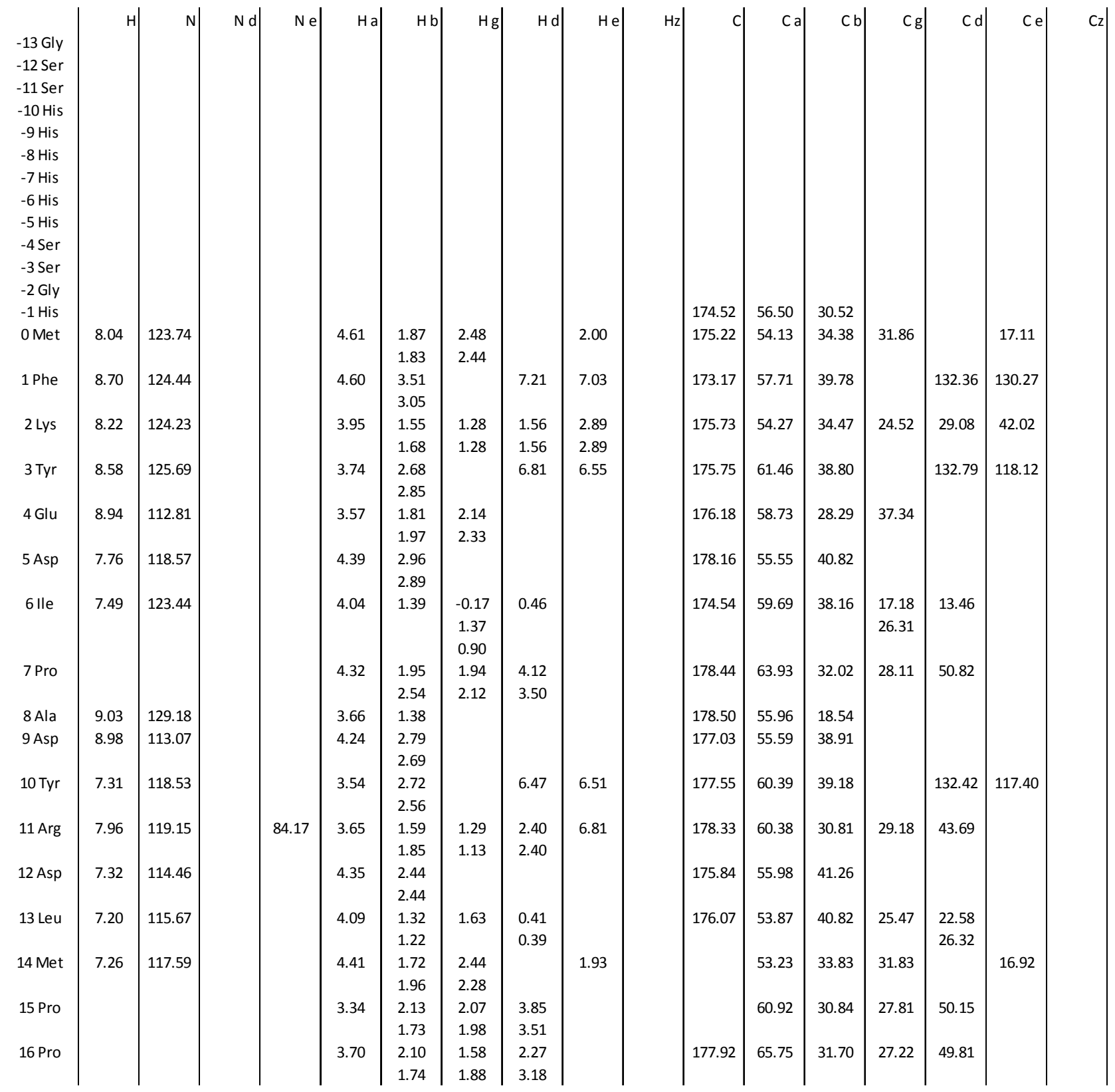




\begin{tabular}{|c|c|c|c|c|c|c|c|c|c|c|c|c|c|c|c|c|c|}
\hline & $\mathrm{H}$ & $\mathrm{N}$ & $\mathrm{Nd}$ & $\mathrm{Ne}$ & $\mathrm{Ha}$ & $\mathrm{Hb}$ & $\mathrm{Hg}$ & $\mathrm{Hd}$ & $\mathrm{He}$ & $\mathrm{Hz}$ & c & $\mathrm{Ca}$ & $\mathrm{Cb}$ & $\mathrm{Cg}$ & $\mathrm{Cd}$ & $\mathrm{Ce}$ & $\mathrm{Cz}$ \\
\hline $17 \mathrm{Glu}$ & 9.84 & 117.06 & & & 3.95 & 1.72 & 2.33 & & & & 179.62 & 60.45 & 28.77 & 36.98 & & & \\
\hline & & & & & & 1.81 & 2.23 & & & & & & & & & & \\
\hline $18 \mathrm{Ala}$ & 7.22 & 121.16 & & & 4.17 & 1.43 & & & & & 179.63 & 54.42 & 18.82 & & & & \\
\hline $19 \mathrm{Arg}$ & 7.62 & 118.37 & & 85.97 & 3.81 & 1.90 & 1.71 & 2.98 & 6.58 & & 177.97 & 60.42 & 30.92 & 28.76 & 44.08 & & \\
\hline & & & & & & 1.81 & 1.48 & 3.31 & & & & & & & & & \\
\hline 20 Asp & 8.31 & 118.08 & & & 4.01 & 2.53 & & & & & 177.94 & 57.42 & 41.12 & & & & \\
\hline $21 \mathrm{Phe}$ & 7.16 & 117.91 & & & 4.11 & $\begin{array}{l}2.45 \\
3.07\end{array}$ & & 7.12 & 7.15 & 6.85 & 177.28 & 60.76 & 39.12 & & 131.92 & 132.27 & 131.60 \\
\hline & & & & & & 3.27 & & & & & & & & & & & \\
\hline 22 Leu & 7.63 & 116.57 & & & 3.79 & 1.41 & 2.22 & 0.96 & & & 179.03 & 57.21 & 43.61 & 27.03 & 26.61 & & \\
\hline & & & & & & 2.07 & & 1.18 & & & & & & & 24.08 & & \\
\hline $23 \mathrm{Gln}$ & 8.16 & 117.17 & & 110.42 & 3.27 & 1.47 & 1.66 & & 6.60 & & 176.49 & 58.29 & 28.90 & 34.18 & 179.97 & & \\
\hline & & & & & & 1.33 & 1.59 & & 6.75 & & & & & & & & \\
\hline 24 Asn & 6.98 & 113.91 & 115.40 & & 4.58 & 2.53 & & 7.47 & & & 174.70 & 53.40 & 39.69 & 177.88 & & & \\
\hline & & & & & & 2.75 & & 6.73 & & & & & & & & & \\
\hline 25 Leu & 6.55 & 119.49 & & & 4.29 & 1.14 & 1.84 & 0.76 & & & 177.28 & 54.96 & 43.36 & 25.18 & 26.66 & & \\
\hline & & & & & & 1.62 & & 0.20 & & & & & & & 22.63 & & \\
\hline 26 Ser & 9.36 & 121.66 & & & 4.56 & 4.30 & & & & & 175.22 & 56.58 & 66.02 & & & & \\
\hline & & & & & & 3.97 & & & & & & & & & & & \\
\hline 27 Asp & 9.00 & 121.65 & & & 4.30 & 2.57 & & & & & 179.36 & 58.20 & 39.61 & & & & \\
\hline & & & & & & 2.57 & & & & & & & & & & & \\
\hline $28 \mathrm{Gly}$ & 8.48 & 109.03 & & & 3.78 & & & & & & 176.50 & 47.10 & & & & & \\
\hline & & & & & 3.78 & & & & & & & & & & & & \\
\hline 29 Asp & 8.00 & 123.30 & & & 4.27 & 2.41 & & & & & 178.38 & 57.18 & 42.18 & & & & \\
\hline & & & & & & 3.01 & & & & & & & & & & & \\
\hline 30 Lys & 8.14 & 117.96 & & & 3.83 & 2.06 & 1.69 & 1.50 & 2.64 & & 179.63 & 60.66 & 32.70 & 27.84 & 30.12 & 42.66 & \\
\hline & & & & & & 2.06 & 1.21 & 1.71 & 2.31 & & & & & & & & \\
\hline $31 \mathrm{Thr}$ & 8.07 & 118.49 & & & 3.94 & 4.41 & 1.24 & & & & 176.02 & 67.20 & 68.75 & 21.59 & & & \\
\hline $32 \mathrm{Val}$ & 7.64 & 122.88 & & & 3.65 & 2.16 & 1.03 & & & & 177.73 & 66.86 & 31.25 & 22.92 & & & \\
\hline & & & & & & & 0.83 & & & & & & & 22.83 & & & \\
\hline 33 Leu & 8.38 & 119.12 & & & 3.77 & 0.80 & 1.61 & 0.55 & & & 178.59 & 58.81 & 41.97 & 26.40 & 26.26 & & \\
\hline & & & & & & 1.70 & & 0.30 & & & & & & & 23.15 & & \\
\hline 34 Lys & 7.88 & 118.80 & & & 3.82 & 2.09 & 1.39 & 1.74 & 3.01 & & 177.63 & 60.71 & 32.29 & 25.41 & 29.90 & 42.21 & \\
\hline & & & & & & 2.09 & 1.39 & 1.73 & 3.01 & & & & & & & & \\
\hline $35 \mathrm{Glu}$ & 7.85 & 116.86 & & & 3.88 & 2.00 & 2.20 & & & & 180.31 & 59.54 & 29.87 & 36.37 & & & \\
\hline & & & & & & 2.14 & 2.44 & & & & & & & & & & \\
\hline $36 \mathrm{Val}$ & 8.74 & 118.10 & & & 3.63 & 1.94 & 0.33 & & & & 180.38 & 66.56 & 32.01 & 20.13 & & & \\
\hline & & & & & & & 0.88 & & & & & & & 24.15 & & & \\
\hline 37 Phe & 8.92 & 118.92 & & & 4.40 & 3.15 & & 7.70 & 7.27 & 7.27 & 178.91 & 63.67 & 37.62 & & 131.34 & 131.26 & 130.17 \\
\hline & & & & & & 3.13 & & & & & & & & & & & \\
\hline 38 Lys & 8.38 & 121.81 & & & 4.23 & 1.95 & 1.53 & 1.64 & 3.00 & & 176.58 & 59.03 & 32.07 & 26.19 & 29.45 & 41.84 & \\
\hline & & & & & & 1.90 & 1.74 & 1.64 & 3.00 & & & & & & & & \\
\hline 39 Ala & 6.95 & 120.84 & & & 4.49 & 1.41 & & & & & 176.33 & 51.54 & 18.50 & & & & \\
\hline 40 Gly & 7.03 & 105.56 & & & 3.13 & & & & & & 171.32 & 43.39 & & & & & \\
\hline & & & & & 2.74 & & & & & & & & & & & & \\
\hline 41 Pro & & & & & 4.38 & 1.91 & 1.77 & 3.36 & & & 175.69 & 62.12 & 35.22 & 24.83 & 50.50 & & \\
\hline & & & & & & 2.31 & 1.67 & 3.36 & & & & & & & & & \\
\hline $42 \mathrm{Tyr}$ & 8.64 & 119.87 & & & 4.63 & 2.58 & & 6.96 & 6.37 & & 176.61 & 57.14 & 40.26 & & 132.75 & 117.07 & \\
\hline & & & & & & 3.15 & & & & & & & & & & & \\
\hline 43 Lys & 9.22 & 122.30 & & & 3.94 & 1.75 & 1.49 & 1.63 & 2.93 & & 176.20 & 58.62 & 33.33 & 24.97 & 29.05 & 42.00 & \\
\hline & & & & & & 1.67 & 1.39 & 1.63 & 2.93 & & & & & & & & \\
\hline 44 Asn & 7.30 & 108.84 & 113.11 & & 4.74 & 3.09 & & 7.44 & & & 175.98 & 51.66 & 39.86 & 175.75 & & & \\
\hline & & & & & & 3.18 & & 6.82 & & & & & & & & & \\
\hline $45 \mathrm{Thr}$ & & & & & 3.80 & 3.75 & 0.81 & & & & & 66.29 & 68.48 & 21.47 & & & \\
\hline $46 \mathrm{Glu}$ & 8.91 & 123.46 & & & 3.64 & 1.84 & 2.39 & & & & 179.44 & 61.49 & 27.98 & 37.67 & & & \\
\hline & & & & & & 2.04 & 2.17 & & & & & & & & & & \\
\hline $47 \mathrm{Glu}$ & 8.35 & 120.16 & & & 4.00 & 2.15 & 2.50 & & & & 179.20 & 59.50 & 30.44 & 37.26 & & & \\
\hline & & & & & & 2.08 & 2.28 & & & & & & & & & & \\
\hline
\end{tabular}




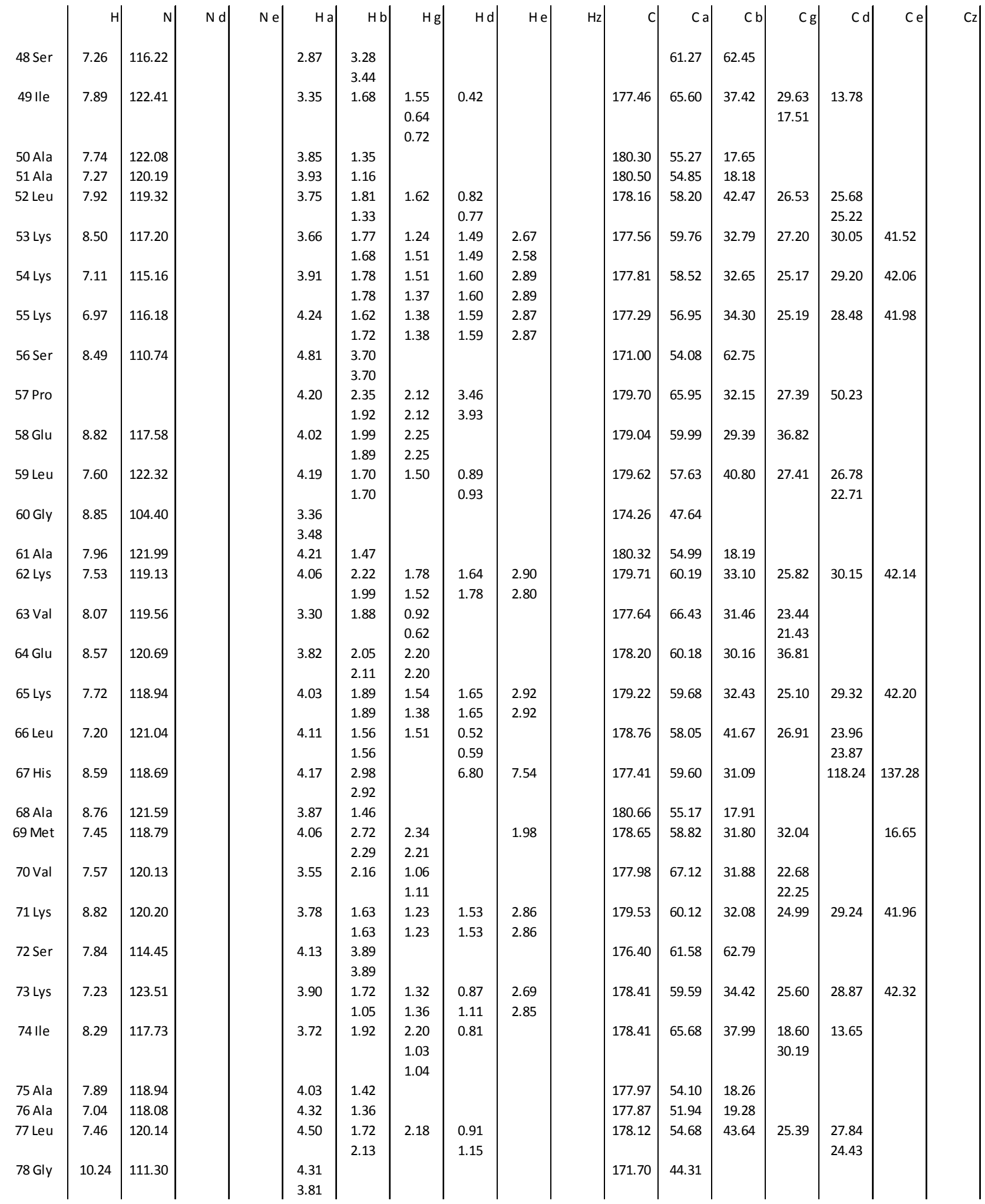




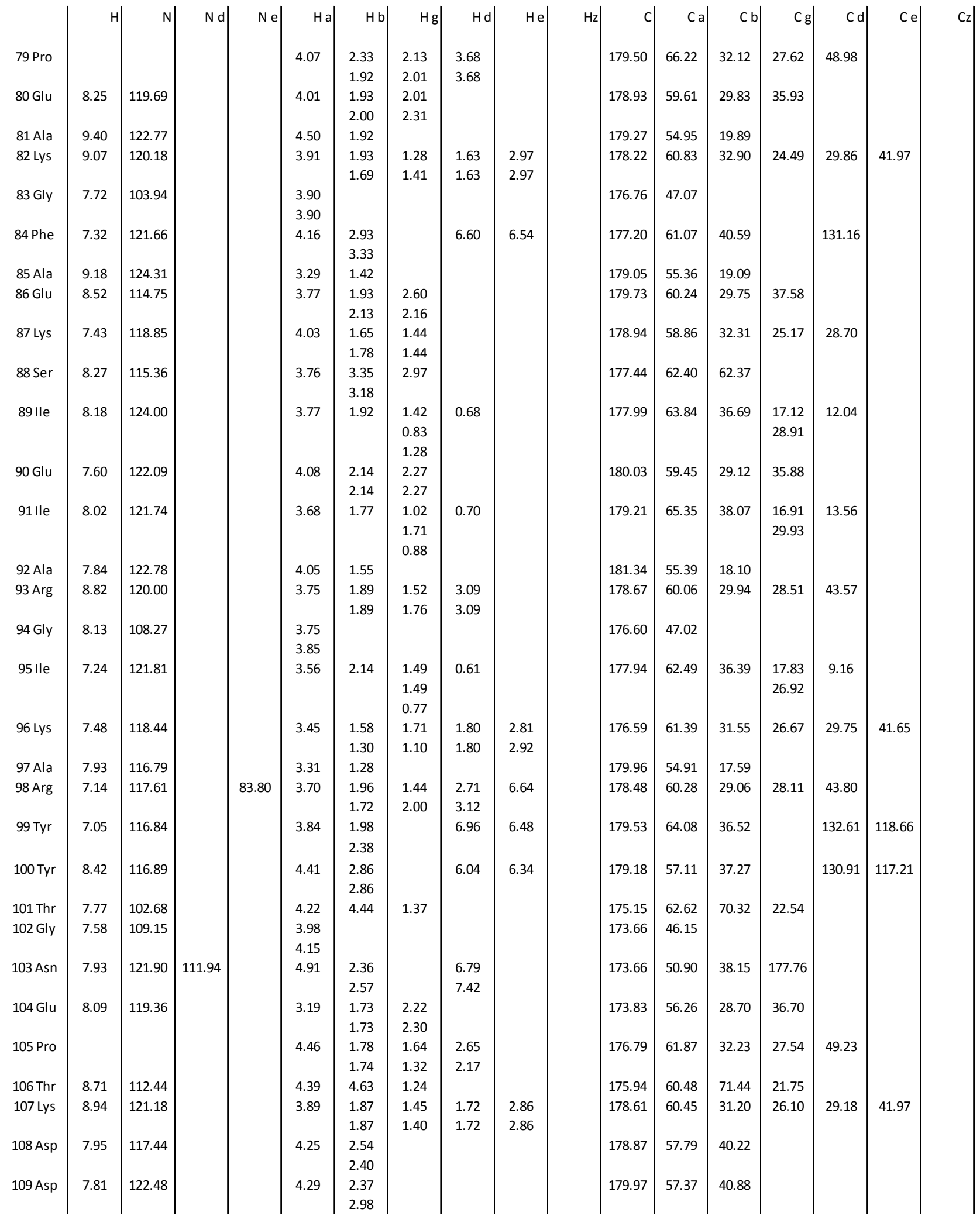




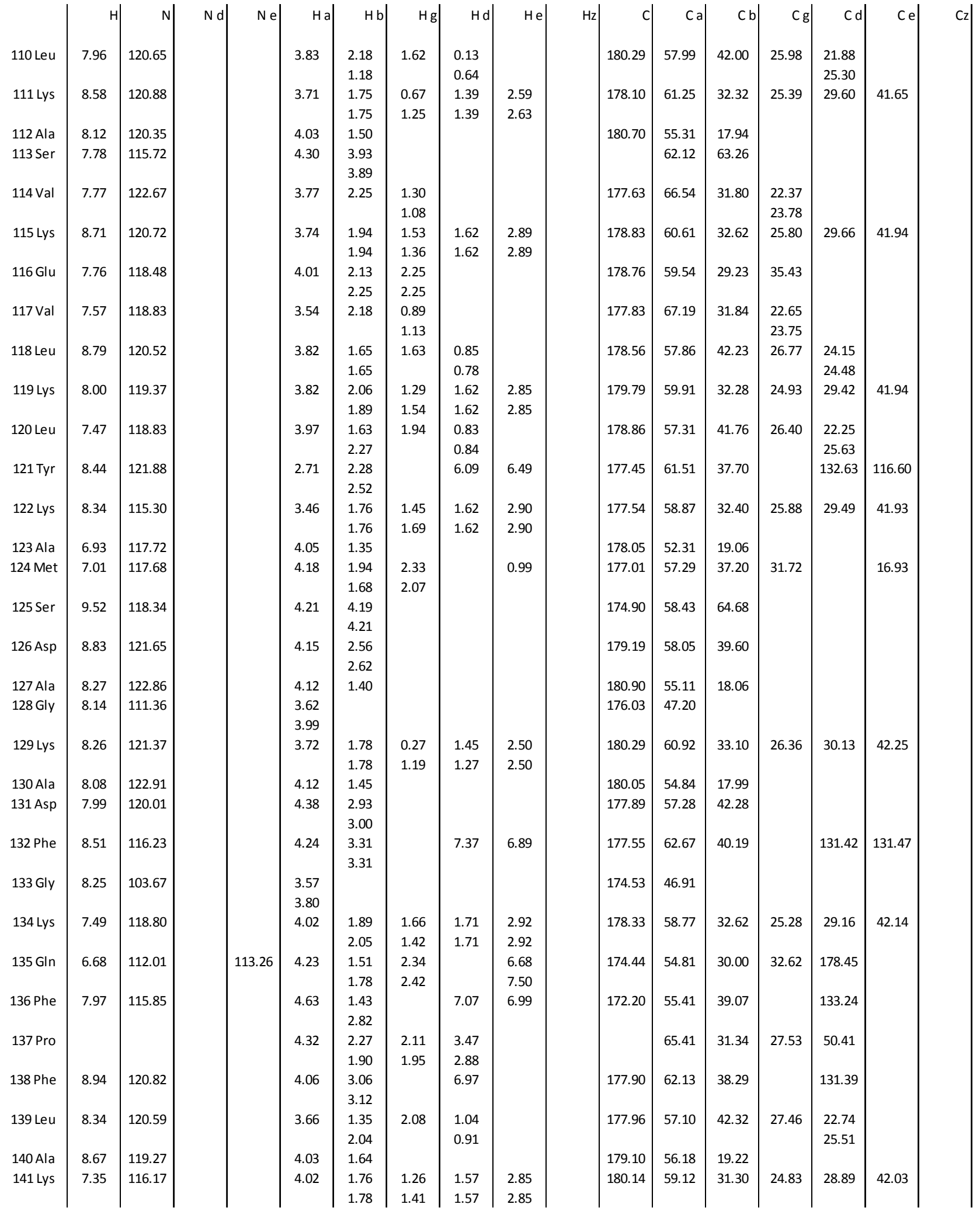




\begin{tabular}{|c|c|c|c|c|c|c|c|c|c|c|c|c|c|c|c|c|c|}
\hline & $\mathrm{H}$ & $\mathrm{N}$ & $N d$ & $\mathrm{Nel}$ & $\mathrm{Hal}$ & $\mathrm{Hhl}$ & $\mathrm{Hol}$ & $\mathrm{HAl}$ & $\mathrm{Hel}$ & $\mathrm{Hz}$ & d & lal & $\mathrm{chl}$ & $\mathrm{Cg}$ & 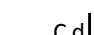 & $\mathrm{cel}$ & $C_{7}$ \\
\hline \multirow[t]{2}{*}{$142 \mathrm{Val}$} & 7.59 & 120.74 & & & 3.35 & 1.90 & 0.53 & & & & 178.16 & 66.71 & 31.11 & 22.79 & & & \\
\hline & & & & & & & 0.48 & & & & & & & 22.43 & & & \\
\hline \multirow[t]{2}{*}{143 Phe } & 7.73 & 117.94 & & & 4.31 & 2.22 & & 6.58 & 7.00 & & 179.05 & 58.98 & 37.17 & & 130.87 & & \\
\hline & & & & & & 2.29 & & & & & & & & & & & \\
\hline \multirow[t]{2}{*}{$144 \mathrm{Glu}$} & 8.97 & 119.97 & & & 4.11 & 2.09 & 2.44 & & & & 178.89 & 58.89 & 30.32 & 36.01 & & & \\
\hline & & & & & & 2.11 & 2.44 & & & & & & & & & & \\
\hline \multirow[t]{2}{*}{$145 \mathrm{Ser}$} & 8.32 & 111.02 & & & 4.29 & 4.04 & & & & & 175.67 & 60.12 & 64.84 & & & & \\
\hline & & & & & & 3.99 & & & & & & & & & & & \\
\hline \multirow[t]{2}{*}{$146 \mathrm{Gly}$} & 7.27 & 108.32 & & & 4.45 & & & & & & 175.21 & 45.61 & & & & & \\
\hline & & & & & 3.93 & & & & & & & & & & & & \\
\hline \multirow[t]{2}{*}{147 Lys } & 7.78 & 122.15 & & & 3.90 & 1.64 & 1.43 & 1.49 & 2.85 & & 179.35 & 60.22 & 32.79 & 25.22 & 29.35 & 41.66 & \\
\hline & & & & & & 1.73 & 1.28 & 1.49 & 2.85 & & & & & & & & \\
\hline $148 \mathrm{Ala}$ & 7.52 & 120.05 & & & 4.00 & 1.30 & & & & & 177.97 & 55.26 & 18.26 & & & & \\
\hline 149 Ala & 8.07 & 120.36 & & & 3.77 & 1.37 & & & & & 179.79 & 55.22 & 17.88 & & & & \\
\hline \multirow[t]{2}{*}{150 Lys } & 8.14 & 118.32 & & & 4.02 & 1.85 & 1.42 & 1.63 & & & 179.27 & 58.86 & 32.13 & 24.99 & 28.90 & & \\
\hline & & & & & & 1.85 & 1.42 & 1.63 & & & & & & & & & \\
\hline \multirow[t]{2}{*}{151 Phe } & 7.54 & 119.47 & & & 4.18 & 3.12 & & 7.07 & 7.09 & 7.08 & 176.18 & 61.01 & 39.50 & & 132.21 & & 131.52 \\
\hline & & & & & & 3.29 & & & & & & & & & & & \\
\hline 152 Ala & 8.13 & 117.08 & & & 3.78 & 1.40 & & & & & 177.08 & 53.36 & 19.25 & & & & \\
\hline \multirow[t]{2}{*}{$153 \mathrm{Gly}$} & 7.59 & 104.24 & & & 3.95 & & & & & & 174.25 & 45.32 & & & & & \\
\hline & & & & & 3.78 & & & & & & & & & & & & \\
\hline \multirow[t]{2}{*}{$154 \mathrm{Glu}$} & 7.99 & 120.01 & & & 4.28 & 1.70 & 2.07 & & & & 175.20 & 56.01 & 31.13 & 36.27 & & & \\
\hline & & & & & & 2.03 & 2.15 & & & & & & & & & & \\
\hline 155 Asn & 7.93 & 124.56 & 112.38 & & 4.34 & $\begin{array}{l}2.64 \\
2.55\end{array}$ & & $\begin{array}{l}7.37 \\
6.68\end{array}$ & & & 179.36 & 54.88 & 40.46 & 178.18 & & & \\
\hline
\end{tabular}




\section{Apéndice $B$.}

\section{Resultados PROCHECK_NMR de Na-FAR-1}

\section{Gráficos Ramachandran (20 modelos)}

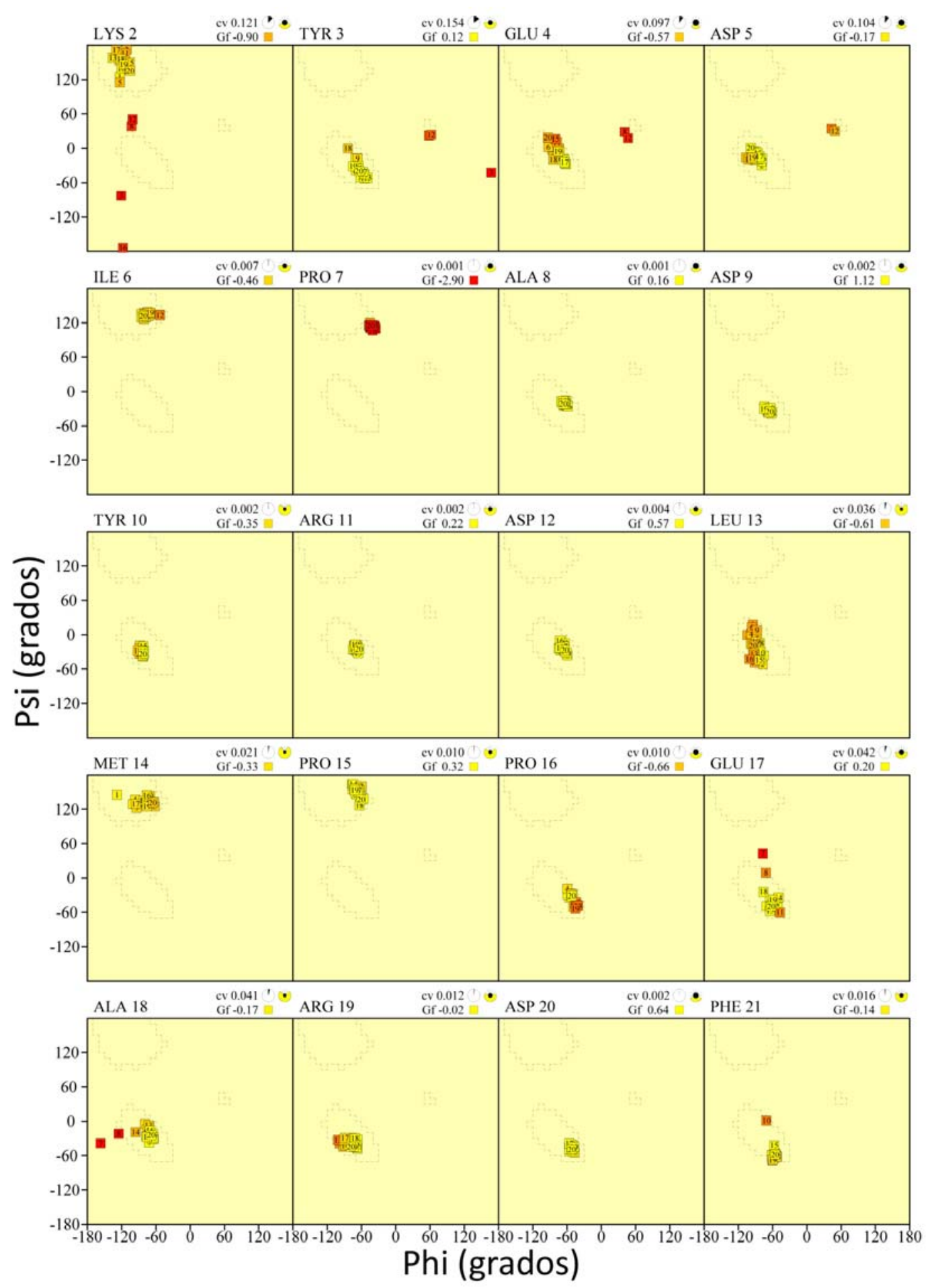




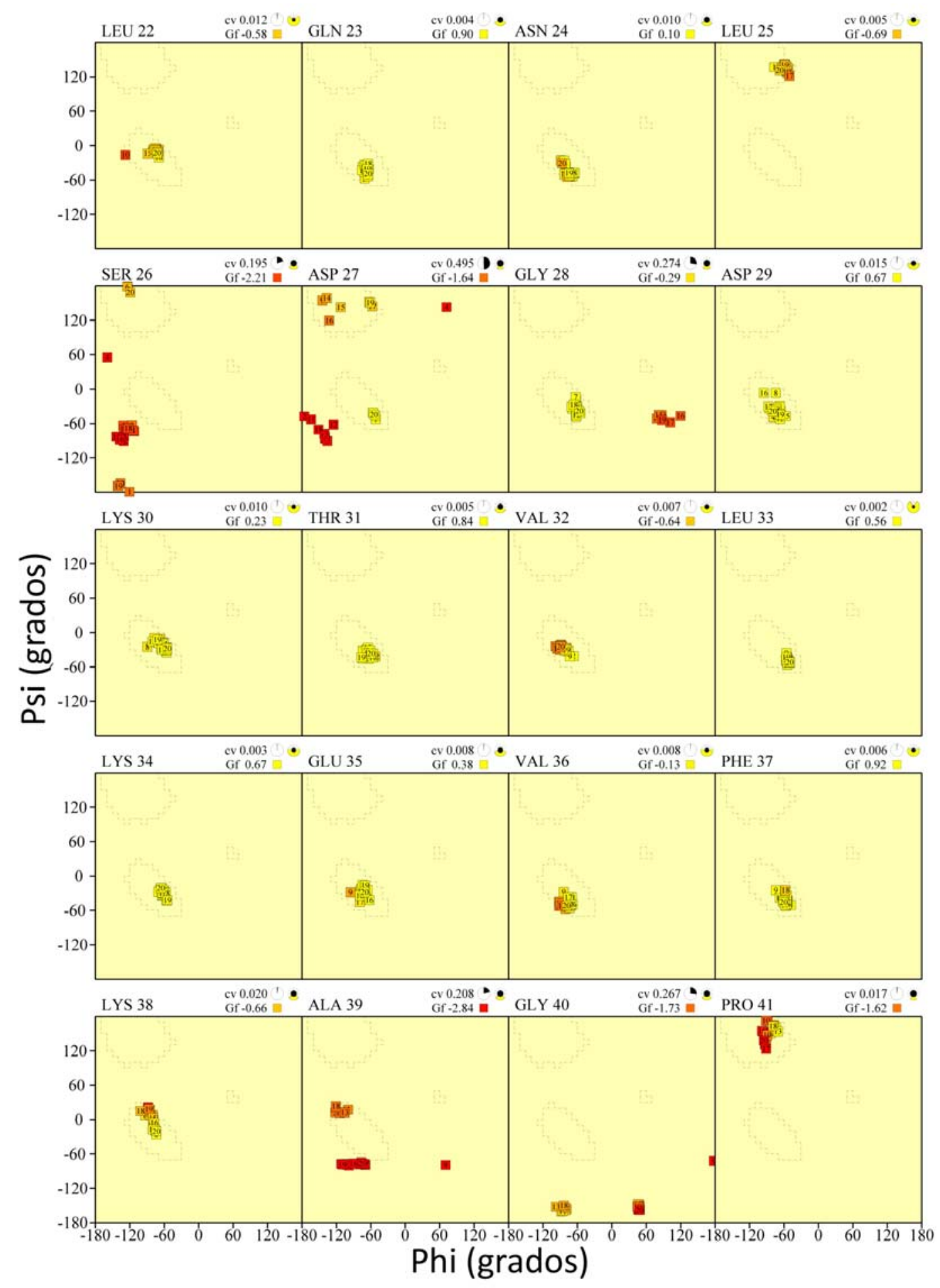




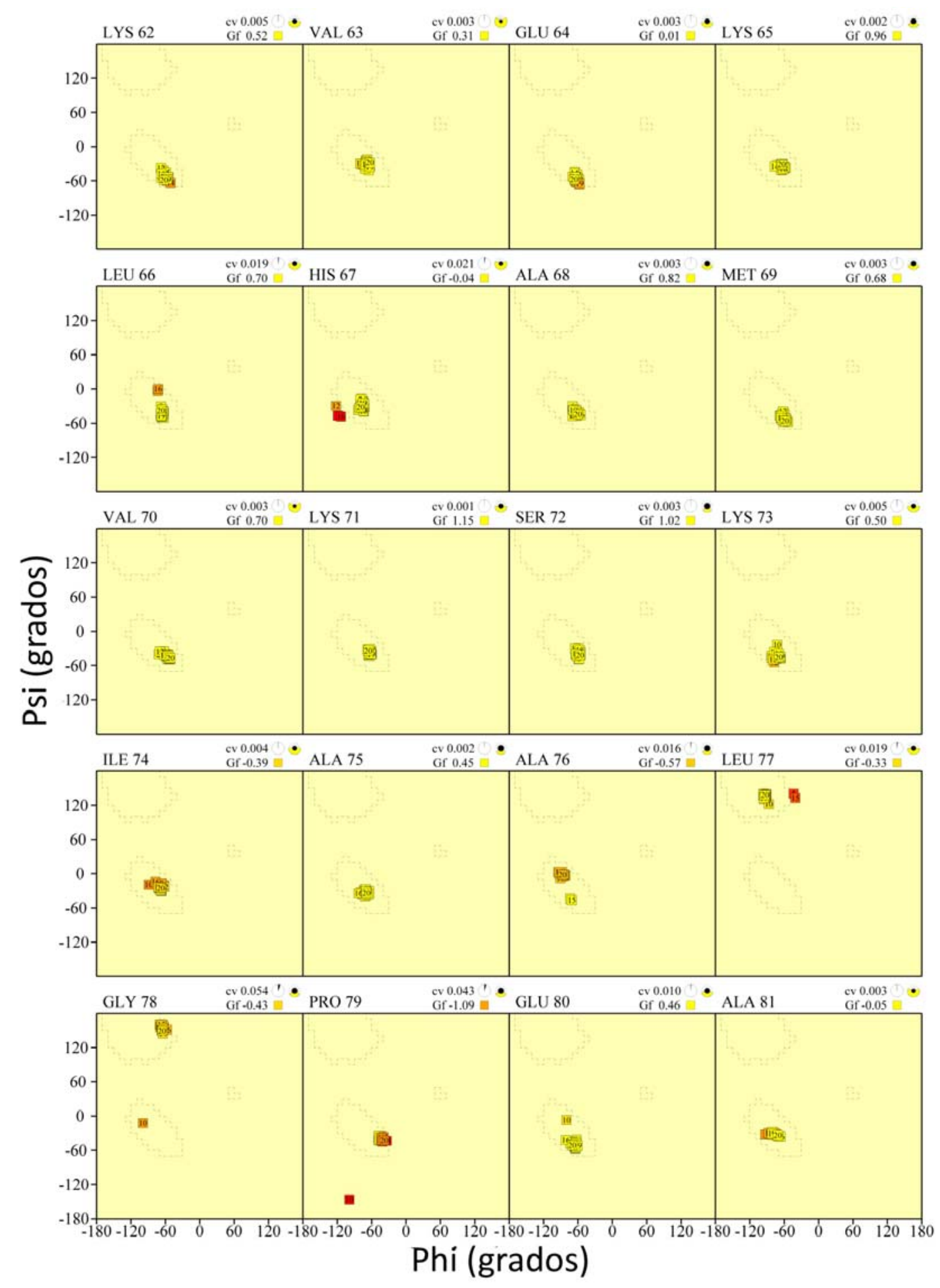




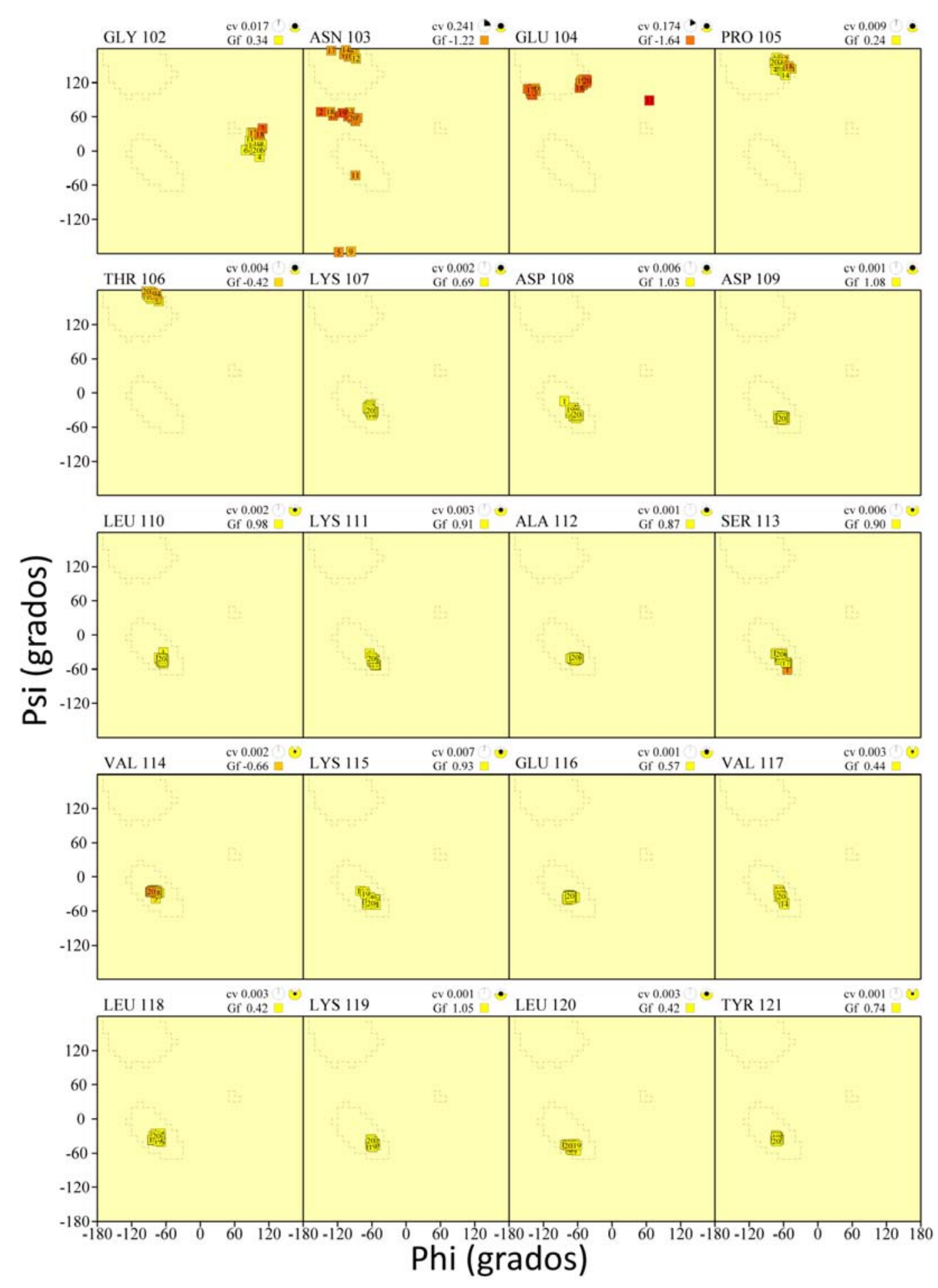




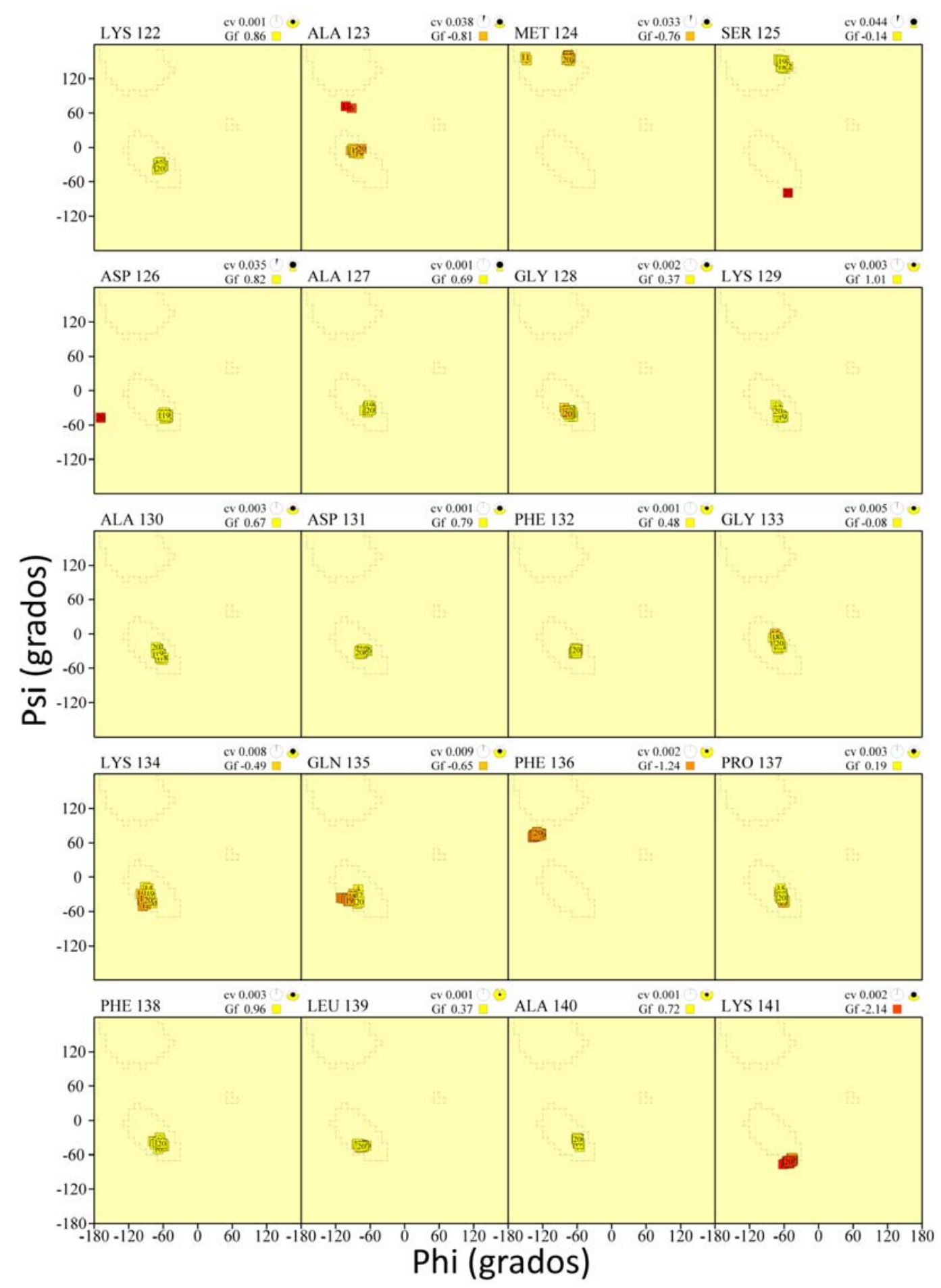




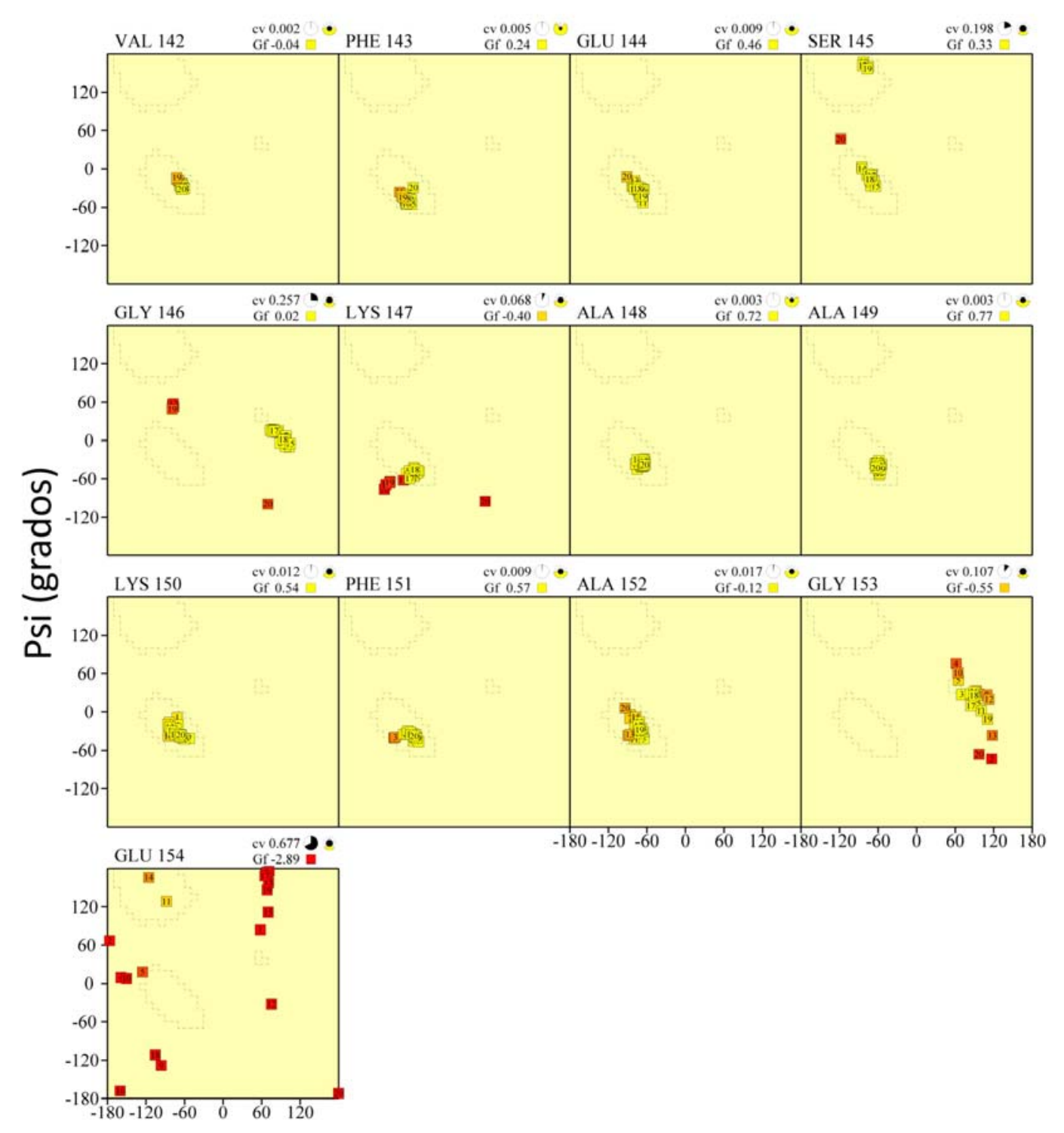

Phi (grados)

$\mathrm{cv}=$ Circular Variance (low values signify high clustering of the data points). * Accessible
$\mathrm{Gf}=$ Average $\mathrm{G}$-factor for the residue (the higher the value the more favourable the conformations) based on analysis of high-res. Xstal structures
Data points coloured according to G-factor: 


\section{Distribución de frecuencia Chi (20 modelos)}

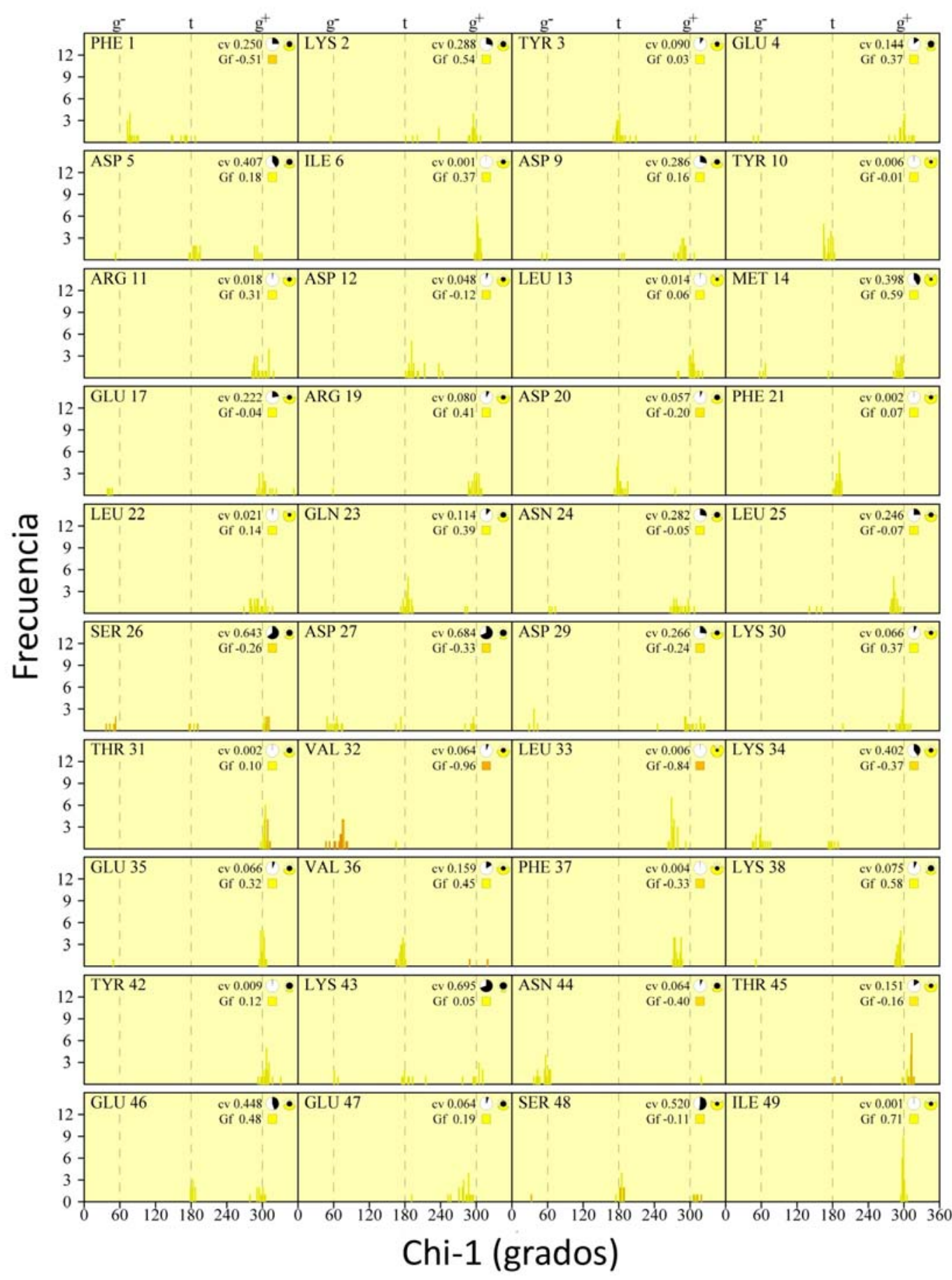




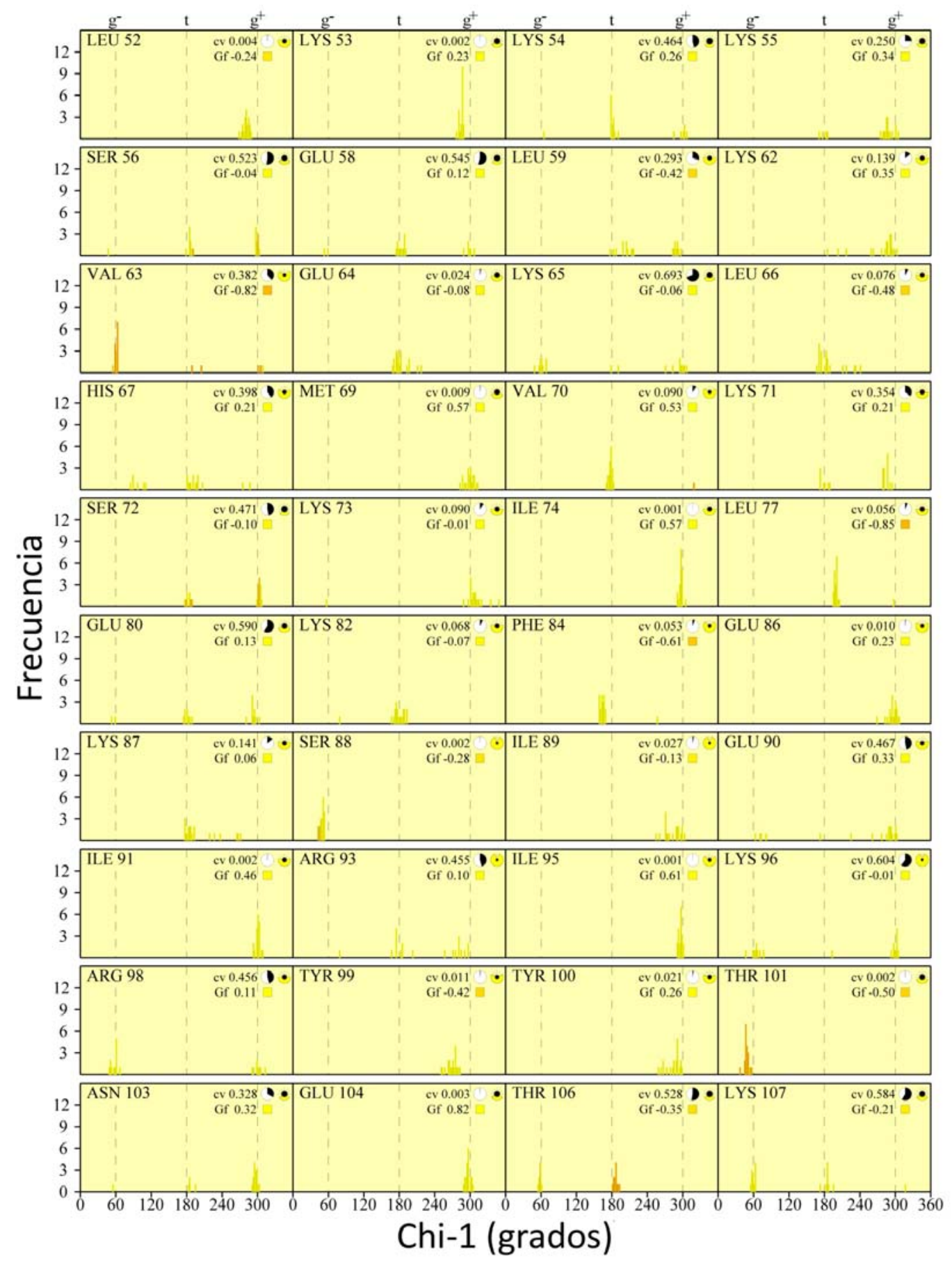




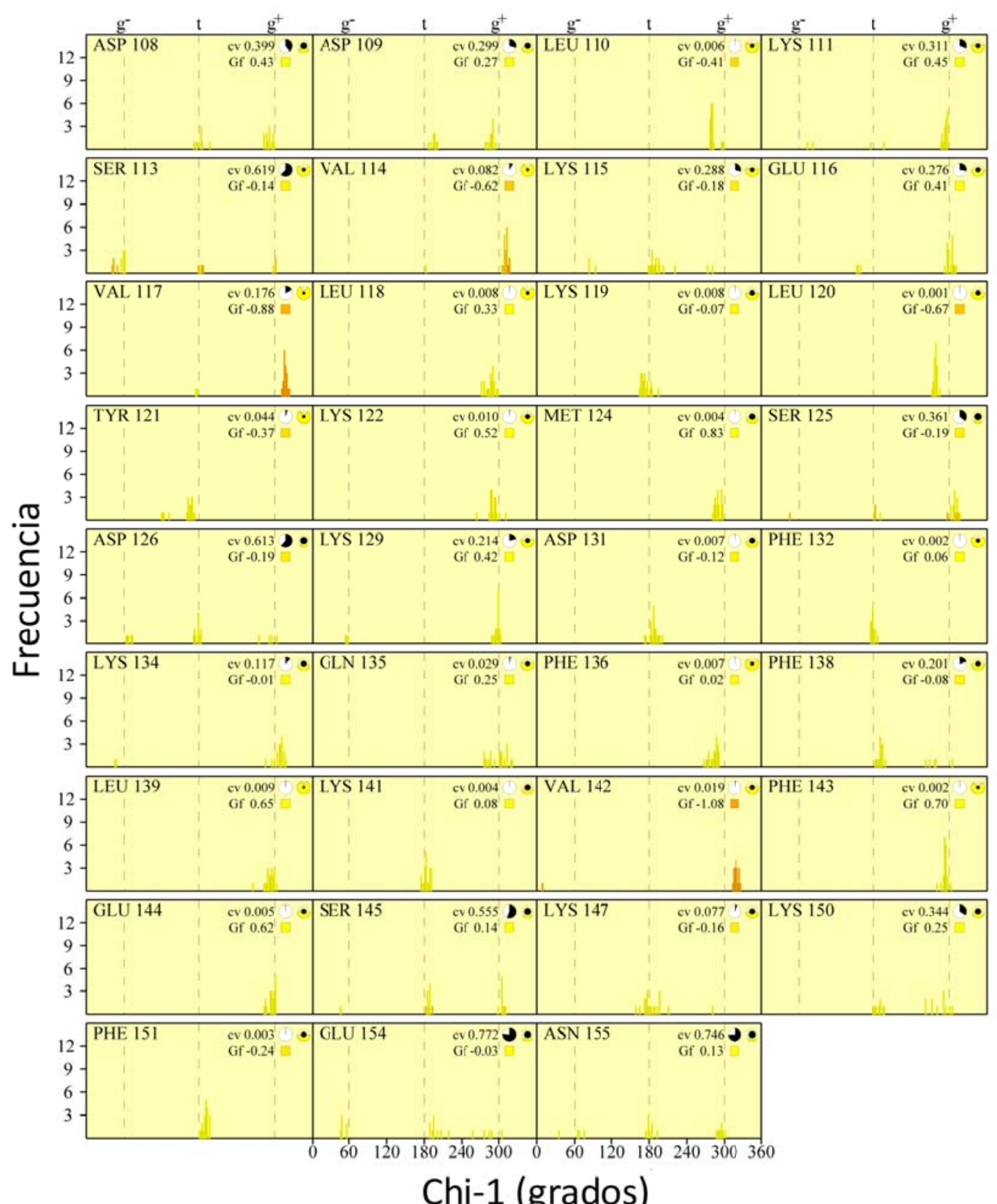

$\mathrm{cv}=$ Circular Variance (low values signify high clustering of the data points).

Accessible 1 . Bunied

$\mathrm{Gf}=$ Average $\mathrm{G}$-factor for the residue (the higher the value the more favourable the conformations) based on analysis of high-res. Xstal structures Data bars coloured according to G-factor: 


\section{Propiedades por residuo (20 modelos)}
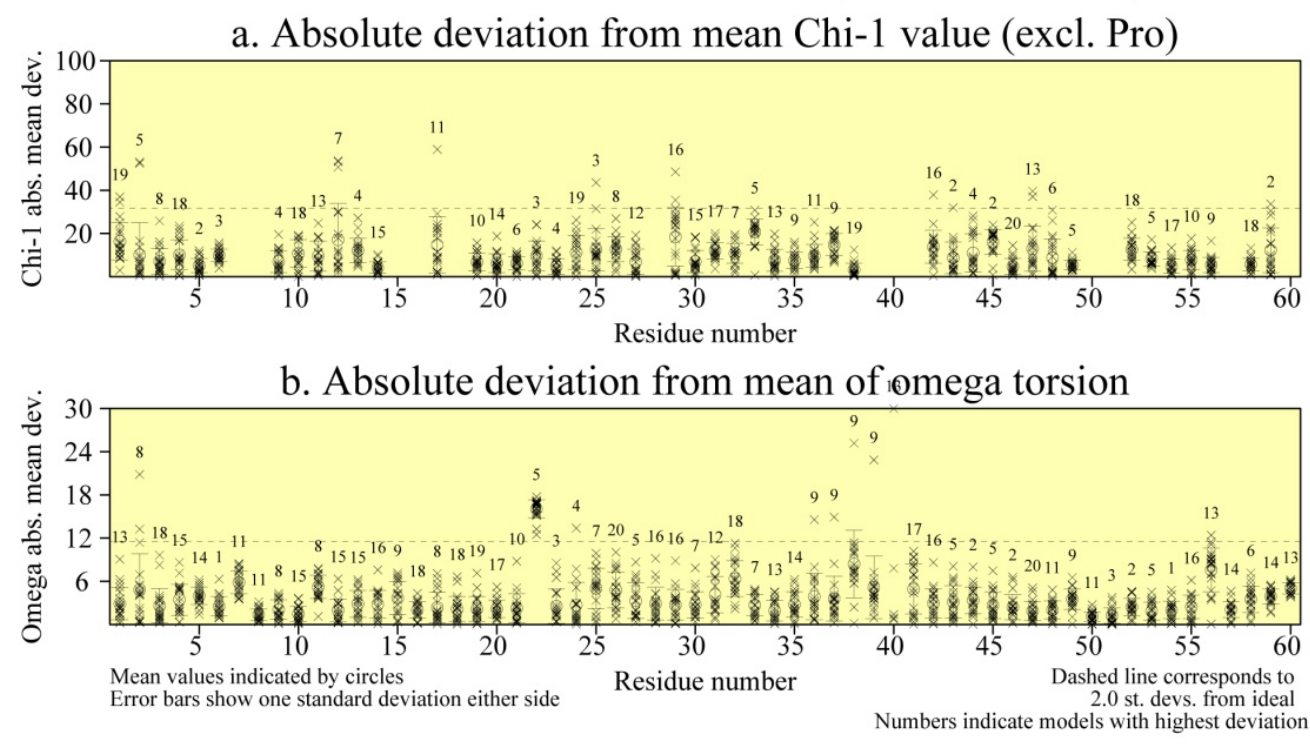

c. RMS devs from mean coords: main-chain (black) and side-chain (grey) 4.0

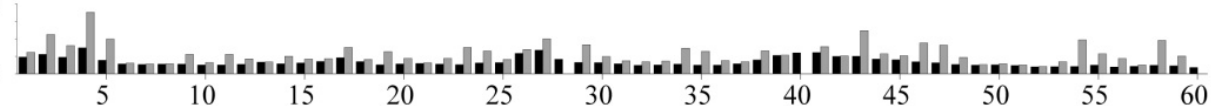

d. Secondary structure \& average estimated accessibility

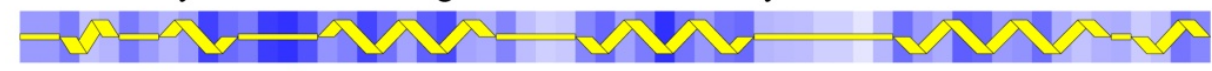

Key:- $\backslash$ Helix $\square$ Beta strand $\Longrightarrow$ Random coil Accessibility shading: $\quad$ Buried $\square$ Accessible

e. Sequence \& average estimated accessibilities $\quad$ Accessible $\bullet$ Buried

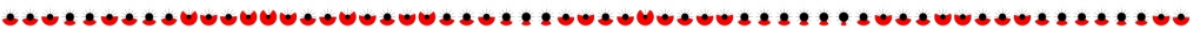

FKYED I PADYRDLMP PEARDF LQNL SDGDKT VLKEVFKAGPYKNTEES I AALKKKS PELG

f. Circular variances

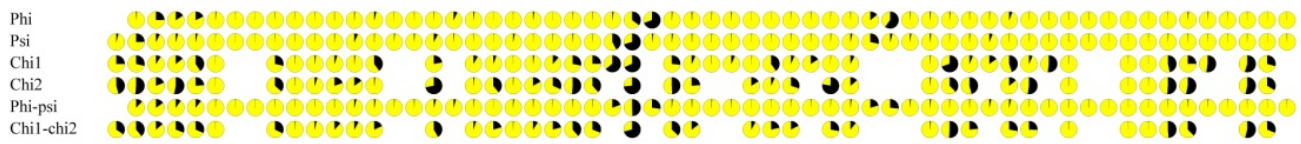

g. G-factors

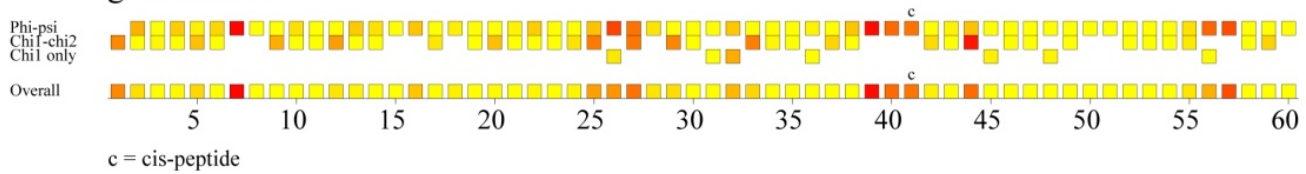



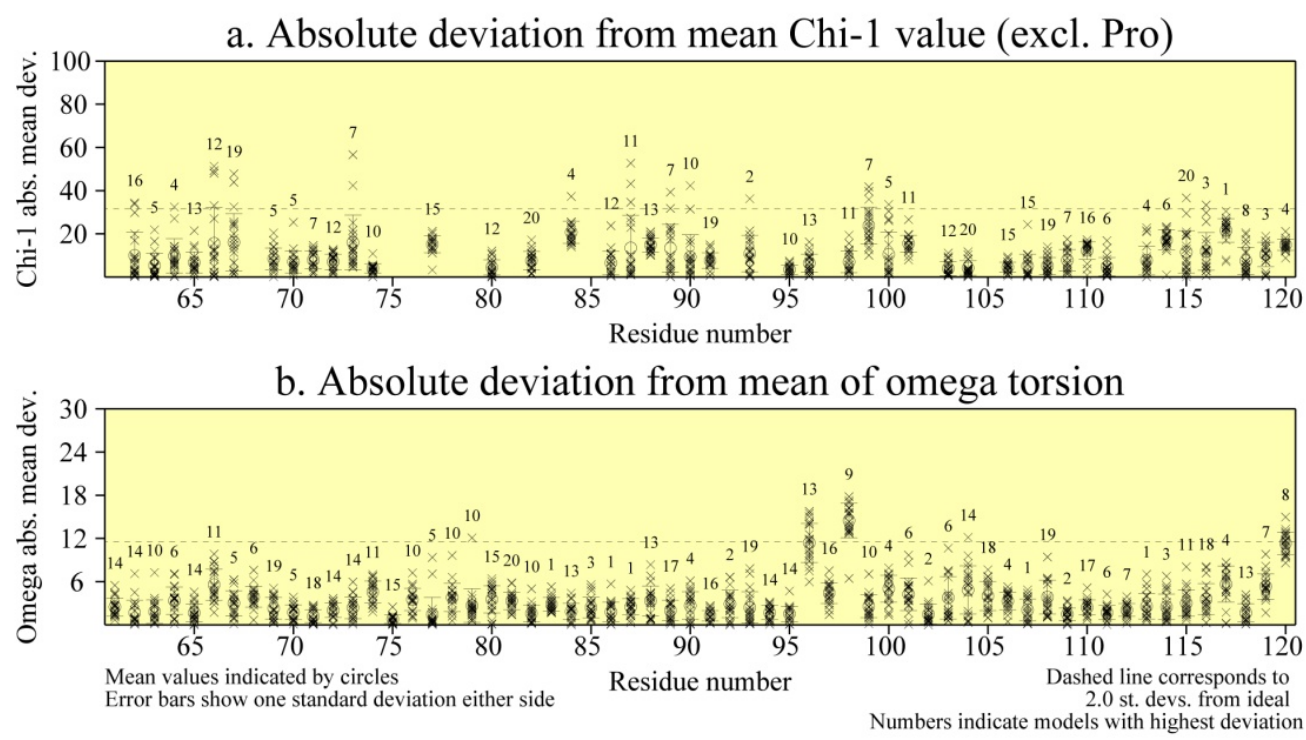

c. RMS devs from mean coords: main-chain (black) and side-chain (grey) 4.0 0.0

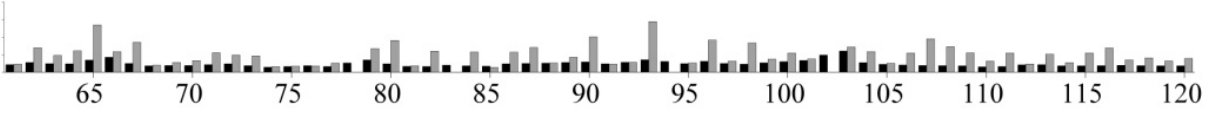

d. Secondary structure \& average estimated accessibility

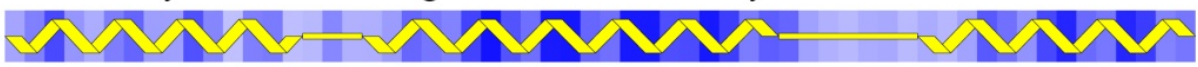

Key:- $\neg$ Helix $\square$ Beta strand $\longrightarrow$ Random coil Accessibility shading: $\square$ Buried $\square$ Accessible

e. Sequence \& average estimated accessibilities $\quad$ Accessible Buried

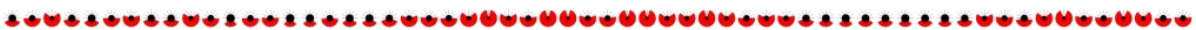

AKVEKLHAMVK SK I AALGPEAKGF AEKS I E I ARG I KARYYTGNE P T KDDLKA S VKEVLKL

f. Circular variances

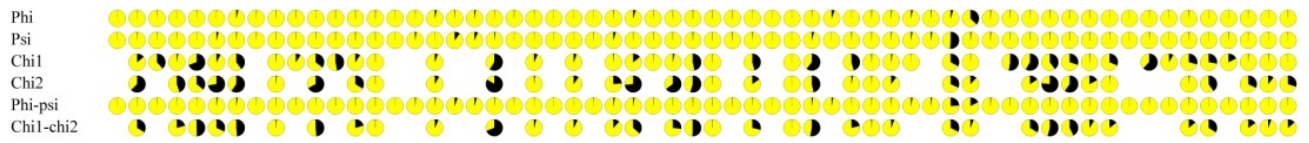

g. G-factors

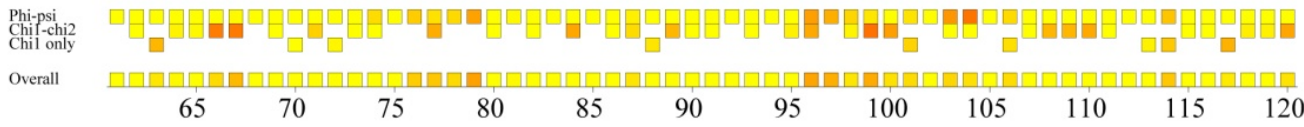



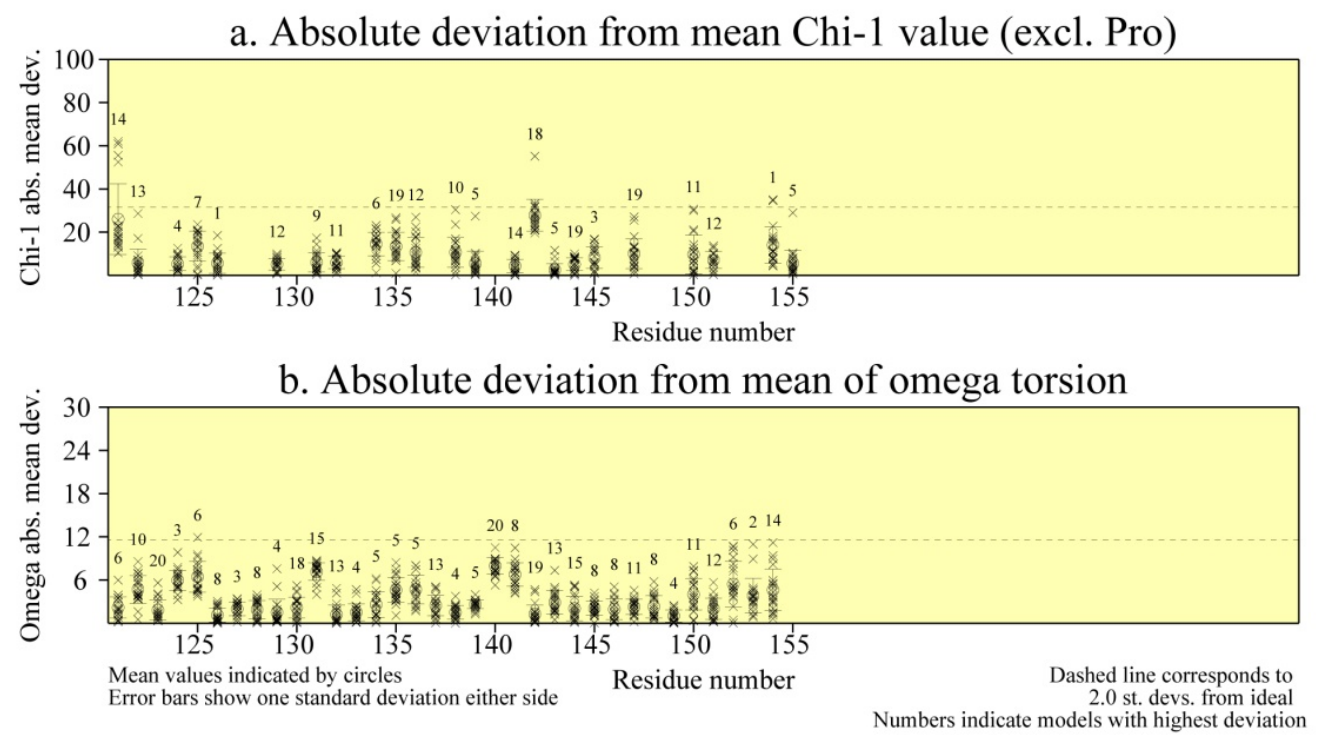

c. RMS devs from mean coords: main-chain (black) and side-chain (grey) 4.0

0.0

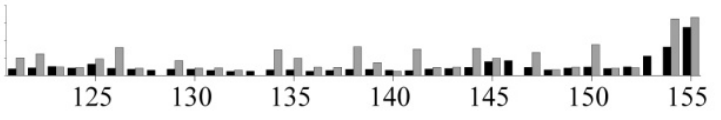

d. Secondary structure \& average estimated accessibility

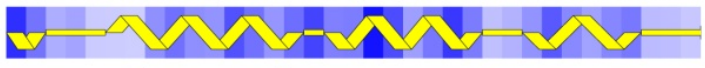

Key:- $\square$ Helix $\square$ Beta strand $\Longrightarrow$ Random coil Accessibility shading: $\quad$ Buried $\square$ Accessible

e. Sequence \& average estimated accessibilities $\quad$ Accessible $\bullet$ Buried

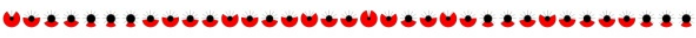

YKAMS DAGKADF GK QF P F L AKVFE S GKAAK F AGEN

f. Circular variances

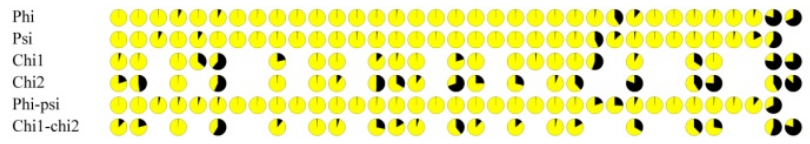

g. G-factors

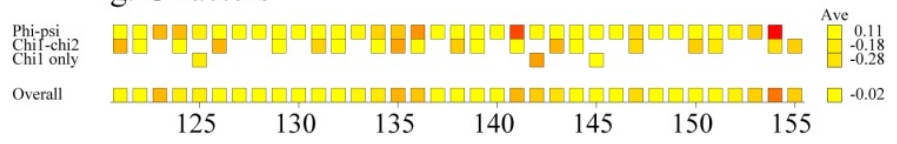




\section{Referencias}

1. Lambshead, P. J. D. \& Boucher, G. Marine nematode deep-sea biodiversity hyperdiverse or hype? J. Biogeogr. 30, 475-485 (2003).

2. Blaxter, M. Nematodes: The Worm and Its Relatives. PLoS Biol. 9, 1-9 (2011).

3. Hotez, P. J., Fenwick, A., Savioli, L. \& Molyneux, D. H. Rescuing the bottom billion through control of neglected tropical diseases. Lancet 373, 1570-5 (2009).

4. Hotez, P. J. Aboriginal Populations and Their Neglected Tropical Diseases. PLoS Negl.Trop. Dis. 8, 1-4 (2014).

5. Hotez, P. J., Bottazzi, M. E., Franco-paredes, C., Ault, S. K. \& Periago, M. R. The Neglected Tropical Diseases of Latin America and the Caribbean: A Review of Disease Burden and Distribution and a Roadmap for Control and Elimination. PLoS Negl. Trop. Dis. 2, 1-11 (2008).

6. Hotez, P. J., Bethony, J., Bottazzi, M. E., Brooker, S. \& Buss, P. Hookworm: "the great infection of mankind."PLoS Med. 2, e67 (2005).

7. Geerts, S., Coles, G. C. \& Gryseels, B. Anthelmintic Resistance in Human Helminths: Learning from the Problems with Worm Control in Livestock. Parasitol. Today 13, 149151 (1997).

8. Jia, T., Melville, S., Utzinger, J., King, C. H. \& Zhou, X. Soil-Transmitted Helminth Reinfection after Drug Treatment: A Systematic Review and Meta-Analysis. PLoS Negl. Trop. Dis. 6, 1-11 (2012).

9. Hotez, P. J. et al. New technologies for the control of human hookworm infection. Trends Parasitol. 22, 327-31 (2006).

10. Hotez, P. J. \& Pecoul, B. "' Manifesto "' for Advancing the Control and Elimination of Neglected Tropical Diseases. PLoS Negl. Trop. Dis. 4, 1-7 (2010).

11. Utzinger, J. A Research and Development Agenda for the Control and Elimination of Human Helminthiases. PLoS NegI Trop Dis 6, 1-7 (2012).

12. Franco-paredes, C. \& Santos-preciado, J. I. Freedom, Justice, and Neglected Tropical Diseases. PLoS Negl Trop Dis 5, 1-2 (2011).

13. Brooker, S., Bethony, J. \& Hotez, P. J. UKPMC Funders Group Human Hookworm Infection in the 21 st Century. Adv. Parasitol. 197-288 (2004).

14. Hotez, P. J. Neglected Tropical Disease Control in the "' Post-American World .'"PLoS Negl. Trop. Dis. 4, 2-5 (2010).

15. Hotez, P. J. Neglected Tropical Diseases in the Catholic World. PLoS Negl. Trop. Dis. 5, 4-6 (2011).

16. Maizels, R., Blaxter, M. \& Kennedy, M. Parasitic helminths: from genomes to vaccines. Parasitol. Today 14, 131-2 (1998).

17. Chmurzyńska, A. The multigene family of fatty acid-binding proteins (FABPs): function, structure and polymorphism. J. Appl. Genet. 47, 39-48 (2006).

18. Franchini, G. R. et al. Análisis estructural y funcional de proteínas solubles que unen lípidos de parásitos helmintos. Acta Bioquímica Clínica Latinoam. 47, 1-6 (2013). 
Referencias

19. Lee, E.-G. et al. A hydrophobic ligand-binding protein of the Taenia solium metacestode mediates uptake of the host lipid: implication for the maintenance of parasitic cellular homeostasis. Proteomics 7, 4016-30 (2007).

20. Han, G. W. et al. Structural basis of non-specific lipid binding in maize lipid-transfer protein complexes revealed by high-resolution X-ray crystallography. J. Mol. Biol. 308, 263-78 (2001).

21. Tree, T. I. et al. Characterisation of an immunodominant glycoprotein antigen of Onchocerca volvulus with homologues in other filarial nematodes and Caenorhabditis elegans. Mol. Biochem. Parasitol. 69, 185-95 (1995).

22. Bath, J. L. et al. Identification of a secreted fatty acid and retinol-binding protein (HpFAR-1) from Heligmosomoides polygyrus. J. Nematol. 41, 228-33 (2009).

23. Rodríguez-Pérez, J., Rodríguez-Medina, J. R., García-Blanco, M. a \& Hillyer, G. V. Fasciola hepatica: molecular cloning, nucleotide sequence, and expression of a gene encoding a polypeptide homologous to a Schistosoma mansoni fatty acid-binding protein. Exp. Parasitol. 74, 400-7 (1992).

24. McDermott, L., Cooper, a \& Kennedy, M. W. Novel classes of fatty acid and retinol binding protein from nematodes. Mol. Cell. Biochem. 192, 69-75 (1999).

25. Esteves, A. \& Ehrlich, R. Invertebrate intracellular fatty acid binding proteins. Comp. Biochem. Physiol. C. Toxicol. Pharmacol. 142, 262-74 (2006).

26. Jakobsson, E., Alvite, G., Bergfors, T., Esteves, A. \& Kleywegt, G. J. The crystal structure of Echinococcus granulosus fatty-acid-binding protein 1. Biochim. Biophys. Acta Proteins Proteomics 1649, 40-50 (2003).

27. Porfido, J. L. et al. Direct interaction between EgFABP1, a fatty acid binding protein from Echinococcus granulosus, and phospholipid membranes. PLoS Negl. Trop. Dis. 6, e1893 (2012).

28. Alvite, G., Di Pietro, S. M., Santomé, J. a, Ehrlich, R. \& Esteves, a. Binding properties of Echinococcus granulosus fatty acid binding protein. Biochim. Biophys. Acta 1533, 293302 (2001).

29. Kennedy, M. W. Secretion of a Novel, Developmentally Regulated Fatty Acid-binding Protein into the Perivitelline Fluid of the Parasitic Nematode, Ascaris suum. J. Biol. Chem. 272, 9933-9941 (1997).

30. Ibáñez-Shimabukuro, M. et al. Resonance assignment of As-p18, a fatty acid binding protein secreted by developing larvae of the parasitic nematode Ascaris suum. Biomol. NMR Assign. (2012). doi:10.1007/s12104-012-9447-1

31. Oriol, R., Williams, J., Pérez Esandi, M. \& Oriol, C. Purification of liprotein antigens of Echinococcus granulosus from sheep hidatic fluid. Am. J. Trop. Med. Hyg. 20, 569-74 (1971).

32. Obal, G. et al. Characterisation of the native lipid moiety of Echinococcus granulosus antigen B. PLoS Negl.Trop. Dis. 6, e1642 (2012).

33. Kuang, L. et al. The complexity of the secreted NPA and FAR lipid-binding protein families of Haemonchus contortus revealed by an iterative proteomics-bioinformatics approach. Mol. Biochem. Parasitol. 168, 84-94 (2009).

34. Hewitson, J. P., Grainger, J. R. \& Maizels, R. M. Helminth immunoregulation: the role of parasite secreted proteins in modulating host immunity. Mol. Biochem. Parasitol. 167, 1-11 (2009). 
Referencias

35. Moore, J. et al. Sequence-divergent units of the ABA-1 polyprotein array of the nematode Ascaris suum have similar fatty-acid- and retinol-binding properties but different binding-site environments. Biochem. J. 340, 337-343 (1999).

36. Meenan, N. a G. et al. Solution structure of a repeated unit of the ABA-1 nematode polyprotein allergen of Ascaris reveals a novel fold and two discrete lipid-binding sites. PLoS Negl. Trop. Dis. 5, e1040 (2011).

37. Kennedy, M. W. et al. The Ov20 Protein of the Parasitic Nematode Onchocerca volvulus. 272, 29442-29448 (1997).

38. Sani, B. P. \& Vaid, a. Specific interaction of ivermectin with retinol-binding protein from filarial parasites. Biochem. J. 249, 929-32 (1988).

39. Bradley, J. E., Nirmalan, N., Klager, S. L., Faulkner, H. \& Kennedy, M. W. River blindness: a role for parasite retinoid-binding proteins in the generation of pathology? Trends Parasitol 17, 471-475 (2001).

40. Nirmalan, N., Cordeiro, N. J., Kläger, S. L., Bradley, J. E. \& Allen, J. E. Comparative analysis of glycosylated and nonglycosylated filarial homologues of the 20-kilodalton retinol binding protein from Onchocerca volvulus (Ov20). Infect. Immun. 67, 6329-34 (1999).

41. Prior, A. et al. A surface-associated retinol- and fatty acid-binding protein (Gp-FAR-1) from the potato cyst nematode Globodera pallida : lipid binding activities, structural analysis and expression pattern. Biochem. J. 356, 387-394 (2001).

42. Basavaraju, S. V et al. Ac-FAR-1, a $20 \mathrm{kDa}$ fatty acid- and retinol-binding protein secreted by adult Ancylostoma caninum hookworms: gene transcription pattern, ligand binding properties and structural characterisation. Mol. Biochem. Parasitol. 126, 63-71 (2003).

43. Burbelo, P. D., Leahy, H. P., ladarola, M. J. \& Nutman, T. B. A four-antigen mixture for rapid assessment of Onchocerca volvulus infection. PLoS Negl Trop Dis 3, e438 (2009).

44. Iberkleid, I. et al. Fatty acid-and retinol-binding protein, Mj-FAR-1 induces tomato host susceptibility to root-knot nematodes. PLoS One 8, e64586 (2013).

45. Fairfax, K. C. et al. Characterisation of a fatty acid and retinol binding protein orthologue from the hookworm Ancylostoma ceylanicum. Int. J. Parasitol. 39, 1561-71 (2009).

46. Garofalo, A. et al. The FAR protein family of the nematode Caenorhabditis elegans. Differential lipid binding properties, structural characteristics, and developmental regulation. J. Biol. Chem. 278, 8065-74 (2003).

47. McDermott, L. et al. How helminth lipid-binding proteins offload their ligands to membranes: differential mechanisms of fatty acid transfer by the ABA-1 polyprotein allergen and Ov-FAR-1 proteins of nematodes and Sj-FABPc of schistosomes. Biochemistry 41, 6706-13 (2002).

48. Blaxter, M. Genes and genomes of Necator americanus and related hookworms. Int. J. Parasitol. 30, 347-55 (2000).

49. Tang, Y. T. et al. Genome of the human hookworm Necator americanus. Nat. Genet. (2014).

50. Jordanova, R. et al. Fatty acid- and retinoid-binding proteins have distinct binding pockets for the two types of cargo. J. Biol. Chem. 284, 35818-26 (2009). 
Referencias

51. Daub, J., Loukas, A., Pritchard, D. I. \& Blaxter, M. A survey of genes expressed in adults of the human hookworm, Necator americanus. Parasitology 120 ( Pt 2, 171-184 (2000).

52. Nielsen, H., Engelbrecht, J., Brunak, S. \& Von Heijne, G. Identification of prokaryotic and eukaryotic signal peptides and prediction of their cleavage sites. Protein Eng. 10, 1-6 (1997).

53. Waterhouse, A. M., Procter, J. B., Martin, D. M. a, Clamp, M. \& Barton, G. J. Jalview Version 2--a multiple sequence alignment editor and analysis workbench. Bioinformatics 25, 1189-91 (2009).

54. Notredame, C., Higgins, D. G. \& Heringa, J. T-Coffee: A novel method for fast and accurate multiple sequence alignment. J. Mol. Biol. 302, 205-17 (2000).

55. Tang, Y. T. et al. Genome of the human hookworm Necator americanus. Nat. Genet. 176 (2014).

56. Hotez, P. J. et al. Hookworm infection. N. Engl. J. Med. 351, 799-807 (2004).

57. Botero Ramos, D. \& Restrepo, M. Parasitosis humanas. 418 (Corporación para Investigaciones Biológicas, 1992).

58. Rea, M. F. J., Borda, C. E., Rosa, J. R., Mosqueda, L. A. \& Benitez, O. D. Parasitismo Intestinal en una Zona Rural , San Luis del Palmar - Corrientes -Argentina. 2-4 (1998).

59. Menghi, C. I., luvaro, F. R., Dellacasa, M. A. \& Gatta, C. L. INVESTIGACION DE PARASITOS INTESTINALES EN UNA COMUNIDAD ABORIGEN DE LA PROVINCIA DE SALTA. Med. (Buenos Aires) 705-708 (2007).

60. Sambrook, J. P. \& Russell, D. W. Molecular Cloning: A Laboratory Manual. vol 1, 2 and 3 (Cold Spring Harbor Laboratory Press, 2001).

61. Gill, S. \& von Hippel, P. Calculation of protein extinction coefficients from amino acid sequence data. Anal Biochem 182, 319-2 (1989).

62. Laemmli, U. Cleavage of structural proteins during the assembly of the head of bacteriophage T4. Nature 15, 680-5 (1970).

63. Kelly, S. M., Jess, T. J. \& Price, N. C. How to study proteins by circular dichroism. Biochim. Biophys. Acta 1751, 119-39 (2005).

64. Corsico, B., Cistola, D. P., Frieden, C. \& Storch, J. The helical domain of intestinal fatty acid binding protein is critical for collisional transfer of fatty acids to phospholipid membranes. Proc. Natl. Acad. Sci. U. S. A. 95, 12174-8 (1998).

65. Garofalo, A., Kennedy, M. W. \& Bradley, J. E. The FAR proteins of parasitic nematodes: their possible involvement in the pathogenesis of infection and the use of Caenorhabditis elegans as a model system to evaluate their function. Med. Microbiol. Immunol. 192, 47-52 (2003).

66. Mori, S., Abeygunawardana, C., O’Neil-Johnson, M. \& Van Zijil, P. C. M. Improved Sensitivity of HSQC Spectra of Exchanging Protons at Short Interscan Delays Using a New Fast HSQC (FHSQC) Detection Scheme That Avoids Water Saturation. J. Magn. Reson. Ser. B 108, 94-98 (1995).

67. Hornak, J. The Basics of NMR, a hypertext book on nuclear magnetic resonance spectroscopy. www.cis.rit.edu/htbooks/nmr (1997).

68. Griesinger, C. \& Sattler, M. Heteronuclear multidimensional NMR experiments for the structure determination of proteins in solution employing pulsed field gradients. 34, 93-158 (1999). 
Referencias

69. Barna, J. C. J. et al. Exponential Sampling, an Alternative Method for Sampling in TwoDimensional NMR Experiments. 77, 69-77 (1987).

70. Rovnyak, D. et al. Accelerated acquisition of high resolution triple-resonance spectra using non-uniform sampling and maximum entropy reconstruction. J. Magn. Reson. 170, 15-21 (2004).

71. Wishart, D. S. et al. $1 \mathrm{H}, 13 \mathrm{C}$ and $15 \mathrm{~N}$ chemical shift referencing in biomolecular NMR. J. Biomol. NMR 6, 135-140 (1995).

72. Sibisi, S., Skilling, J., Brereton, R. G., Laue, E. D. \& Staunton, J. Maximum entropy signal processing in practical NMR spectroscopy. Nature 311, 446-447 (1984).

73. Vranken, W. F. et al. The CCPN data model for NMR spectroscopy: development of a software pipeline. Proteins 59, 687-96 (2005).

74. Wittekind, M. \& Mueller, L. HNCACB, a High-Sensitivity 3D NMR Experiment to Correlate Amide-Proton and Nitrogen Resonances with the Alpha- and Beta-Carbon Resonances in Proteins. J. Magn. Reson. Ser. B 102, 201- 205 (1993).

75. Grzesiek, S. \& Bax, a. Amino acid type determination in the sequential assignment procedure of uniformly 13C/15N-enriched proteins. J. Biomol. NMR 3, 185-204 (1993).

76. Clubb, R. T., Thanbal, V. \& Wagner, G. A Constant-Time Three-Dimensional TripleResonance Pulse Scheme to Correlate Intraresidue "H N, 15N, and 13C" Chemical Shifts in “N- 13C-Labeled Proteins. J. Magn. Reson. 97, 213-217 (1992).

77. Montelione, G. T., Lyons, B. A., Emerson, S. D. \& Tashiro, M. An efficient triple resonance experiment using carbon-13 isotropic mixing for determining sequencespecific resonance assignments of isotopically-enriched proteins. J. Am. Chem. Soc. 10974-10975 (1992).

78. Logan, T. M., Olejniczak, E. T., Xu, R. X. \& Fesik, S. W. A general method for assigning NMR spectra of denatured proteins using 3D $\mathrm{HC}(\mathrm{CO}) \mathrm{NH}-\mathrm{TOCSY}$ triple resonance experiments. J. Biomol. NMR 3, 225-31 (1993).

79. Grzesiek, S., Anglister, J. \& Bax, A. Correlation of Backbone Amide and Aliphatic SideChain Resonances in $13 \mathrm{C} / 15 \mathrm{~N}$-Enriched Proteins by Isotropic Mixing of $13 \mathrm{C}$ Magnetization. J. Magn. Reson. 102, 114-119 (1993).

80. Bermel, W., Bertini, I., Felli, I. C., Kümmerle, R. \& Pierattelli, R. 13C direct detection experiments on the paramagnetic oxidized monomeric copper, zinc superoxide dismutase. J. Am. Chem. Soc. 125, 16423-9 (2003).

81. Kay, L. E., Xu, G.-Y., Singer, A. U., Muhandiran, D. R. \& Forman-Kay, J. D. A GradientEnhanced HCCH-TOCSY Experiment for Recording Side-Chain $1 \mathrm{H}$ and $13 \mathrm{C}$ Correlations in H2O Samples of Proteins. J. Magn. Reson. Ser. B 101, 333-337 (1993).

82. Yamazaki, T., Forman-Kay, J. \& Kay, L. Two-dimensional NMR experiments for correlating carbon-13.beta. and proton.delta./.epsilon. chemical shifts of aromatic residues in 13C-labeled proteins via scalar couplings. J. Am. Chem. Soc. 115, 1105411055 (1993).

83. Zhang, H., Neal, S. \& Wishart, D. S. RefDB: a database of uniformly referenced protein chemical shifts. J. Biomol. NMR 25, 173-95 (2003).

84. Neuhaus, D. \& Williamson, M. P. THE NUCLEAR OVERHAUSER EFFECT IN STRUCTURAL AND CONFORMATIONAL ANALYSIS. Wiley-VCH (2000).

85. Cavanagh, J., Palmer III, A. G. \& Skelton, N. J. Protein NMR Spectroscopy Principles and Practice. (Academic Press Limited, 1996). 
Referencias

86. Cheung, M. S., Maguire, M. L., Stevens, T. J. \& Broadhurst, R. W. DANGLE: A Bayesian inferential method for predicting protein backbone dihedral angles and secondary structure. J. Magn. Reson. 202, 223-233 (2010).

87. Prestegard, J. H., al-Hashimi, H. M. \& Tolman, J. R. NMR structures of biomolecules using field oriented media and residual dipolar couplings. Q. Rev. Biophys. 33, 371-424 (2000).

88. Lipsitz, R. S. \& Tjandra, N. Residual dipolar couplings in NMR structure analysis. Annu. Rev. Biophys. Biomol. Struct. 33, 387-413 (2004).

89. Hansen, M. R., Mueller, L. \& Pardi, a. Tunable alignment of macromolecules by filamentous phage yields dipolar coupling interactions. Nat. Struct. Biol. 5, 1065-74 (1998).

90. Prestegard, J. H., Bougault, C. M. \& Kishore, a I. Residual dipolar couplings in structure determination of biomolecules. Chem. Rev. 104, 3519-40 (2004).

91. Ottiger, M., Delaglio, F. \& Bax, a. Measurement of J and dipolar couplings from simplified two-dimensional NMR spectra. J. Magn. Reson. 131, 373-8 (1998).

92. Ball, G. et al. Measurement of one-bond 13Calpha-1Halpha residual dipolar coupling constants in proteins by selective manipulation of CalphaHalpha spins. J Magn Reson 180, 127-136 (2006).

93. Zweckstetter, M. \& Bax, A. Prediction of Sterically Induced Alignment in a Dilute Liquid Crystalline Phase: Aid to Protein Structure Determination by NMR. J. Am. Chem. Soc. 3791-3792 (2000).

94. Tjandra, N., Omichinski, J., Gronenborn, A., Clore, G. \& Bax, A. Use of dipolar 1H-15N and $1 \mathrm{H}-13 \mathrm{C}$ couplings in the structure determination of magnetically oriented macromolecules in solution. Nat. Struct. Biol. 4, 732-738 (1997).

95. Nilges, M. Calculation of protein structures with ambiguous distance restraints. Automated assignment of ambiguous NOE crosspeaks and disulphide connectivities. J. Mol. Biol. 245, 645-60 (1995).

96. Brünger, A. T. et al. Crystallography \& NMR system: A new software suite for macromolecular structure determination. Acta Crystallogr. D. Biol. Crystallogr. 54, 905921 (1998).

97. Linge, J. P. \& Nilges, M. Influence of non-bonded parameters on the quality of NMR structures: a new force field for NMR structure calculation. J. Biomol. NMR 13, 51-9 (1999).

98. Habeck, M., Rieping, W., Linge, J. P. \& Nilges, M. in Methods Mol. Biol. 278, 379-402 (Humana Press, 2004).

99. Linge, J. P., Williams, M. a, Spronk, C. a E. M., Bonvin, A. M. J. J. \& Nilges, M. Refinement of protein structures in explicit solvent. Proteins 50, 496-506 (2003).

100. Nabuurs, S. B., Spronk, C. a. E. M., Vriend, G. \& Vuister, G. W. Concepts and tools for NMR restraint analysis and validation. Concepts Magn. Reson. 22A, 90-105 (2004).

101. Morris, a L., MacArthur, M. W., Hutchinson, E. G. \& Thornton, J. M. Stereochemical quality of protein structure coordinates. Proteins 12, 345-64 (1992).

102. Laskowski, R. a., MacArthur, M. W., Moss, D. S. \& Thornton, J. M. PROCHECK: a program to check the stereochemical quality of protein structures. J. Appl. Crystallogr. 26, 283291 (1993). 
Referencias

103. Abragam, A. The principles of nuclear magnetism. (Oxford University Press, 1994).

104. Farrow, N. a, Zhang, O., Forman-Kay, J. D. \& Kay, L. E. Comparison of the backbone dynamics of a folded and an unfolded $\mathrm{SH} 3$ domain existing in equilibrium in aqueous buffer. Biochemistry 34, 868-78 (1995).

105. Carr, H. \& Purcell, E. Effects of Diffusion on Free Precession in Nuclear Magnetic Resonance Experiments. Am J Phys 21, 630-638 (1953).

106. Meiboom, S. \& Gill, D. Modified Spin-Echo Method for Measuring Nuclear Relaxation Times. Rev. Sci. Instrum. 29, 688 (1958).

107. William H. Press, Saul A. Teukolsky, William T. Vetterling, B. P. F. NUMERICAL RECIPES The Art of Scientific Computing. (2007).

108. Kay, L. E., Torchia, D. a \& Bax, a. Backbone dynamics of proteins as studied by $15 \mathrm{~N}$ inverse detected heteronuclear NMR spectroscopy: application to staphylococcal nuclease. Biochemistry 28, 8972-9 (1989).

109. Brüschweiler, R., Liao, X. \& Wright, P. E. Long-range motional restrictions in a multidomain zinc-finger protein from anisotropic tumbling. Science 268, 886-9 (1995).

110. Lee, L. K., Rance, M., Chazin, W. J. \& Palmer, a G. Rotational diffusion anisotropy of proteins from simultaneous analysis of $15 \mathrm{~N}$ and $13 \mathrm{C}$ alpha nuclear spin relaxation. J. Biomol. NMR 9, 287-98 (1997).

111. Woessner, D. E. Nuclear Spin Relaxation in Ellipsoids Undergoing Rotational Brownian Motion. J. Chem. Phys. 37, 647-654 (1962).

112. Halle, B. \& Wennerström, H. Interpretation of magnetic resonance data from water nuclei in heterogeneous systems. J. Chem. Phys. 75, 1928-1943 (1981).

113. Barbato, G., Ikura, M., Kay, L. E., Pastor, R. W. \& Bax, A. Backbone Dynamics of Calmodulin Studied by $15 \mathrm{~N}$ Relaxation Using Inverse Detected Two-Dimensional NMR Spectroscopy: The Central Helix Is Flexible. Biochemistry 31, 5269-5278 (1992).

114. d'Auvergne, E. J. \& Gooley, P. R. Optimisation of NMR dynamic models I. Minimisation algorithms and their performance within the model-free and Brownian rotational diffusion spaces. J. Biomol. NMR 40, 107-19 (2008).

115. d'Auvergne, E. J. \& Gooley, P. R. Optimisation of NMR dynamic models II. A new methodology for the dual optimisation of the model-free parameters and the Brownian rotational diffusion tensor. J. Biomol. NMR 40, 121-33 (2008).

116. Lipari, G. \& Szabo, A. Model-free approach to the interpretation of nuclear magnetic resonance relaxation in macromolecules. 1. Theory and range of validity. J. Am. Chem. Soc. 104, 4546-4559 (1982).

117. Lipari, G. \& Szabo, A. Model-Free Approach to the Interpretation of Nuclear Magnetic Resonance Relaxation in Macromolecules. 2. Analysis of Experimental Results. J. Am. Chem. Soc. 104, 4559-4570 (1982).

118. Clore, G., Szabo, A., Bax, A. \& Kay, L. Deviations from the simple two-parameter modelfree approach to the interpretation of nitrogen-15 nuclear magnetic relaxation of proteins. J. (1990).

119. Cole, R. \& Loria, J. P. FAST-Modelfree: a program for rapid automated analysis of solution NMR spin-relaxation data. J. Biomol. NMR 26, 203-13 (2003). 
Referencias

120. Mandel, M., Akke, M. \& Palmer, G. Backbone dynamics of Escherichia coli ribonuclease $\mathrm{HI}$ : correlations with structure and function in an active enzyme. J. Mol. Biol. 246, 14463 (1995).

121. Chen, J., Brooks, C. L. \& Wright, P. E. Model-free analysis of protein dynamics: assessment of accuracy and model selection protocols based on molecular dynamics simulation. J. Biomol. NMR 29, 243-57 (2004).

122. Flower, D. R., North, a C. \& Attwood, T. K. Structure and sequence relationships in the lipocalins and related proteins. Protein Sci. 2, 753-61 (1993).

123. Shin, D. H., Lee, J. Y., Hwang, K. Y., Kim, K. K. \& Suh, S. W. High-resolution crystal structure of the non-specific lipid-transfer protein from maize seedlings. Structure 3 , 189-99 (1995).

124. Gomar, J. et al. Solution structure and lipid binding of a nonspecific lipid transfer protein extracted from maize seeds. Protein Sci. 5, 565-77 (1996).

125. Lee, H. S., Choi, J. \& Yoon, S. QHELIX: a computational tool for the improved measurement of inter-helical angles in proteins. Protein J. 26, 556-61 (2007).

126. Jaeger, J. \& York, N. Macromolecular Structure Determination by X-ray Crystallography. (2004).

127. Gabrielsen, M. et al. Two crystal forms of a helix-rich fatty acid- and retinol-binding protein, Na-FAR-1, from the parasitic nematode Necator americanus. Acta Crystallogr. Sect. F. Struct. Biol. Cryst. Commun. 68, 835-8 (2012).

128. Krishnan, V. V \& Rupp, B. in John Wiley Sons (2012).

129. Dundas, J. et al. CASTp: computed atlas of surface topography of proteins with structural and topographical mapping of functionally annotated residues. Nucleic Acids Res. 34, W116-8 (2006).

130. Holm, L. \& Park, J. DaliLite workbench for protein structure comparison. Bioinformatics 16, 566-7 (2000).

131. Folch, J., Lees, M. \& Stanley, G. H. S. A SIMPLE METHOD FOR THE ISOLATION AND PURIFICATION OF TOTAL LIPIDES FROM ANIMAL TISSUES. J. Biol. Chem. 226, 497-509 (1957).

132. De Siervo, A. J. Alterations in the phospholipid composition of Escherichia coli B during growth at different temperatures. J Bacteriol 100, 1342-1349 (1969).

133. Morrison, W. R. \& Smith, L. M. Preparation of Fatty Acid Methyl Esters and Dimethylacetals From Lipids With Boron Fluoride--Methanol. J. Lipid Res. 5, 600-8 (1964).

134. Marr, A. G. \& Ingraham, J. L. Effect of temperature on the composition of fatty acids in Escherichia coli. J. Bacteriol. 84, 1260-1267 (1962).

135. Goldflam, M., Tarragó, T., Gairí, M. \& Giralt, E. in Protein NMR Tech. Methods Mol. Biol. vol. 831 (Shekhtman, A. \& Burz, D. S.) 831, 233-259 (Humana Press, 2012).

136. Pellecchia, M., Sem, D. S. \& Wüthrich, K. NMR in drug discovery. Nat. Rev. Drug Discov. 1, 211-9 (2002).

137. He, Y. et al. A nuclear magnetic resonance-based structural rationale for contrasting stoichiometry and ligand binding site(s) in fatty acid-binding proteins. Biochemistry 50 , 1283-95 (2011). 
Referencias

138. Richieri, G. V, Ogata, R. T. \& Kleinfeld, a M. A fluorescently labeled intestinal fatty acid binding protein. Interactions with fatty acids and its use in monitoring free fatty acids. J. Biol. Chem. 267, 23495-501 (1992).

139. Davis, B. in Protein-Ligand Interact. Methods Appl. Methods Mol. Biol. vol. 1008 (Williams, M. A. \& Daviter, T.) 1008, 389-413 (Humana Press, 2013).

140. Lakowicz JR. Principles of Fluorescence Spectroscopy. (Kluwer Academic/Plenum Publishers, 1999).

141. Xu, Z. H., Buelt, M. K., Banaszak, L. J. \& Bernlohr, D. a. Expression, purification, and crystallization of the adipocyte lipid binding protein. J. Biol. Chem. 266, 14367-70 (1991).

142. De Gerónimo, E., Hagan, R. M., Wilton, D. C. \& Córsico, B. Natural ligand binding and transfer from liver fatty acid binding protein (LFABP) to membranes. Biochim. Biophys. Acta 1801, 1082-9 (2010).

143. Huang, C. \& Thompson., T. E. Preparation of homogeneous, single-walled phosphatidylcholine vesicles. Method. Enzym. 32, 485-489 (1974).

144. Storch, J. \& Kleinfeld, A. M. Transfer of long-chain fluorescent free fatty acids between unilamellar vesicles. Biochemistry 25, 1717-1726 (1986).

145. Gomori, G. A modification of the colorimetric phosphorus determination for use with the photoelectric colorimeter. J. Lab. Clin. Med 27, 955-960 (1942).

146. Massey, J. B., Bick, D. H. \& Pownall, H. J. Spontaneous transfer of monoacyl amphiphiles between lipid and protein surfaces. Biophys. J. 72, 1732-43 (1997).

147. Jian, X. et al. Necator americanus: maintenance through one hundred generations in golden hamsters (Mesocricetus auratus). I. host sex-associated differences in hookworm burden and fecundity. Exp. Parasitol. 104, 62-66 (2003).

148. Williamson, A. L. et al. Cleavage of hemoglobin by hookworm cathepsin D aspartic proteases and its potential contribution to host specificity. FASEB J. 16, 1458-60 (2002).

149. Garofalo, A. et al. The FAR proteins of filarial nematodes: secretion, glycosylation and lipid binding characteristics. Mol. Biochem. Parasitol. 122, 161-70 (2002).

150. Brusca, R. C. \& Brusca, G. J. Invertebrates. (Sinauer Associates, 2002).

151. Tuan, R. S., Shepley, K. J., Mulligan, M. M., Abraham, D. \& Perler, F. B. Histochemical localization of gene expression in Onchocerca volvulus: in situ DNA histohybridization and immunocytochemistry. Mol. Biochem. Parasitol. 49, 191-203 (1991).

152. Beames, C. G. \& King, G. A. in Comp. Biochem. Parasites (Van den Bossche, H.) 275-282 (Academic Press, 1968).

153. Thompson, D. P. \& Geary, T. G. in Biochem. Mol. Biol. Parasites (Academic Press Limited, 1995).

154. Marcelino, A. M. C., Smock, R. G. \& Gierasch, L. M. Evolutionary coupling of structural and functional sequence information in the intracellular lipid-binding protein family. Proteins 63, 373-84 (2006).

155. Curry, S., Mandelkow, H., Brick, P. \& Franks, N. Crystal structure of human serum albumin complexed with fatty acid reveals an asymmetric distribution of binding sites. Nat. Struct. Biol. 5, 827-35 (1998).

156. Kader, J.-C. Lipid-Transfer Proteins in Plants. Annu. Rev. Plant Physiol. Plant Mol. Biol. 47, 627-654 (1996). 